\title{
WestVirginiaUniversity
}

THE RESEARCH REPOSITORY @ WVU

Graduate Theses, Dissertations, and Problem Reports

2012

\section{Detection and characterization of pyromarkers of smoked drugs of abuse}

Rona Kiyomi Nishikawa

West Virginia University

Follow this and additional works at: https://researchrepository.wvu.edu/etd

\section{Recommended Citation}

Nishikawa, Rona Kiyomi, "Detection and characterization of pyromarkers of smoked drugs of abuse" (2012). Graduate Theses, Dissertations, and Problem Reports. 4904.

https://researchrepository.wvu.edu/etd/4904

This Dissertation is protected by copyright and/or related rights. It has been brought to you by the The Research Repository @ WVU with permission from the rights-holder(s). You are free to use this Dissertation in any way that is permitted by the copyright and related rights legislation that applies to your use. For other uses you must obtain permission from the rights-holder(s) directly, unless additional rights are indicated by a Creative Commons license in the record and/ or on the work itself. This Dissertation has been accepted for inclusion in WVU Graduate Theses, Dissertations, and Problem Reports collection by an authorized administrator of The Research Repository @ WVU.

For more information, please contact researchrepository@mail.wvu.edu. 


\title{
DETECTION AND CHARACTERIZATION OF PYROMARKERS OF SMOKED DRUGS OF ABUSE
}

\author{
Rona Kiyomi Nishikawa
}

Dissertation submitted to the Eberly College of Arts and Sciences at West Virginia University in partial fulfillment of the requirements for the degree of

Doctor of Philosophy

in

Chemistry

Committee of Advisors:

Suzanne C. Bell, Ph.D., Chair

R. Lloyd Carroll, Ph.D.

Patrick S. Callery, Ph.D.

Harry O. Finklea, Ph.D.

Keith B. Morris, Ph.D.

\section{Eugene Bennett Department of Chemistry Morgantown, West Virginia 2012}

Keywords: Fentanyl, Heroin, Pyrolysis, Pyromarkers, GC/MS Copyright (C) 2012 Rona Kiyomi Nishikawa 


\title{
Abstract \\ DETECTION AND CHARACTERIZATION OF PYROMARKERS OF SMOKED DRUGS OF ABUSE
}

\author{
Rona Kiyomi Nishikawa
}

Smoking or inhalation has increased in popularity as the choice route of administration of drugs of abuse amongst drug abusers. Combustion products associated with the smoking event (pyromarkers) of these smoked drugs of abuse can be useful in post mortem toxicological analysis both for investigative and public health applications. A method using analytical pyrolysis was developed to simulate the smoking process used for illicit drugs, which is significantly different than methods used for studies of conventional tobacco smoking, This method was used to identify possible markers associated smoked fentanyl and mixes of heroin and fentanyl. Thermocouple temperature probes were used to analyze the temperatures obtained through smoking the fentanyl transdermal patches (FTPs) in means of the "chasing the dragon" technique. These temperatures were then applied to the pyrolysis gas chromatography (Py-GC/MS) to mimic these smoking conditions to determine pyromarkers that were produced. The presence of a trap on the pyrolysis unit allowed for aerobic conditions by exposing the pyromarkers to air. A second advantage of trapping is preconcentration of pyromarkers. The method enhanced the recovery and afforded a positive identification of the pyromarkers. The methods and models developed here can be extended to any smoked drug, including drugs of current concern such as cannabinomimetics and incense/bath salt compositions. 


\section{Dedication}

This dissertation is dedicated to my parents, grandparents, sister, brother-in-law, niece, Uncle Jim, Aunty June, Aunty Georgia, cousins Kyle and Blaine, and Thomas. It was their endless love, support, encouragement, and endless boxes of care packages have undoubtedly provided me the foundation and motivation for me to succeed. 


\section{Acknowledgments}

First and foremost, I would like to acknowledge Dr. Suzanne Bell, for her help, advice, mentorship, support, and friendship throughout my graduate study. My exploration of smoked drugs of abuse would not have been possible without the help of Dr. Patrick Callery and Dr. James Kraner who never hesitated to share their advice, suggestions, and ideas. I am most grateful to Dr. R Lloyd Carroll for his enthusiasm in chemistry, advice, and endless support from my very start at WVU. Technical assistance of Allen Burns and Phillip Tucker is also greatly appreciated. I would like to thank my committee members for their time and patience in reviewing this research. Their helpful suggestions and valuable discussions are greatly acknowledged. I would like to thank Jennifer Mercer and Melissa Gayton Ely and the other current and past members of the Bell Group whom I have had pleasure to work with.

Lastly, I firmly believe that I would not have survived graduate school if it had not been for my research group members Holly McCall, Jordan Moran, and Xinya Zhang. The true genuine friendships shared between us have undoubtedly made this journey not only successful, but also sore to my stomach with humor and laughter. We learned, guided, and took care of one another like a family. Each has made huge impact on my life and the memories shared between us will never be forgotten and will continue to flourish into the future. 


\section{Table of Contents}

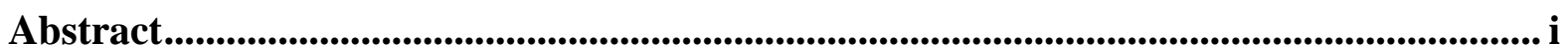

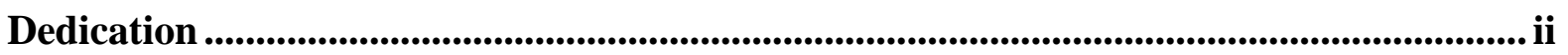

Acknowledgments ....................................................................................................................................... iii

Table of Contents .......................................................................................................................................... iv

List of Tables ..................................................................................................................... vii

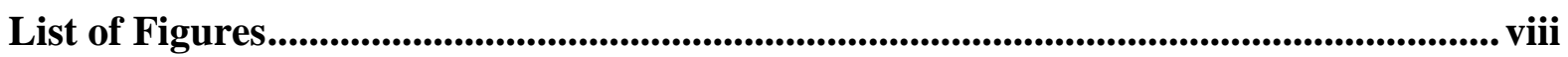

List of Abbreviations, Symbols/Nomenclature........................................................................... $\mathrm{x}$

Chapter 1: Introduction ......................................................................................................................... 1

1.1.0 Development of Research .................................................................................... 2

1.2.0 Compounds of Interest ................................................................................... 9

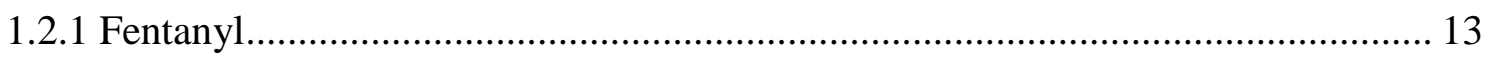

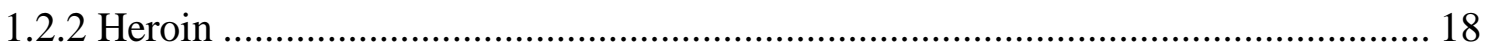

1.2.3 Smoking Opioids by "Chasing the Dragon" .......................................................... 24

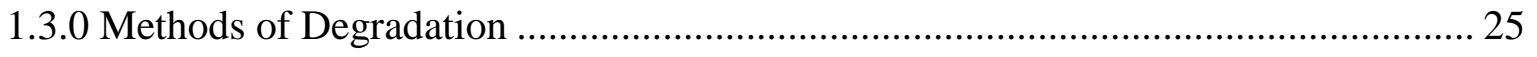

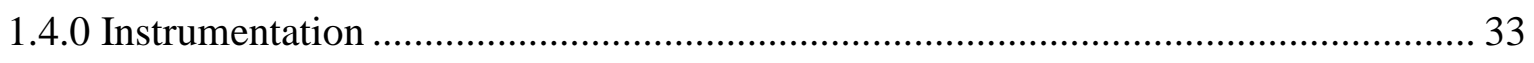

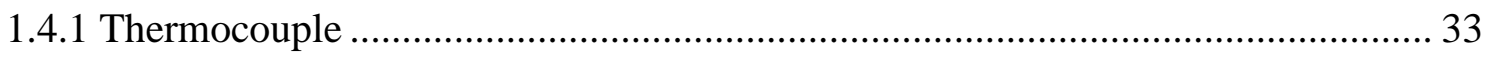

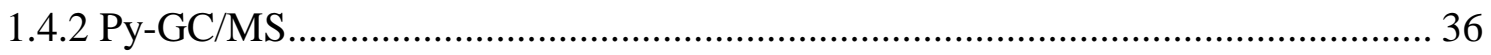

Chapter 2: Application of the Py-GC/MS to Mimic the Smoking Conditions of Fentanyl

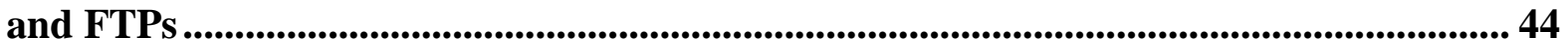

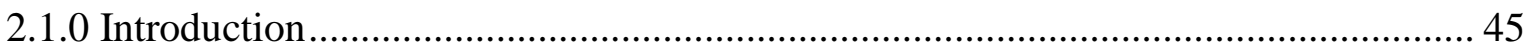

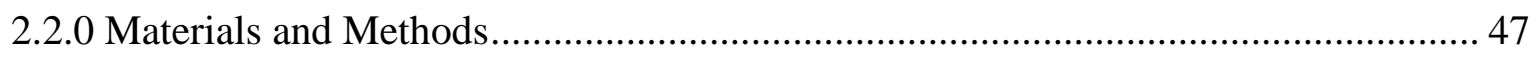

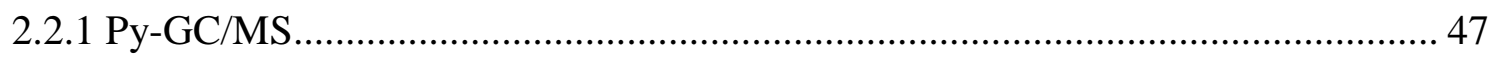

2.3.0 Results and Discussion ....................................................................................... 51

2.3.1 Pyrolytic Degradation Pathways of Pyromarkers ................................................... 54

2.3.2 Comparison of Fentanyl $\mathrm{HCl}$ and FTPs Under Anaerobic and Aerobic Conditions

59

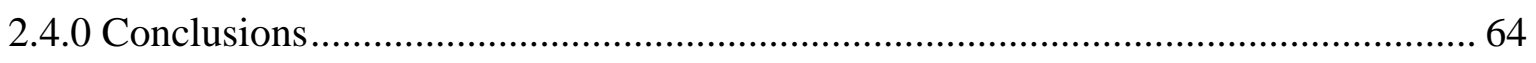


Chapter 3: Determination of the Temperature Characteristics of Smoking FTPs Using the "Smoking the Dragon" Method....................................................................................... 65

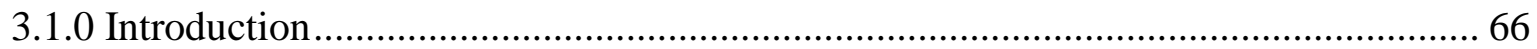

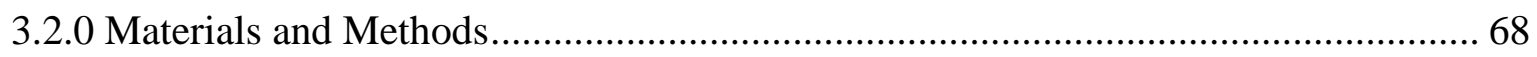

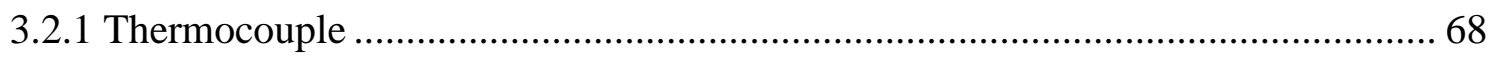

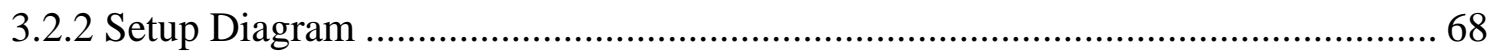

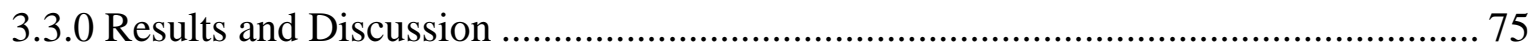

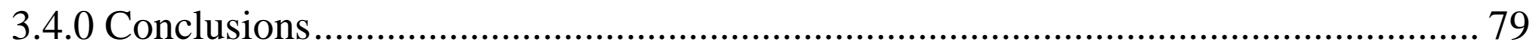

Chapter 4: Application of Temperatures Characteristics Obtained from Smoking FTPs By Means of "Chasing the Dragon” on the Py-GC/MS .................................................. 80

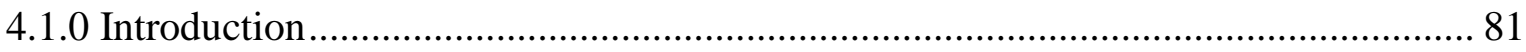

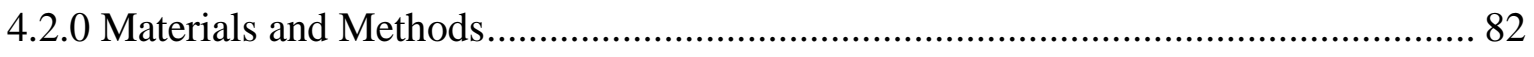

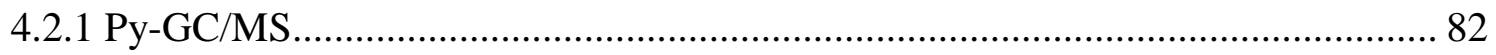

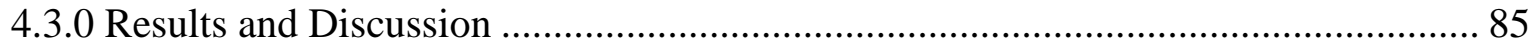

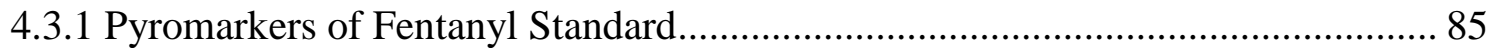

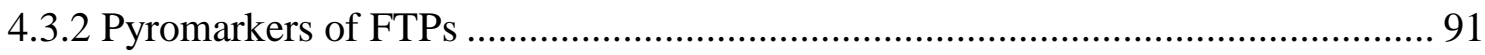

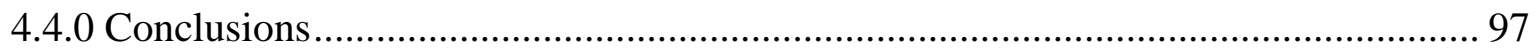

Chapter 5: Pyrolysis of Fentanyl and Heroin Mixtures .................................................. 98

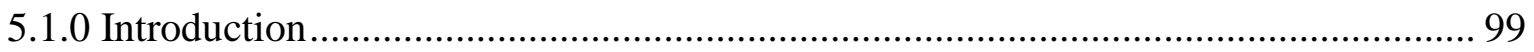

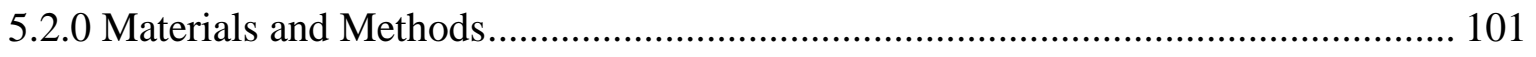

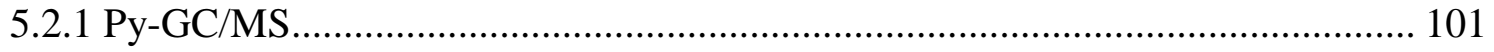

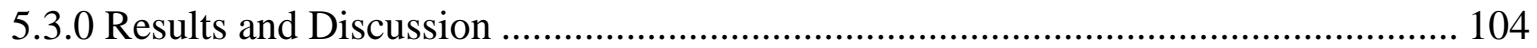

5.3.1 Pyromarkers of the Pyrolysis of the 3:1 Heroin to Fentanyl Mix....................... 105

5.3.2 Pyromarkers of the Pyrolysis of the 1:1 Heroin to Fentanyl Mix....................... 105

5.3.3 Pyromarkers of the Pyrolysis of the 1:3 Heroin to Fentanyl Mix....................... 105

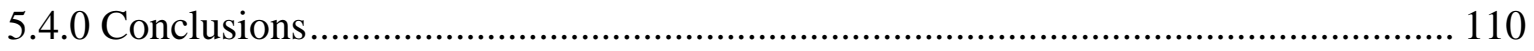

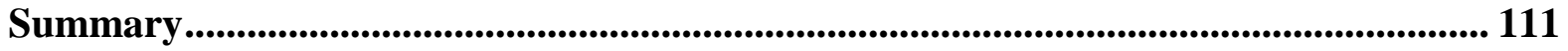

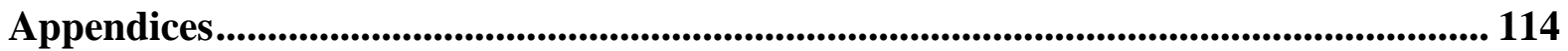

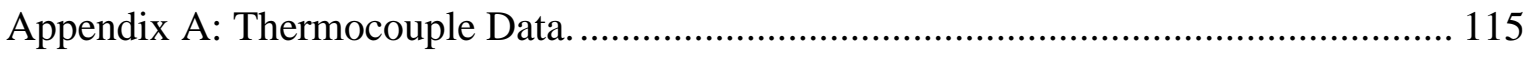

Appendix B: Extended data of the pyromarkers of the pyrolysis of fentanyl standard and

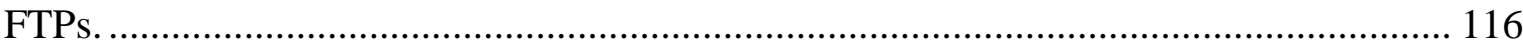


Appendix C: Extended data and GC Chromatograms of the pyromarkers of the pyrolysis

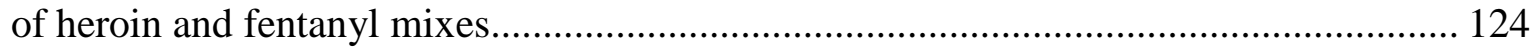

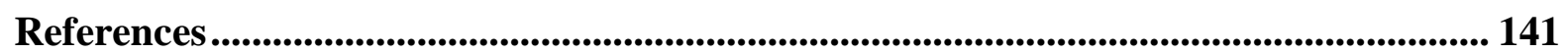




\section{List of Tables}

Table 1-1. Common smoked drugs of abuse with the DEA drug schedule.......................... 8

Table 1-2. Properties and strucutre of fentanyl and heroin............................................... 11

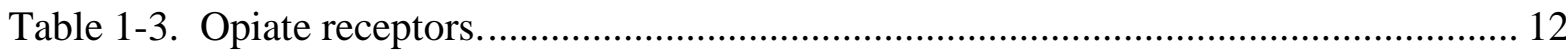

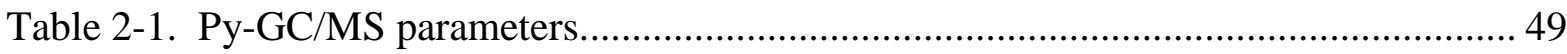

Table 2-2. Pyromarkers of fentanyl and FTPs under anaerobic and aerobic conditions....... 52

Table 3-1. Temperature data of smoking FTPs using the "chasing the dragon" method...... 77

Table 4-1. Py-GC/MS parameters for the pyrolysis of fentanyl standards and FTPs........... 84

Table 4-2. Pyromarkers of the pyrolysis of the fentanyl standard.................................... 87

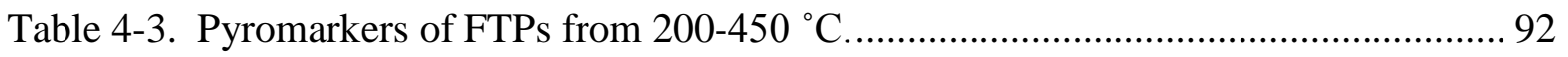

Table 5-1. Py-GC/MS parameters for the pyrolysis of heroin standards and mixes.......... 103

Table 5-2. Pyromarkers of the pyrolysis of the 3:1 heroin to fentanyl mix...................... 107

Table 5-3. Pyromarkers of the pyrolysis of the $1: 1$ heroin to fentanyl mix....................... 108

Table 5-4. Pyromarkers of the pyrolysis of the $1: 3$ heroin to fentanyl mix........................ 109 


\section{List of Figures}

Figure 1-1. Schematic representation of a reservoir type patch (A) and a matrix type patch (B).

Figure 1-2. Known fentanyl metabolites. .......................................................................... 17

Figure 1-3. Heroin Metabolism...................................................................................... 20

Figure 1-4. Known pyromarkers of heroin...................................................................... 23

Figure 1-5. Scheme of common degradation mechanisms observed in pyrolysis.................. 26

Figure 1-6. Pyrolytic Elimination Reactions. …………….................................................... 28

Figure 1-7. Pyrolytic elimination reactions involving free radicals. ...................................... 29

Figure 1-8. Pyrolysis in the presence of oxygen................................................................. 32

Figure 1-9. Schematic of A) the basic thermoelectric circuit and B) a practical circuit for thermocouple voltage measurements............................................................................... 35

Figure 1-10. Schematic of a pyroprobe unit coupled to a GC-MS......................................... 38

Figure 1-11. Representation of pyroprobe temperature program in trapping mode, where $\mathrm{T}$ is

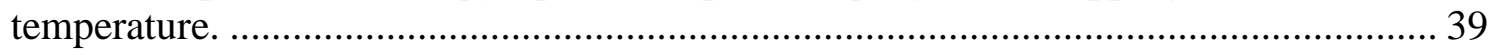

Figure 2-1. Schematic of a pyroprobe unit coupled to a GC/MS. .......................................... 50

Figure 2-2. Fentanyl pyromarkers comparisons in anaerobic and aerobic trapping conditions. 53

Figure 2-3. Possible pyrolysis degradation pathways of fentanyl. .......................................... 57

Figure 2-5. Fentanyl $\mathrm{HCl}$ and FTPs in anaerobic conditions................................................... 61

Figure 2-6. Fentanyl $\mathrm{HCl}$ and FTPs in aerobic conditions.................................................... 62

Figure 2-7. FTP chromatogram using 50\% Tenax-TA and 50\% glass bead trap................... 63

Figure 3-1. Schematic of box set up with A) front angle view, B) front view, C) left view

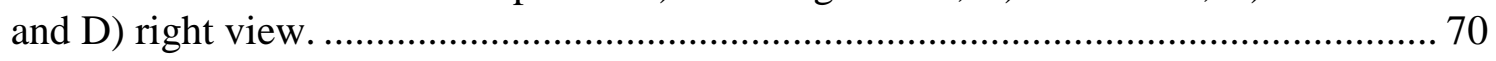

Figure 3-2. "Chasing the dragon" temperature analysis setup inside the smoking box with two thermocouples and a dual input datalogger. ………................................................. 73

Figure 3-3. Close-up view of the T1 sandwiched in the middle and T2 rested on the top of

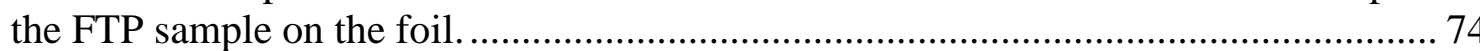




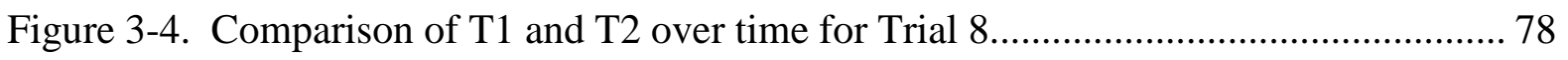

Figure 4-1. Chromatograms of the pyrolysis of fentanyl standard at $200-450{ }^{\circ} \mathrm{C} \ldots \ldots \ldots \ldots \ldots . . . . . .89$

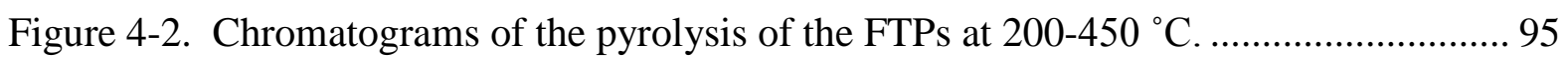




\title{
List of Abbreviations, Symbols/Nomenclature
}

\author{
1-SPO - 1-Styryl-1H-pyridin-2-one \\ 2-EECA - 2-Ethylhexyl ester cyclobutanecarboxylic acid \\ 2-EEFA - 2-Ethylhexyl ester 2-furancarboxylic acid \\ 2-EH - 2-Ethyl-1-hexenol \\ 3-MAM - 3-O-Monoacetylmorphine \\ 6-MAM - 6-O-Monoacetylmorphine, 6-Acetylmorphine \\ $\mu \mathrm{g}$ - Microgram \\ $\mu \mathrm{mol} / \mathrm{kg}$ - Micromole per kilogram \\ $\mu \mathrm{L}$ - Microliter \\ $\mu \mathrm{m}$ - Micrometer \\ ${ }^{\circ} \mathrm{C}$ - Celsius \\ ${ }^{\circ} \mathrm{C} /$ min - Celsius per minute \\ ${ }^{\circ} \mathrm{C} / \mathrm{mL}$ - Celsius per milliliter \\ ${ }^{\circ} \mathrm{C} / \mathrm{s}$ - Celsius per second \\ $\mathrm{C}-\mathrm{C}$ - Carbon-carbon bond \\ $\mathrm{CH}_{3}-$ Methyl group \\ $\mathrm{cm}$ - Centimeter \\ $\mathrm{C}-\mathrm{N}$ - Carbon-nitrogen bond \\ CNS - Central nervous system \\ Da - Dalton \\ DC - Direct current \\ DI - Deionized water \\ $\mathrm{ED}_{50}$ - Effective median dose \\ EI - Electron impact \\ emf - Electromotive force \\ $\mathrm{eV}$ - Electron volt \\ FTP - Fentanyl transdermal patch \\ GC - Gas Chromatography \\ $\mathrm{g} / \mathrm{mol}$ - Grams per mole \\ $\mathrm{h}-$ Hour \\ $\mathrm{HCl}$ - Hydrogen chloride \\ He - Helium \\ i.d. - Inner diameter \\ $\mathrm{K}$ - Kelvin \\ $\mathrm{K} / \mathrm{s}$ - Kelvin per second \\ $\mathrm{LD}_{50}$ - Dose that is lethal to $50 \%$ of the test subjects \\ $\mathrm{m}^{2}-$ Meter squared \\ $\mathrm{m} / \mathrm{z}$ - Mass to charge ratio \\ min - Minute \\ mg - Milligram \\ $\mathrm{mL}$ - Milliliter \\ $\mathrm{mm}$ - Millimeter \\ mol - Mole \\ MPTP - 1-methyl-4-phenyl-1,2,3,6-tetrahydropyridine
}




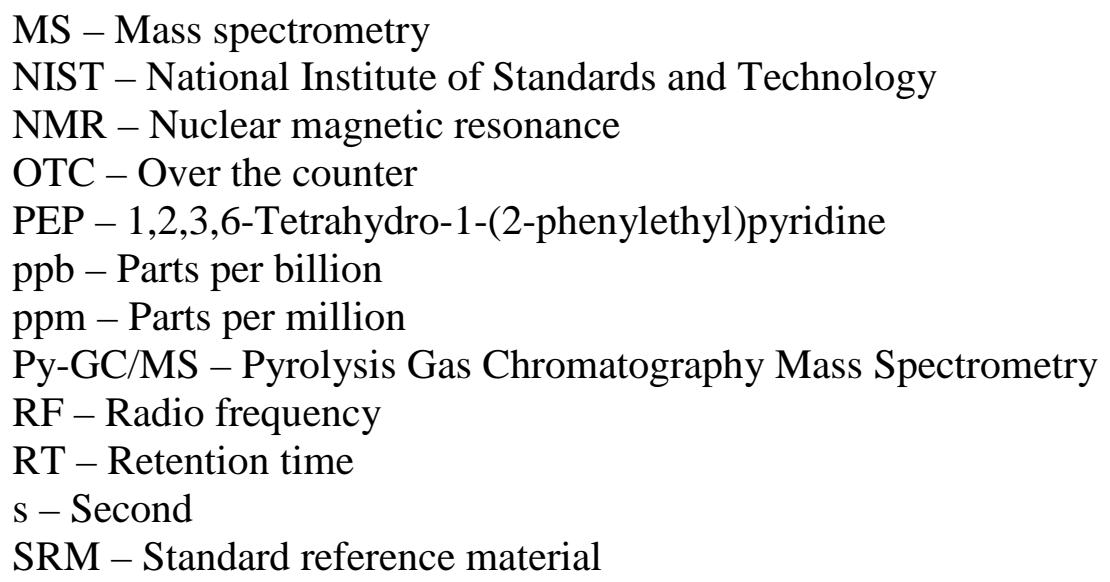




\section{Chapter 1: Introduction}




\subsubsection{Development of Research}

Smoking or inhalation of drugs has become a popular route of administration amongst drug abusers. The physiological goal drug abusers see when smoking commonly smoked drugs of abuse, as listed in Table 1-1, is to obtain the sought after drug induced sensations, which can range from euphoric, to sexual, and analgesic effects. ${ }^{1-3}$ Because smoked drugs are rapidly introduced into the bloodstream through absorption in the lungs, there is an increased risk of overdose and the potential production of toxic pyrolytic products that are not associated with other modes of administration. Thermal degradation of the parent drugs or other impurities can lead to the potential production of toxic pyrolytic products and can increase the risk of overdose. The drug pathway can also be heavily influenced by the anatomy and physiology of the lungs.

The term pyromarkers used here is any substance that is an indicator of a compound that undergoes pyrolysis. Pyrolysis is simply the breaking apart of chemical bonds by the use of thermal energy only, whereas combustion involve the exposure to oxygen to allow oxidation to take place. ${ }^{4,5}$ Analytical pyrolysis is the technique of studying molecules either by observing their behavior during pyrolysis or by studying the resulting molecular fragments that can infer much about the nature and identity of the original larger molecule. ${ }^{5}$ Detecting pyromarkers of smoked illicit drugs in human biological fluids can be used as a means of identifying individuals who are chronic users and abusers. The confirmatory methods that provide this information are widely used as tools for investigative purposes. The identification of the chemical composition of smoked drugs of abuse, in conjunction with enzymatic studies, can be used to identify potential unique pyromarkers in human biological matrices of those exposed. In addition, identification of these pyromarkers would 
aid in the understanding of pharmacological and toxicological effects associated with exposure as a result of smoking drugs of abuse. In many instances, the drug abusers unknowingly expose themselves to something more toxic than the drug itself in which case the cause of death is not what might otherwise be assumed.

Although an intravenous injection produces the fastest rate of onset of toxic effects, smoking or inhalation is often preferred by users due to the fear of contracting AIDs, hepatitis, or other blood-borne infectious diseases from needle sharing. ${ }^{6}$ Other problems of infection include abscesses, collapsed veins, necrosis, sepsis, and endocarditis. ${ }^{7}$ Needle marks, such as bruising and scar tissue, can be avoided if smoking is used instead of injection. Smoking is not perceived to be as culturally deviant and drugs abusers associate intravenous injections with "hardcore users" due to extensive tobacco and marijuana smoking in many areas. ${ }^{8}$ An increase in the availability of some drugs of abuse has led to a decline in price and subsequent shift in the trend towards smoking drugs. Also, the willingness of many individuals to smoke drugs can play a major role in the emergence of drugs, such as the crack cocaine upsurge in the 1980s. ${ }^{8}$

The process of smoking may increase the risk of other hazardous effects caused by pyromarkers that are not associated with other modes of administration. Inhalation as the route of administration of a drug incorporates the anatomy and physiology of the lung that heavily influences the drug action. This is partly due to the large surface area of the lungs and extensive capillary network in close association with the alveoli with particles less than 1 $\mu \mathrm{m}$ in diameter. ${ }^{9,10}$ First, there is the absorption of the inhaled drug. There is an increased bioavailability when the fentanyl is inhaled, given that first-pass metabolism in the liver does not occur. The fast absorption from nasal mucosa and extensive lung capillaries results in an 
immediate elevation of arterial blood drug concentration. ${ }^{6}$ Many drugs of abuse, particularly non-ionized lipophilic, drugs move rapidly from the alveolar spaces into the systemic circulation. ${ }^{8} \quad$ The total distance between this alveolar space and plasma is estimated to be about 0.5 and $2.5 \mu \mathrm{m}$ of cellular layers of the respiratory membrane. ${ }^{9,11,12}$ In addition, although absorption may take place over the entire respiratory tract, the largest surface area is presented by the alveolar epithelium with an estimated area of an adult is $35 \mathrm{~m}^{2}$ during expiration and $100 \mathrm{~m}^{2}$ in maximal inspiration., ${ }^{9,13,14}$ There is a relatively small total volume of blood in lungs $(60-140 \mathrm{~mL}$ ) that is spread over the large surface area, which results in a thin film of blood with a thickness of $8 \mu \mathrm{m}$ that is similar to the diameter of pulmonary capillaries. $^{9,12}$ This optimizes the process of absorption from the alveolar space into the plasma. When drugs are inhaled, they are delivered and distributed to target organs rapidly due to the high pulmonary capillary blood flow. Rapid delivery of drugs to the brain may also lead to other adverse effects, such as pulmonary disease or deleterious cardiovascular consequences. ${ }^{6}$ The high concentration of drug in the arterial blood can produce an intense psychoactive effect which can be qualitatively different from the drug's steady state effect. ${ }^{8}$ Other routes of administration do not typically experience the desired "rush" feeling felt by the abuser while smoking.

Secondly, uptake by the lungs allows the retention and short-term accumulation of the drug being smoked. This is due to the extensive involvement of extra- and/or intra-cellular binding to various proteins, receptors, and in some cases energy-dependent active transport. ${ }^{8}$ The lung becomes a reservoir for slow and persistent release of drug into the circulation and at high concentrations could result in local toxicity in the lungs. 
Lastly, the lung is able to metabolize some drugs and endogenous chemicals by similar pathways as the liver. ${ }^{8}$ The ultimate goal of lung cells is to facilitate the elimination of lipophilic substances that would otherwise accumulate in cellular lipids. ${ }^{15}$ The concentration of drugs brought into contact with drug-metabolizing enzymes in the lungs is much greater than the liver due to the higher blood flow, even though the lung tissues have lower concentrations of drug-metabolizing enzymes than the liver. ${ }^{8}$ Therefore, metabolism by the lung can contribute substantially to total drug metabolism. Cytochrome P450 activity is primarily in nonciliated bronchial epithelial and Type 2 alveolar cells, which are most susceptible to injury as a result of metabolism of certain drugs and chemicals to reactive metabolites. ${ }^{8}$

In addition, the thermal degradation of the parent drug or other impurities can lead to the inhalation of toxic pyromarkers. An example of this, reported in the 1980s, is heroin leucoencephalopathy, a life-threatening condition of the brain that has occurred in individuals after smoking heroin. ${ }^{16,17}$ Heroin leucoencephalopathy is not associated with intravenous injection administration and no impurities present in the drug were identified as the cause. Pyromarkers of either the heroin or impurities present in the samples may have been the cause of this condition. ${ }^{16,17}$

In all, the increased popularity of smoking drugs of abuse raises much concern about drugs that are currently being abused by other routes of administration. Consequently, little is known about whether side effects and toxicity would be increased by smoking. Table 1 provides a list of some of the most commonly smoked drugs and prescription drugs of abuse. ${ }^{1,2}$ These drugs listed on this table may be potential targets that can be evaluated using these methods developed here. 
Analytical pyrolysis is the technique of studying molecules either by observing their behavior during pyrolysis or by studying the resulting molecular fragments. ${ }^{5}$ It has frequently considered being a technique mainly applied to the analysis of natural and synthetic polymers in forms of paints, plastics, adhesives, etc.,18 Recent work in our laboratory has demonstrated the utility of analytical pyrolysis for studying pyromarkers of smoked drugs of abuse for cocaine and methamphetamine. ${ }^{19,20}$ These results have been confirmed in literature of toxicological case samples of urine. ${ }^{21,22}$ The smoking process and conditions can be mimicked by interfacing a pyroprobe unit via gas chromatography coupled with mass spectrometry (Py-GC/MS).

The goal of this dissertation is a qualitative study of the pyrolysis of fentanyl and fentanyl transdermal patches (FTPs) in the typical route of administration of inhalation through the method of "chasing the dragon" (discussed in further detail in Section 1.2.3). In addition, the pyrolysis of heroin mixed with fentanyl is also analyzed to determine significant pyromarkers.

With regard to smoking parameters, literature reviews have provided extensive data about manufactured tobacco cigarettes. Smoking machines have been used that take into account puffing and smoldering characteristics of the active process of smoking. Baker and Bishop have done extensive temperature analysis on manufactured tobacco cigarettes and have observed high temperatures of $605-770{ }^{\circ} \mathrm{C} .{ }^{23,24}$ More discussion on manufactured tobacco smoking is discussed later in section 3.1.0. The pyrolysis of fentanyl was initially analyzed and modeled after these findings of the manufactured cigarettes. However, it was later determined that temperatures of pyrolysis were much lower by the use of a smoking box with temperature probes that was created to observe actual readings of smoking fentanyl. 
This simple experiment indicated that manufactured tobacco cigarette smoking temperatures cannot be directly translated to drug abuse. These lower temperatures were then applied to further pyrolysis analysis.

Once the pyromarkers are determined, identifying metabolites formed by an in vitro breakdown of those compounds may lead to the discovery of a potential marker that could be used in human studies. Human lung and liver microsomes containing cytochrome P450 could be used for metabolic studies of the pyromarkers in the future. 
Table 1-1. Common smoked drugs of abuse with the DEA drug schedule., ${ }^{2,25}$

\begin{tabular}{|c|c|c|}
\hline $\begin{array}{c}\text { Substance: Category \& } \\
\text { Name }\end{array}$ & Examples of Commercial and Street Names & $\begin{array}{c}\text { DEA } \\
\text { Schedule }\end{array}$ \\
\hline \multicolumn{3}{|l|}{ Tobacco } \\
\hline Nicotine & $\begin{array}{l}\text { Found in cigarettes, cigars, bidis, and smokeless } \\
\text { tobacco (snuff, spit tobacco, chew) }\end{array}$ & \\
\hline \multicolumn{3}{|l|}{ Cannabinoids } \\
\hline Marijuana & $\begin{array}{c}\text { weed, pot, dope, skunk, sinsemilla, ganja, blunt, } \\
\text { dope, herb, Mary Jane, reefer, joint, green, trees, } \\
\text { smoke, bud }\end{array}$ & I \\
\hline Hashish & hash, hash oil, boom, hemp, chronic, gangster & I \\
\hline \multicolumn{3}{|l|}{ Opioids } \\
\hline Fentanyl and analogs & $\begin{array}{c}\text { Actiq, Duragesic, Sublimase: china white, Apache, } \\
\text { China girl, dance, fever, friend, goodfella, jackpot, } \\
\text { murder 8, TNT, Tango and Cash }\end{array}$ & I, II \\
\hline Heroin & $\begin{array}{l}\text { Diacetylmorphine: brown sugar, skag, smack, horse } \\
\text { dope, H, junk, skunk, white horse, China white; } \\
\text { cheese (with OTC cold medicine and antihistamine) }\end{array}$ & $\mathrm{I}$ \\
\hline Morphine & Roxanol, Durgamorph: Miss Emma, monkey, M & II, III \\
\hline Opium & $\begin{array}{c}\text { Laudanum, paregoric: big O, black stuff, block, gum, } \\
\text { hop }\end{array}$ & II, III, V \\
\hline \multicolumn{3}{|l|}{ Stimulants } \\
\hline Cocaine & $\begin{array}{l}\text { Cocaine hydrochloride: blow, candy, rock, C, } \\
\text { Charlie, coke, crack, flake, snow, toot }\end{array}$ & II \\
\hline Amphetamine & $\begin{array}{c}\text { Biphetamine, Dexedrine, Adderall: bennies, speed, } \\
\text { black beauties, crosses, hearts, LA turnaround, truck } \\
\text { drivers, uppers }\end{array}$ & II \\
\hline Methamphetamine & Desoxyn: chalk, fire, ice, meth & II \\
\hline Methylphenidate & Ritalin: JIF, MPH, vitamin R & II \\
\hline \multicolumn{3}{|l|}{ Dissociative Anesthetics } \\
\hline Ketamine & Ketalar SV: cat Valium, Special K, vitamin K & III \\
\hline Phencyclidine and analogs & $\begin{array}{l}\text { Phencyclidine: angel dust, boat, hog, love boat, peace } \\
\text { pill }\end{array}$ & I, II \\
\hline Salvia divinorum & $\begin{array}{l}\text { Salvia, Shepherdess's Herb, Maria Pastora, magic } \\
\text { mint, Sally-D }\end{array}$ & \\
\hline \multicolumn{3}{|l|}{ Hallucinogens } \\
\hline Mescaline & peyote, cactus, buttons, mesc & $\mathrm{I}$ \\
\hline
\end{tabular}




\subsubsection{Compounds of Interest}

The compounds of interest in this study were fentanyl and heroin that are classified as opiates. Table 1-2 shows the structure and basic properties of both. Opiates is a term that refers to compounds that are not only derived from the opium poppy, Papaver somniferum, but also applies to compounds that are either pharmacologically similar or closely related structurally to morphine. ${ }^{3}$ Narcotic is also a term used and is similar to the opiates that mean a central nervous system (CNS) depressant that has a numbing action. The opium poppy is cultivated in temperate climates and is indigenous to Burma, Laos, and Thailand, commonly referred to during the last half of the $20^{\text {th }}$ century as the Golden Triangle. ${ }^{26}$ In addition to those three countries, much of the world's illicit supply of opium is cultivated in Afghanistan, Colombia, Mexico, and Pakistan, with Afghanistan being the largest

producer. $^{26,27}$ Opiates are typically divided into the naturally occurring, semi-synthetics and synthetics. Morphine and codeine are naturally occurring opiates. Semi-synthetics that are manufactured most easily by using starting materials that are themselves opiates are considered as hydrocodone, hydromorphone, oxycodone, oxymorphone, and heroin. Fentanyl is a synthetic opiate that may be prepared by synthesis from non-opiate precursors.

The mechanism of action of opiates begins with the opioid receptors within the brain, spinal cord, and other organs which structures bind natural, endogenous compounds known as endorphin peptide transmitters or beta endorphins. ${ }^{3}$ The endorphins bind to the opioid receptors that allow for the diminishing of the perception of pain throughout the pain pathway. Opiates enhance the opioid receptor response by stimulating these receptors in a manner similar to that induced by the natural compounds, endorphins. ${ }^{3}$ The binding of the receptor by the endogenous compound, beta endorphins, or the exogenous opiates inhibits the 
release of a specific neurotransmitter or the substance $\mathrm{P}$ in the pain pathway. Opioid dependency is believed to be related to the opioid receptors existing within the limbic system. It is this part of the brain that is related to the drug dependence. It is this binding of the opiates within the limbic system that is presumably associated with the drug dependence that develops within the user.

The four kinds of opioid receptors are listed in the Table 1-3. The $\delta$ and $\mu$ receptors have the same functions, but are located in different regions. Receptor stimulation causes euphoria, analgesia, sedation, and respiratory depression. Those overdosed on opiates are in CNS depression with side effects ranging from lethargy to deep coma. ${ }^{3}$ Severe, acute overdose may result in death and is preceded by respiratory depression to the point of apnea, myocardial depression, rhabdomyolysis, seizures, and coma. The antidote of choice is naloxone (Narcan $\left.{ }^{\circledR}\right)$, which is a pure opioid antagonist that has no actions that are additive to those of opiates. ${ }^{3}$ Naloxone displaces the opiate molecules form their receptor sites in the brain. Within 1 or 2 minutes respiration is dramatically improved with a dose of just 0.4 mg. ${ }^{3}$ Depending on the severity of overdose, naloxone is given repeatedly since it has a short half-life of about $60 \mathrm{~min}^{3}$ 
Table 1-2. Properties and strucutre of fentanyl and heroin. ${ }^{28,29}$

\begin{tabular}{|l|l|l|}
\hline \\
\hline
\end{tabular}


Table 1-3. Opiate receptors.

\begin{tabular}{|l|l|l|}
\hline Receptor & Location & Actions \\
\hline $\mathrm{Mu}(\mu)$ & Cerebral cortex, thalamus & $\begin{array}{l}\text { Analgesia, respiratory depression dependence, } \\
\text { euphoria, constipation }\end{array}$ \\
\hline Delta $(\delta)$ & Frontal cortex, limbic system & Euphoria, analgesia, respiratory depression \\
\hline Kappa $(\kappa)$ & Spinal cord & $\begin{array}{l}\text { Spinal analgesia, sedation, physical dependence, } \\
\text { miosis }\end{array}$ \\
\hline Sigma $(\sigma)$ & Endoplasmic reticulum & $\begin{array}{l}\text { Hallucinations, dysphoria, tachyardia, vasomotor } \\
\text { stimulation }\end{array}$ \\
\hline
\end{tabular}




\subsubsection{Fentanyl}

Fentanyl is a lipophilic synthetic opiate used for anesthesia and analgesia. It was originally synthesized in Belgium in the late 1950s and patented by Janssen-Cilag International $1963 .^{30}$ It was introduced to the United States in the 1970 s for the use in the induction of anesthesia and the relief of postoperative pain. ${ }^{31}$ Aside from clinical therapeutic pertinence, it is the euphoric effects of fentanyl that are sought after by drug users, making it increasingly popular as a choice drug of abuse..$^{27,31-35}$ Fentanyl is approximately 50 to 100 times more potent than morphine and 30-50 times more potent than heroin depending on the physiological or behavioral endpoints being measured, the route of administration, and other factors. $^{36}$

Fentanyl may be administered by the transdermal route in a form of the FTP as an effective alternative to oral morphine in patients with stable opioid requirements. ${ }^{37,38}$ In particular, in patients who are not able to take oral medication, it provides a continuous delivery of fentanyl and is a less invasive alternative to subcutaneous opioid infusion. ${ }^{37,38}$ The form of fentanyl used in the FTPs is fentanyl citrate. The fentanyl citrate has a higher melting point of $153-154{ }^{\circ} \mathrm{C}$, instead of $83-84{ }^{\circ} \mathrm{C}$ as noted in Table $1-2 .{ }^{39}$ FTPs are often obtained through the black market, prescription fraud, and improper disposal. The reservoir FTPs has been in use since the early 1990s, but was associated with misuse and was

consequently discontinued and phased out by most companies by $2009 .^{31-33,38,40,41}$ JanssenCilag International developed the Durogesic ${ }^{\circledR}$ D Trans ${ }^{\circledR}$ developed the matrix FTPs (Figure 1-1B) after the initial reservoir FTPs (Figure 1-1A). To limit the potential of fentanyl abuse by the extraction of the fentanyl gel from the drug reservoir of the FTPs, an alternative generation of transdermal matrix FTP was developed where the active drug is dissolved in a 
semi-solid polymer matrix. Other companies have developed different technologies of the matrix FTPs, such as Martifen (Nycomed Roskilde, Denmark), where fentanyl-containing dipropylene glycol droplets dispersed in a silicone matrix. The plastic matrix makes the patches far less suitable to transbuccal use and far more difficult to use illicitly than its gel filled counterpart.

There have been reports of abuse of reservoir FTPs by the following pathways: oral ingestion by either licking or chewing on the FTP; ${ }^{42}$ intravenous injection; ${ }^{43}$ transdermal application of multiple patches cutaneously; ${ }^{44}$ rectal insertion; ${ }^{45}$ and inhalation by volatilization. ${ }^{41}$ One of the first reported cases of death by inhaled fentanyl was published by Mardquardt et al. in 1994. ${ }^{41}$ The fentanyl in a gel matrix was scraped off the drug reservoir of a FTP, heated on aluminum foil, and then inhaled. Another means of intoxication is by smoking illicitly manufactured fentanyl laced with heroin or cocaine, both of which are reported to have been prevalent in Delaware, Illinois, Maryland, Michigan, Missouri, New Jersey, and Pennsylvania. ${ }^{36}$ 

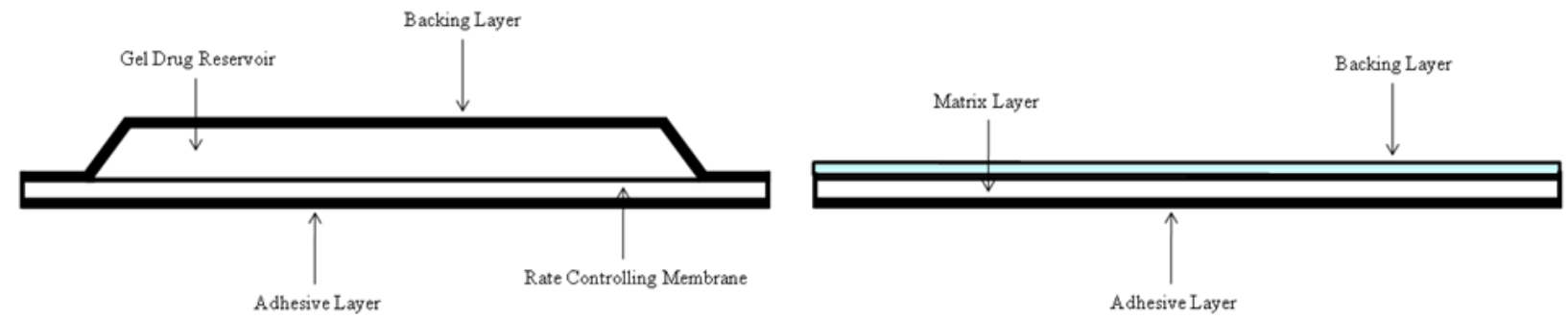

(A)

(B)

Figure 1-1. Schematic representation of a reservoir type patch (A) and a matrix type patch (B). 
Fentanyl is rapidly metabolized in the liver and intestinal catalyzed by CYP3A4. ${ }^{46}$ Norfentanyl and despropionly fentanyl are two commonly reported metabolites of fentanyl in the human body produced by piperidine N-dealkylation and amide hydrolysis, respectively. $^{46,47}$ There is a significant overlap between therapeutic and toxic fentanyl concentrations in serum. ${ }^{31}$ Typical therapeutic and toxic fentanyl concentrations in serum are 1-3 ppb and $>3$ ppb, respectively. ${ }^{31,41,42}$ However, there are some reports of fentanyl deaths from as low as $2 \mathrm{ppb}^{33}$ and therapeutic concentration of 8-9 ppb perhaps due to gain in tolerance. $^{35}$ Tolerance simply refers to a phenomenon in which the exposure to a drug results in the diminution of an effect or the need for a higher dose to maintain an effect that is dependent on genetics and/or acquired tolerance. ${ }^{48}$ Therapeutic concentrations can be even greater with respiratory assistance, since, like all opioids, fentanyl suppresses respiration. ${ }^{33}$ 


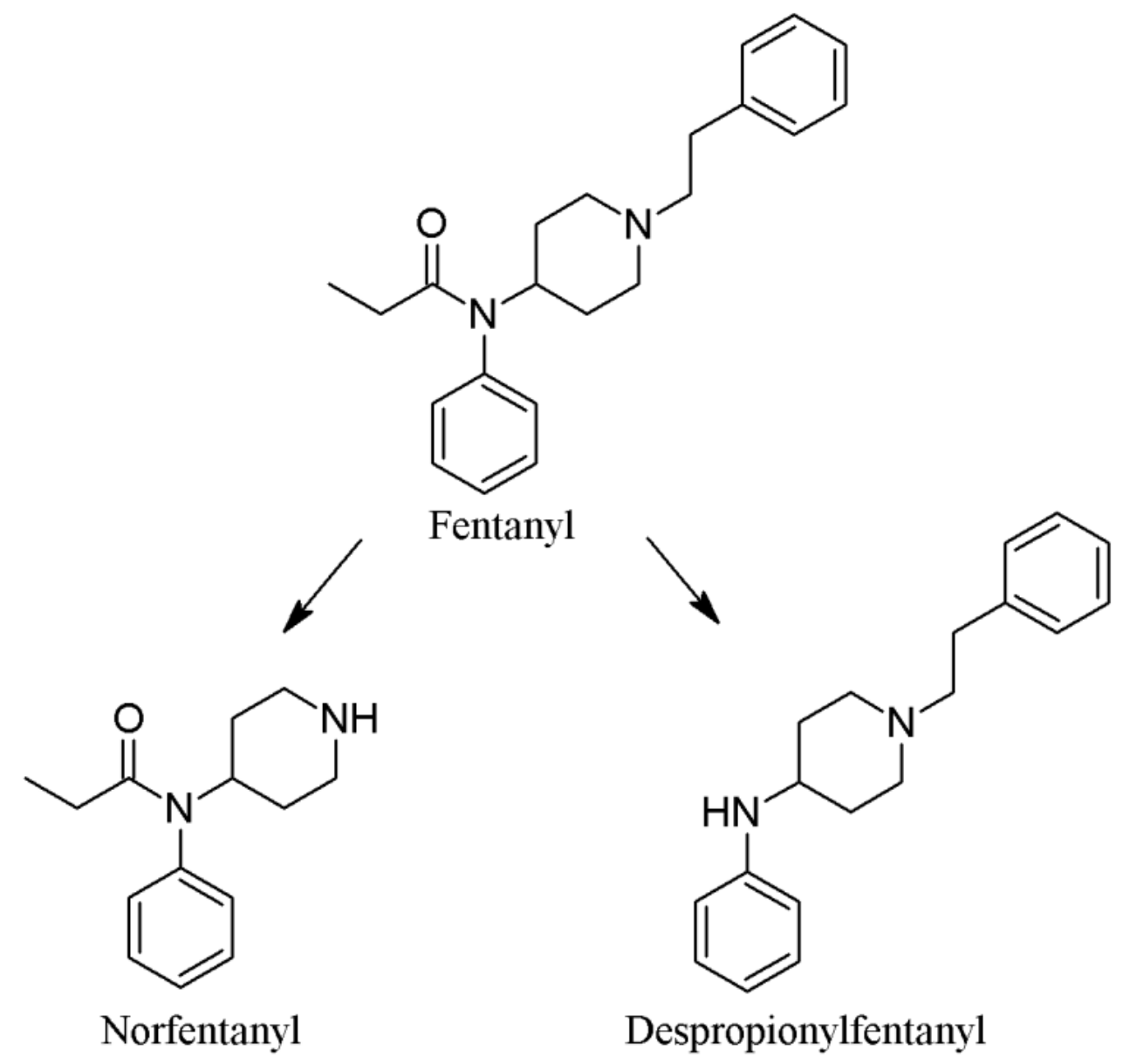

Figure 1-2. Known fentanyl metabolites. 


\subsubsection{Heroin}

Heroin (diacetylmorphine) was first synthesized and introduced into clinical practice over 125 years ago as a non-addictive treatment for soldiers since they had become physically dependent on morphine during the American Civil War. ${ }^{26}$ In North American, heroin obtained are primarily produced illicitly in clandestine chemical laboratories located in Colombia, France and Italy. ${ }^{26}$ In the 1980 s, primary route of administration of heroin was through intravenous injection. However, the risk of transmitting HIV through shared needles and the increased availability of significantly purer form of heroin from $5 \%$ to over $90 \%$ the preferred route of administration had shifted to intranasal snorting and smoking. ${ }^{26}$ Intranasal snorting of heroin can cause acute, potentially life-threatening exacerbation of asthma. With a short elimination half-life, heroin is not detectable in plasma after oral or rectal administration.

When heroin is orally ingested, it is rapidly deacetylated in the liver and GI tract and undergoes first-pass hepatic metabolism, to morphine. ${ }^{26}$ Therefore, heroin offers no advantage over morphine and similarly, heroin offers no advantage over methadone in opiate-dependence maintenance programs. ${ }^{26}$ Esterase enzymes that are present in the blood, the liver, and the brain rapidly converts heroin to 6-monacetylmorphine (6-MAM) and morphine (Figure 1-3). ${ }^{7,49-51}$

Literature reports have suggested that deacetylation (hydrolysis) of 6-MAM to morphine is significantly impaired by the presence of high blood alcohol concentrations which has been postulated to contribute to the higher rate of heroin over dose deaths when alcohol intoxication is simultaneously present. $^{26}$ Administration through intravenous injection rapidly deacetylates heroin to 6-MAM with which is further deacetylated to 
morphine and undergoes metabolism to morphine-3-glucuronide and morphine 6-Oglucuronide. $^{26}$ The elimination half-life of heroin after intravenous injection is 1.3 to 2.2 $\min ^{26}$ Even in laboratory analysis, heroin hydrolyzes in aqueous solution to 3-Omonoacetylmorphine (3-MAM) and 6-MAM and morphine to a significant extent at room temperature. $^{52}$

The dangers of intravenous administration of heroin are increased due to many possible health complications that typically result from the bad quality of the product. The quality of the heroin can be limited by impurities, adulterants, diluents, and contamination with microorganisms. ${ }^{53-56}$ Inhalation of heroin therefore poses several advantages over intravenous administration besides blood-borne infectious diseases. Through inhalation, a given dose takes more time to consume that allows the abuser to have more control of the dosage and lessens the risk of drug overdose. ${ }^{7}$ In addition, the toxicity to systemic exposure to impurities and adulterants present in street heroin is less likely since there some will not be volatilized for inhalation exposure. ${ }^{7}$ Conversely, the heating of street heroin will cause degradation of components present that could be of more health hazardous than intravenous injection. 

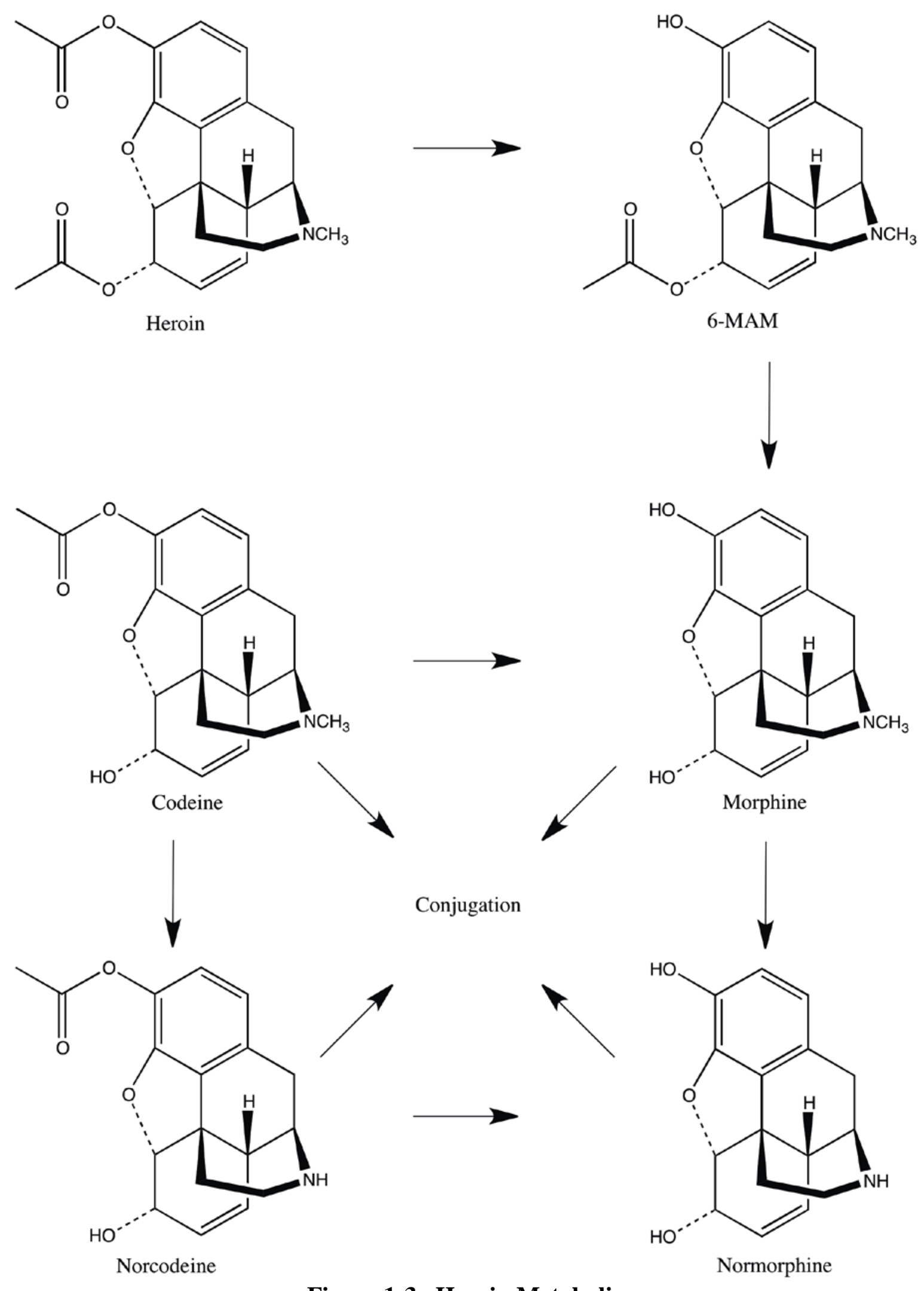

Figure 1-3. Heroin Metabolism. 
When heroin is heated to produce vapors for inhalation, significant amounts of the drug is decomposed during the heating process. In 1985, Cook and Brine studied the pyromarkers of both heroin and heroin $\mathrm{HCl}$ using 20-41 mg of drug on a quartz boat and connected with dry and bubble traps to collect the pyromarkers. The traps were solvent washed and the collected pyromarkers were analyzed by a combination of proton and 13carbon NMR and MS. It was determined that 6-MAM, N,6-O-diacetylnormorphine, and N,3-O,6-O-triacetylnormorphine were the major pyromarkers at $250{ }^{\circ} \mathrm{C}$, with $3,4-$ diacetoxyphenanthrene being the minor pyromarker found (Figure 1-4). ${ }^{57-59}$

Unlike fentanyl, the potency of heroin administration is lowered through the route of inhalation rather than injection. This can be evaluated by the effective median dose $\left(\mathrm{ED}_{50}\right)$. Heroin was somewhat less potent than by inhalation ( $\left.\mathrm{ED}_{50} 1.9 \mu \mathrm{mol} / \mathrm{kg}\right)$ administration than intravenous injection $\left(\mathrm{ED}_{50}\right.$ of $\left.0.69 \mu \mathrm{mol} / \mathrm{kg}\right) .{ }^{60} \quad$ In contrast, a similar compound like morphine has a higher potency by inhalation $\left(\mathrm{ED}_{50} 0.77 \mu \mathrm{mol} / \mathrm{kg}\right)$ administration than intravenous injection $\left(\mathrm{ED}_{50} 3.9 \mu \mathrm{mol} / \mathrm{kg}\right){ }^{60}$ This is likely due to the fact that 6-MAM was found to be more potent at the $\mu$-receptors than morphine. Although 6-MAM is a major pyromarker, it accounted for less than $5 \%$ of the recovered sample in one study, ${ }^{60}$ whereas, heroin rapidly converts to 6-MAM in the blood stream during intravenous injection. The exposure to 6-MAM is higher during intravenous injection rather than inhalation. Inhalation exposure to heroin produced significantly more analgesic effects when volatized at $250{ }^{\circ} \mathrm{C}$ than at $200^{\circ} \mathrm{C}^{60}$

In 1987, Huizer evaluated the volatization of heroin under a variety of conditions, particularly in the presence of various diluents often used in the smoking process. ${ }^{61}$ "Heroin pills" or "red pills" were seen as early as the 1920s in China, which were mixtures typically 
of heroin, caffeine, a cinchona alkaloid (quinine cinchonine, or cinchonide), strychnine, and aspirin or salicyclic acid mixed with starch, cane sugar or lactose, perfume and dye to color the pills. ${ }^{62}$ Today, typical diluent for heroin smoking are caffeine, strychnine, lactose, acetaminophen, and diphenhydramine. ${ }^{26,57,63-65}$ Studies have shown that caffeine enhanced the volatilization and changes the ratio of the pyromarkers with 6-MAM to be the most abundant. $^{66}$ Thus, the amount of heroin inhaled by smoking is strongly dependent on the presence of the diluents. Diluents can also influence the ratio of the pyromarkers.

Near the end of 2005 and early into 2006, the government and media reported an increase in the number of individuals who have overdosed on heroin that was laced with fentanyl as a diluent. The largest number of reported fatalities was in Chicago, in addition with Pittsburgh, St. Louis, and Camden, New Jersey reporting cases as well. ${ }^{67}$ It was thought that these samples were sold by a network or gang that was producing tainted heroin; to counter this, they added fentanyl to improve the low quality heroin. The first time drugs were mixed with fentanyl were sold on the street was documented in Orange County, CA, in 1979. ${ }^{68}$ As previously noted, the pyromarkers of heroin are known. However, the combination of fentanyl and heroin pyromarkers has not been studied and is evaluated here. 


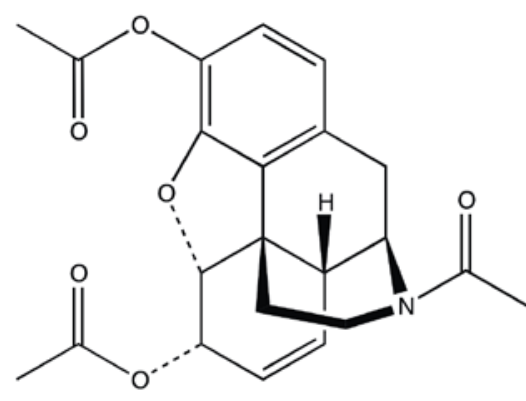

$\mathrm{N}, 3-0,6-0$-triacetylnormorphine

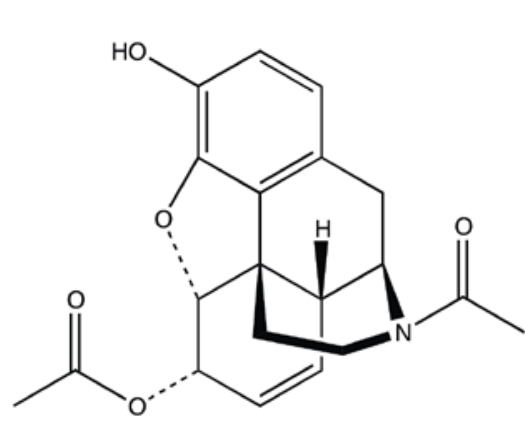

N,6-0-diacetylnormorphine
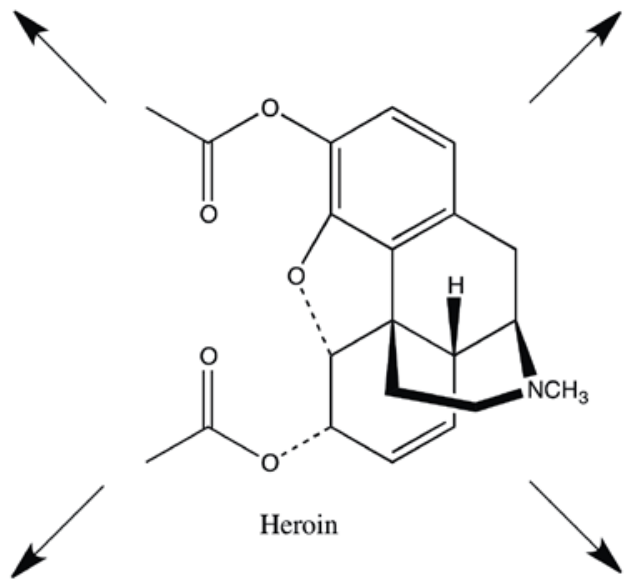
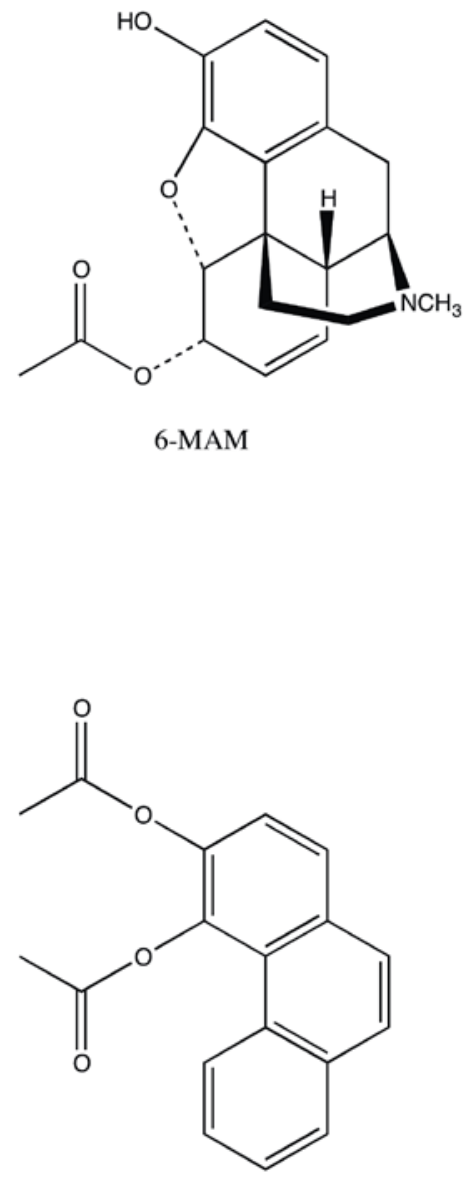

3,4-diacetoxyphenanthrene*

Figure 1-4. Known pyromarkers of heroin. * Denotes minor pyromarker. 


\subsubsection{Smoking Opioids by "Chasing the Dragon”}

The coming of the method "chasing the dragon" is due in part to the smoking of heroin. The first report of heroin smoking originated in Shanghai, China, in the 1920s, where it then spread across much of Eastern Asia and to the United States over the next decade. ${ }^{69}$ The smoking of heroin existed alongside the longer established use of opium both by swallowing and by smoking. ${ }^{69}$ Early accounts of heroin smoking involved smoking heroin pills in which small china jar or porcelain vase into which a hole had been drilled and through which the heroin pill was heated gently so that the heroin smoker could inhale the fumes of the pill through a bamboo tube. ${ }^{62,69}$

An early account of “chasing the dragon” is described in Bulletin on Narcotics, 1958. Cheap crude quality heroin that is typically unfit for injection, had a tendency to run into a single mass when heat was applied and the outsides became charred creating a heat barrier resulting in an incomplete combustion..$^{70}$ A barbiturate, commonly known at the time as “daai fan,” was sold with the crude heroin which prolonged the effects of the heroin and aided in the sublimation during heating. ${ }^{71}$ The refinement of the technique soon utilized a piece of foil, a straw, and cardboard. Both base powder and heroin placed half an inch apart in the crease of the foil where then the flame from the lit piece of cardboard is applied. The foil is then tilted back and forth whilst the flame is applied directly under the crease; at the same time the smoker directs the straw, which is held in the mouth over the foil and inhales the fumes emanating from the heated mixture. ${ }^{70}$ To obtain the best effect the abuser chases the "smoky tail" of the liquid with the straw in mouth while moving the foil back and forth over the flame until nothing is left on the foil except for a black stain. ${ }^{70}$ For this reason, the whole procedure was phrased as "chui lung” or "chasing the dragon."70 
Today, websites and blogs showcase stories of individuals of utilizing this method for abusing fentanyl and FTPs. ${ }^{72-74}$ Prior to the dwindling manufacturing of drug reservoir FTPs, abusers would extract the fentanyl gel from the drug reservoir and placed it on a piece of aluminum foil, heated with a lighter until it sizzles, and then vapors are inhaled through a straw or pen casing. Matrix type FTPs were smoked similarly by placing pieces of the FTPs on foil, thus introducing the pyrolysis of plasticizers and adhesives that were incorporated in the manufacture of the FTPs.

\subsubsection{Methods of Degradation}

Pyrolysis is a process that breaks the chemical bonds of a compound using thermal energy. The products produced by pyrolysis are typically referred to as pyrolytic products. To study the pyromarkers of fentanyl, recent work in this laboratory has demonstrated the utility of analytical pyrolysis. ${ }^{75,76}$ Heating fentanyl beyond a certain temperature will allow for thermal degradation since its chemical bonds have a limited thermal stability. These chemical changes are similar to those occurring during the smoking process and high temperature conditions.

Analytical pyrolysis allows for reproducible control of parameters such as temperature, heating rate, and atmosphere. This enables researchers to study the fragmentation products that are characteristic of the parent compound. ${ }^{77}$ Fragmentation is primarily based upon the bond strengths between each atom of a molecule, where weaker bonds are broken first. Thermal degradation reactions, given from most common to least, include eliminations, fragmentation, rearrangements, oxidations, reductions, substitutions, and additions (Figure 1-5). 
(A) Eliminations

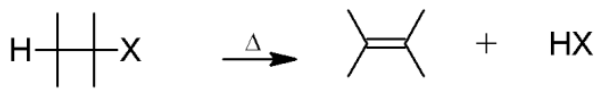

(B) Fragmentation

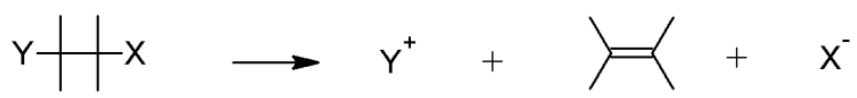

(C) Rearrangements

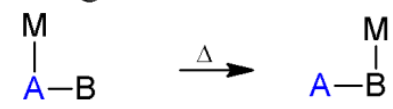

(D) Oxidations/Reductions<smiles>O=Cc1ccccc1</smiles>

(E) Substitutions

$$
\ddot{Y}+R-X \longrightarrow R-Y+\ddot{X}
$$

(F) Additions

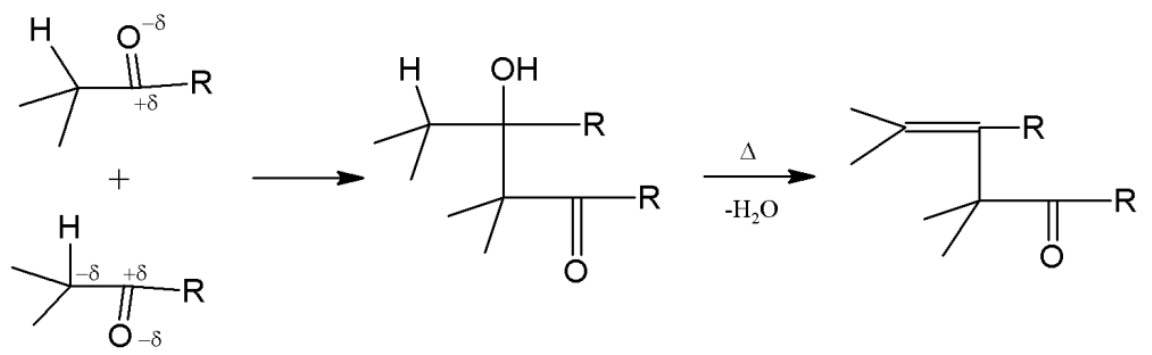

Figure 1-5. Scheme of common degradation mechanisms observed in pyrolysis. 
Pyrolytic elimination is the most common amongst the above processes. Elimination does not always take place from the 1,2 positions, and depending on which atoms are involved in the elimination, these reactions are classified as $\alpha$-eliminations, $\beta$-eliminations, 1,3-eliminations, etc. ${ }^{78}$ Based on their mechanism, these eliminations has an radical $E_{i}$ mechanism or in unusual cases an $\mathrm{E}_{1}$ or $\mathrm{E}_{2}$ mechanism. ${ }^{78}$ Since pyrolytic elimination takes place with no other reagent present and often requires gas phase, the typical $E_{2}$ mechanism where a proton is pulled by a base is not common. ${ }^{77}$

Pyrolytic $\alpha$-eliminations involve two leaving groups connected to the same carbon (Figure 1-6A). Typically $\alpha$-eliminations are encountered when the more common $\beta$ elimination is not possible. Pyrolytic $\beta$-eliminations are the most common type of elimination reactions that take place typically by an $\mathrm{E}_{\mathrm{i}}$ mechanism with two groups lost from adjacent atoms (Figure 1-6B). If a double bond is present during an $\mathrm{E}_{\mathrm{i}}$ type pyrolytic reaction the formation of a conjugate system is preferred if sterically possible. Otherwise, the orientation in the pyrolytic elimination is statistical and is determined by the number of $\beta$ hydrogens. Any newly formed double bond goes toward the least substituted carbon as governed by Hofmann's rule. $^{78}$

In addition, there are eliminations involving free radicals that are frequent at temperatures between $600{ }^{\circ} \mathrm{C}$ and $900{ }^{\circ} \mathrm{C} .{ }^{78}$ The initiation reaction typically takes place with a high probability at the bonds with a lower energy, whereas at higher temperatures, even bonds with higher energy are cleaved. ${ }^{78}$ Figure 1-7 shows a generic elimination involving free radicals that includes the initiation, propagation, and termination step. 
(A) $\alpha$-Eliminations
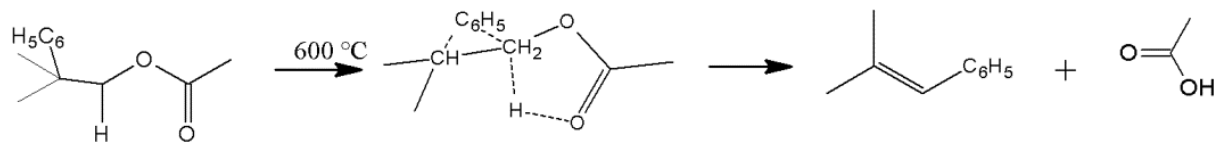

(B) $\beta$-Eliminations
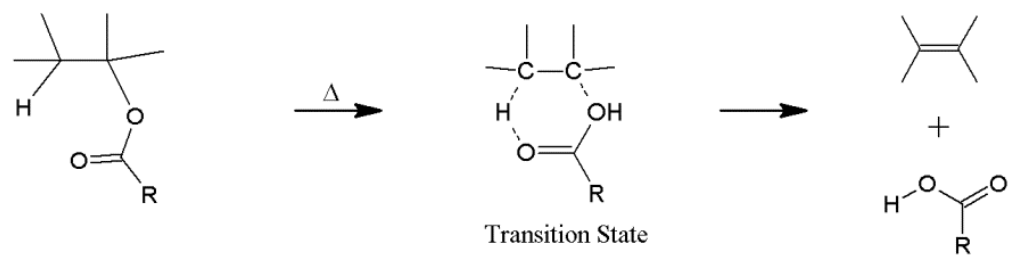

(C) 1,3-Eliminations<smiles>CC(=O)OC1CC2CCC1C2</smiles>
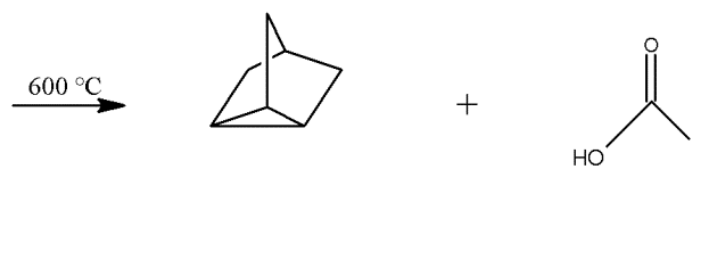

Figure 1-6. Pyrolytic Elimination Reactions. 


$$
\begin{aligned}
& \text { Initiation: } \mathrm{R}_{2} \mathrm{CH}-\mathrm{CH}_{2} \mathrm{X} \stackrel{\Delta}{\rightarrow} \mathrm{R}_{2} \mathrm{CH}-\mathrm{CH}_{2}+\mathrm{X} \\
& \text { Propagation: } \mathrm{R}_{2} \mathrm{CH}-\mathrm{CH}_{2} \mathrm{X}+\mathrm{X} \rightarrow \mathrm{R}_{2} \mathrm{C}-\mathrm{CH}_{2} \mathrm{X}+\mathrm{HX} \\
& \mathrm{R}_{2} \mathrm{C}^{\cdot}-\mathrm{CH}_{2} \mathrm{X} \rightarrow \mathrm{R}_{2} \mathrm{C}=\mathrm{CH}_{2}+\mathrm{H}^{\cdot} \\
& \text { Termination: } 2 \mathrm{R}_{2} \mathrm{C}-\mathrm{CH}_{2} \mathrm{X} \rightarrow \mathrm{R}_{2} \mathrm{C}=\mathrm{CH}_{2}+\mathrm{R}_{2} \mathrm{CX}-\mathrm{CH}_{2} \mathrm{X} \\
& 2 \mathrm{X}^{\cdot} \rightarrow \mathrm{X}_{2} \\
& \mathrm{R}_{2} \mathrm{C}^{*}-\mathrm{CH}_{2} \mathrm{X}+\mathrm{X} \cdot \mathrm{R}_{2} \mathrm{C}=\mathrm{CH}_{2}+\mathrm{HX} \\
& \text { Final: } \mathrm{R}_{2} \mathrm{CH}-\mathrm{CH}_{2} \mathrm{X} \stackrel{\Delta}{\rightarrow} \mathrm{R}_{2} \mathrm{C}=\mathrm{CH}_{2}+\mathrm{HX}
\end{aligned}
$$

Figure 1-7. Pyrolytic elimination reactions involving free radicals. 
The nature of molecular fragments generated in pyrolysis is analogous to ion formation in electron impact mass spectrometry. ${ }^{78}$ The difference is that during pyrolysis, there are no ions formed because the energies involved in the pyrolytic process are much lower than the required ion formation. Also, pyrolysis can be done on many molecules in condensed phase and can be performed at different temperatures. ${ }^{78}$ Figure $1-6 \mathrm{~B}$ is an example of a Grob fragmentation where one carbocation is the leaving group.

Rearrangements are very common in pyrolytic reactions following eliminations and fragmentation. Rearrangement reactions involve an atom or migration group moving from one place to another on the same molecule. Figure 1-6C is an example of a 1,2 shift that is a common rearrangement reaction. Rearrangement can also be observed in positions that are farther apart and usually involves a free radical being formed followed by a free radical rearrangement occurring between the two positions. ${ }^{77}$

Oxidations, reductions, substitutions and additions more commonly follow an initial step that produces a elimination, fragmentation, or a rearrangement. ${ }^{78}$ However, these reactions may sometimes be the first step in pyrolysis and are caused by higher reaction rates as a result of increased temperature. In general, all of the degradation products, as well as minor constituents and deviations can be simplified in three statements: 1) the mechanism behind degradation involves free radical processes and are initiated by breaking the weakest bond first; 2) pyromarkers are based on the stability of the free radicals involved and on the stabilities of the product molecules; 3) free radical stability follows the order of $3^{\circ}>2^{\circ}>1^{\circ}$ $>\mathrm{CH}_{3}{ }^{5}$

To mimic realistic smoking conditions, pyrolysis must be performed in the presence of additional catalysts such as oxygen, water and hydrogen. This can be explained by 
considering oxygen, which has the properties of a diradical, since in its ground state each of the two higher occupied molecular orbitals contain an unpaired electron. Figure 1-7 shows that diradical oxygen can rapidly react with many other radicals in a chain oxidation. Since a pyrolysis reaction typically generates free radicals, the formation of hydroxyperoxide is likely. Oxygen may also react at the elevated temperatures with the parent compound that is subject to pyrolysis. ${ }^{78}$

The pyrolysis process can be more than the decomposition of one single molecular species, since the products of the initial decomposition may undergo further reaction under the influence of heat. Also, the initial process can be unique or more pyrolytic reactions occurring simultaneously can contribute to the generation of the pyromarkers. Even the cooling rate of the pyromarkers can influence the pyrolysis outcome. ${ }^{78}$ 


$$
\begin{gathered}
\mathrm{R} \cdot+\mathrm{O}_{2} \rightarrow \mathrm{ROO} . \\
\mathrm{ROO}+\mathrm{RH} \rightarrow \mathrm{ROOH}+\mathrm{R} .
\end{gathered}
$$

Figure 1-8. Pyrolysis in the presence of oxygen. 


\subsubsection{Instrumentation}

A thermocouple was used in this work for measuring temperatures associated with smoking FTPs by means of "chasing the dragon.” The pyrolysis gas chromatography/mass spectrometry (Py-GC/MS) was used to mimic analytically the smoking conditions to analyze the products produced by application of different temperatures of heat.

\subsubsection{Thermocouple}

The thermocouple is one of the most common temperature transducers that essentially convert thermal energy to electric energy. It is the amount of electric energy that is produced, that can be used to measure the temperature, which is based on the continuous current that flows in the thermoelectric circuit. T. J. Seebeck discovered this thermoelectricity in 1821. It was first suggested that this could be used for high temperature measurement within five years of this discovery by A.C. Becquerel. ${ }^{79}$ Seebeck's work showed that a small electric current will flow in a close circuit composed of two dissimilar metallic conductors when their junctions are kept at different temperatures. ${ }^{80}$ In Figure 8a, the current flows from the positive metal $\mathrm{C}$ with respect to metal $\mathrm{B}$ at the hot junction where temperature is measured. Under these conditions, the electromotive force (emf) is produced and is known as the Seebeck emf. It is the pair of conductors, or thermocouple elements, which constituted the thermoelectric circuit that is called a thermocouple. ${ }^{80}$ If this circuit is broken at the center, the net open circuit voltage (the Seebeck voltage) is a function of the junction temperature and the composition of the two metals. ${ }^{81}$ All dissimilar metals exhibit this effect and for small changes in the temperature the Seebeck voltage is linearly proportional to temperature (eq. 1).

$$
\Delta e_{A B}=\alpha \Delta T
$$


Where $\alpha$ is the Seebeck coefficient that is constant of proportionality, $\mathrm{T}$ is the temperature and $e_{A B}$ is the Seebeck voltage.

The cold junction of the thermocouple is connected to a voltmeter and the leads of the voltmeter themselves create a new thermoelectric circuit (Figure 1-9B). Higher the temperature difference creates higher voltage. The right pair of metals is needed to measure the targeted temperatures of $20 \mathrm{~K}$ to $2000 \mathrm{~K}$. There is seven "standardized thermocouples" with different alloy combinations that has internationally agreed reference tables for thermal emf vs. temperature with letter designations ${ }^{82}$. Base metal thermocouples are composed of inexpensive metals like nickel, iron, and copper. The thermocouple types, E, J, K, N, and T are among this group. These are the most commonly used type of thermocouple. Each leg of these different thermocouples is composed of a special alloy, which is usually referred to by their common names. 
A)
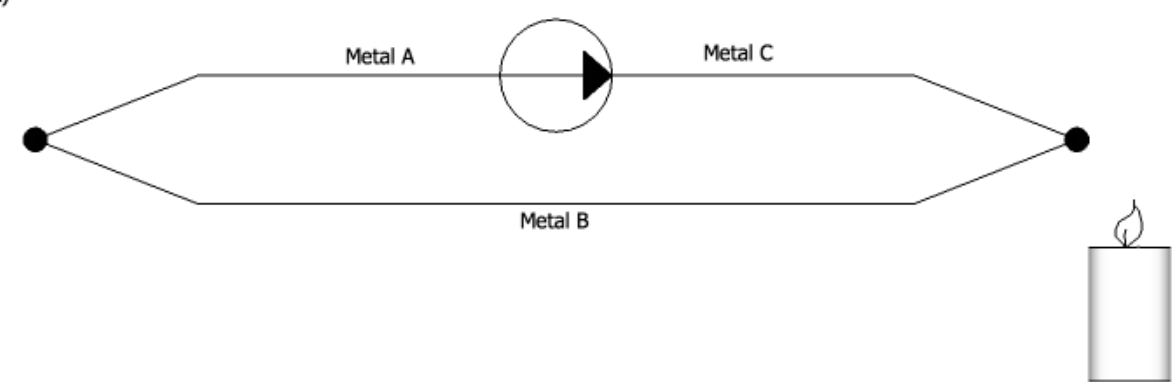

B)

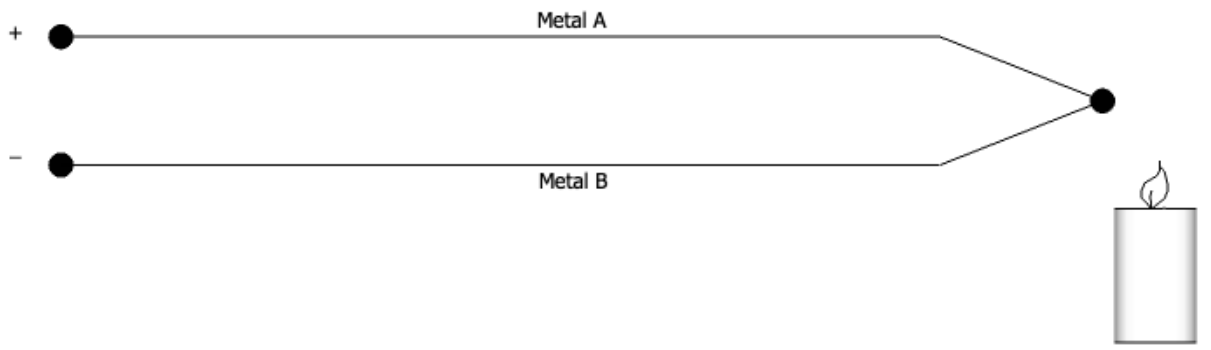

Figure 1-9. Schematic of A) the basic thermoelectric circuit and B) a practical circuit for thermocouple voltage measurements. 


\subsubsection{Py-GC/MS}

The components of a pyroprobe unit consisted of a pyroprobe, trap, accessory, valve oven, and the transfer line (Figure 1-10). The pyroprobe is interfaced with a heated transfer line to a GC/MS with an electron ionization source and a single quadrupole mass analyzer. For most commercially available pyrolyzers, the sample size should be in the low microgram range to produce better results than larger ones. ${ }^{83}$ The unit consist of three modes of operation that include: Clean, to remove residual material from the filament; Dry, to remove solvent from a sample deposit; and Run, for pyrolysis of the sample to be analyzed. Here, solid samples of approximately 10-100 $\mu \mathrm{g}$ are sandwiched between quartz wool inside the quartz tube. Liquid samples of approximately $10 \mu \mathrm{g}$ are injected in the middle of the quartz wool plug inside the quartz tube and put through the dry method prior to pyrolysis. The quartz tube is inserted into the platinum coil filament of the pyroprobe and is capable of reaching temperatures of up to $1400{ }^{\circ} \mathrm{C}$ at rate of $0.01{ }^{\circ} \mathrm{C} / \mathrm{min}$ to $2000{ }^{\circ} \mathrm{C} / \mathrm{s}^{84}$ The microprocessor of the unit controls the temperature of the filament by calculating the resistance of the filament at setpoint temperature and supplying the correct voltage to achieve that temperature. ${ }^{84}$ The pyroprobe is inserted inside the heated chamber, known as the accessory region, of the pyrolysis unit on the left of Figure 1-10.

The unit can operate in both non-trap and trapping modes. The use of the trap allows the pyrolysis to be performed in a different atmosphere from the carrier gas. ${ }^{5,18,85}$ In trapping mode, there is a second heated zone connected to the valve oven, which there is an option to add a reactant gas, such as air, to the volatile sample in the trap region. Figure 1-11 is a representation of the pyroprobe temperature program in non-trapping mode and trapping mode. In trapping mode, the sample is swept into the trap that is shown with a dotted line. 
As the pyroprobe is being heated by a controlled ramp rate inside the valve oven, the reactant gas carries the volatile components to the sorbent tube trap packed with 20:35 mesh TenaxTA. The Tenax-TA is 2,6-diphenylene oxide that is commonly used for thermal desorption and is stable below $350{ }^{\circ} \mathrm{C} .{ }^{86}$ The combination of interface and trapping programs allows any volatile compounds to be vented during the interface program. The pyroprobe would then fire after the 8 port valve rotor had rotated to allow any pyrolysis and oxidation products to be collected on the trap. During the last minute of flow to the trap, the carrier gas is automatically changed to helium to remove the residual air from the trap before desorption of analytes to the GC-MS for continuous separation and detection using the transfer line. In general, the desorption temperature should be at least $20^{\circ} \mathrm{C}$ above the boiling point of the adsorbed compounds, so the range of compounds which can be analyzed with thermal desorption is limited by the thermal stability of the sorbent. ${ }^{86}$ 


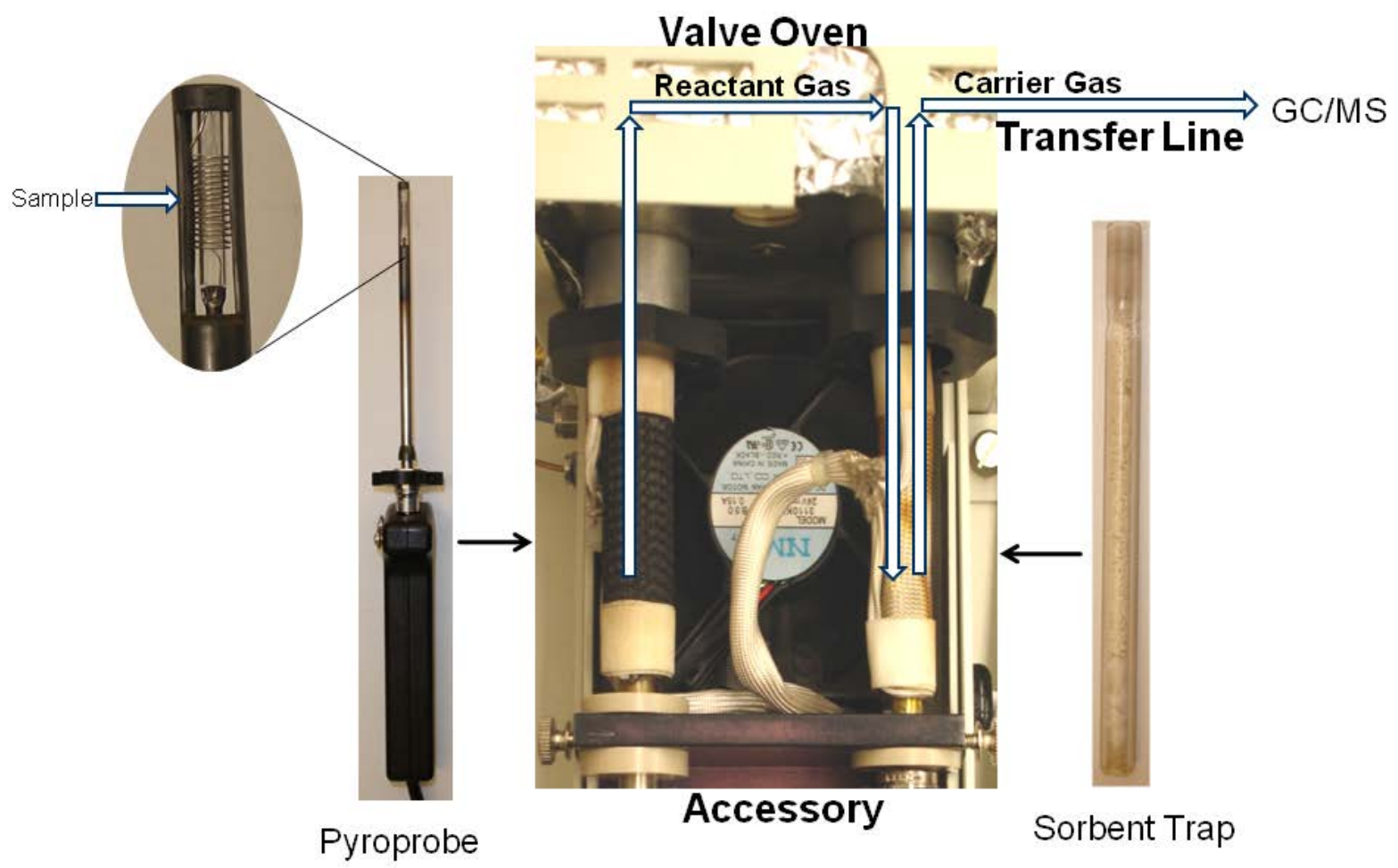

Figure 1-10. Schematic of a pyroprobe unit coupled to a GC-MS. 


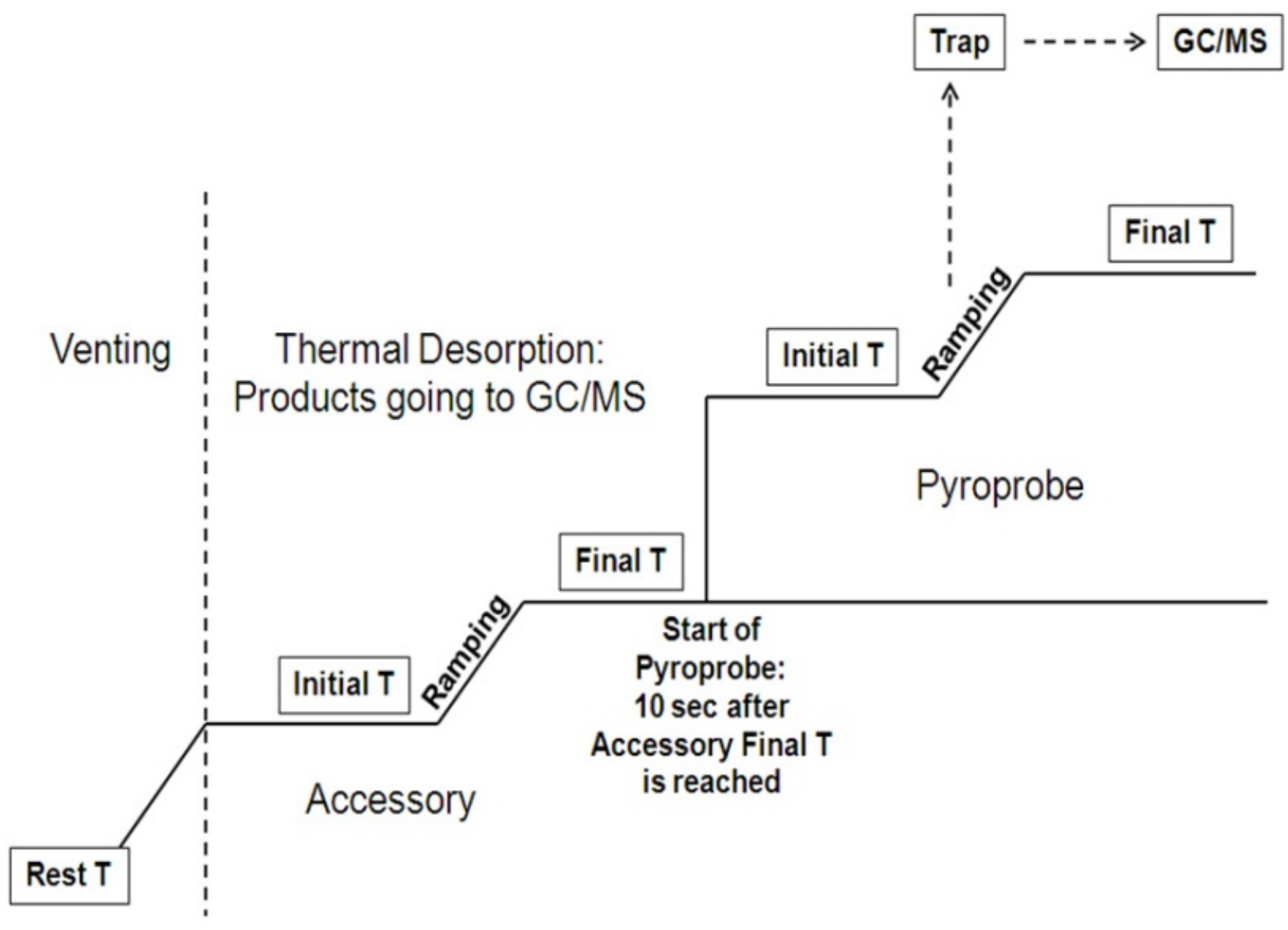

Figure 1-11. Representation of pyroprobe temperature program in trapping mode, where $T$ is temperature. 
In the GC used in this research, the mobile phase is gaseous and the stationary phase is a tethered liquid inside of silicon capillaries. The partitioning of analytes between the stationary and mobile phases facilitates chromatographic separation. As the analytes move through the capillary, the analyte partitioning reaches equilibria. In chromatography, retention time of an analyte is a factor of dead time (time for the mobile phase to reach the detector) and time spent in the stationary phase.

The GC composed of the following: a gas supply (mobile phase); pressure regulators, gauges, and flow meters to control and maintain a constant flow rate; a sample injection chamber; a column contained in a thermostatted oven; and a detector that is networked to a data collection system. ${ }^{87}$ For this research a quadrupole mass spectrometer was used as a detector, a standard detector available in forensic laboratories.

A mass spectrometer consists of three zones: an ionization region, a mass analyzer, and a detector. In this research, electron ionization (EI) was used to transition gas phase molecules to gas phase ions for mass spectrometric detection. Since GC and EI require the sample to be stable and volatile, coupling these two methods is ideal. The EI requires the use of an ion beam to react with and ionize analytes as they exit the column. It is classified as hard ionization which means fragmentation is usual and may be extensive. This can be advantageous by means that EI can provide the molecular mass and structural information of the molecule. The molecular ion $\mathrm{M}^{+}$may form, but generally this ion contains too much energy and fragments, therefore, under reproducible conditions (70 eV), EI spectra may be used to build searchable databases of fragmentation patterns. A large number of organic molecules that are less than 600 Da can be ionized using EI and well over 100,000 spectral library databases have been developed and accessed through most GC/MS software. ${ }^{88}$ 
Limitations of using EI are the requirement of volatile and stable samples. Unstable compounds may over fragment to a point that the molecular ion cannot be determined from the mass spectrum that can return provide no structural information.

A quadrupole mass analyzer was used as the detector in this portion of the study. A quadrupole mass analyzer features four hyperbolic poles with oscillating applied DC and RF potentials. The RF signal influences the trajectory of light ions while the DC signal influences the trajectory of heavy ions. If an ion is destabilized by the oscillating signals, it will collide into the quadrupoles and lose charge. Stable ions travel through the quadrupole to the detector. The quadrupole mass analyzer may be scanned such that ions of varying mass to charge ratios arrive at the detector to form a spectrum. For detection, an electron multiplier was used. An electron multiplier is used to amplify signal (with a typical gain of $10^{6}$ to $10^{11}$ electrons) prior to arrival of electrons at a Faraday cup. ${ }^{88}$ A Faraday cup is grounded and as electrons strike a current is generated and measured. Identification solely based on mass spectral comparison using the MS database provided tentative identification of the analytes. Whilst, identification based on the database and standard reference materials (SRMs), where both retention time and MS spectra were compared, provides confirmatory identifications.

Py-GC/MS can provide both qualitative and quantitative information regarding pyromarkers. One common purpose for this technique is to determine the nature of the material that was pyrolyzed. This is possible either through the use of the composition of the pyrolytic products as a chromatographic pattern of the parent molecule, or from the similarity of the structure of fragment molecules from the pyrolytic product with that parent compound. Qualitative analysis in Py-GC/MS is based on the identification of various peaks in the 
chromatogram with the help of MS database. The analysis can be limited to the identification of the main components in the pyrolytic products, or it may include minor components and sometimes trace compounds.

Py-GC/MS can be applied for quantitative purposes, although less common than qualitative analysis. Quantitative analysis is applied more frequently in polymer analysis, for example, in the determination of the amount of a specific polymer in a given complex matrix, such as a composite material, inorganic matrix, etc. ${ }^{78,89,90}$ Quantitative measurement of a pyrolysis product can be used successfully even for the analysis of other organic molecules. $^{78,89}$ In order to have a reliable quantitative result by Py-GC/MS, an important requirement is the repeatability of the analysis. It has long been recognized that small samples, typically less than $1 \mathrm{mg}$, good heat transfer and rapid heating of the pyrolysis element are essential in achieving reproducibility. ${ }^{77,78,83,89}$ With same instrumental conditions and the same amount of sample, the reproducibility can be good with replicate analysis with relative standard deviations less than $1 \%$ frequently reported. ${ }^{78,83}$ Calibration is typically necessary by using internal standards, external standards, or a standard addition procedure.

A limitation to this process is that Py-GC-MS cannot completely mimic all factors of the smoking conditions such as humidity, airflow, and fluctuations in temperature. The pyrolysis unit can only perform and alter one temperature condition at a time. Even with these apparent limitations, pyromarkers produced by pyrolysis have been consistent with literature reports of smoked markers for cocaine and methamphetamine. ${ }^{21,22,91}$ Work produced by the Bell Research Group, including this research, has led to publications in the Journal of Forensic Science and the Journal of Analytical Toxicology, and both have been 
cited in literature. Further research on this method will be used to study other smoked drugs such as Ritalin and other new designer drugs such as "bath salts" and synthetic cannabinoids. 


\section{Chapter 2: Application of the Py-GC/MS to Mimic the Smoking Conditions of Fentanyl and FTPs}




\subsubsection{Introduction}

The method by which fentanyl is smoked can influence in the prominent pyromarkers observed. Methods used to smoke fentanyl include: glass pipes, cigarettes, and a method known as "chasing the dragon." For over 30 years, Baker has been the pioneer on manufactured tobacco cigarette studies carrying out extensive analysis on temperature distribution and designed effects on tobacco pyromarkers. As recently as 2005, Baker and Bishop had used a similar pyrolysis unit to analyze non-volatile tobacco ingredients. ${ }^{23,24}$ Fentanyl smoking studies was therefore be based on what has been learned from manufactured tobacco cigarette studies, since cigarettes studies have been the forefront of smoking analysis due to its popularity tobacco over many years. Old dried gel drug reservoir FTPs or matrix type FTPs are smoked in a cigarette fashion, therefore the temperature distribution can be compared to temperatures which can reach from ambient to about $950{ }^{\circ} \mathrm{C}$ in the presence of varying concentrations of oxygen. ${ }^{92}$

In general, Baker indicated that smoke from a tobacco cigarette is formed in two distinct zones of puffing and smoldering. The combustion zone takes place in the region of the lit cigarette where temperatures generally exceed $600{ }^{\circ} \mathrm{C}$, called the coal. ${ }^{93}$ From temperatures that can exceed $\sim 900{ }^{\circ} \mathrm{C}$ with heating rates as high as $500{ }^{\circ} \mathrm{C} / \mathrm{s}$ at the center of the coal in the presence of varying concentrations of oxygen such as during the puff of the cigarette. ${ }^{94-97}$ The second zone, immediately behind the coal, has temperatures below $600{ }^{\circ} \mathrm{C}$ and the tobacco is distilled and/or pyrolyzed to produce more chemically complex mixture of gases and vapor. ${ }^{98}$ The generation of smoke is the result of a self-sustaining combustion cycle in which occurs puffing and smoldering conditions. During the puff, air is drawn in through the coal increasing the combustion rate and the coal temperature, with a typical puff 
cycle of $2 \mathrm{~s}$, can achieve heating rates as high as $500 \mathrm{~K} / \mathrm{s} .{ }^{95}$ During the puff, the smoke generated during travels through the tobacco column. These mixtures of hot gases/vapors cool as they transfer down the column. As the distance from the coal to the filter reduces, the average temperature in the tobacco column increases, permitting more of the higher molecular weight compounds to remain in the vapor or aerosol phase. ${ }^{95}$ The result is a more concentrated mainstream smoke further down the column as the tobacco is smoked.

During smoldering, combustion is maintained by convective flow around the burning zone that utilizes the natural airflow to carry the gases and vapors. Baker goes into further detail that incorporates distinction generation sites for side stream smoke. However, the author indicates that little change occurs in the oxygen concentration and temperature profiles of the side stream cigarette smoke, even during the puff. ${ }^{99}$ By this, the authors demonstrated the independence of the combustion processes occurring at the surface and within the burning zone.

The intensity, duration and number of puffs, depth of inhalation, degree of mixing of smoke with air, and other factors influence the dose making smoking parameters complex to mimic. $^{8}$ The absorption and bioavailability of inhaled drugs vary from person to person and potentially from smoke to smoke permitting the smoker considerable latitude in adjusting the dose to desired levels. ${ }^{8}$ Although these limitations are apparent and difficult to mimic using analytical pyrolysis, the products produced by pyrolysis of methamphetamines studied previously have been consistent with literature reports of smoked markers. ${ }^{20-22,91,100}$

Although fentanyl produces the greatest analgesic effects is when it is volatilized at $300{ }^{\circ} \mathrm{C}$, it is perceived that most drug abusers do not ascertain this temperature while smoking the drug. ${ }^{60}$ Based on the reported average temperature during the rested smoldering 
of coal for a manufactured tobacco cigarette ${ }^{93,95}$ and the recent successful pyrolysis analysis on cocaine and methamphetamine, ${ }^{20} 750{ }^{\circ} \mathrm{C}$ was used to assess pyromarkers of fentanyl here. In addition, the pyrolysis unit is utilized in the trapping mode to afford collection of the pyromarkers and the use of a reactant gas as the carrier gas without introducing that gas to the GC. The reactant gas used here for analysis was helium and air for both anaerobic and aerobic conditions, respectively.

\subsubsection{Materials and Methods}

Pyridine, benzaldehyde, benzyl chloride, phenylacetaldehyde, (2chloroethyl)benzene, propionanilide, and methanol were purchased from Sigma Aldrich (St. Louis, MO, USA). Fentanyl $\mathrm{HCl}$ was provided by the Department of Basic Pharmaceutical Sciences at West Virginia University. Norfentanyl oxalate was purchased from Cerilliant (Round Rock, TX, USA). Despropionyl fentanyl was purchased from Biomol (Plymouth Meeting, PA, USA). Unopened Duragesic ${ }^{\circledR} 75 \mu \mathrm{g} / \mathrm{h}$ reservoir FTPs were recovered from cases at the West Virginia Office of the Chief Medical Examiner.

\subsubsection{Py-GC/MS}

A CDS Analytical 5200 Pyroprobe was used in trapping mode to pyrolyze the samples under anaerobic and aerobic conditions using helium and air, respectively (CDS Analytical, Inc., Oxford, PA, USA). The sorbent tube traps were purchased from CDS Analytical, Inc. One was packed full with 20:35 mesh Tenax-TA and the other was one halfglass filled with glass beads and the other half filled with 20:35 mesh Tenax-TA. The pyroprobe was interfaced with a heated transfer line to a Perkin Elmer Clarus 500 GC/MS (PerkinElmer, Wellesley, MA, USA). The GC was equipped with an Equity-5 column (30 m, $0.25 \mathrm{~mm}, 0.25 \mu \mathrm{m}$ film thickness, Supelco, Bellefonte, PA, USA). The MS was equipped 
with an electron ionization source and quadrupole mass analyzer with a scanning range of $\mathrm{m} / \mathrm{z}$ 50-600.

The components of the CDS pyroprobe unit consist of the pyroprobe, trap, accessory, valve oven, and transfer line (Figure 1-10). Solid sample analyses were performed by sandwiching 50-100 $\mu \mathrm{g}$ of fentanyl $\mathrm{HCl}$ between quartz wool inside the quartz tube. The quartz tube was inserted into the platinum coil filament of the pyroprobe. Each Duragesic ${ }^{\circledR}$ $75 \mathrm{mcg} / \mathrm{h}$ reservoir FTP contains $7.5 \mathrm{mg}$ of fentanyl. ${ }^{101}$ Less than $6 \%$ of the gel matrix was extracted from the drug reservoir for each run (Figure 1-1A). The pyrolysis and GC conditions for solid fentanyl $\mathrm{HCl}$ and the gel from the reservoir of the patch are presented in Table 2-1. Solid fentanyl $\mathrm{HCl}$ and the FTP gel samples were analyzed using anaerobic and aerobic conditions. All samples were analyzed in triplicate to establish precision. Under the anaerobic conditions helium was used as the carrier gas in the pyroprobe and GC unit. For aerobic conditions, air was used as the reactant gas and helium was used as the carrier gas.

Figure 2-1 is a representation of the pyroprobe temperature program in trapping mode. As the pyroprobe is being heated, the reactant gas carries the volatile components to the sorbent trap. During the last minute of flow to the trap, the carrier gas is automatically changed to helium to remove the residual air from the trap before transferring the trap to the GC using the transfer line. 
Table 2-1. Py-GC/MS parameters.

\begin{tabular}{|ll|}
\hline Pyroprobe Conditions & \\
\hline & \\
Pyroprobe Temperatures & \\
Initial & $50^{\circ} \mathrm{C}, 1 \mathrm{~s}$ \\
Ramp Rate & $20^{\circ} \mathrm{C} / \mathrm{s}$ \\
Final & $750^{\circ} \mathrm{C}, 10 \mathrm{~s}$ \\
Accessory Parameters & \\
Rest & $50^{\circ} \mathrm{C}$ \\
Initial & $90^{\circ} \mathrm{C}, 1 \mathrm{~min}$ \\
Ramp Rate & $100^{\circ} \mathrm{C} / \mathrm{min}$ \\
Final & $350^{\circ} \mathrm{C}, 5 \mathrm{~min}$ \\
Trap Temperatures & \\
Reactant Gas & $7.10 \mathrm{~min}$ \\
Rest & $50^{\circ} \mathrm{C}$ \\
Desorb & $300^{\circ} \mathrm{C}, 2$ min \\
Iso Zones & \\
Transfer Line & $305^{\circ} \mathrm{C}$ \\
Valve Oven & $305^{\circ} \mathrm{C}$ \\
& \\
\hline GC Conditions & \\
\hline Injector Port & $305^{\circ} \mathrm{C}$ \\
Initial & $70^{\circ} \mathrm{C}$ \\
Ramp Rate & \\
Final & $325^{\circ} \mathrm{C}, 3 \mathrm{~min}$ hold \\
\hline
\end{tabular}




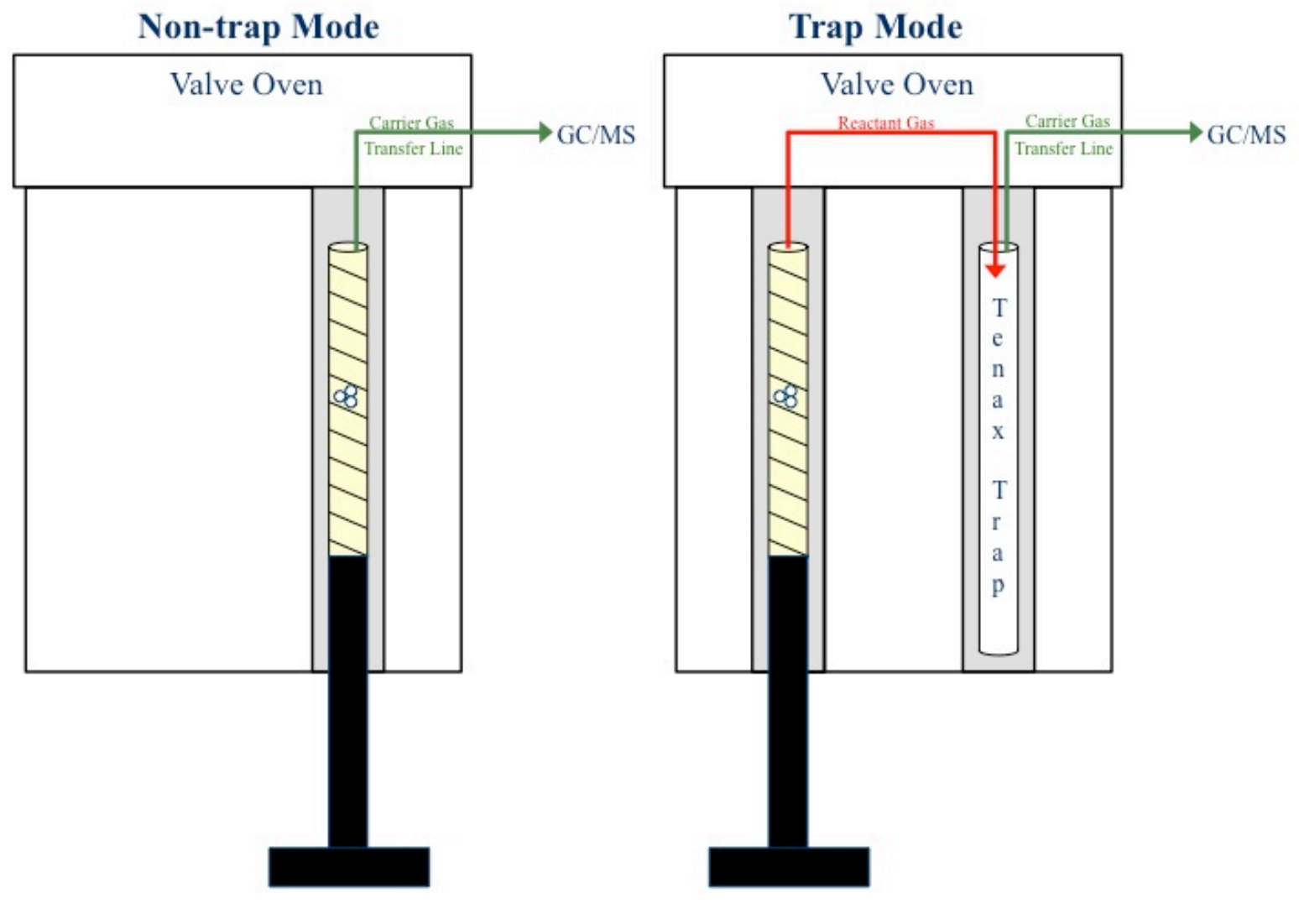

Figure 2-1. Schematic of a pyroprobe unit coupled to a GC/MS. 


\subsubsection{Results and Discussion}

The pyromarkers of fentanyl $\mathrm{HCl}$ and FTPs under anaerobic and aerobic conditions are listed in Table 2-2. Pyromarkers were initially identified using the National Institute of Standards and Technology (NIST) MS library. Identification was confirmed by analysis of SRMs and comparison of retention times and mass spectra. Styrene and aniline were the only pyromarkers that were tentatively identified solely by NIST MS database. The percent areas of each pyrolytic product were normalized relative to the largest peak area in the chromatogram. Under all conditions, propionanilide resulted in the largest peak area in the chromatograms under both anaerobic and aerobic conditions.

Norfentanyl and despropionyl fentanyl are two commonly reported metabolites of fentanyl in the human body by piperidine N-dealkylation and amide hydrolysis, respectively. $^{46}$ Despropionyl fentanyl, aniline and phenylacetaldehyde were only observed under anaerobic conditions of the pyrolysis of fentanyl $\mathrm{HCl}$. Norfentanyl and benzyl chloride were observed only in aerobic conditions of the pyrolysis of fentanyl HCl. Figure 22 displays commonality and differences in pyromarkers under the both anaerobic and aerobic conditions along with their structures. 
Table 2-2. Pyromarkers of fentanyl and FTPs under anaerobic and aerobic conditions.

\begin{tabular}{|l|l|c|l|c|}
\hline & Anaerobic & Area \% & Aerobic & Area \% \\
\hline Fentanyyl HCl & Pyridine & 35.1 & Pyridine & 18.7 \\
& Styrene & 36.9 & Styrene & 17 \\
& Benzaldehyde & 1.1 & Benzaldehyde & 18.9 \\
& Aniline & 5.4 & Benzyl chloride & 8.8 \\
& Phenylacetaldehyde & 3.7 & Phenylacetaldehyde & 16.1 \\
& (2-Chloroethyl)benzene & 7.5 & Propionanilide & 100 \\
& Propionanilide & 100 & Despropionyl fentanyl & 1.1 \\
& Despropionyl fentanyl & 1.9 & Fentanyl & 3.1 \\
Fentanyl & 6.9 & & \\
\hline FTP & Pyridine & 17.4 & Propionanilide & 100 \\
& Styrene & 39.8 & Fentanyl & 7.9 \\
& Propionanilide & 100 & & \\
& Fentanyl & 41.6 & & \\
\hline
\end{tabular}




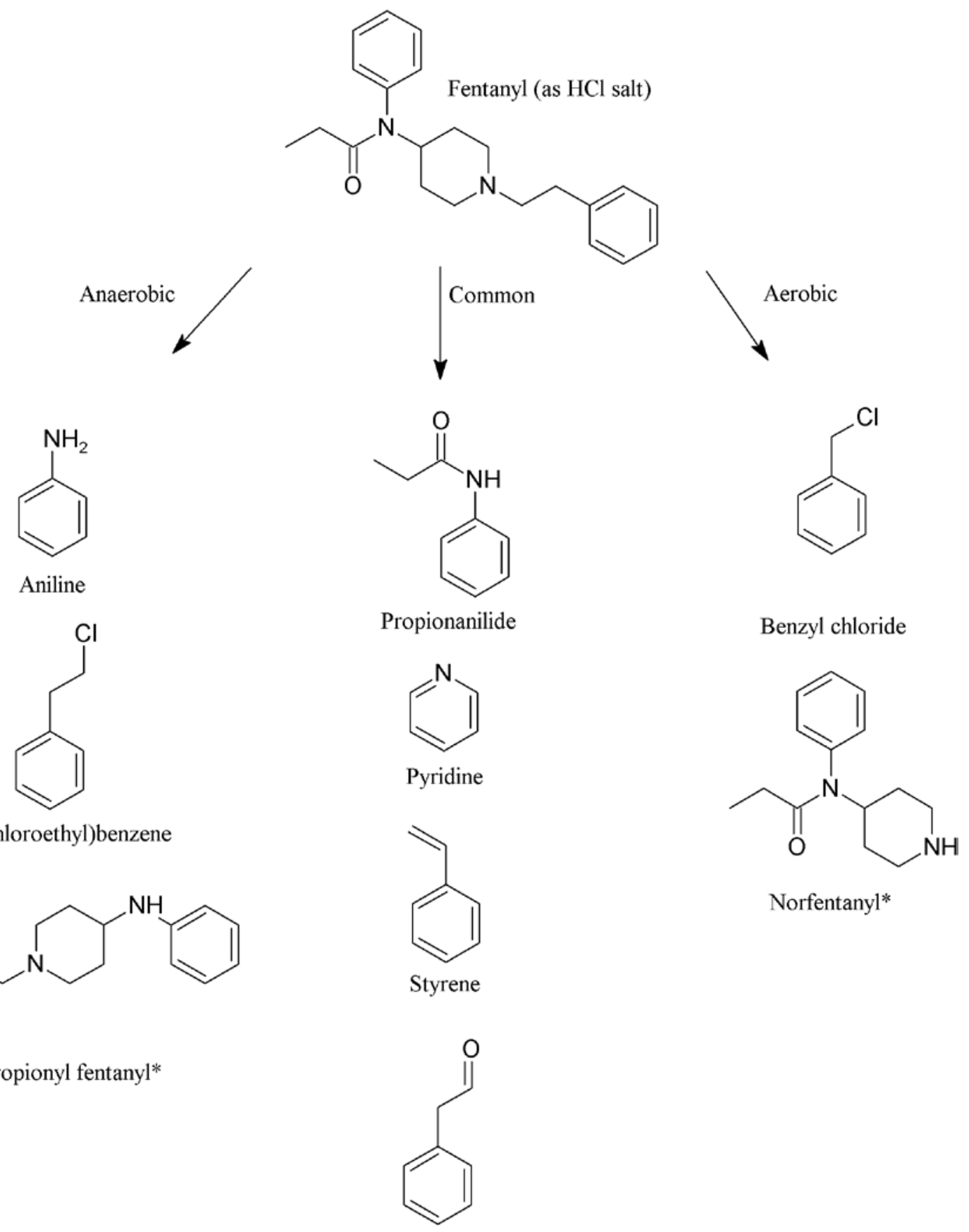

Phenylacetaldehyde<smiles>O=Cc1ccccc1</smiles>

Benzaldehyde

Figure 2-2. Fentanyl pyromarkers comparisons in anaerobic and aerobic trapping conditions. *Denotes commonly reported metabolites. ${ }^{46}$ 


\subsubsection{Pyrolytic Degradation Pathways of Pyromarkers}

Figure 2-3 shows the possible pyrolysis degradation pathways of fentanyl. The pyrolysis degradation mechanisms are typically free radical processes and are initiated by breaking the weakest bonds first. ${ }^{5}$ The compositions of these pyromarkers are typically based on the stability of the free radicals involved and the stabilities of the product molecules. ${ }^{5}$ The bond break at F1 of the carbonyl group at the amide site can result in the minor pyromarker of despropionyl fentanyl. Aniline is likely due to the less common $\alpha$ elimination on two C-N bonds at F1 and F2 at the amide site. At temperatures above $700{ }^{\circ} \mathrm{C}$, it has been reported that aniline starts decomposing with the formation of benzene, $\mathrm{N}_{2}, \mathrm{HCN}$, and other molecules including low levels of carbazol. ${ }^{85}$ Cleaving at F1 and the C-N bond (F3) at the piperidine ring of fentanyl allowed for the formation of norfentanyl.

The formation of propionanilide is possibly a result of the cleavage of the C-N bond (F2) at the amide site where a $\beta$-elimination reaction occurred with the hydrogen of piperidine ring of fentanyl. The formation of pyridine can be explained by the initial formation of free radical during elimination cleaving at F2 and F3. The unsaturated piperidine ring may undergo dehydrogenation producing the pyridine ring. ${ }^{102}$

Styrene, phenylacetyladehyde, and (2-chloroethyl)benzene is due to the fragmentation at F3 producing a free radical. The phenyl group, which are $s p^{2}$ hybridized and more electronegative that $s p^{3}$ hybridized carbon atoms of alkyl groups, were not disrupted. ${ }^{103}$ In the presence of free oxygen, slight differences can be observed. In its ground state, each of the two highest occupied molecular orbitals, which are degenerated, contain unpaired electrons, which allows ordinary oxygen the property of a diradical. ${ }^{85}$ This can react with the pyromarker free radical producing phenylacetaldehyde. Since fentanyl $\mathrm{HCl}$ salt was used for 
analysis, free radical halogenation can occur, which may explain the results of (2chloroethyl)benzene.

The cleavage of the C-C bond (F4) next to the nitrogen at the piperidine ring of fentanyl likely caused the formation of benzaldehyde and benzyl chloride. It is feasible that these similar elimination reactions, as previously mentioned, produce free radicals that react with oxygen and chlorine to produced benzaldehyde and benzyl chloride, respectively.

Mass spectral fragmentation patterns were as expected, with one exception. Based on the abundance of propionanilide, it was thought that some form of phenyl-substituted pyridine might be observed such as 1,2,3,6-tetrahydro-1-(2-phenylethyl)pyridine (PEP) shown in Figure 2-3. This was of toxicological interest given structural similarities of PEP to 1-methyl-4-phenyl-1,2,3,6-tetrahydropyridine (MPTP), which is a known neurotoxin. ${ }^{104-106}$ Under the chromatographic conditions used, this compound, if present, would have been detected. However, none was observed in the total ion chromatograms. Using known spectral data, ${ }^{107}$ a selected ion monitoring experiment was performed using all the same conditions except monitoring ions $187(\mathrm{M}+)$, 96, 91, 77, 65, and 42. The compound was not observed and it was hypothesized that a rearrangement occurred leading to the products that were observed.

Manral et. al. however, had observed PEP, along with propionanilide, at $500{ }^{\circ} \mathrm{C}$ using a direct injection and no reactant gas. ${ }^{102}$ Further pyrolysis at $750{ }^{\circ} \mathrm{C}$ showed increased degradation believed to be formed as a result of intramolecular rearrangements in the parent molecule. ${ }^{102}$ This is of toxicological importance in the observation by Manral et al. that at $750{ }^{\circ} \mathrm{C}$ phenylisocyanate may lead to the formation of hydrogen cyanide, which would be a large factor in the toxicity of smoked fentanyl. ${ }^{102}$ 
Garg et al. also has observed this PEP through thermal degradation of the fentanyl residues and not the volatile vapors. It is explained the fentanyl is converted to PEP and propionanilide via solvent mediated thermal $\beta$-elimination, followed by $\mathrm{N}$-oxidation, protonation, and rapid dehydration. ${ }^{108}$ Garg et al. explained in detail how PEP is further degraded and reacted to form PEP salts and 1-styryl-1H-pyridin-2-one (1-SPO) detected in thermal degradation residues. 


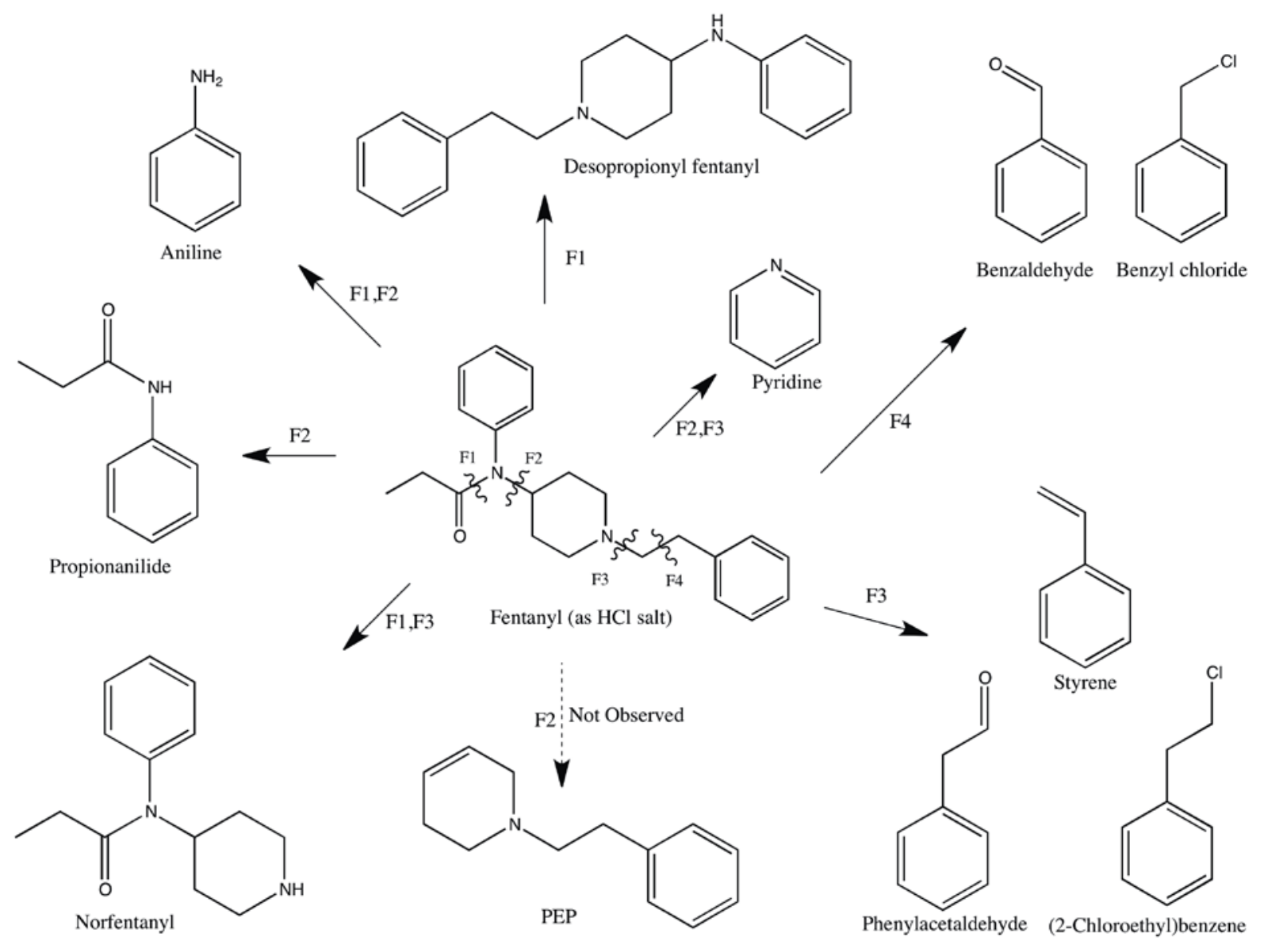

Figure 2-3. Possible pyrolysis degradation pathways of fentanyl. 


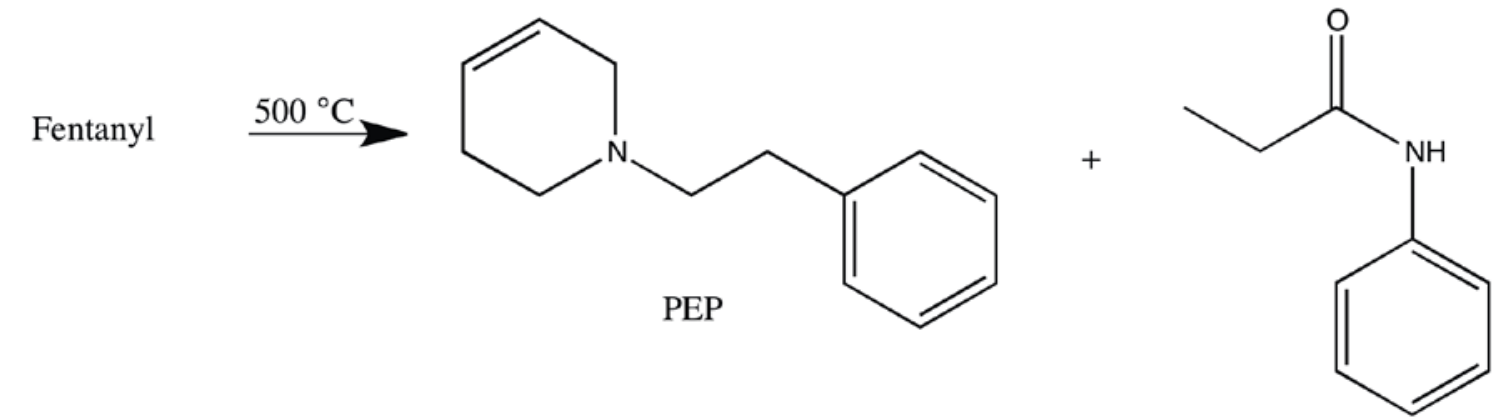

Propionanilide

Propionanilide $750^{\circ} \mathrm{C}$

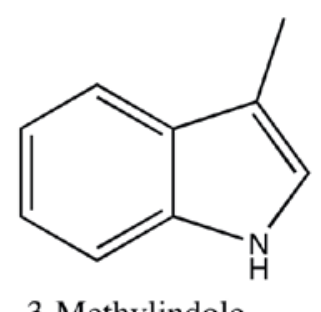

3-Methylindole

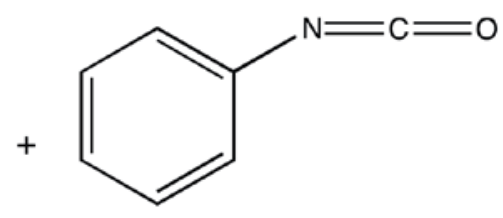

Phenylisocyanate
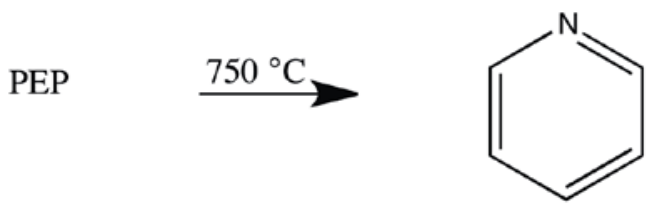

Various hydrocarbons

Pyridine

Figure 2-4. Fentanyl pyromarkers from Manral et al. 


\subsubsection{Comparison of Fentanyl HCl and FTPs Under Anaerobic and Aerobic Conditions}

A comparison of the pyrolysis of fentanyl $\mathrm{HCl}$ and FTPs under anaerobic conditions is shown in Figure 2-5. Fentanyl $\mathrm{HCl}$ and the FTP pyrolyzed under anaerobic conditions produce pyridine, styrene, propionanilide, and fentanyl. The peaks enclosed by the circle on the FTP chromatogram resulted from phthalates and longer chain alcohols. The remaining peaks in the FTP chromatogram could not be identified. Under aerobic conditions, propionanilide and fentanyl were observed in both the pyrolysis of fentanyl $\mathrm{HCl}$ and FTP (Figure 2-6). Again, phthalates and long chain alcohols were present throughout the FTP chromatogram hindering the identification of the well-defined peaks. Chlorine-containing pyromarkers obtained with the neat drug were not observed for the FTPs since fentanyl in the gel reservoir of the FTPs is in citrate salt form. This difference could potentially be useful as an investigative tool. Also, significant long chain alcohols and phthalates were seen and likely derived from the gel matrix of the drug reservoir. Area and peak height ratios were not reproducible for the pyrolysis of the FTPs due to difficulty in controlling the amount of gel in each sample introduction.

A trap that consisted of 50\% glass beads (60:80) and 50\% Tenax-TA (60:80) was employed in an attempt to address carryover problems. It was anticipated that some of the fentanyl would condense on the glass beads before reaching the Tenax-TA. Since the glass beads possess minimal sorbent characteristics, they should simply provide a surface area for condensation. The fentanyl should be stripped from the glass beads when the tube is heated. However, this trap configuration displayed poor desorption efficiency (Figure 2-7) compared to Tenax-TA alone. Therefore, a full Tenax-TA trap was employed for the remaining experiments. 
A drawback of using the pyroprobe without a trap is poor chromatography of pyridine and styrene following pyrolysis of fentanyl. This is likely due to their volatile properties for the adsorption of the molecules and its physical adherences to the surface of the Tenax-TA that allow for the collection and efficient desorption. In addition, identification of some compounds was problematic without the trapping mode. No significant differences were seen beyond this observation. The trap enhanced the more volatile pyromarkers and afforded a positive identification in mass spectral comparison due to the improved chromatographic peak shape. 

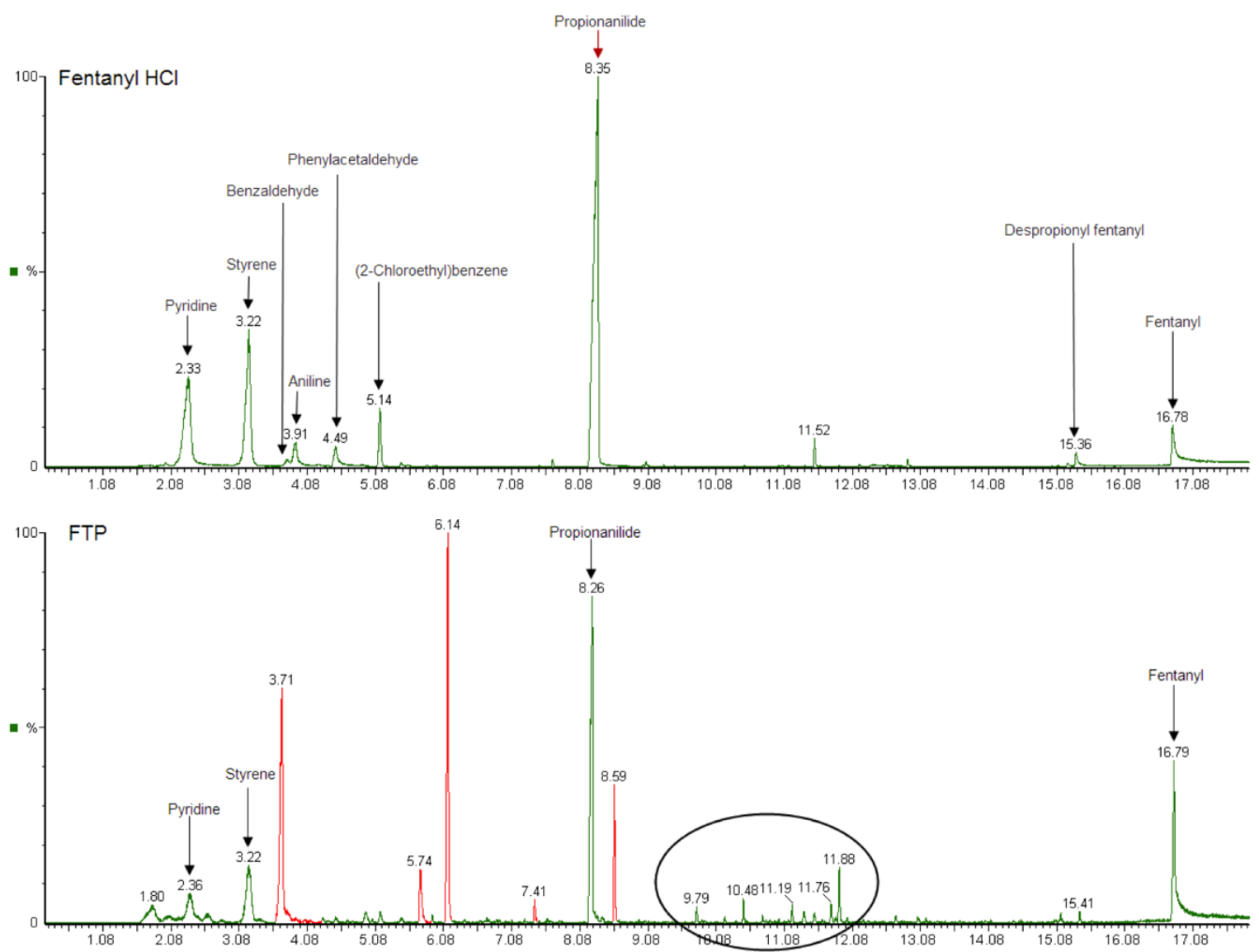

Figure 2-5. Fentanyl $\mathrm{HCl}$ and FTPs in anaerobic conditions. 

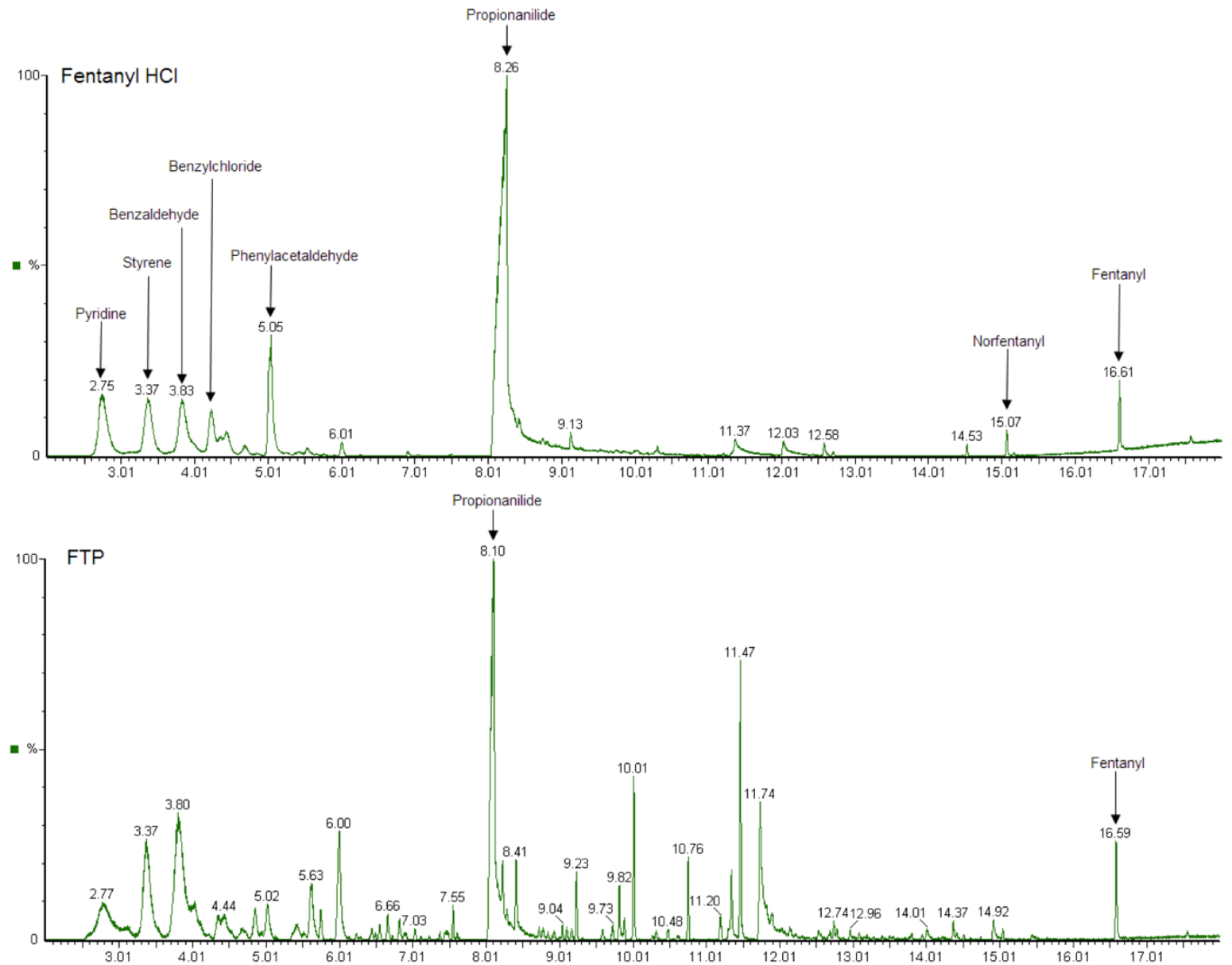

Figure 2-6. Fentanyl $\mathrm{HCl}$ and FTPs in aerobic conditions. 


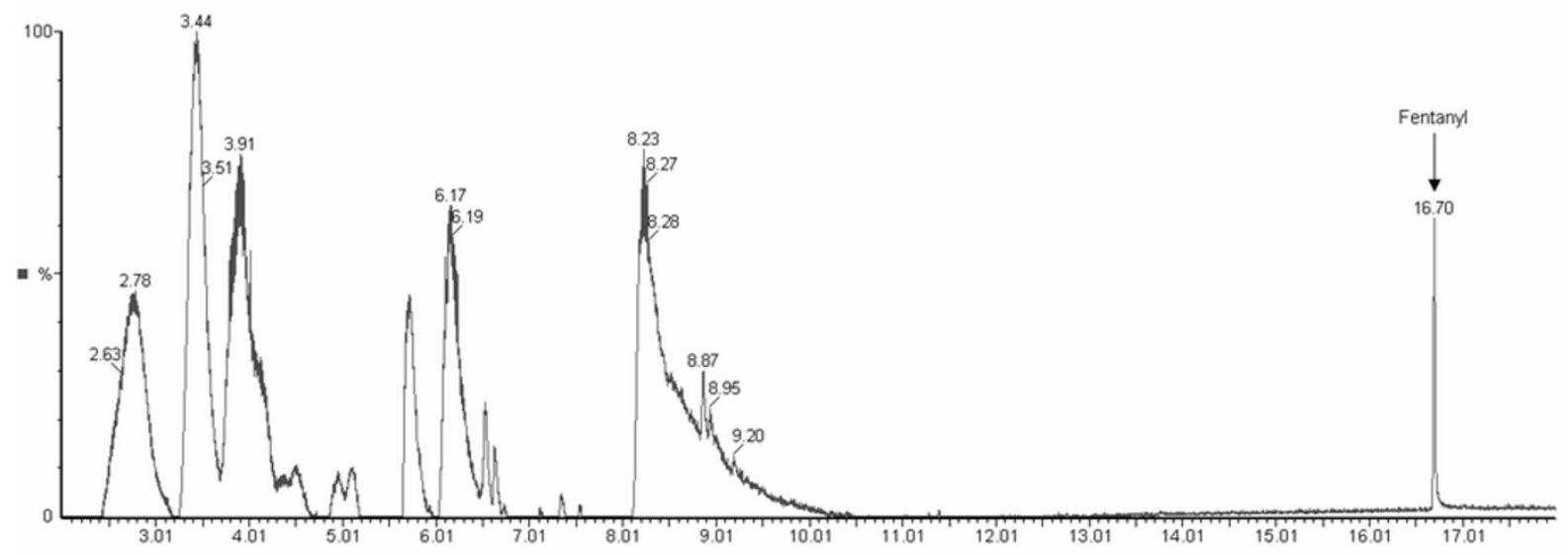

Figure 2-7. FTP chromatogram using 50\% Tenax-TA and 50\% glass bead trap. 


\subsubsection{Conclusions}

Propionanilide is a major pyromarker that was observed under both aerobic and anaerobic conditions in the pyrolysis of fentanyl $\mathrm{HCl}$ and FTPs. Aerobic and anaerobic conditions yielded slightly different products in the pyrolysis of fentanyl $\mathrm{HCl}$. This study shows the possibility of differentiation between smoked fentanyl $\mathrm{HCl}$ salt and the FTPs.

Pyrolysis of fentanyl $\mathrm{HCl}$ and FTPs resulted in identification of several potential pyromarkers distinctive to smoked fentanyl and not seen as typical metabolites. The following was observed consistently in the pyrolysis of the fentanyl $\mathrm{HCl}$ under both the anaerobic and aerobic conditions: pyridine, styrene, benzaldehyde, phenylacetaldehyde, and propionanilide. Pyridine could be amenable to a simple headspace assay. When patches are smoked directly, a large suite of potential pyromarkers was identified. In this application, it may also be possible to identify what salt form of the drug was smoked based on the pyromarkers produced.

An assessment of actual accrued temperatures of smoking fentanyl patches is done in later chapters. This will focus on any changes and possible differences of pyromarkers at different temperatures reached. The next chapter will discuss the determination of these data points using thermocouple temperature analysis of smoking FTPs. 


\section{Chapter 3: Determination of the Temperature Characteristics of Smoking FTPs Using the "Smoking the Dragon" Method}




\subsubsection{Introduction}

The previous chapter has discussed the pyromarkers at a temperature that was determined through the analysis of manufactured tobacco cigarettes. Here, the temperature analysis would need to be determined first to examine which pyromarkers are produced and most abundant between various smoking methods of FTPs. Temperature variance between methods of smoking drugs may lead to the production of different pyromarkers. Smoking methods can result in different temperature ramping rate and peak temperatures and therefore, a smoking method with higher peak temperature will further degrade pyromarkers than a lower temperature smoking method. As a result, this can produce adversely different effects in drug abuser since the dominant or more pronounced pyromarkers would change as a result of different smoking method used.

It is shown by Baker that the highest solid phase temperatures of $\sim 900{ }^{\circ} \mathrm{C}$, occurs in the periphery of the coal, whilst the gas phase temperature in the same region is $605-770{ }^{\circ} \mathrm{C}$. Also, fentanyl smoking methods do not have a well defined/designed coal zone for smoldering like manufactured tobacco cigarettes. If fentanyl were to be smoked like a cigarette it would be hand-rolled and not uniform. One obvious difference in their burning characteristics is that hand-rolled cigarettes tend to go out unless puffed by the smoker, whereas a cigarette with tightly packed tobacco will smolders for about twenty minutes with

no assistance from the smoker. ${ }^{109}$ In most cases, drug abusers want to extinguish the burning of the drugs so as not to waste anything before the next hit. Also, it has been reported that the temperatures reached from “chasing the dragon" with heroin were between $200{ }^{\circ} \mathrm{C}$ and $300{ }^{\circ} \mathrm{C}$, which is much lower than the tobacco cigarette studies. ${ }^{110}$ 
In the past, a number of temperature measurement methods have been used to determine the temperature distribution of tobacco cigarettes. These include thermocouples inserted into the cigarette, optical pyrometry, infrared photometry, and X-ray scanning of beads embedded in the tobacco, which melt at various temperatures. ${ }^{95}$ Temperature distribution detection methods will be modeled on those described by Baker. In the analysis of tobacco cigarette temperature distribution, Baker employed two different methods of measurements, one for the solid phase (infrared system) and one for the gas phase (thermocouple system), and his results are generally accepted as being representative of the temperatures encountered inside a burning cigarette. ${ }^{111}$ Although Laszlo et al. criticized that the thermocouple measurements for the solid phase inside a cigarette coal was inaccurate due to the poor thermal contact between the thermocouple junction and tobacco strands, Baker proved its insignificance. ${ }^{112}$ The authors showed that occasionally $(<1 \%)$ one of the replicates values would be significantly different from the mean. This was presumably caused by an abnormal strand-junction contact, the thermocouple indicating a temperature dependence on both the gas and solid phases. ${ }^{112}$

Here a method was developed to determine the maximum temperature achieved and the rate of temperature increase by smoking FTPs using the common method of "chasing the dragon.” Bare thermocouple sensors were used for temperature analysis in a setup is furthered explained in this chapter. A box fabricated with Lexan ${ }^{\circledR}$ with an open top was constructed to shield airflow whilst under the fume hood. At the time of analysis, reservoir FTPs (Figure 1-1A) had entirely phased out of the pharmaceutical market due to the misuse and only matrix FTPs (Figure 1-1B) were available. 


\subsubsection{Materials and Methods}

Duragesic® 100 mcg/h fentanyl transdermal system patches were obtained from McKesson (San Francisco, CA, USA). HPLC grade methanol was purchased from Fisher Science (Fair Lawn, NJ, USA).

\subsubsection{Thermocouple}

Temperature analysis was performed using a Type K, CHAL-010 thermocouple (Omega, Inc., Stamford, CT, USA). The Type K unsheathed fine gage thermocouples were $0.25 \mathrm{~mm}$ in diameter and 24 inches in length. The thermocouple sensors were composed solely of a Chromega ${ }^{\circledR}$ (nickel-Chromium) positive leg and an Alomega ${ }^{\circledR}$ (nickelaluminum) negative leg that are beaded to create the thermocouple circuit. SMPW glass filled nylon Type K miniature connectors were used to connect the thermocouple sensors to the Datalogger. Temperature range for Type $\mathrm{K}$ alloys is -270 to $1372{ }^{\circ} \mathrm{C} .{ }^{81}$

A HH506RA Dual Input, High Accuracy Datalogger/Thermometer with NIST traceable calibration with points was used (Omega, Inc., Stamford, CT, USA). The datalogger is a portable digital thermometer that can measure $\mathrm{K}, \mathrm{J}, \mathrm{S}, \mathrm{T}, \mathrm{E}$, and $\mathrm{N}$ thermocouples with real-time data and data logging capabilities. A RS-232 cable was installed to connect the datalogger to the computer com port. Data acquisition was set to record the temperatures of the two thermocouples at $1{ }^{\circ} \mathrm{C} / \mathrm{s}$ using the HH506RA software provided. Data obtained were in seconds for the time, temperature in Celsius for both T1 and $\mathrm{T} 2$, as well the as the temperature difference between $\mathrm{T} 1$ and $\mathrm{T} 2$ was recorded on the computer software. Data is then exported to Microsoft Excel worksheet.

\subsubsection{Setup Diagram}


Due to safety hazards associated with burning FTPs, the apparatus was position under a fume hood. A barrier was constructed to shield airflow from the fume hood so that the butane lighter could produce a steady laminar flame. Using Lexan ${ }^{\circledR}$, a four-sided box shaped barrier was constructed according to the sketch show as Figure 3-1. Slip-over panel piano hinges made of a polyvinyl carbon and polyester were used for ease of construction and manipulation.

This box here contained a ring stand to hold the FTP sample on single layer of typical household aluminum foil and a sliding butane flame platform. Holes in the box were arranged so that the thermocouple sensors could go into the box and that the butane flame introducer could be position under the FTP sample. 
A)

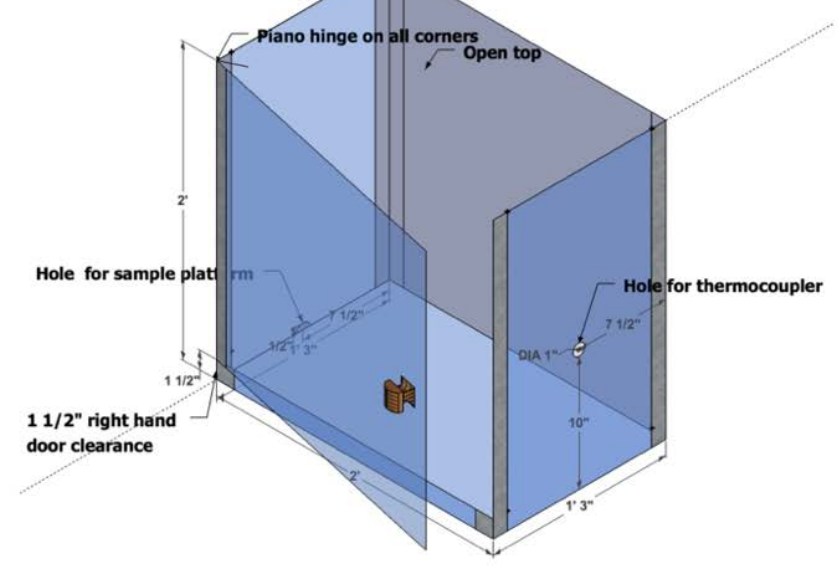

C)

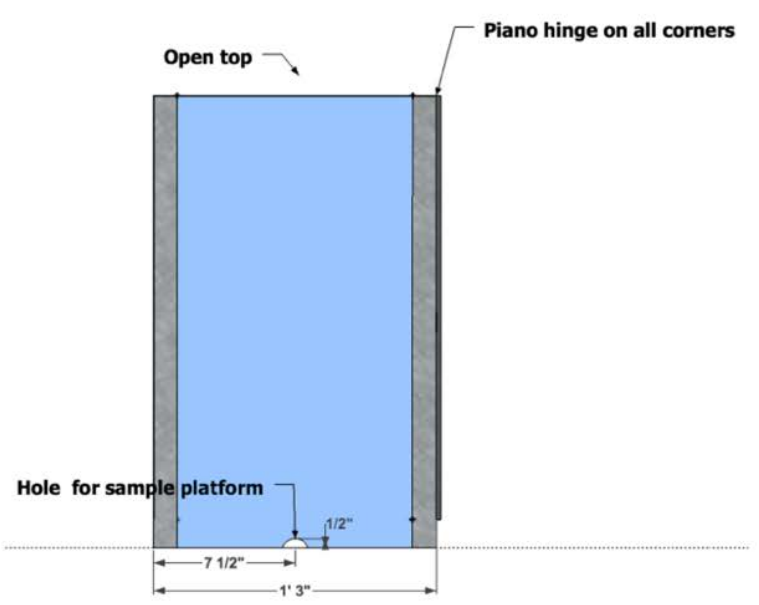

B)

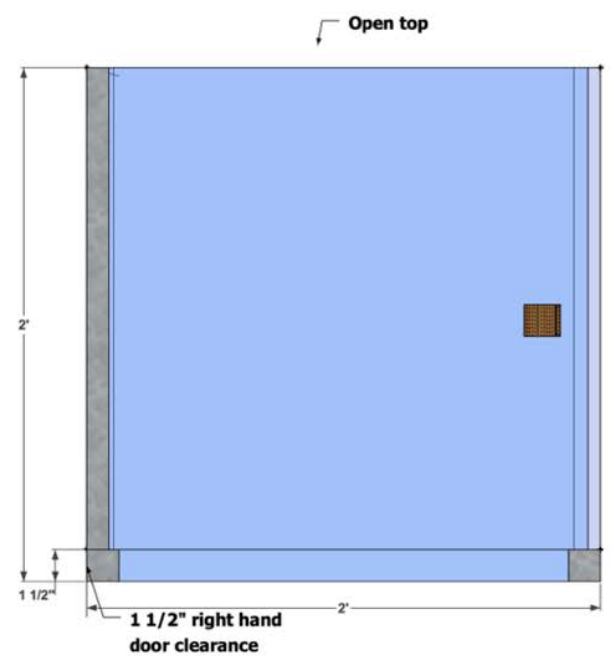

D) Piano hinge on all comers

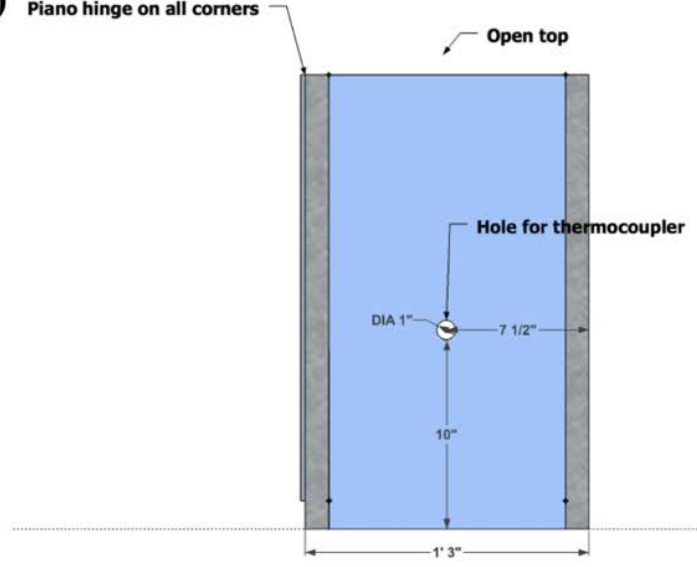

Figure 3-1. Schematic of box set up with A) front angle view, B) front view, C) left view and $D)$ right view. 
The sample was heated in single layer of typical aluminum foil that was cut in a circle with a diameter of $6.5 \mathrm{~cm}$ and placed on a $6 \mathrm{~cm}$ in diameter ring on a stand. Due to safety features and the constant need for pressure to depress the gas release valve on typical cigarette lighters, a Microflame Torch Model B with only butane gas was used. A relaxed laminar flame allowed for an accurate simulation for the street practice of smoking FTPs by means of "chasing the dragon." The tip of the flame was centered in the middle of the foil and was approximately $0.8 \mathrm{~cm}$ away from the underneath of the foil (Figure 3-2). The exact location of the flame was fixed as much as possible to eliminate variables of the analysis.

The pieces of the FTP were cut in $1.0 \mathrm{~cm}$ in width and $3.6 \mathrm{~cm}$ in length. The FTP piece was folded over thermocouple in channel port 1 on the datalogger (T1) and sandwiched in the middle of the FTP sample (Figure 3-3). The thermocouple in channel port 2 on the data logger (T2) rested on the very top of the sandwiched piece of FTP (Figure 3-3). Glass rods, electrical tape, and custom made glass rod holders were used to help position the thermocouple sensors accordingly.

For each FTP sample analysis the following events occurred: The butane release valve was rotated and a flint striker was used to create the spark to ignition. The butane lighter was then positioned on the platform within the designated markers. The door to the Lexan ${ }^{\circledR}$ box was closed and the fume hood sash was lowered. Data acquisition by the computer software was initiated and the flame was introduced by sliding the butane flame platform within the designated marking to insure fixed positioning after repeated runs. Once smoke was observed visually, the flame remained positioned for $10 \mathrm{~s}$. After $10 \mathrm{~s}$ elapsed, the flame was removed by sliding the butane lighter platform back to its original location. Data 
collection on the software remained approximately $30 \mathrm{~s}$ after flame was removed from the FTPs. Data from the software was then exported to Microsoft Excel worksheets.

Due to the cost of FTPs, the process was developed and optimized using typical office tape to mimic the FTPs. Here the markers for positioning were affixed into position using colored tape. Once a protocol was set, FTPs were used for a total of 16 trials. 


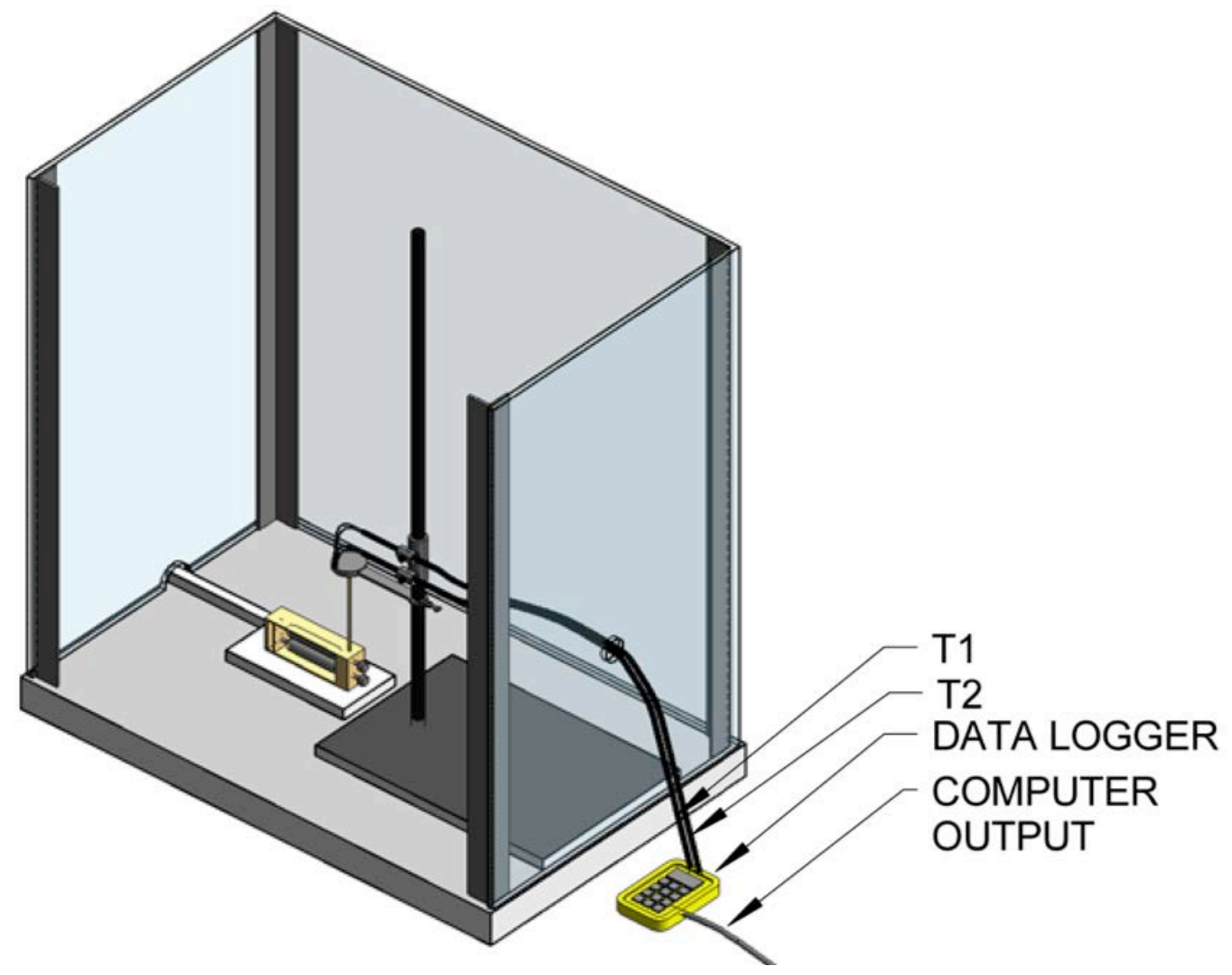

Figure 3-2. “Chasing the dragon" temperature analysis setup inside the smoking box with two thermocouples and a dual input datalogger. 


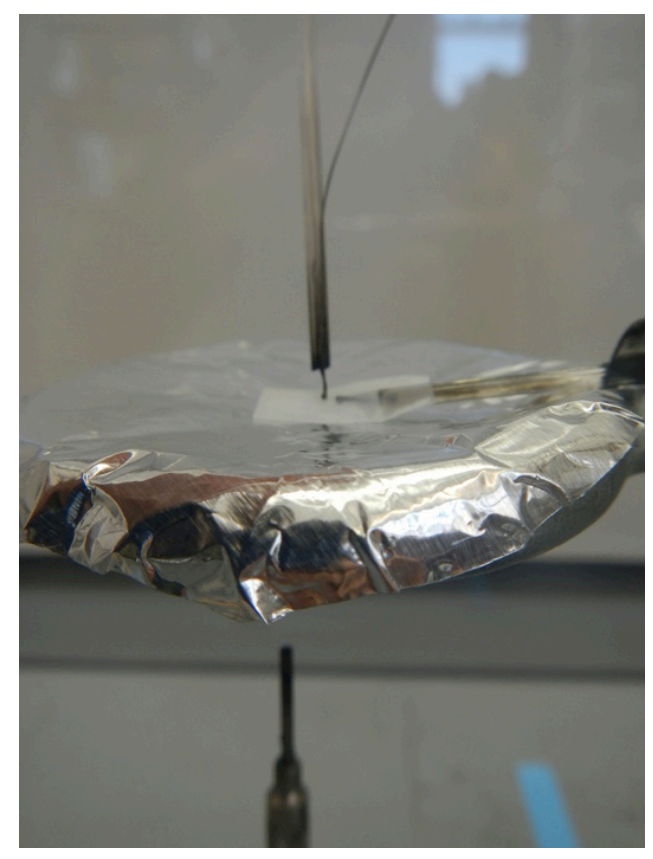

Figure 3-3. Close-up view of the T1 sandwiched in the middle and T2 rested on the top of the FTP sample on the foil. 


\subsubsection{Results and Discussion}

The temperature results of the 16 trials in regards to the moment smoke was visually observed, maximum temperature obtained while burning, and the rate of temperature increase is summarized in Table 3-1. The full results of each trial run are located in Appendix A, where the asterisked denotes trial where the setup failed where the thermocouple sensors fell out of place during the burning process. The smoke temperature is the temperature at which smoke was visually observed emanating from the sample. These values were not consistent between trials as noted in Appendix A. This is most likely due to the fact that the heating of the FTP was not evenly distributed which is expected with the smoking method being studied. This factor is not critical in the scope of the present analysis; rather, determining the range of temperatures observed was crucial. Using this method, the maximum recorded temperature was $315.1^{\circ} \mathrm{C}$. This temperature is in rough agreement with that report for the heroin studies, but significantly lower for other fentanyl studies mentioned earlier.

The maximum temperature is the highest temperature obtained in the smoking process. This temperature was of importance in this study since the values used in Chapter 2 were of temperatures obtained in manufactured tobacco cigarettes. The temperature under cigarette smoldering conditions was hypothesized to be high relative to "chasing the dragon". The temperatures recorded ranged from 214.1 - $441.6^{\circ} \mathrm{C}$, with most trials being between 250 ${ }^{\circ} \mathrm{C}$ and $300{ }^{\circ} \mathrm{C}$ (failed trials omitted).

The rate of temperature increase was assessed by the starting recorded room temperature of the FTPs to the maximum temperature obtained by the FTPs by heating. The rates were given as ${ }^{\circ} \mathrm{C} / \mathrm{s}$. These values ranged from $8.3^{\circ} \mathrm{C} / \mathrm{s}$ to $23.0^{\circ} \mathrm{C} / \mathrm{s}$, with most of the 
recorded values being around $20^{\circ} \mathrm{C} / \mathrm{s}$. This value is the same rate of increase as the one used in the previous pyrolysis study in Chapter 2 .

Figure 3-4 is a plot of T1 and T2 over time for Trial 8 analysis. This is just one example of the general trend of the temperature increase of each of the thermocouples. In this specific trial, it is observed that $\mathrm{T} 1$ has a faster rate of temperature increase and has a higher maximum temperature. In general, the trends vary slightly between trials, however, this is also not a critical factor of the overall scope of the analysis. 
Table 3-1. Temperature data of smoking FTPs using the "chasing the dragon" method.

\begin{tabular}{|c|c|c|c|c|c|c|}
\cline { 2 - 7 } \multicolumn{1}{c|}{} & \multicolumn{2}{c|}{ Smoke Observed Temp. } & \multicolumn{2}{c|}{ Max. Temp. } & \multicolumn{2}{c|}{ Rate Increase } \\
\cline { 2 - 7 } & $\mathrm{T} 1\left({ }^{\circ} \mathrm{C}\right)$ & $\mathrm{T} 2\left({ }^{\circ} \mathrm{C}\right)$ & $\mathrm{T} 1\left({ }^{\circ} \mathrm{C}\right)$ & $\mathrm{T} 2\left({ }^{\circ} \mathrm{C}\right)$ & $\mathrm{T} 1\left({ }^{\circ} \mathrm{C} / \mathrm{s}\right)$ & $\mathrm{T} 2\left({ }^{\circ} \mathrm{C} / \mathrm{s}\right)$ \\
\hline Max & 315.1 & 308.6 & 441.6 & 397.7 & 28.0 & 24.9 \\
\hline Average & 87.6 & 110.2 & 274.1 & 289.5 & 12.0 & 16.7 \\
\hline
\end{tabular}




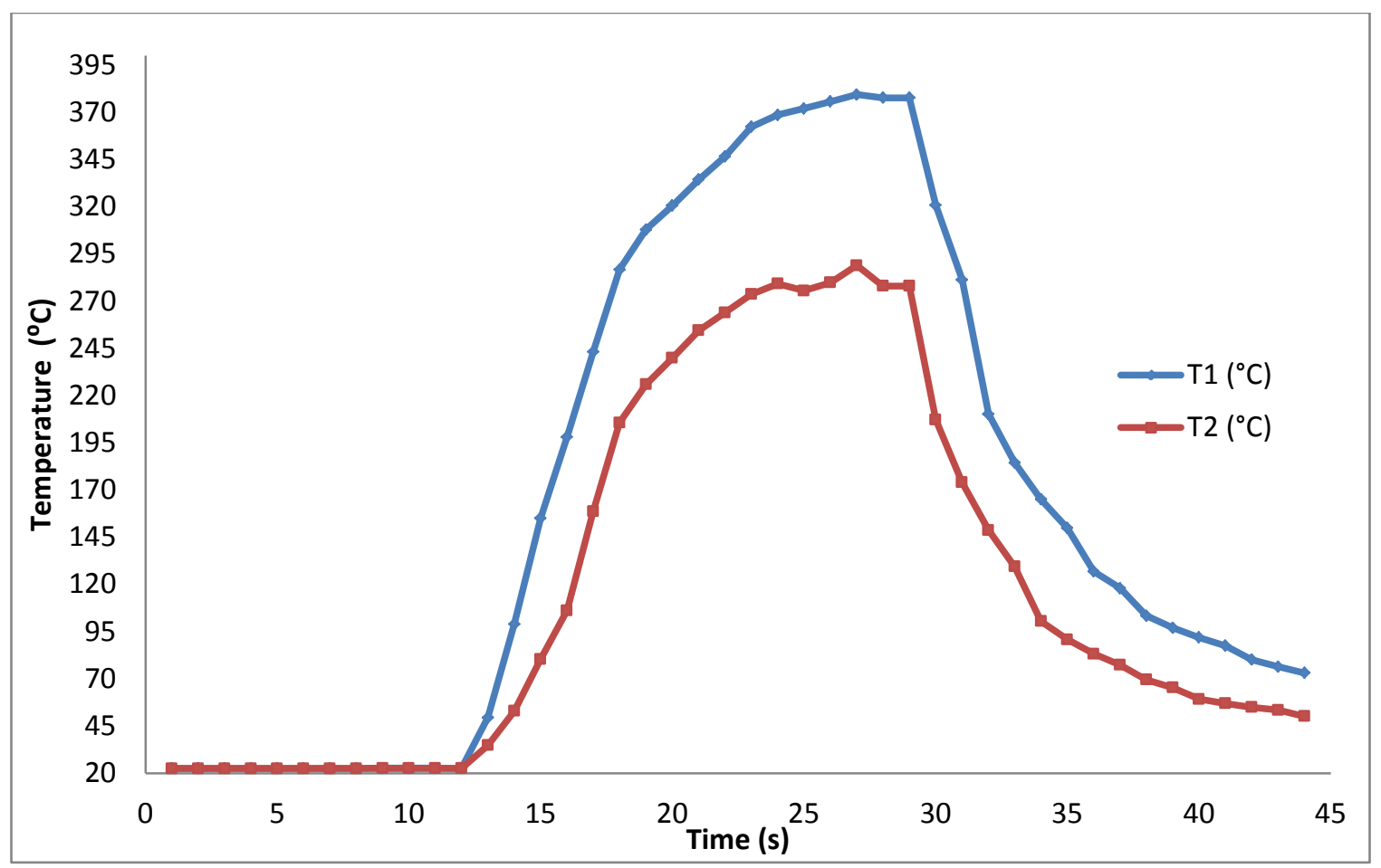

Figure 3-4. Comparison of T1 and T2 over time for Trial 8. 


\subsubsection{Conclusions}

The temperature analysis was essential for determining realistic temperature estimations obtained during smoking of the FTPs by means of the "chasing the dragon" method. This experimentation allowed for a more accurate determination of parameters settings for the Py-GC/MS analysis of fentanyl rather than basing the parameters on manufactured tobacco cigarettes studies. Here it is noted that temperatures never exceeded $450{ }^{\circ} \mathrm{C}$ at either the smoke temperature or the maximum temperature readings. This is well below the $750{ }^{\circ} \mathrm{C}$ pyrolysis temperature used in Chapter 2 that was again based on manufactured tobacco cigarettes. The rate of temperature increase was approximately 20 ${ }^{\circ} \mathrm{C} / \mathrm{s}$ for most of the trial runs in the experiment. Data obtained indicates that manufactured tobacco cigarette temperature is not applicable here under. The knowledge gained here will help determine if at lower temperatures different pyromarkers are present or even different pyromarkers is most dominant besides propionanilide noted in Chapter 2. The temperature parameters determined here is applied to the Py-GC/MS for the analysis of pyromarkers in both fentanyl and FTPs samples in the following chapter. 


\section{Chapter 4: Application of Temperatures Characteristics Obtained from Smoking FTPs By Means of "Chasing the Dragon" on the Py-GC/MS}




\subsubsection{Introduction}

This chapter reflects the pyrolysis parameters that were obtained in the previous chapter that used thermocouples for temperatures analysis on smoking FTPs by means of the "chasing the dragon" method. The results from Chapter 3 indicated that the temperatures obtained by smoking FTPs by means of "chasing the dragon" did not reach to the $750{ }^{\circ} \mathrm{C}$ temperatures that were used in the previous study. Although $450{ }^{\circ} \mathrm{C}$ is the maximum temperature observed in the thermocouple temperature study, these lower increments of temperature were evaluated to see if $50{ }^{\circ} \mathrm{C}$ temperature variations made any differences.

As stated previously, Manral et al. analyzed the pyrolysis of fentanyl from temperature of 250 to $900{ }^{\circ} \mathrm{C}$ using a large sample size of $50 \mathrm{mg} .{ }^{102}$ It has long been recognized that small samples, typically less than $1 \mathrm{mg}$, good heat transfer and rapid heating of the pyrolysis element are essential in achieving reproducibility. ${ }^{89,113}$ The smaller the sample size, the more likely it is to pyrolyze in a uniform and reproducible way by having all of the sample material in close contact with the pyrolyzer to experience the same temperature at the same time..$^{83,90}$

Manral et al., also found only fentanyl and no pyromarkers observed up to $350{ }^{\circ} \mathrm{C}$, therefore concluding that fentanyl was stable up to $350{ }^{\circ} \mathrm{C}$. At $500{ }^{\circ} \mathrm{C}$, propionanilide and PEP were the only pyromarkers observed. With this, the authors concluded that higher temperatures of $750{ }^{\circ} \mathrm{C}$ resulted in extensive degradation of not only the parent fentanyl compound itself, but also of the propionanilide and PEP. Manral et al. pyrolyzed propionanilide and PEP at $750{ }^{\circ} \mathrm{C}$ and determined 3-methylindone and phenylisocyanate as a result of intramolecular rearrangements (Figure 2-4). ${ }^{102}$ As stated before, the authors 
ascertained that phenylisocyanate may lead to the formation of hydrogen cyanide, which would be a large factor in the toxicity of smoked fentanyl. ${ }^{102}$

Data from this project does not support the idea that fentanyl is stable up to $350{ }^{\circ} \mathrm{C}$ as stated by Manral et al. and is evaluated at lower temperatures. Here six temperatures of were evaluated from 200 to $450{ }^{\circ} \mathrm{C}$ in $50{ }^{\circ} \mathrm{C}$ increments on the Py-GC/MS. This is to observe any differences seen in regards to unique or prevalent pyromarkers present in the smoking process in comparison to the higher pyrolysis temperature previously studied.

\subsubsection{Materials and Methods}

Fentanyl and norfentanyl oxalate, both in methanol solvent were obtained from Cerilliant Corporation (Round Rock, TX, USA). Despropionyl fentanyl was purchased from Biomol (Plymouth Meeting, PA, USA). Duragesic ${ }^{\circledR} 100 \mathrm{mcg} / \mathrm{h}$ fentanyl transdermal system patches were obtained from McKesson (San Francisco, CA, USA). Pyridine, benzaldehyde, phenylacetaldehyde, propionanilide, and HPLC grade methanol were purchased from Sigma Aldrich (St. Louis, MO, USA).

\subsubsection{Py-GC/MS}

Here the same CDS Analytical 5200 Pyroprobe was used in trapping mode to pyrolyze the samples under aerobic conditions using air and a full 20:35 mesh Tenax-TA sorbent tube trap (CDS Analytical, Inc., Oxford, PA). However, instead of the Perkin Elmer GC/MS, a Shimadzu GC/MS QP2010S was used (Shimadzu Corporation, Kyoto, Japan). The GC was equipped with an Rxi ${ }^{\circledR}-5 S i l$ MS with Integra-Guard ${ }^{\circledR}$ (30 m, 0.25 mm i.d., 0.50 $\mu \mathrm{m}$ film thickness, Restek, Bellefonte, PA, USA). The MS was equipped with an electron ionization source and quadrupole mass analyzer with a scanning range of $\mathrm{m} / \mathrm{z} 50-600$. The 
interface and ion source temperatures were $300{ }^{\circ} \mathrm{C}$ and $250{ }^{\circ} \mathrm{C}$, respectively. GC/MS parameters were slightly altered from previous analysis with a lower final GC oven temperature to minimize the capillary column bleeding and prolong the life of the column (Table 4-1).

The components and workings of the CDS analytical pyroprobe unit were explained previously in Section 2.2.1. Analysis was done only in aerobic conditions where air was used as the reactant gas and helium was used as the carrier gas. Table 4-1 lists the parameters for the Py-GC/MS at the 6 different pyrolysis temperatures for both the fentanyl standards and the FTPs. All samples were run in triplicate to determine repeatability of the method, at least qualitatively. With the sorbent tube trap, the desorb temperature is necessary to desorb the collected analytes and transfer them to the GC at the beginning of the run. In addition, a $250{ }^{\circ} \mathrm{C}$ desorption temperature was assessed in the $200{ }^{\circ} \mathrm{C}$ pyrolysis analysis run. This is to observe any pyromarkers that were not able to desorb at $200{ }^{\circ} \mathrm{C}$.

With a quartz tube filled with a plug of quartz wool inside the filament of the pyrolysis probe, $10 \mu \mathrm{g}$ of the fentanyl solution was deposited using a microliter syringe. The fentanyl in methanol solution was a concentration of $1000 \mathrm{ppm}$. The sample was then dried to remove some of the excess solvent by heating the filament to $50{ }^{\circ} \mathrm{C}$ for $30 \mathrm{~s}$. The probe was then inserted into the pyroprobe unit for pyrolysis under the set conditions. 
Table 4-1. Py-GC/MS parameters for the pyrolysis of fentanyl standards and FTPs.

\begin{tabular}{|c|c|c|c|c|c|c|c|}
\hline Pyroprobe Conditions & $200{ }^{\circ} \mathrm{C}$ & $\begin{array}{c}200^{\circ} \mathrm{C} \text { w/ } 250 \\
{ }^{\circ} \mathrm{C} \text { desorb }\end{array}$ & $250{ }^{\circ} \mathrm{C}$ & $300{ }^{\circ} \mathrm{C}$ & $350{ }^{\circ} \mathrm{C}$ & $400{ }^{\circ} \mathrm{C}$ & $450{ }^{\circ} \mathrm{C}$ \\
\hline \multicolumn{8}{|l|}{ Pyroprobe Temperatures } \\
\hline Initial & $50^{\circ} \mathrm{C}, 1 \mathrm{~s}$ & $50^{\circ} \mathrm{C}, 1 \mathrm{~s}$ & $50^{\circ} \mathrm{C}, 1 \mathrm{~s}$ & $50^{\circ} \mathrm{C}, 1 \mathrm{~s}$ & $50^{\circ} \mathrm{C}, 1 \mathrm{~s}$ & $50^{\circ} \mathrm{C}, 1 \mathrm{~s}$ & $50^{\circ} \mathrm{C}, 1 \mathrm{~s}$ \\
\hline Ramp Rate & $20^{\circ} \mathrm{C} / \mathrm{s}$ & $20^{\circ} \mathrm{C} / \mathrm{s}$ & $20^{\circ} \mathrm{C} / \mathrm{s}$ & $20^{\circ} \mathrm{C} / \mathrm{s}$ & $20^{\circ} \mathrm{C} / \mathrm{s}$ & $20^{\circ} \mathrm{C} / \mathrm{s}$ & $20^{\circ} \mathrm{C} / \mathrm{s}$ \\
\hline Final & $200^{\circ} \mathrm{C}, 10 \mathrm{~s}$ & $200^{\circ} \mathrm{C}, 10 \mathrm{~s}$ & $250^{\circ} \mathrm{C}, 10 \mathrm{~s}$ & $300^{\circ} \mathrm{C}, 10 \mathrm{~s}$ & $350^{\circ} \mathrm{C}, 10 \mathrm{~s}$ & $400^{\circ} \mathrm{C}, 10 \mathrm{~s}$ & $450^{\circ} \mathrm{C}, 10 \mathrm{~s}$ \\
\hline \multicolumn{8}{|l|}{ Accessory Parameters } \\
\hline Rest & $50^{\circ} \mathrm{C}$ & $50^{\circ} \mathrm{C}$ & $50^{\circ} \mathrm{C}$ & $50^{\circ} \mathrm{C}$ & $50^{\circ} \mathrm{C}$ & $50{ }^{\circ} \mathrm{C}$ & $50^{\circ} \mathrm{C}$ \\
\hline Initial & $50^{\circ} \mathrm{C}, 1 \mathrm{~min}$ & $50^{\circ} \mathrm{C}, 1 \mathrm{~min}$ & $50^{\circ} \mathrm{C}, 1 \mathrm{~min}$ & $50^{\circ} \mathrm{C}, 1 \mathrm{~min}$ & $50^{\circ} \mathrm{C}, 1 \mathrm{~min}$ & $50^{\circ} \mathrm{C}, 1 \mathrm{~min}$ & $50^{\circ} \mathrm{C}, 1 \mathrm{~min}$ \\
\hline Ramp Rate & $100^{\circ} \mathrm{C} / \mathrm{min}$ & $100^{\circ} \mathrm{C} / \mathrm{min}$ & $100^{\circ} \mathrm{C} / \mathrm{min}$ & $100^{\circ} \mathrm{C} / \mathrm{min}$ & $100^{\circ} \mathrm{C} / \mathrm{min}$ & $100^{\circ} \mathrm{C} / \mathrm{min}$ & $100^{\circ} \mathrm{C} / \mathrm{min}$ \\
\hline Final & $200^{\circ} \mathrm{C}, 5 \mathrm{~min}$ & $200^{\circ} \mathrm{C}, 5 \mathrm{~min}$ & $250^{\circ} \mathrm{C}, 5 \mathrm{~min}$ & $300^{\circ} \mathrm{C}, 5 \mathrm{~min}$ & $300^{\circ} \mathrm{C}, 5 \mathrm{~min}$ & $300^{\circ} \mathrm{C}, 5 \mathrm{~min}$ & $300^{\circ} \mathrm{C}, 5 \mathrm{~min}$ \\
\hline \multicolumn{8}{|l|}{ Trap Temperatures } \\
\hline Reactant Gas & $6.50 \mathrm{~min}$ & $6.50 \mathrm{~min}$ & $7.00 \mathrm{~min}$ & $7.50 \mathrm{~min}$ & $7.50 \mathrm{~min}$ & $7.50 \mathrm{~min}$ & $7.50 \mathrm{~min}$ \\
\hline Rest & $50^{\circ} \mathrm{C}$ & $50^{\circ} \mathrm{C}$ & $50^{\circ} \mathrm{C}$ & $50^{\circ} \mathrm{C}$ & $50^{\circ} \mathrm{C}$ & $50^{\circ} \mathrm{C}$ & $50^{\circ} \mathrm{C}$ \\
\hline Desorb & $200^{\circ} \mathrm{C}, 2 \mathrm{~min}$ & $250^{\circ} \mathrm{C}, 2 \mathrm{~min}$ & $250^{\circ} \mathrm{C}, 2 \mathrm{~min}$ & $300^{\circ} \mathrm{C}, 2 \mathrm{~min}$ & $300^{\circ} \mathrm{C}, 2 \mathrm{~min}$ & $300^{\circ} \mathrm{C}, 2 \mathrm{~min}$ & $300^{\circ} \mathrm{C}, 2 \mathrm{~min}$ \\
\hline \multicolumn{8}{|l|}{ Iso Zones } \\
\hline Transfer Line & $200{ }^{\circ} \mathrm{C}$ & $250{ }^{\circ} \mathrm{C}$ & $250{ }^{\circ} \mathrm{C}$ & $300{ }^{\circ} \mathrm{C}$ & $300{ }^{\circ} \mathrm{C}$ & $300{ }^{\circ} \mathrm{C}$ & $300{ }^{\circ} \mathrm{C}$ \\
\hline Valve Oven & $200{ }^{\circ} \mathrm{C}$ & $250{ }^{\circ} \mathrm{C}$ & $250{ }^{\circ} \mathrm{C}$ & $300{ }^{\circ} \mathrm{C}$ & $300{ }^{\circ} \mathrm{C}$ & $300{ }^{\circ} \mathrm{C}$ & $300{ }^{\circ} \mathrm{C}$ \\
\hline \multicolumn{8}{|l|}{ GC Conditions } \\
\hline Injector Port & $200{ }^{\circ} \mathrm{C}$ & $250{ }^{\circ} \mathrm{C}$ & $250{ }^{\circ} \mathrm{C}$ & $300{ }^{\circ} \mathrm{C}$ & $300{ }^{\circ} \mathrm{C}$ & $300{ }^{\circ} \mathrm{C}$ & $300{ }^{\circ} \mathrm{C}$ \\
\hline Initial & $70^{\circ} \mathrm{C}$ & $70^{\circ} \mathrm{C}$ & $70^{\circ} \mathrm{C}$ & $70^{\circ} \mathrm{C}$ & $70^{\circ} \mathrm{C}$ & $70{ }^{\circ} \mathrm{C}$ & $70^{\circ} \mathrm{C}$ \\
\hline Ramp Rate & $15^{\circ} \mathrm{C} / \mathrm{min}$ & $15^{\circ} \mathrm{C} / \mathrm{min}$ & $15^{\circ} \mathrm{C} / \mathrm{min}$ & $15^{\circ} \mathrm{C} / \mathrm{min}$ & $15^{\circ} \mathrm{C} / \mathrm{min}$ & $15^{\circ} \mathrm{C} / \mathrm{min}$ & $15^{\circ} \mathrm{C} / \mathrm{min}$ \\
\hline Final & $300{ }^{\circ} \mathrm{C}, 4.67 \mathrm{~min}$ & $300^{\circ} \mathrm{C}, 4.67 \mathrm{~min}$ & $300^{\circ} \mathrm{C}, 4.67 \mathrm{~min}$ & $300^{\circ} \mathrm{C}, 4.67 \mathrm{~min}$ & $300^{\circ} \mathrm{C}, 4.67 \mathrm{~min}$ & $300^{\circ} \mathrm{C}, 4.67 \mathrm{~min}$ & $300{ }^{\circ} \mathrm{C}, 4.67 \mathrm{~min}$ \\
\hline
\end{tabular}


For the FTPs, the backings were removed and the entire patch was folded over on itself on the adhesive side for ease of handling. Then small pieces of approximately $1 \mathrm{~mm}$ by $1 \mathrm{~mm}$ were cut resulting to a weight ranging from 200-300 $\mu \mathrm{g}$. Each piece was then sandwiched between two plugs of quartz wool in the quartz sample tube. The sample tube was then inserted in the coiled filament of the probe and successively into the pyroprobe unit for pyrolysis under the set conditions.

\subsubsection{Results and Discussion}

The pyromarkers of the fentanyl standard and the FTPs listed in Table 4-2 and 4-3. Appendix B includes results of all pyromarkers observed for each trial run. These pyromarkers were initially identified using NIST MS library. Identification was confirmed by analysis of SRMs by the comparison of retention times and mass spectra for the following analytes: pyridine, benzaldehyde, phenylacetaldehye, propionanilide, norfentanyl,

despropionyl fentanyl, and fentanyl. The other pyromarkers observed were considered to be tentatively identified based solely by the NIST MS database. The percent areas of each pyromarker were normalized relative to the largest peak area in the chromatogram.

\subsubsection{Pyromarkers of Fentanyl Standard}

It is shown here that propionanilide is observed under all pyrolysis temperature conditions with the highest peak area, as low at $200{ }^{\circ} \mathrm{C}$, for the pyrolysis of the fentanyl standard (Table 4-2). This indicates that fentanyl itself is not stable below $350{ }^{\circ} \mathrm{C}$ as found in literature and hence is not likely suitable for volatilization for inhalation administration as sought by Manral et al. At $200{ }^{\circ} \mathrm{C}$, only pyridine and fentanyl was observed; however, with $250{ }^{\circ} \mathrm{C}$ for in desorption temperature, styrene, benzaldehyde, aniline, phenylacetaldehyde, 
and propionanilide was observed in addition. This increase in $50{ }^{\circ} \mathrm{C}$ in temperature was necessary of these pyromarkers to desorb off of the Tenax-TA trap.

Since fentanyl $\mathrm{HCl}$ was not used in this analysis due to availability, chlorinated pyromarkers were not observed as seen for the pyrolysis at $750{ }^{\circ} \mathrm{C}$ in aerobic conditions (Table 2-2). The only pyromarker other than the chlorinated ones observed at $750{ }^{\circ} \mathrm{C}$ and not here under any of these temperatures was despropionyl fentanyl. This may have been due the smaller sample size used here in comparison to the previous studies where 50-100 $\mu \mathrm{g}$ of solid fentanyl $\mathrm{HCl}$ were used. Overall, pyridine, styrene, benzaldehyde, aniline, phenylacetaldehyde, propionanilide, and fentanyl were consistently detected at all six temperatures of pyrolysis.

The pyrolytic degradation pathways of pyridine, styrene, benzaldehyde, aniline, phenylacetaldehyde, and propionanilide likely underwent the same reactions as explained in section 2.3.1. The only difference observed was 3-methyl-pyridine at $450{ }^{\circ} \mathrm{C}$. The formation of this product is not well understood. It is the likelihood that the piperidine ring free radical allows for dehydrogenation for the pyridine ring and sigmatropic rearrangement for a 1,5migration of the methyl group. ${ }^{85}$ 
Table 4-2. Pyromarkers of the pyrolysis of the fentanyl standard.

\begin{tabular}{|c|c|c|c|c|c|c|}
\hline & & $250{ }^{\circ} \mathrm{C}$ desorb & & & & \\
\hline $200{ }^{\circ} \mathrm{C}$ & $\%$ Area & $\%$ Area & $250{ }^{\circ} \mathrm{C}$ & $\%$ Area & $300{ }^{\circ} \mathrm{C}$ & $\%$ Area \\
\hline 1. Pyridine & & 24.0 & 1. Pyridine & 20.8 & 1. Pyridine & 56.5 \\
\hline 2. Styrene & & 20.0 & 2. Styrene & 21.8 & 2. Styrene & 47.2 \\
\hline 3. Benzaldehyde & & 12.2 & 3. Benzaldehyde & 8.3 & 3. Benzaldehyde & 26.5 \\
\hline 4. Aniline & & 3.8 & 4. Aniline & 1.0 & 4. Aniline & 2.9 \\
\hline 5. Phenylacetaldehyde & & 2.9 & 5. Phenylacetaldehyde & 3.3 & 5. Phenylacetaldehyde & 8.9 \\
\hline 1,6. Propionanilide & 100 & 100 & 6. Propionanilide & 100 & 6. Propionanilide & 100 \\
\hline 2,7. Fentanyl & 8.2 & 3.1 & 7. Fentanyl & 12.4 & 7. Fentanyl & 63.2 \\
\hline $350{ }^{\circ} \mathrm{C}$ & $\%$ Area & & $400{ }^{\circ} \mathrm{C}$ & $\%$ Area & $450{ }^{\circ} \mathrm{C}$ & $\%$ Area \\
\hline 1. Pyridine & 58.5 & & 1. Pyridine & 46.2 & 1. Pyridine & 42.2 \\
\hline 2. Styrene & 47.1 & & 2. Styrene & 38.6 & 2. 3-Methyl-pyridine & 1.1 \\
\hline 3. Benzaldehyde & 24.5 & & 3. Benzaldehyde & 20.2 & 3. Styrene & 32.3 \\
\hline 4. Aniline & 2.5 & & 4. Aniline & 1.5 & 4. Benzaldehyde & 21.1 \\
\hline 5. Phenylacetaldehyde & 7.8 & & 5. Phenylacetaldehyde & 6.3 & 5. Aniline & 3.8 \\
\hline 6. Propionanilide & 100 & & 6. Propionanilide & 100 & 6. Phenylacetaldehyde & 4.3 \\
\hline 7. Fentanyl & 42.1 & & 7. Fentanyl & 65.5 & 7. Propionanilide & 100 \\
\hline & & & & & 8. Fentanyl & 24.6 \\
\hline
\end{tabular}


Figure 4-2 shows the comparison of the GC chromatograms of the pyrolysis of the fentanyl standard under all pyrolysis temperature conditions. The chromatographic peaks labeled with numbers corresponding to their identification listed on Table 4-2. Peaks that are not labeled could not be identified using the NIST MS database. It is seen here that the chromatography pattern is similar and is observed at all three trials at each temperature condition.

There is a noticeable difference in comparison of the GC chromatograms of $200{ }^{\circ} \mathrm{C}$ with $200{ }^{\circ} \mathrm{C}$ (Figure 4-1A) and $250^{\circ} \mathrm{C}$ (Figure 4-1B) for desorption of pyromarkers off the TenaxTA trap to the GC/MS for analysis. In all instances, propionanilide is observed with the highest peak area, as well as peak intensity, at RT $~ 9.329$ min. As the temperature of pyrolysis increases, the intensity of the pyromarkers increases. 
Figure 4-1. Chromatograms of the pyrolysis of fentanyl standard at $200-450{ }^{\circ} \mathrm{C}$.

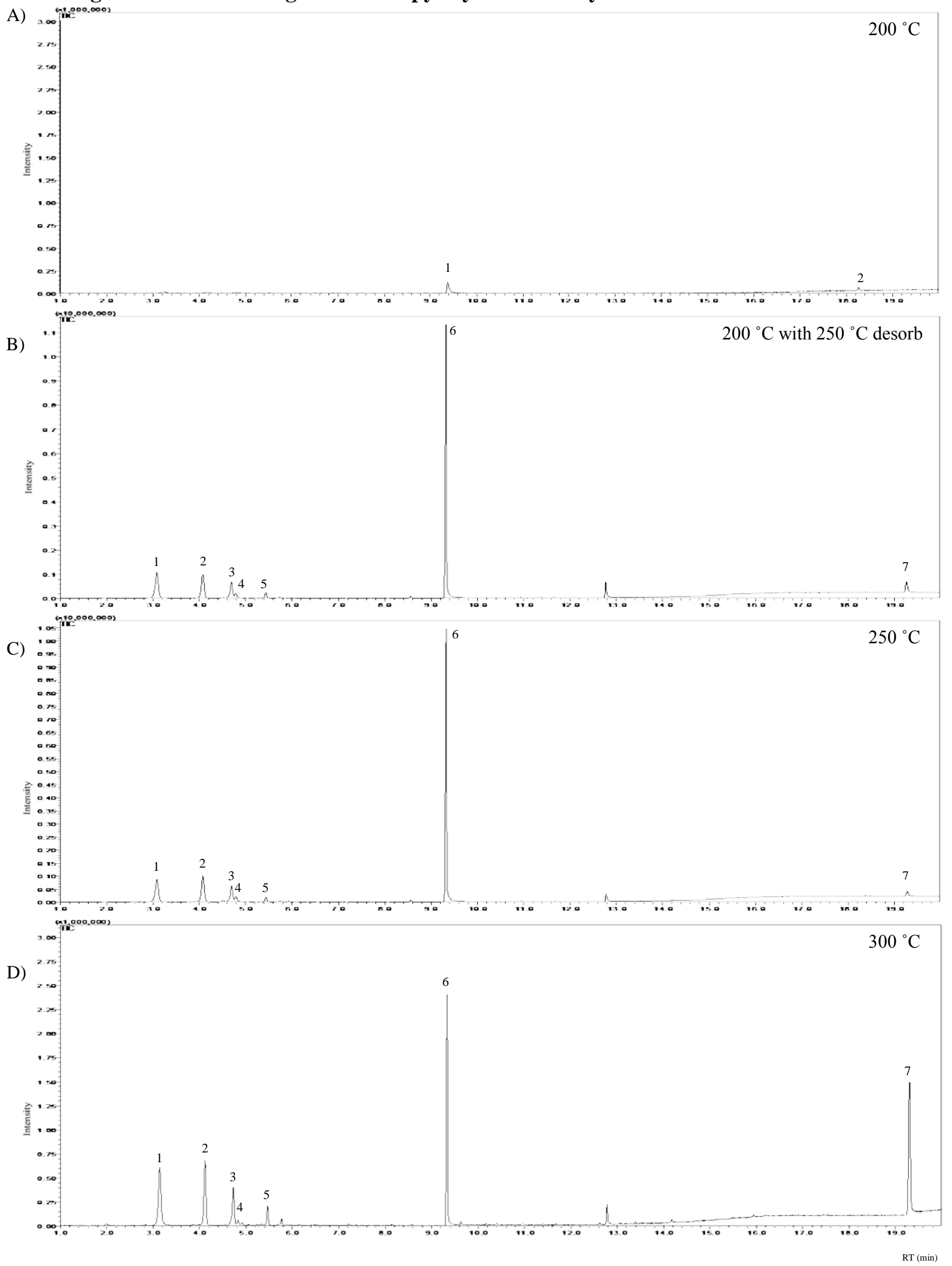


Figure 4-1. Continued.
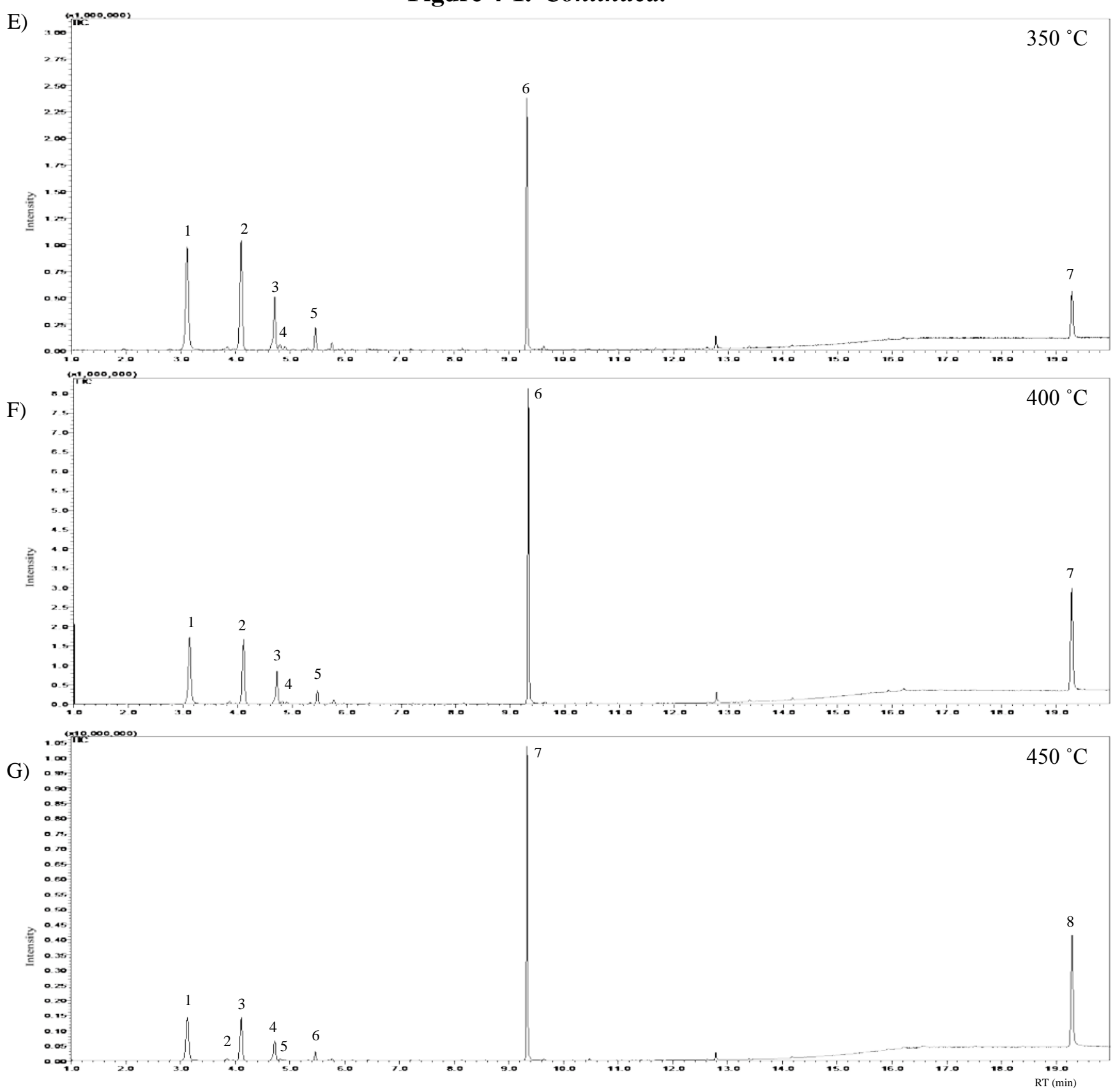


\subsubsection{Pyromarkers of FTPs}

The pyromarkers observed under all temperature conditions for the pyrolysis of the FTPs are located in Table 4-3. The analytes reported in this table were observed consistently in all triplicate analyses. All observed pyromarkers, including those that were detected in all three replicates, for each trial run are located in Appendix B. The same pyromarkers observed for the pyrolysis of fentanyl standard under all six temperature conditions were detected in the pyrolysis of the FTPs at the under the same conditions with the exception of aniline. Aniline contained the lowest percent area for the fentanyl standard, and thus, not surprising that aniline is not observed in the pyrolysis of the FTPs.

Additional pyromarkers observed besides those see in Table 4-2 can be attributed to the other unknown material that is incorporated into the manufacturing of the FTPs. Again, these materials include plasticizers and adhesives to allow the patch to adhere to the skin of patients for dermal absorption. At the pyrolysis of $200{ }^{\circ} \mathrm{C}$, both of the desorbing temperatures produced the same pyromarkers. This is likely due to the increase in sample size of the FTP in comparison to the fentanyl standard sample size deposited on the quartz wool.

It can be noted that from $200{ }^{\circ} \mathrm{C}$ to $300{ }^{\circ} \mathrm{C}$, propionanilide has the greatest peak area. At $300{ }^{\circ} \mathrm{C}$, 2-ethyl-1-hexanol (2-EH) increases in peak area until $400{ }^{\circ} \mathrm{C}$, where it surpasses the peak area of propionanilide. 2-EH is considered to be not acutely toxic in regards to inhalation in rat studies and is a synthetic alcohol that is mainly used in the manufacture of ester plasticizer

primarily to used in produce soft polyvinyl chloride. ${ }^{114}$ Although it is commonly found in the environment, it has the potential to be a pyromarker of importance for investigative purposes. 
Table 4-3. Pyromarkers of FTPs from 200-450 ${ }^{\circ} \mathrm{C}$.

\begin{tabular}{|c|c|c|c|c|c|c|}
\hline $200{ }^{\circ} \mathrm{C}$ & $\%$ Area & $\begin{array}{c}250^{\circ} \mathrm{C} \text { desorb } \\
\% \text { Area }\end{array}$ & $250^{\circ} \mathrm{C}$ & $\%$ Area & $300^{\circ} \mathrm{C}$ & $\%$ Area \\
\hline 1. Pyridine & 21.9 & 14.6 & 1. Pyridine & 27.6 & 1. Pyridine & 30.5 \\
\hline 2. Styrene & 25.9 & 23.0 & 2. Styrene & 33.1 & 2. 3-Methylene-heptane & 41.1 \\
\hline 4. Phenylacetaldehyde & 9.1 & 7.2 & 4. Aniline & 2.2 & 4. Styrene & 31.6 \\
\hline 5. Propionanilide & 100 & 100 & 5. 3-Pyridinecarboxaldehyde & 1.1 & 5. 2-Ethyl-2-hexenal & 2.1 \\
\hline \multirow{6}{*}{ 6. Fentanyl } & & & 8. 1-Phenyl-1,2-propanedione & 1.5 & 8. 2-EH & 57.7 \\
\hline & & & 9. Benzenecarboxylic acid & 1.2 & 9. Phenylacetaldehyde & 10.1 \\
\hline & & & 10. Propionanilide & 100 & 10. 1-Phenyl-1,2-propanedione & 2.0 \\
\hline & & & 11. N-(2-phenylethyl)-formamide & 2.0 & 11. 2-Ethylhexyl ester acetic acid & 1.2 \\
\hline & & & 12. Fentanyl & 1.5 & 12. Benzenecarboxylic acid & 3.4 \\
\hline & & & & & 17. Fentanyl & 1.8 \\
\hline
\end{tabular}


Table 4-3. Continued.

\begin{tabular}{|c|c|c|c|c|c|}
\hline $350{ }^{\circ} \mathrm{C}$ & $\%$ Area & $400{ }^{\circ} \mathrm{C}$ & $\%$ Area & $450{ }^{\circ} \mathrm{C}$ & $\%$ Area \\
\hline 1. Pyridine & 32.0 & 1. Pyridine & 23.2 & 1. Pyridine & 23.5 \\
\hline 2. 3-Methylene-heptane & 36.1 & 2. 3-Methylene-heptane & 50.0 & 2. 3-Methylene-heptane & 65.9 \\
\hline 3. 3-Heptanone & 5.1 & 3. 3-Heptanone & 5.6 & 3. 3-Heptanone & 7.9 \\
\hline 4. Styrene & 34.2 & 4. Styrene & 17.8 & 4. Styrene & 13.5 \\
\hline 5. 2-Ethyl-hexanal & 10.8 & 5. 2-Ethyl-2-hexenal & 3.2 & 5. 2-Ethyl-hexanal & 12.6 \\
\hline 6. Benzaldehyde & 27.6 & 6. 2-Ethyl-hexanal & 13.6 & 6. Benzaldehyde & 26.1 \\
\hline 7. 2-EH & 55.8 & 7. Benzaldehyde & 21.1 & 7. 2-EH & 100 \\
\hline 8. Benzyl Alcohol & 1.8 & 8. 2-EH & 100 & 8. Phenylacetaldehyde & 4.2 \\
\hline 9. Phenylacetaldehyde & 8.3 & 9. Phenylacetaldehyde & 5.0 & 9. 2-Ethylhexyl ester acetic acid & 4.3 \\
\hline 10. 2-Ethylhexyl ester acetic acid & 1.1 & 10. 2-Ethylhexyl ester acetic acid & 1.8 & 10. Benzenecarboxylic acid & 3.4 \\
\hline 11. Benzenecarboxylic acid & 2.8 & 11. Benzenecarboxylic acid & 2.7 & 11. 2-Ethylhexyl ester 2-propenoic acid & 27.9 \\
\hline 12. 2-Ethylhexyl ester 2-propenoic acid & 4.8 & 12. 2-Ethylhexyl ester 2-propenoic acid & 13.1 & 12. 2-Ethylhexyl methacrylate & 3.1 \\
\hline 13. Propionanilide & 100 & 13. 2-Ethylhexyl methacrylate & 1.6 & 13. n-Butyric acid 2-ethylhexyl ester & 1.3 \\
\hline 14. 2-EEFA & 2.1 & 14. 2-EECA & 1.8 & 14. 2-EECA & 2.7 \\
\hline \multirow[t]{4}{*}{ 15. Fentanyl } & 1.7 & 15. Propionanilide & 69.1 & 15. Propionanilide & 63.0 \\
\hline & & 16. 2-Ethylhexyl ester pentanoic acid & 3.8 & 16. 2-Ethylhexyl ester pentanoic acid & 5.2 \\
\hline & & 17. 2-EEFA & 3.8 & 17. 2-EEFA & 1.9 \\
\hline & & 18. Fentanyl & 2.7 & 18. Fentanyl & 1.0 \\
\hline
\end{tabular}


Figure 4-3 shows all the GC chromatograms of the pyrolysis of the FTPs under all pyrolytic temperature conditions. The peaks are labeled with numbers that coincide with the pyromarkers listed in Table 4-3. Peaks that were not labeled could not be identified through the NIST MS database. Again, most of these unidentifiable peaks were likely pyromarkers of the plasticizers of the FTPs since they are not observed in the fentanyl standard alone. For the $200{ }^{\circ} \mathrm{C}$, both desorbing temperatures resulted in similar pyromarkers with higher peak intensity and areas for $250{ }^{\circ} \mathrm{C}$ (Figure 4-3A) than $200^{\circ} \mathrm{C}$ (Figure 4-3B). Again, this higher temperature afforded more of the pyromarkers to desorb off of the Tenax-TA in the trap.

In Figure 4-3C, there is a magnified view of the chromatographic peaks for enhance viewing purposes. The pattern of the chromatograms is similar with greater intensity as the pyrolytic temperature increases. The increase in pyrolytic temperature produces an increase in number of peaks; however, most of those peaks were unidentifiable using the NIST MS database. At $350{ }^{\circ} \mathrm{C}$ and below, propionanilide dominates as having the largest peak area. Not until $400{ }^{\circ} \mathrm{C}$ and above, does 2-EH has the largest peak area and intensity in the chromatograms (Figure 4-3F and G). 
Figure 4-2. Chromatograms of the pyrolysis of the FTPs at 200-450 ${ }^{\circ} \mathrm{C}$.

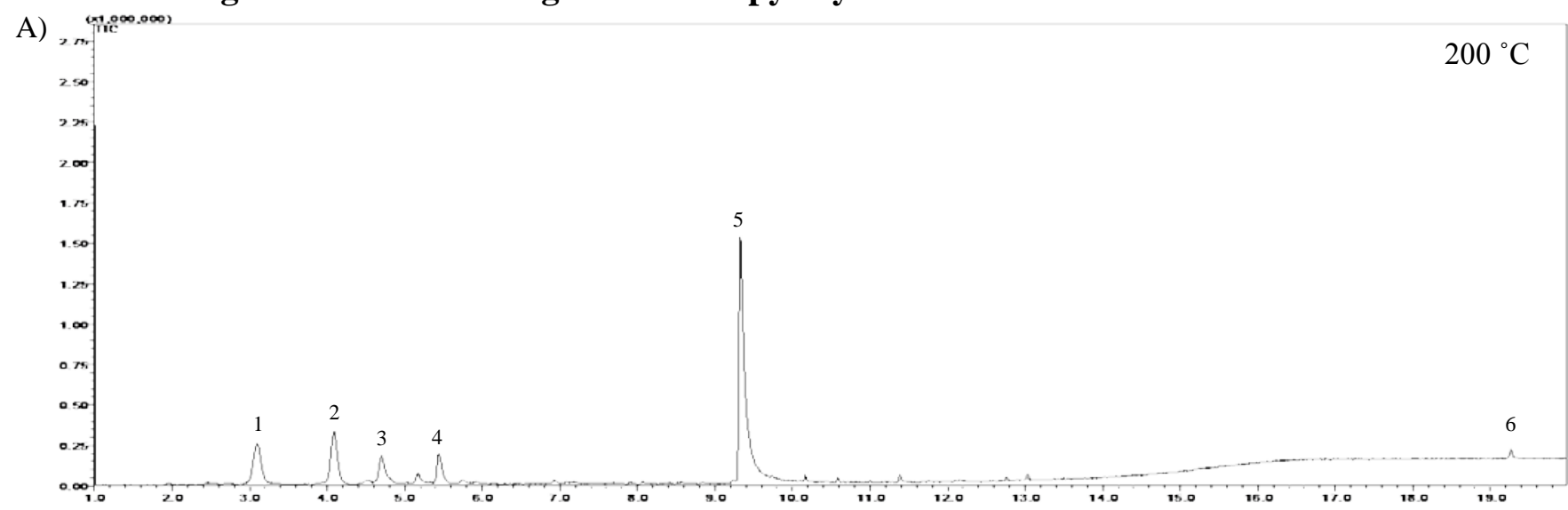

B)

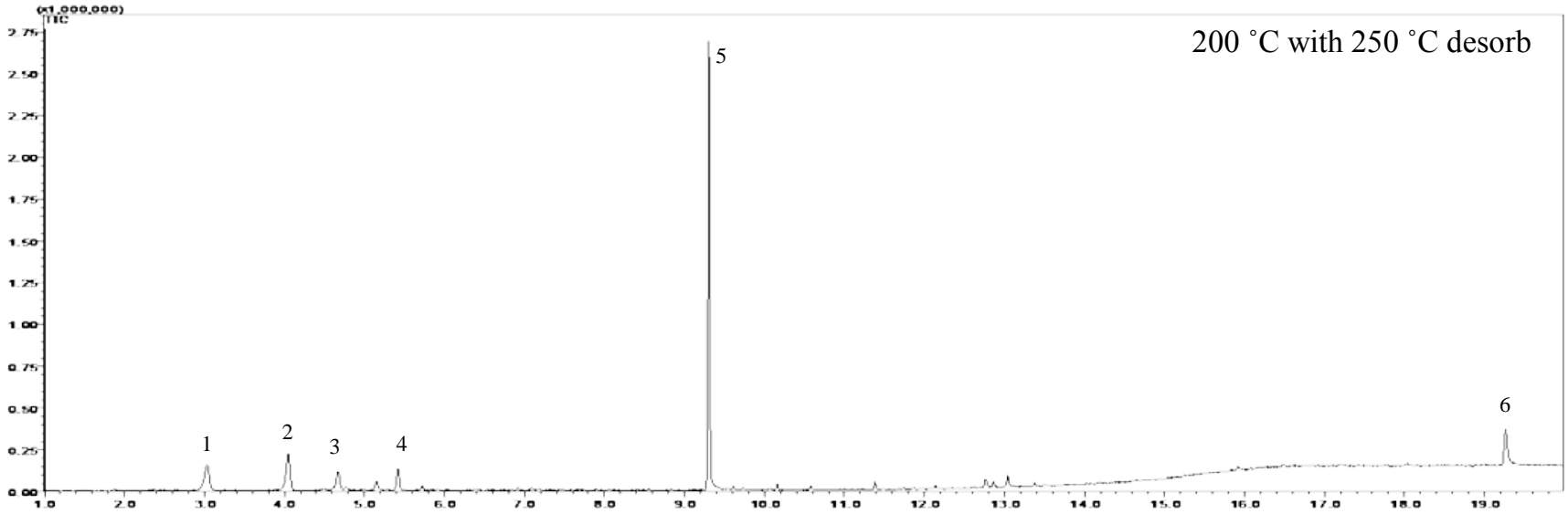

C)

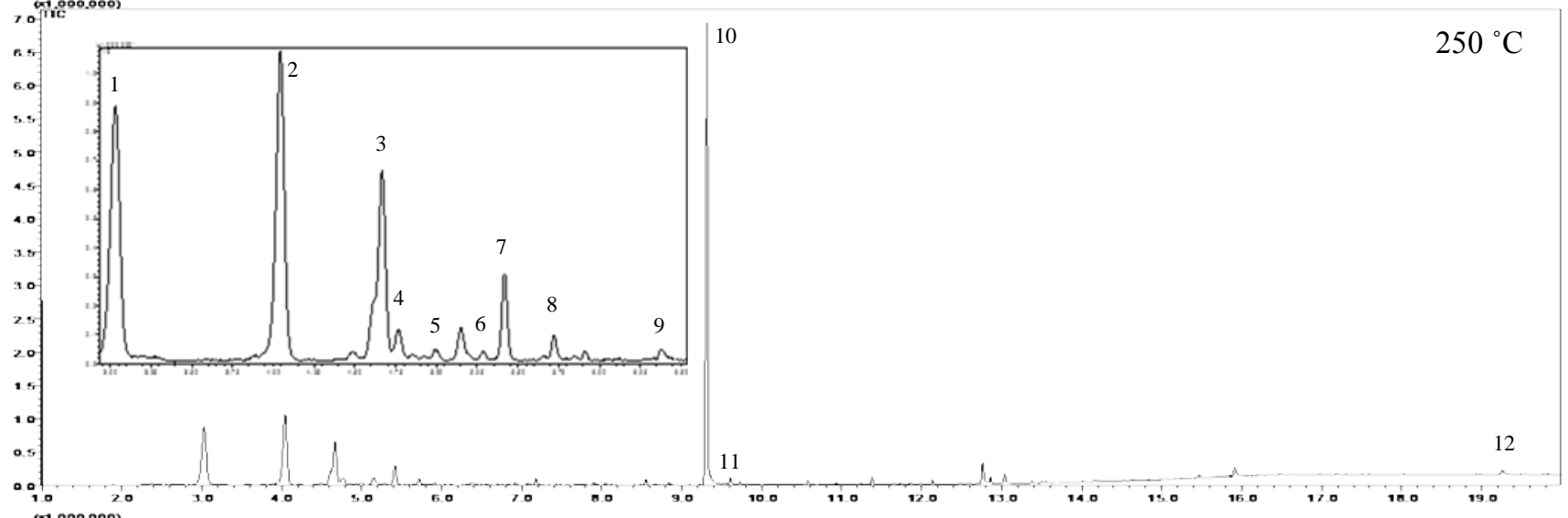

D)

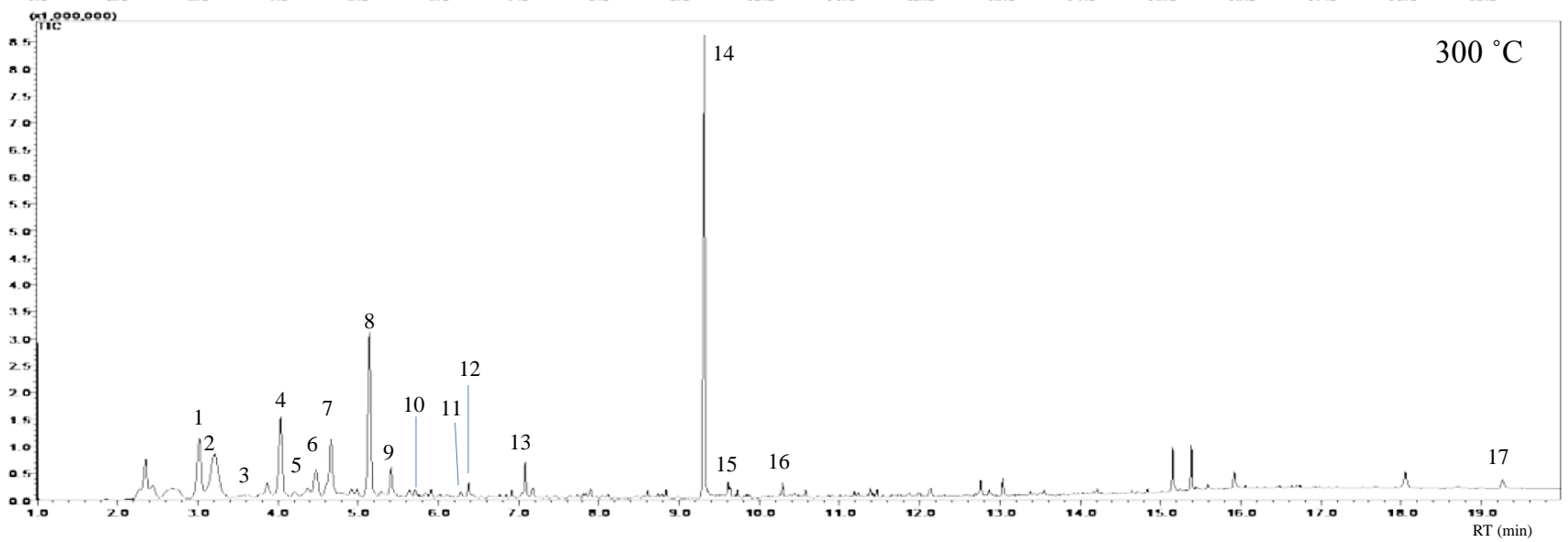


Figure 4-2. Continued.

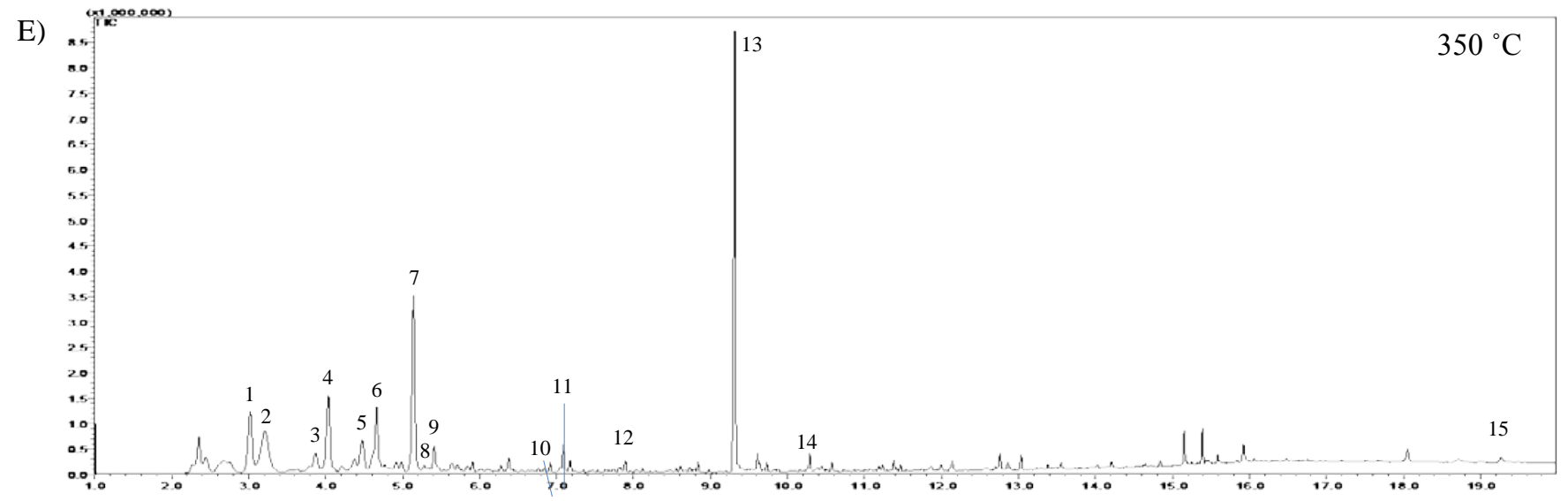

F)

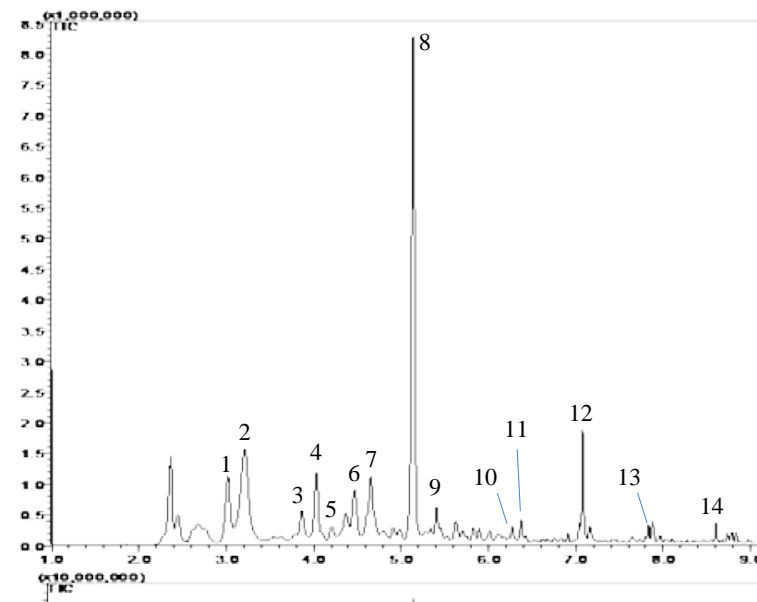

G)

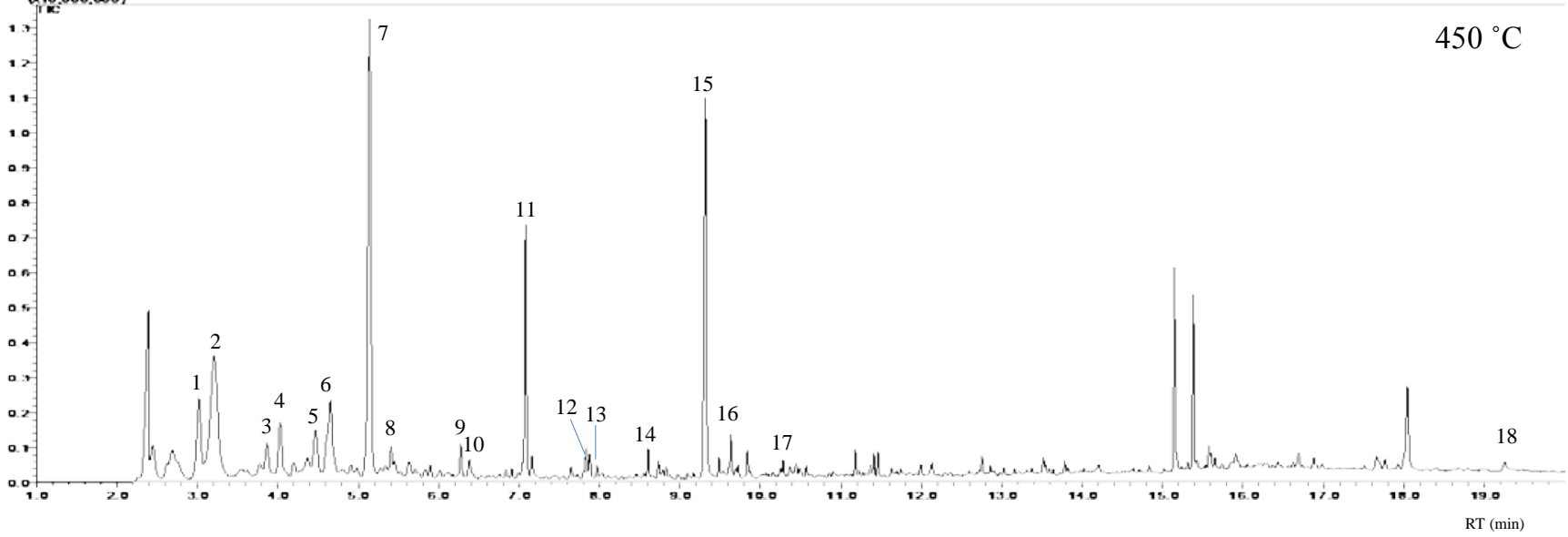




\subsubsection{Conclusions}

Overall, pyridine, styrene, benzaldehyde, phenylacetaldehyde, propionanilide, and fentanyl were consistently detected at all six temperatures of pyrolysis of both the fentanyl standard and the FTPs. These pyromarkers seen here were similar to that of the results under the pyrolytic conditions of $750{ }^{\circ} \mathrm{C}$ in section 2 . Propionanilide has shown to have the highest peak area for both fentanyl standard and FTPs at all pyrolytic temperatures with exception to $400{ }^{\circ} \mathrm{C}$ and $450{ }^{\circ} \mathrm{C}$ for the FTPs analysis. At those temperature 2-EH increases to obtain the highest peak area and intensity. Although this plasticizer can be commonly found in the environment, it has the potential to be an additional marker for investigative purposes to link those who have smoked FTPs as mean of ingestion.

The increase in pyrolytic temperature for both the pyrolysis of the fentanyl standard and the FTPs increase the intensity of the pyromarkers detected. This increase in temperature has also allowed more chromatographic peak for the FTPs that were likely the inclusion of plasticizers, adhesives, and other materials that are incorporated into the manufacturing of the FTPs by the pharmaceutical company. Lastly, even as low as $200{ }^{\circ} \mathrm{C}$ for a pyrolytic temperature fentanyl is shown to degrade through elimination reaction to propionanilide. This clearly disputes the previously discussed literature references that stated fentanyl was stable up to $350^{\circ} \mathrm{C}$. 


\section{Chapter 5: Pyrolysis of Fentanyl and Heroin Mixtures}




\subsubsection{Introduction}

Illicit drugs commonly contain other substances in addition to the active ingredient, which can have serious adverse health consequences or even cause premature death. In general, an "adulterant" typically refers to the pharmacologically active ingredients; "contaminant" refers to the by-products of the manufacturing process, and the "diluent" refers to inert substances. ${ }^{115}$ However, many have generalized the categories previously mentioned as adulterants. It has been seen that the adulterants used by drug dealers, drug users, and the general public include but not limited to mannitol, sugars, gravy powder, chalk, codeine, rat poison, ground glass, household cleaning products, and brick dust. ${ }^{115}$ Multiple combinations and variations of adulterants have been in illicit street samples of heroin. Some of the many reasons for the use of these adulterants in illicit drugs include to bulk, dilute, complement or even to enhance the effects of the drugs itself. ${ }^{115}$ Other explanations allude to unintentional addition as a result of manufacturing, productions, or storage techniques.

The quality assurance, sterile production, and accurate dosage administration cannot be upheld in the illicit manufacture in which drug sellers and users can only make inadequate assessments of the quality, purity, and chemical composition of any of the drugs they buy, sell, or use. ${ }^{116}$ Cases seen in recent years of heroin laced with fentanyl seem to enhance or mimic the illicit drug effects, either to give the impression of a better quality or mask the poor quality of the heroin obtained. This has been seen in other drugs, for examples: procaine and lidocaine have similar anaesthetic properties to cocaine; phenacetin has similar physical properties to cocaine; acetominophen has similar bitter taste to (white) heroin; methylsulfonylmethane looks physically similar to methamphetamine; and caffeine has 
similar (but milder) stimulant properties to cocaine, amphetamine, and ecstasy. ${ }^{115}$ Again, as mentioned earlier, caffeine in heroin has been observed to facilitate in volatilization of heroin.

As mentioned previously, near the end of 2005 and early into 2006, the government and media reported an increase in the number of individuals who have overdosed on heroin laced with fentanyl as a diluent. This fentanyl-laced heroin was a means of making up for the poor quality heroin. Given its toxicity drug dealers have trouble adjusting pure fentanyl into proper dosage concentrations. As a result, heroin users who knowingly or unknowingly use the substance containing fentanyl have difficulty determining how much to take to get their "high" and can mistakenly take lethal quantities of fentanyl. ${ }^{36}$ Only a slight excess in the amount of fentanyl taken can be, and is often, fatal because the resulting level of respiratory depression is sufficient to cause the user to stop breathing. ${ }^{36,63,66}$ As previously noted, the pyromarkers of heroin are known. However, the combination of fentanyl and heroin pyromarkers has not been studied and is evaluated here. It was suspected that the pyrolysis of the combination of two different drugs had the potential to produce different pyromarkers not observed by pyrolysis as separate entities. This has been seen by the pyrolysis of methamphetamine mixed with tobacco. ${ }^{117,118}$

Heroin base is preferred to heroin $\mathrm{HCl}$, since the bases has a lower melting point of $173{ }^{\circ} \mathrm{C}$ than the $\mathrm{HCl}$ salt of $243-244{ }^{\circ} \mathrm{C}$ and because of its relative insensitivity to degradation. ${ }^{66,119}$ However, due to the availability, high cost, and time to obtain heroin base, heroin $\mathrm{HCl}$ was used here for analysis instead. Cook and Brine had observed heroin pyromarkers located in Figure 1-4 for both heroin base and heroin $\mathrm{HCl}$ at $250{ }^{\circ} \mathrm{C}^{57-59}$ 


\subsubsection{Materials and Methods}

Fentanyl and 6-MAM standards were obtained from Cerilliant Corporation (Round Rock, TX, USA) and Sigma Aldrich (St. Louis, MO, USA). Heroin HCl standards were obtained from Sigma-Aldrich (St. Louis, MO, USA). HPLC grade methanol was purchased from Fisher Science (Fair Lawn, NJ, USA).

\subsubsection{Py-GC/MS}

The CDS Analytical 5200 Pyroprobe was used in trapping mode to pyrolyze the samples under aerobic conditions using air and a full 20:35 mesh Tenax-TA sorbent tube trap (CDS Analytical, Inc., Oxford, PA, USA). The pyrolysis unit was interfaced the Shimadzu GC/MS QP2010S. The GC was equipped with an Rxi ${ }^{\circledR}-5$ Sil MS with Integra-Guard® (30 m, 0.25 mm i.d., $0.50 \mu \mathrm{m}$ film thickness, Restek, Bellefonte, PA). The MS was equipped with an electron ionization source and quadrupole mass analyzer with a scanning range of $\mathrm{m} / \mathrm{z}$ 50-600. The interface and ion source temperatures were $300{ }^{\circ} \mathrm{C}$ and $250{ }^{\circ} \mathrm{C}$, respectively.

Analysis was done only in aerobic conditions where air was used as the reactant gas and helium was used as the carrier gas. All samples were run in triplicate for repeatability of method analysis. Table 5-1 lists the parameters for the Py-GC/MS at the 6 different pyrolysis temperatures for both the heroin standards and the heroin and fentanyl mixes. With the sorbent tube trap, a desorption temperature is necessary to desorb the collected analytes and transfer them to the GC at the beginning of the run. In addition, a $300{ }^{\circ} \mathrm{C}$ desorption temperature was determined to be necessary for to desorb the pyromarkers at $200{ }^{\circ} \mathrm{C}$ and 250 ${ }^{\circ} \mathrm{C}$ pyrolysis temperatures. 
A sample of $1000 \mathrm{ppm}$ solution was made for the pyrolysis of heroin alone. The 10 $\mu \mathrm{g}$ sample was deposited on a plug of quartz wool in the sample tube. In addition, three different samples mixes of heroin and fentanyl were prepared in ratios of 3:1, 1:1, and 1:3. Each sample mix was made from $1000 \mathrm{ppm}$ stock solution of heroin and fentanyl. With a quartz tube filled with a plug of quartz wool inside the filament of the pyrolysis probe, $10 \mu \mathrm{L}$ of the mixed solution was deposited using a microliter syringe. The sample was then dried to remove some of the excess solvent by heating the filament to $50{ }^{\circ} \mathrm{C}$ for $30 \mathrm{~s}$. The probe was then inserted into the pyroprobe unit for pyrolysis under the set conditions. 
Table 5-1. Py-GC/MS parameters for the pyrolysis of heroin standards and mixes.

\begin{tabular}{|c|c|c|c|c|c|c|}
\hline Pyroprobe Conditions & $200{ }^{\circ} \mathrm{C}$ & $250{ }^{\circ} \mathrm{C}$ & $300{ }^{\circ} \mathrm{C}$ & $350{ }^{\circ} \mathrm{C}$ & $400{ }^{\circ} \mathrm{C}$ & $450{ }^{\circ} \mathrm{C}$ \\
\hline \multicolumn{7}{|l|}{ Pyroprobe Temperatures } \\
\hline Initial & $50^{\circ} \mathrm{C}, 1 \mathrm{~s}$ & $50^{\circ} \mathrm{C}, 1 \mathrm{~s}$ & $50^{\circ} \mathrm{C}, 1 \mathrm{~s}$ & $50^{\circ} \mathrm{C}, 1 \mathrm{~s}$ & $50^{\circ} \mathrm{C}, 1 \mathrm{~s}$ & $50^{\circ} \mathrm{C}, 1 \mathrm{~s}$ \\
\hline Ramp Rate & $20^{\circ} \mathrm{C} / \mathrm{s}$ & $20^{\circ} \mathrm{C} / \mathrm{s}$ & $20^{\circ} \mathrm{C} / \mathrm{s}$ & $20^{\circ} \mathrm{C} / \mathrm{s}$ & $20^{\circ} \mathrm{C} / \mathrm{s}$ & $20^{\circ} \mathrm{C} / \mathrm{s}$ \\
\hline Final & $200^{\circ} \mathrm{C}, 10 \mathrm{~s}$ & $250^{\circ} \mathrm{C}, 10 \mathrm{~s}$ & $300^{\circ} \mathrm{C}, 10 \mathrm{~s}$ & $350^{\circ} \mathrm{C}, 10 \mathrm{~s}$ & $400^{\circ} \mathrm{C}, 10 \mathrm{~s}$ & $450^{\circ} \mathrm{C}, 10 \mathrm{~s}$ \\
\hline \multicolumn{7}{|l|}{ Accessory Parameters } \\
\hline Rest & $50^{\circ} \mathrm{C}$ & $50^{\circ} \mathrm{C}$ & $50^{\circ} \mathrm{C}$ & $50^{\circ} \mathrm{C}$ & $50^{\circ} \mathrm{C}$ & $50^{\circ} \mathrm{C}$ \\
\hline Initial & $50^{\circ} \mathrm{C}, 1 \mathrm{~min}$ & $50{ }^{\circ} \mathrm{C}, 1 \mathrm{~min}$ & $50{ }^{\circ} \mathrm{C}, 1 \mathrm{~min}$ & $50^{\circ} \mathrm{C}, 1 \mathrm{~min}$ & $50^{\circ} \mathrm{C}, 1 \mathrm{~min}$ & $50{ }^{\circ} \mathrm{C}, 1 \mathrm{~min}$ \\
\hline Ramp Rate & $100{ }^{\circ} \mathrm{C} / \mathrm{min}$ & $100^{\circ} \mathrm{C} / \mathrm{min}$ & $100{ }^{\circ} \mathrm{C} / \mathrm{min}$ & $100{ }^{\circ} \mathrm{C} / \mathrm{min}$ & $100{ }^{\circ} \mathrm{C} / \mathrm{min}$ & $100{ }^{\circ} \mathrm{C} / \mathrm{min}$ \\
\hline Final & $200^{\circ} \mathrm{C}, 5 \mathrm{~min}$ & $250^{\circ} \mathrm{C}, 5 \mathrm{~min}$ & $300^{\circ} \mathrm{C}, 5 \mathrm{~min}$ & $300^{\circ} \mathrm{C}, 5 \mathrm{~min}$ & $300^{\circ} \mathrm{C}, 5 \mathrm{~min}$ & $300^{\circ} \mathrm{C}, 5 \mathrm{~min}$ \\
\hline \multicolumn{7}{|l|}{ Trap Temperatures } \\
\hline Reactant Gas & $6.50 \mathrm{~min}$ & $7.00 \mathrm{~min}$ & $7.50 \mathrm{~min}$ & $7.50 \mathrm{~min}$ & $7.50 \mathrm{~min}$ & $7.50 \mathrm{~min}$ \\
\hline Rest & $50^{\circ} \mathrm{C}$ & $50^{\circ} \mathrm{C}$ & $50^{\circ} \mathrm{C}$ & $50^{\circ} \mathrm{C}$ & $50^{\circ} \mathrm{C}$ & $50^{\circ} \mathrm{C}$ \\
\hline Desorb & $300^{\circ} \mathrm{C}, 2 \mathrm{~min}$ & $300^{\circ} \mathrm{C}, 2 \mathrm{~min}$ & $300^{\circ} \mathrm{C}, 2 \mathrm{~min}$ & $300^{\circ} \mathrm{C}, 2 \mathrm{~min}$ & $300^{\circ} \mathrm{C}, 2 \mathrm{~min}$ & $300^{\circ} \mathrm{C}, 2 \mathrm{~min}$ \\
\hline \multicolumn{7}{|l|}{ Iso Zones } \\
\hline Transfer Line & $300{ }^{\circ} \mathrm{C}$ & $300{ }^{\circ} \mathrm{C}$ & $300{ }^{\circ} \mathrm{C}$ & $300{ }^{\circ} \mathrm{C}$ & $300{ }^{\circ} \mathrm{C}$ & $300{ }^{\circ} \mathrm{C}$ \\
\hline Valve Oven & $300{ }^{\circ} \mathrm{C}$ & $300{ }^{\circ} \mathrm{C}$ & $300{ }^{\circ} \mathrm{C}$ & $300{ }^{\circ} \mathrm{C}$ & $300{ }^{\circ} \mathrm{C}$ & $300{ }^{\circ} \mathrm{C}$ \\
\hline \multicolumn{7}{|l|}{ GC Conditions } \\
\hline Injector Port & $300^{\circ} \mathrm{C}$ & $300{ }^{\circ} \mathrm{C}$ & $300{ }^{\circ} \mathrm{C}$ & $300{ }^{\circ} \mathrm{C}$ & $300^{\circ} \mathrm{C}$ & $300{ }^{\circ} \mathrm{C}$ \\
\hline Initial & $70^{\circ} \mathrm{C}$ & $70^{\circ} \mathrm{C}$ & $70^{\circ} \mathrm{C}$ & $70^{\circ} \mathrm{C}$ & $70^{\circ} \mathrm{C}$ & $70^{\circ} \mathrm{C}$ \\
\hline Ramp Rate & $15^{\circ} \mathrm{C} / \mathrm{min}$ & $15^{\circ} \mathrm{C} / \mathrm{min}$ & $15^{\circ} \mathrm{C} / \mathrm{min}$ & $15^{\circ} \mathrm{C} / \mathrm{min}$ & $15^{\circ} \mathrm{C} / \mathrm{min}$ & $15^{\circ} \mathrm{C} / \mathrm{min}$ \\
\hline Final & $300^{\circ} \mathrm{C}, 4.67 \mathrm{~min}$ & $300^{\circ} \mathrm{C}, 4.67 \mathrm{~min}$ & $300{ }^{\circ} \mathrm{C}, 4.67 \mathrm{~min}$ & $300^{\circ} \mathrm{C}, 4.67 \mathrm{~min}$ & $300^{\circ} \mathrm{C}, 4.67 \mathrm{~min}$ & $300^{\circ} \mathrm{C}, 4.67 \mathrm{~min}$ \\
\hline
\end{tabular}




\subsubsection{Results and Discussion}

Appendix C contains the chromatograms for the pyrolysis of the heroin standard and the results of identified pyromarkers of each of the heroin to fentanyl mixes. The pyromarkers of the heroin standard resulted in 6-MAM and heroin under all pyrolysis parameters. All pyromarkers were initially identified using NIST MS library. Identification was confirmed by analysis of SRMs and the comparison of retention times and mass spectra for the following analytes: pyridine, benzaldehyde, phenylacetaldehye, propionanilide, norfentanyl, despropionyl fentanyl, fentanyl, 6-MAM, and heroin. The other pyromarkers observed were considered tentatively identified by NIST MS library search. The percent areas of each pyromarker were normalized relative to the largest peak area in the chromatogram. Under all temperature conditions, propionanilide resulted in the largest peak area in the chromatograms for both the fentanyl standard and FTPs.

The pyrolysis of heroin under all conditions resulted in the detection of heroin and 6MAM (Appendix C). Unfortunately, heroin in the $\mathrm{HCl}$ salt form has a much higher melting point than the base form and did not produce any of the other pyromarkers with this method at the analyzed temperature that were previously reported in the literature. Nonetheless, it was interesting to note these results and how it would affect the pyromarkers with the addition of fentanyl.

Table 5-2, 5-3, and 5-4 show the results under all the pyrolytic conditions for the heroin to fentanyl mixes of $3: 1,1: 1$, and $1: 3$, respectively with a repeatability of $n=3$. All pyromarkers detected at each trial run as well as GC chromatograms are located in Appendix C. The pyromarkers that were common in all heroin to fentanyl mixes at all pyrolytic temperatures were the following: pyridine, styrene, benzaldehyde, phenylacetaldehyde, 
propionanilide, 6-MAM, heroin, and fentanyl. Like the pyrolysis of the FTPs, aniline was not detected repeatedly in all trial runs.

\subsubsection{Pyromarkers of the Pyrolysis of the 3:1 Heroin to Fentanyl Mix}

For the 3:1 heroin to fentanyl mix, the only differences observed was the detection of norfentanyl at $200{ }^{\circ} \mathrm{C}$ and acetylbenzoyl at $250{ }^{\circ} \mathrm{C}$ (Table 5-2). It is unclear as to why the metabolite norfentanyl is observed here and not at any other pyrolytic temperature or other previous chapter. Also, at a 3:1 ratio, fentanyl is at its lowest concentration for analysis in comparison. The pathway for the formation of acetylbenzoyl is not clear as the formation could be likely similar to of phenylacetaldehyde from fentanyl or heroin which is due to the elimination reaction producing a free radical with a phenyl ring. The presence of oxygen allows the formation of acetylbenzoyl. This pyromarker has been detected in both the pyrolysis of the fentanyl standard and the FTPs; however it was not consistently observed in all three replicates (Appendix B).

\subsubsection{Pyromarkers of the Pyrolysis of the 1:1 Heroin to Fentanyl Mix}

For the 1:1 heroin to fentanyl mix, both norfentanyl and acetylbenzoyl was observed at $200{ }^{\circ} \mathrm{C}$ (Table 5-3). At $250{ }^{\circ} \mathrm{C}$, acetylbenzoyl was similarly observed at $250{ }^{\circ} \mathrm{C}$. In addition, at $400{ }^{\circ} \mathrm{C}$, phthalic anhydride is observed. All other consistant reported pyromarkers were the same as mentioned.

\subsubsection{Pyromarkers of the Pyrolysis of the 1:3 Heroin to Fentanyl Mix}

For the $1: 3$ heroin to fentanyl mix, acetylbenzoyl is observed at $250{ }^{\circ} \mathrm{C}$ to $400{ }^{\circ} \mathrm{C}$. With fentanyl having the higher concentration here, it is likely that that the formation of 
acetylbenzoyl stems from the fentanyl component of the mix. Norfentanyl is observed at 400 ${ }^{\circ} \mathrm{C}$, which is unusual given the previous results and trends. 
Table 5-2. Pyromarkers of the pyrolysis of the 3:1 heroin to fentanyl mix.

\begin{tabular}{|c|c|c|c|c|c|}
\hline $200{ }^{\circ} \mathrm{C}$ & \% Area & $250{ }^{\circ} \mathrm{C}$ & \% Area & $300^{\circ} \mathrm{C}$ & $\%$ Area \\
\hline 1. Pyridine & 4.7 & 1. Pyridine & 8.1 & 1. Pyridine & 14.1 \\
\hline 2. Styrene & 3.6 & 2. Styrene & 5.6 & 2. Styrene & 9.2 \\
\hline 3. Benzaldehyde & 1.8 & 3. Benzaldehyde & 3.8 & 3. Benzaldehyde & 5.7 \\
\hline 4. Phenylacetaldehyde & 0.8 & 4. Phenylacetaldehyde & 1.0 & 4. Phenylacetaldehyde & 1.4 \\
\hline 5. Propionanilide & 29.1 & 5. Acetylbenzoyl & 0.4 & 5. Propionanilide & 31.5 \\
\hline 6. Norfentanyl & 0.2 & 6. Propionanilide & 29.1 & 6. 6-MAM & 9.5 \\
\hline 7. 6-MAM & 6.2 & 7. 6-MAM & 8.6 & 7. Heroin & 100 \\
\hline 8. Heroin & 100 & 8. Heroin & 100 & 8. Fentanyl & 19.0 \\
\hline 9. Fentanyl & 21.7 & 9. Fentanyl & 21.8 & & \\
\hline $350{ }^{\circ} \mathrm{C}$ & \% Area & $400{ }^{\circ} \mathrm{C}$ & \% Area & $450{ }^{\circ} \mathrm{C}$ & $\%$ Area \\
\hline 1. Pyridine & 18.3 & 1. Pyridine & 18.7 & 1. Pyridine & 22.1 \\
\hline 2. Styrene & 10.5 & 2. Styrene & 12.2 & 2. Styrene & 14.4 \\
\hline 3. Benzaldehyde & 8.3 & 3. Benzaldehyde & 7.9 & 3. Benzaldehyde & 7.8 \\
\hline 4. Phenylacetaldehyde & 1.8 & 4. Phenylacetaldehyde & 1.7 & 4. Phenylacetaldehyde & 2.3 \\
\hline 5. Propionanilide & 37.5 & 5. Propionanilide & 35.4 & 5. Propionanilide & 34.9 \\
\hline 6. 6-MAM & 4.0 & 6. 6-MAM & 3.2 & 6. 6-MAM & 17.0 \\
\hline 7. Heroin & 100 & 7. Heroin & 100 & 7. Heroin & 100 \\
\hline 8. Fentanyl & 11.7 & 8. Fentanyl & 11.3 & 8. Fentanyl & 95.3 \\
\hline
\end{tabular}


Table 5-3. Pyromarkers of the pyrolysis of the 1:1 heroin to fentanyl mix.

\begin{tabular}{|c|c|c|c|c|c|}
\hline $200{ }^{\circ} \mathrm{C}$ & \% Area & $250^{\circ} \mathrm{C}$ & \% Area & $300^{\circ} \mathrm{C}$ & \% Area \\
\hline 1. Pyridine & 10.3 & 1. Pyridine & 19.4 & 1. Pyridine & 33.6 \\
\hline 2. Styrene & 9.1 & 2. Styrene & 14.2 & 2. Styrene & 22.4 \\
\hline 3. Benzaldehyde & 3.8 & 3. Benzaldehyde & 7.1 & 3. Benzaldehyde & 14.1 \\
\hline 4. Phenylacetaldehyde & 1.9 & 4. Phenylacetaldehyde & 2.7 & 4. Phenylacetaldehyde & 3.9 \\
\hline 5. Acetylbenzoyl & 0.5 & 5. Acetylbenzoyl & 0.8 & 5. Propionanilide & 92.5 \\
\hline 6. Propionanilide & 64.1 & 6. Propionanilide & 71.5 & 6. 6-MAM & 8.4 \\
\hline 7. Norfentanyl & 0.9 & 7. 6-MAM & 8.1 & 7. Heroin & 95.3 \\
\hline 8. 6-MAM & 7.5 & 8. Heroin & 92.8 & 8. Fentanyl & 99.2 \\
\hline 9. Heroin & 93.7 & 9. Fentanyl & 98.2 & & \\
\hline 10. Fentanyl & 96.7 & & & & \\
\hline $350{ }^{\circ} \mathrm{C}$ & \% Area & $400{ }^{\circ} \mathrm{C}$ & $\%$ Area & $450{ }^{\circ} \mathrm{C}$ & $\%$ Area \\
\hline 1. Pyridine & 33.5 & 1. Pyridine & 42.0 & 1. Pyridine & 48.0 \\
\hline 2. Styrene & 23.2 & 2. Styrene & 24.8 & 2. Styrene & 35.7 \\
\hline 3. Benzaldehyde & 14.0 & 3. Benzaldehyde & 19.2 & 3. Benzaldehyde & 22.0 \\
\hline 4. Phenylacetaldehyde & 3.8 & 4. Phenylacetaldehyde & 4.4 & 4. Phenylacetaldehyde & 5.5 \\
\hline 5. Propionanilide & 92.9 & 5. Phthalic anhydride & 0.7 & 5. Propionanilide & 69.1 \\
\hline 6. 6-MAM & 8.0 & 6. Propionanilide & 100 & 6. 6-MAM & 6.4 \\
\hline 7. Heroin & 82.9 & 7. 6-MAM & 2.6 & 7. Heroin & 49.4 \\
\hline 8. Fentanyl & 82.0 & 8. Heroin & 58.1 & 8. Fentanyl & 71.0 \\
\hline & & 9. Fentanyl & 40.3 & & \\
\hline
\end{tabular}


Table 5-4. Pyromarkers of the pyrolysis of the 1:3 heroin to fentanyl mix.

\begin{tabular}{|c|c|c|c|c|c|}
\hline $200{ }^{\circ} \mathrm{C}$ & \% Area & $250^{\circ} \mathrm{C}$ & \% Area & $300{ }^{\circ} \mathrm{C}$ & \% Area \\
\hline 1. Pyridine & 12.5 & 1. Pyridine & 22.2 & 1. Pyridine & 45.4 \\
\hline 2. Styrene & 11.5 & 2. Styrene & 16.3 & 2. Styrene & 24.3 \\
\hline 3. Benzaldehyde & 5.1 & 3. Benzaldehyde & 9.4 & 3. Benzaldehyde & 20.2 \\
\hline 4. Phenylacetaldehyde & 2.2 & 4. Phenylacetaldehyde & 2.7 & 4. Phenylacetaldehyde & 3.4 \\
\hline 5. Propionanilide & 67.3 & 5. Acetylbenzoyl & 0.8 & 5. Acetylbenzoyl & 1.2 \\
\hline 6. 6-MAM & 4.2 & 6. Propionanilide & 73.7 & 6. Propionanilide & 67.7 \\
\hline 7. Heroin & 18.0 & 7. 6-MAM & 2.2 & 7. 6-MAM & 1.5 \\
\hline 8. Fentanyl & 100 & 8. Heroin & 20.4 & 8. Heroin & 16.0 \\
\hline & & 9. Fentanyl & 95.1 & 9. Fentanyl & 67.9 \\
\hline $350{ }^{\circ} \mathrm{C}$ & $\%$ Area & $400{ }^{\circ} \mathrm{C}$ & \% Area & $450{ }^{\circ} \mathrm{C}$ & \% Area \\
\hline 1. Pyridine & 38.3 & 1. Pyridine & 43.4 & 1. Pyridine & 54.0 \\
\hline 2. Styrene & 28.9 & 2. Styrene & 31.3 & 2. Styrene & 35.9 \\
\hline 3. Benzaldehyde & 15.0 & 3. Benzaldehyde & 17.5 & 3. Benzaldehyde & 20.0 \\
\hline 4. Phenylacetaldehyde & 4.5 & 4. Phenylacetaldehyde & 4.5 & 4. Phenylacetaldehyde & 6.1 \\
\hline 5. Acetylbenzoyl & 1.4 & 5. Acetylbenzoyl & 1.4 & 5. Propionanilide & 70.7 \\
\hline 6. Propionanilide & 96.9 & 6. Propionanilide & 96.9 & 6. 6-MAM & 5.1 \\
\hline 7. 6-MAM & 1.0 & 7. Norfentanyl & 0.5 & 7. Heroin & 20.6 \\
\hline 8. Heroin & 16.4 & 8. 6-MAM & 0.7 & 8. Fentanyl & 63.7 \\
\hline 9. Fentanyl & 82.3 & 9. Heroin & 15.6 & & \\
\hline & & 10. Fentanyl & 55.1 & & \\
\hline
\end{tabular}




\subsubsection{Conclusions}

Overall, pyridine, styrene, benzaldehyde, phenylacetaldehyde, propionanilide, 6MAM, heroin, and fentanyl were common in all heroin to fentanyl mixes at all pyrolytic temperatures. This is reasonable since only 6-MAM and heroin were observed for the pyrolysis of heroin $\mathrm{HCl}$ standard alone, despite pyromarkers reported in literature for the salt form of heroin. Acetylbenzoyl was more prevalent in these mixes under different pyrolytic temperatures rather than what was observed of solely the drug fentanyl, where it was not seen in all three replicates.

Future research should include the pyrolysis of these mixes using heroin base instead of the heroin $\mathrm{HCl}$ used. These methods and procedure could be used for such an analysis in which there is potential to observe the other pyromarkers of heroin and if it does interact with the form pyromarkers of fentanyl. Also, work could include the heroin and fentanyl mixes of both components in salt form and then converting the mixes in base form to pyrolyze. It would be interesting to observe changes that this process could have an effect of the pyromarkers detected. 


\section{Summary}


Data obtained using the smoking box and thermocouple temperature probes clearly indicated that manufactured tobacco cigarette temperature studies were not applicable here. This simple study showed that the maximum temperature obtain while smoking FTPs under the "chasing the dragon" technique was approximately $450{ }^{\circ} \mathrm{C}$ in comparison to $750{ }^{\circ} \mathrm{C}$. Nonetheless, similar pyromarkers were observed at both the lower and higher temperature of pyrolysis analysis. The literature suggests that fentanyl is stable up to $350{ }^{\circ} \mathrm{C}$, however, it is clear here that fentanyl thermally degraded as low as $200^{\circ} \mathrm{C}$.

In all cases, the following pyromarkers were consistently observed under all conditions were fentanyl standard and FTPs: pyridine, styrene, benzaldehyde, phenylacetaldehyde, propionanilide, and fentanyl. Propionanilide was a major pyromarker that is prevalent under all conditions for both standards and FTPs, with the exception of the higher pyrolysis temperatures of FTPs where the plasticizer, 2-EH, had the highest peak area. Although this plasticizer can be commonly found in the environment, it has the potential to be an additional marker for investigative purposes to link those who have smoked FTPs as mean of ingestion.

For the heroin to fentanyl mixes, pyridine, styrene, benzaldehyde, phenylacetaldehyde, propionanilide, 6-MAM, heroin, and fentanyl were common in all pyrolytic temperatures and ratios. These show similar pyromarkers, with the addition of 6-MAM and heroin, to the standalone fentanyl analysis. Although not all literature pyromarkers were observed for heroin under this method, the stability and the combination of the pyromarkers that was seen here that can still be used for investigative purposes.

Propionanilide was generally observed to have the highest peak area for throughout this project. This pyromarker alone and/or the combination of the other pyromarkers have a 
potential to be a marker in human biological samples to be indicative of the individual of having inhaled volatilized fentanyl.

Little is known regarding human toxicity of these observed pyromarkers. Pyridine, styrene, benzaldehyde, and phenylacetaldehyde are everywhere in the environment and the derivatives of propionanilide is a widely used hormone herbicide. ${ }^{120}$ Typically, these at high concentrations pose as skin and eye irritants. The human oral lethal dose of pyridine is 0.5$5.0 \mathrm{~g} / \mathrm{kg} .{ }^{121}$ The $\mathrm{LD}_{50}$ in rats for oral administration of benzaldehyde, phenylacetaldehyde, and propionanilide range between $1100-1500 \mathrm{mg} / \mathrm{kg} .{ }^{122-124}$ The pyromarker with the lowest peak area for the pyrolysis of fentanyl standard was aniline, which has the lowest $\mathrm{LD}_{50}$ for rats of $250 \mathrm{mg} / \mathrm{kg} .{ }^{125}$ It is not clear whether these pyromarkers would be considered more toxic than the drug itself, since little is known in regards to the human toxicity. In either case, it is not known whether these pyromarkers would metabolize in the human body to other compounds.

The work done here could be used to analyze other smoke drugs of abuse such as the newer designer drugs like bath salts, cannabinomimtics, Ritalin, etc. Temperature assessment using the smoking box and the temperature probe could provide precise temperature of the drug and choice of method to smoke them. Those parameters obtained can then be applied to the Py-GC/MS to mimic those smoking conditions and determine the pyromarkers produced. 


\section{Appendices}




\section{Appendix A: Thermocouple Data.}

\begin{tabular}{|c|c|c|c|c|c|c|}
\hline \multicolumn{2}{|c|}{} & \multicolumn{2}{|c|}{ Smoke Observed Temp. } & \multicolumn{2}{c|}{ Max. Temp. } & \multicolumn{2}{c|}{ Rate Increase } \\
\hline Trial & $\mathrm{T} 1\left({ }^{\circ} \mathrm{C}\right)$ & $\mathrm{T} 2\left({ }^{\circ} \mathrm{C}\right)$ & $\mathrm{T} 1\left({ }^{\circ} \mathrm{C}\right)$ & $\mathrm{T} 2\left({ }^{\circ} \mathrm{C}\right)$ & $\mathrm{T} 1\left({ }^{\circ} \mathrm{C} / \mathrm{s}\right)$ & $\mathrm{T} 2\left({ }^{\circ} \mathrm{C} / \mathrm{s}\right)$ \\
\hline 1 & 69.7 & 128.5 & 248.6 & 286.5 & 13.2 & 15.4 \\
\hline $2^{*}$ & 166.7 & 247.2 & 166.7 & 372.5 & 15.9 & 24.9 \\
\hline 3 & 81.0 & 124.6 & 214.1 & 218.8 & 9.0 & 8.9 \\
\hline $4^{*}$ & 74.8 & 53.9 & 146.6 & 108.3 & 4.5 & 4.0 \\
\hline 5 & 315.1 & 308.6 & 345.7 & 357.9 & 20.2 & 21.0 \\
\hline 6 & 39.2 & 38.1 & 441.6 & 267.4 & 28.0 & 17.6 \\
\hline 7 & 35.3 & 36.2 & 289.4 & 376.1 & 16.7 & 23.6 \\
\hline 8 & 49.4 & 34.8 & 379.5 & 289.0 & 23.8 & 17.8 \\
\hline 9 & 33.8 & 63.0 & 268.1 & 256.9 & 14.5 & 13.8 \\
\hline 10 & 86.0 & 157.3 & 244.9 & 288.2 & 10.6 & 14.6 \\
\hline 11 & 45.6 & 65.0 & 320.6 & 387.0 & 17.6 & 22.8 \\
\hline 12 & 76.6 & 208.1 & 311.9 & 397.7 & 14.5 & 23.4 \\
\hline 13 & 69.2 & 66.9 & 222.8 & 224.2 & 8.3 & 8.8 \\
\hline 14 & 35.0 & 32.4 & 246.7 & 282.1 & 12.5 & 16.3 \\
\hline 15 & 22.4 & 22.3 & 254.4 & 225.2 & 12.9 & 11.9 \\
\hline 16 & 201.4 & 177.0 & 283.8 & 293.7 & 17.4 & 22.7 \\
\hline Average & 87.6 & 110.2 & 274.1 & 289.5 & 15.0 & 16.7 \\
\hline
\end{tabular}

* Denotes trials where setup failed. 


\section{Appendix B: Extended data of the pyromarkers of the pyrolysis of fentanyl standard and FTPs.}

\section{Fentanyl Standards}

\begin{tabular}{|c|c|c|c|c|c|c|c|c|}
\hline $200{ }^{\circ} \mathrm{C}$ & & \multicolumn{2}{|c|}{ Trial \#1 } & \multicolumn{2}{|c|}{ Trial \#2 } & \multicolumn{2}{|c|}{ Trial \#3 } & Average \\
\hline Compound & RT (min) & Area & \% Area & Area & \% Area & Area & $\%$ Area & \% Area \\
\hline Propionanilide & 9.377 & 362246 & 100 & 821486 & 100 & 1821474 & 100 & 100 \\
\hline Fentanyl & 19.285 & 42245 & 11.7 & 69950 & 8.5 & 81259 & 4.5 & 8.2 \\
\hline
\end{tabular}

\begin{tabular}{|c|c|c|c|c|c|c|c|c|}
\hline \multirow{2}{*}{$\begin{array}{l}200{ }^{\circ} \mathrm{C} \text { with } 250{ }^{\circ} \mathrm{C} \text { desorb } \\
\text { Compound }\end{array}$} & \multirow[b]{2}{*}{ RT (min) } & \multicolumn{2}{|c|}{ Trial \#1 } & \multicolumn{2}{|c|}{ Trial \#2 } & \multicolumn{2}{|c|}{ Trial \#3 } & \multirow{2}{*}{$\begin{array}{l}\text { Average } \\
\% \text { Area }\end{array}$} \\
\hline & & Area & $\%$ Area & Area & \% Area & Area & $\%$ Area & \\
\hline Pyridine & 3.080 & 5939578 & 27.6 & 5449021 & 23.2 & 4291684 & 21.1 & 24.0 \\
\hline Styrene & 4.074 & 4500970 & 20.9 & 4352362 & 18.6 & 4145217 & 20.4 & 20.0 \\
\hline Benzaldehyde & 4.694 & 2847604 & 13.2 & 2743127 & 11.7 & 2394119 & 11.8 & 12.2 \\
\hline Aniline & 4.792 & 1035521 & 4.8 & 774770 & 3.3 & 697714 & 3.4 & 3.8 \\
\hline Phenylacetaldehyde & 5.437 & 605213 & 2.8 & 739240 & 3.2 & 538169 & 2.6 & 2.9 \\
\hline 1-Phenyl-1,2-propanedione & 5.740 & 105415 & 0.5 & 183023 & 0.8 & & & \\
\hline Benzoic acid, methyl ester & 5.932 & & & & & 92229 & 0.5 & \\
\hline Propionanilide & 9.324 & 21512135 & 100 & 23447387 & 100 & 20351090 & 100 & 100 \\
\hline N-(2-phenylethyl)-formamide & 9.617 & & & 153470 & 0.7 & & & \\
\hline Azobenzene & 10.934 & 106871 & 0.5 & & & & & \\
\hline Fentanyl & 19.264 & 37389 & 0.2 & 1460802 & 6.2 & 581155 & 2.9 & 3.1 \\
\hline
\end{tabular}

\begin{tabular}{|c|c|c|c|c|c|c|c|c|}
\hline $250{ }^{\circ} \mathrm{C}$ & & \multicolumn{2}{|c|}{ Trial \#1 } & \multicolumn{2}{|c|}{ Trial \#2 } & \multicolumn{2}{|c|}{ Trial \#3 } & \multirow{2}{*}{$\begin{array}{l}\text { Average } \\
\% \text { Area }\end{array}$} \\
\hline Compound & RT (min) & Area & \% Area & Area & \% Area & Area & \% Area & \\
\hline Pyridine & 3.261 & 3572919 & 21.9 & 2737378 & 20.7 & 2429237 & 19.8 & 20.8 \\
\hline Styrene & 4.233 & 3794564 & 23.3 & 2837650 & 21.5 & 2544587 & 20.8 & 21.8 \\
\hline Benzaldehyde & 4.837 & 1608732 & 9.9 & 1075989 & 8.1 & 832241 & 6.8 & 8.3 \\
\hline Aniline & 4.931 & 256179 & 1.6 & 146084 & 1.1 & 24462 & 0.2 & 1.0 \\
\hline Phenylacetaldehyde & 5.567 & 543428 & 3.3 & 398155 & 3.0 & 426109 & 3.5 & 3.3 \\
\hline
\end{tabular}




\begin{tabular}{|c|c|c|c|c|c|c|c|c|}
\hline 1-Phenyl-1,2-propanedione & 5.867 & 92413 & 0.6 & & & 51187 & 0.4 & \\
\hline Isothiocyanato-cyclohexane & 7.625 & 195835 & 1.2 & & & & & \\
\hline Propionanilide & 9.431 & 16315338 & 100 & 13211941 & 100 & 12249779 & 100 & 100 \\
\hline N-(2-phenylethyl)-formamide & 9.731 & & & 49774 & 0.4 & & & \\
\hline Fentanyl & 19.287 & 3618244 & 22.2 & 735800 & 5.6 & 1170893 & 9.6 & 12.4 \\
\hline
\end{tabular}

\begin{tabular}{|c|c|c|c|c|c|c|c|c|}
\hline \multirow{2}{*}{$\begin{array}{l}300^{\circ} \mathrm{C} \\
\text { Compound } \\
\end{array}$} & \multirow[b]{2}{*}{ RT (min) } & \multicolumn{2}{|c|}{ Trial \#1 } & \multicolumn{2}{|c|}{ Trial \#2 } & \multicolumn{2}{|c|}{ Trial \#3 } & \multirow{2}{*}{$\begin{array}{c}\text { Average } \\
\% \text { Area } \\
\end{array}$} \\
\hline & & Area & \% Area & Area & $\%$ Area & Area & $\%$ Area & \\
\hline Pyridine & 3.142 & 4239862 & 34.6 & 3079778 & 78.4 & 2503003 & 56.6 & 56.5 \\
\hline Styrene & 4.117 & 3307059 & 27.0 & 2540695 & 64.7 & 2216487 & 50.1 & 47.2 \\
\hline Benzaldehyde & 4.727 & 1980298 & 16.2 & 1401793 & 35.7 & 1226698 & 27.7 & 26.5 \\
\hline Aniline & 4.827 & 271332 & 2.2 & 135448 & 3.4 & 138588 & 3.1 & 2.9 \\
\hline Phenylacetaldehyde & 5.465 & 557313 & 4.5 & 466656 & 11.9 & 450030 & 10.2 & 8.9 \\
\hline Phenylglyoxal & 5.764 & & & 186939 & 4.8 & & & \\
\hline 1-Phenyl-1,2-propanedione & 5.788 & 141150 & 1.2 & & & 145839 & 3.3 & \\
\hline Propionanilide & 9.334 & 12259111 & 100 & 3928913 & 100 & 4425958 & 100 & 100 \\
\hline N-(2-phenylethyl)-formamide & 9.637 & 43471 & 0.4 & 46780 & 1.2 & & & \\
\hline Fentanyl & 19.296 & 5747589 & 46.9 & 1927851 & 49.1 & 4150003 & 93.8 & 63.2 \\
\hline $350{ }^{\circ} \mathrm{C}$ & & \multicolumn{2}{|c|}{ Trial \#1 } & \multicolumn{2}{|c|}{ Trial \#2 } & \multicolumn{2}{|c|}{ Trial \#3 } & Average \\
\hline Compound & RT (min) & Area & \% Area & Area & $\%$ Area & Area & $\%$ Area & $\%$ Area \\
\hline Pyridine & 3.116 & 4845712 & 37.7 & 3668289 & 87.2 & 1809296 & 50.7 & 58.5 \\
\hline Styrene & 4.103 & 3498986 & 27.3 & 3238319 & 77.0 & 1318662 & 36.9 & 47.1 \\
\hline Benzaldehyde & 4.718 & 2299901 & 17.9 & 1452773 & 34.5 & 751686 & 21.1 & 24.5 \\
\hline Aniline & 4.812 & 375804 & 2.9 & 128549 & 3.1 & 53675 & 1.5 & 2.5 \\
\hline Phenylacetaldehyde & 5.457 & 583222 & 4.5 & 474141 & 11.3 & 273693 & 7.7 & 7.8 \\
\hline 1-Phenyl-1,2-propanedione & 5.783 & 147865 & 1.2 & & & & & \\
\hline Propionanilide & 9.324 & 12838082 & 100 & 4206713 & 100 & 3569270 & 100 & 100 \\
\hline Fentanyl & 19.285 & 1756961 & 13.7 & 1180791 & 28.1 & 3019079 & 84.6 & 42.1 \\
\hline
\end{tabular}




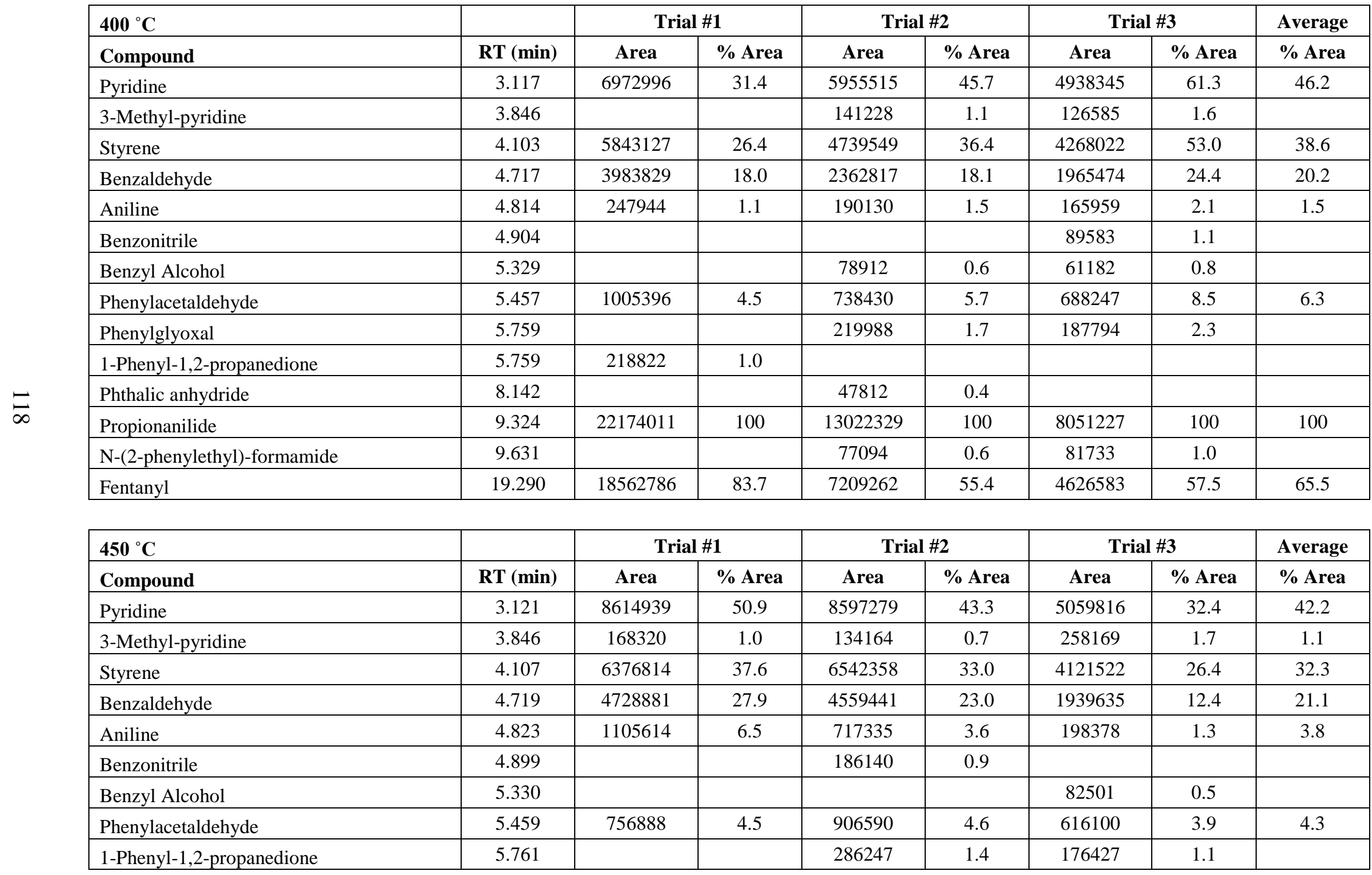




\begin{tabular}{|c|c|c|c|c|c|c|c|c|}
\hline Phthalic anhydride & 8.163 & & & 64465 & 0.3 & & & \\
\hline Propionanilide & 9.330 & 16939476 & 100 & 19839327 & 100 & 15629638 & 100 & 100 \\
\hline N-(2-phenylethyl)-formamide & 9.633 & & & 87799 & 0.4 & 100800 & 0.6 & \\
\hline Azobenzene & 10.989 & 107059 & 0.6 & 70750 & 0.4 & & & \\
\hline Fentanyl & 19.292 & 180978 & 1.1 & 1703020 & 8.6 & 10032023 & 64.2 & 24.6 \\
\hline
\end{tabular}

\section{FTPs}

\begin{tabular}{|l|c|c|c|c|c|c|c|c|}
\hline $\mathbf{2 0 0}{ }^{\circ} \mathbf{C}$ & & \multicolumn{2}{|c|}{ Trial \#1 } & \multicolumn{2}{c|}{ Trial \#2 } & \multicolumn{2}{c|}{ Trial \#3 } & Average \\
\hline Compound & RT (min) & Area & \% Area & Area & \% Area & Area & \% Area & \% Area \\
\hline Pyridine & 3.099 & 1174722 & 19.8 & 1584118 & 20.5 & 1120842 & 25.4 & 21.9 \\
\hline Styrene & 4.089 & 1857401 & 31.3 & 1832391 & 23.7 & 999575 & 22.7 & 25.9 \\
\hline Benzaldehyde & 4.697 & 757351 & 12.8 & 889564 & 11.5 & 485626 & 11.0 & 11.8 \\
\hline Phenylacetaldehyde & 5.449 & 499583 & 8.4 & 819594 & 10.6 & 370116 & 8.4 & 9.1 \\
\hline Propionanilide & 9.333 & 5929884 & 100 & 7716474 & 100 & 4408695 & 100 & 100 \\
\hline Fentanyl & 19.262 & 127672 & 2.2 & 125871 & 1.6 & 101860 & 2.3 & 2.0 \\
\hline
\end{tabular}

\begin{tabular}{|l|c|c|c|c|c|c|c|c|}
\hline $\mathbf{2 0 0}$ & \multicolumn{2}{|c|}{${ }^{\circ} \mathbf{C}$ with 250} & \multicolumn{2}{|c|}{ Trial \#2 } & \multicolumn{2}{c|}{ Trial \#3 } & Average \\
\hline Compound & RT (min) & Area & \% Area & Area & \% Area & Area & \% Area & \% Area \\
\hline Pyridine & 3.033 & 453716 & 13.4 & 434242 & 14.5 & 669399 & 15.8 & 14.6 \\
\hline Styrene & 4.049 & 915139 & 27.0 & 706582 & 23.6 & 782192 & 18.5 & 23.0 \\
\hline Benzaldehyde & 4.672 & 248490 & 7.3 & 214076 & 7.2 & 400799 & 9.5 & 8.0 \\
\hline Phenylacetaldehyde & 5.420 & 257017 & 7.6 & 197614 & 6.6 & 318023 & 7.5 & 7.2 \\
\hline Propionanilide & 9.307 & 3387918 & 100 & 2993393 & 100 & 4234396 & 100 & 100 \\
\hline Fentanyl & 19.268 & 524291 & 15.5 & 466113 & 15.6 & 746520 & 17.6 & 16.2 \\
\hline
\end{tabular}

\begin{tabular}{|l|c|c|c|c|c|c|c|c|}
\hline $\mathbf{2 5 0}{ }^{\circ} \mathbf{C}$ & & \multicolumn{2}{|c|}{ Trial \#1 } & \multicolumn{2}{|c|}{ Trial \#2 } & \multicolumn{2}{c|}{ Trial \#3 } & Average \\
\hline Compound & RT (min) & Area & \% Area & Area & \% Area & Area & \% Area & \% Area \\
\hline Methyl formate & 2.363 & & & & & 194764 & 1.6 & \\
\hline Pyridine & 3.033 & 4645393 & 27.6 & 3677279 & 27.9 & 3368802 & 27.4 & 27.6 \\
\hline
\end{tabular}




\begin{tabular}{|c|c|c|c|c|c|c|c|c|}
\hline 3-Methylene-heptane & 3.216 & & & & & 424316 & 3.4 & \\
\hline Styrene & 4.046 & 6249682 & 37.2 & 3880539 & 29.4 & 4024155 & 32.7 & 33.1 \\
\hline 2-Ethyl-hexanal & 4.485 & 177225 & 1.1 & & & 191364 & 1.6 & \\
\hline Benzaldehyde & 4.667 & 2570474 & 15.3 & 2514348 & 19.1 & 2202299 & 17.9 & 17.4 \\
\hline Aniline & 4.769 & 267022 & 1.6 & 381918 & 2.9 & 242562 & 2.0 & 2.2 \\
\hline 3-Pyridinecarboxaldehyde & 4.998 & 168249 & 1.0 & 147578 & 1.1 & 128754 & 1.0 & 1.1 \\
\hline 2-EH & 5.147 & & & & & 510698 & 4.2 & \\
\hline Benzyl Alcohol & 5.284 & 137351 & 0.8 & 87079 & 0.7 & 87003 & 0.7 & 0.7 \\
\hline Phenylacetaldehyde & 5.417 & 1469933 & 8.7 & 747348 & 5.7 & 916529 & 7.4 & 7.3 \\
\hline 1-Phenyl-1,2-propanedione & 5.722 & 193995 & 1.2 & 245588 & 1.9 & 177907 & 1.4 & 1.5 \\
\hline Benzenecarboxylic acid & 6.381 & 184751 & 1.1 & 132061 & 1.0 & 180713 & 1.5 & 1.2 \\
\hline Propionanilide & 9.317 & 16808919 & 100 & 13187542 & 100 & 12303657 & 100 & 100 \\
\hline $\mathrm{N}$-(2-phenylethyl)-formamide & 9.612 & 284173 & 1.7 & 294823 & 2.2 & 251358 & 2.0 & 2.0 \\
\hline Fentanyl & 19.263 & 73189 & 0.4 & 197784 & 1.5 & 314725 & 2.6 & 1.5 \\
\hline
\end{tabular}

\begin{tabular}{|l|c|c|c|c|c|c|c|c|}
\hline $\mathbf{3 0 0}{ }^{\circ} \mathbf{C}$ & & \multicolumn{2}{|c|}{ Trial \#1 } & \multicolumn{2}{|c|}{ Trial \#2 } & \multicolumn{2}{c|}{ Trial \#3 } & Average \\
\hline Compound & RT (min) & Area & \% Area & Area & \% Area & Area & \% Area & \% Area \\
\hline Pyridine & 3.021 & 4394098 & 35.4 & 3815696 & 26.4 & 4337389 & 29.7 & 30.5 \\
\hline 3-Methylene-heptane & 3.210 & 6534789 & 52.6 & 4276059 & 29.6 & 5975715 & 40.9 & 41.1 \\
\hline 3-Heptanone & 3.870 & 1645940 & 13.3 & 526918 & 3.7 & 953806 & 6.5 & 7.8 \\
\hline Styrene & 4.036 & 4496873 & 36.2 & 3579109 & 24.8 & 4941010 & 33.8 & 31.6 \\
\hline 2-Ethyl-2-hexenal & 4.209 & 380592 & 3.1 & 201238 & 1.4 & 283967 & 1.9 & 2.1 \\
\hline 2-Ethyl-hexanal & 4.477 & 3084532 & 24.8 & 1305480 & 9.0 & 1677692 & 11.5 & 15.1 \\
\hline Benzaldehyde & 4.662 & 4371825 & 35.2 & 3054965 & 21.2 & 3391789 & 23.2 & 26.5 \\
\hline Aniline & 4.767 & 419414 & 3.4 & & & & & \\
\hline 2-EH & 5.142 & 8470103 & 68.2 & 6772988 & 46.9 & 8463971 & 57.9 & 57.7 \\
\hline Benzyl Alcohol & 5.286 & & & 290241 & 2.0 & 357358 & 2.4 & \\
\hline Phenylacetaldehyde & 5.413 & 1154824 & 9.3 & 1489212 & 10.3 & 1565208 & 10.7 & 10.1 \\
\hline 1-Phenyl-1,2-propanedione & 5.716 & 242203 & 2.0 & 288615 & 2.0 & 290961 & 2.0 & 2.0 \\
\hline
\end{tabular}




\begin{tabular}{|c|c|c|c|c|c|c|c|c|}
\hline 2-Ethylhexyl ester acetic acid & 6.278 & 176039 & 1.4 & 141742 & 1.0 & 182871 & 1.3 & 1.2 \\
\hline Benzenecarboxylic acid & 6.376 & 459858 & 3.7 & 407890 & 2.8 & 520743 & 3.6 & 3.4 \\
\hline 2-Ethylhexyl ester 2-propenoic acid & 7.084 & 903269 & 7.3 & 754311 & 5.2 & 1044978 & 7.2 & 6.6 \\
\hline 2-Ethylhexyl methacrylate & 7.838 & 112829 & 0.9 & & & & & \\
\hline Phthalic anhydride & 8.115 & 120630 & 1.0 & 106943 & 0.7 & & & \\
\hline Propionanilide & 9.314 & 12412608 & 100 & 14435342 & 100 & 14614471 & 100 & 100 \\
\hline Acrylanilide & 9.363 & 115729 & 0.9 & & & & & \\
\hline $\mathrm{N}$-(2-phenylethyl)-formamide & 9.611 & 288808 & 2.3 & 318006 & 2.2 & 377024 & 2.6 & 2.4 \\
\hline 2-EEFA & 10.290 & 382202 & 3.1 & 241536 & 1.7 & 315548 & 2.2 & 2.3 \\
\hline Fentanyl & 19.267 & 20166 & 0.2 & 322358 & 2.2 & 423443 & 2.9 & 1.8 \\
\hline
\end{tabular}

\begin{tabular}{|l|c|c|c|c|c|c|c|c|}
\hline $\mathbf{3 5 0}{ }^{\circ} \mathbf{C}$ & & \multicolumn{2}{|c|}{ Trial \#1 } & \multicolumn{2}{c|}{ Trial \#2 } & \multicolumn{2}{c|}{ Trial \#3 } & Average \\
\hline Compound & RT (min) & Area & \% Area & Area & \% Area & Area & \% Area & \% Area \\
\hline Pyridine & 3.018 & 5007167 & 34.7 & 4617613 & 31.8 & 4375933 & 29.6 & 32.0 \\
\hline 3-Methylene-heptane & 3.212 & 5938456 & 41.2 & 4330641 & 29.8 & 5509295 & 37.2 & 36.1 \\
\hline 3-Heptanone & 3.867 & 680975 & 4.7 & 687879 & 4.7 & 872715 & 5.9 & 5.1 \\
\hline Styrene & 4.035 & 5484007 & 38.0 & 5163947 & 35.5 & 4315403 & 29.2 & 34.2 \\
\hline 2-Ethyl-2-hexenal & 4.215 & 296156 & 2.1 & & & & & \\
\hline 2-Ethyl-hexanal & 4.471 & 1340437 & 9.3 & 1276284 & 8.8 & 2110434 & 14.3 & 10.8 \\
\hline Benzaldehyde & 4.662 & 4096522 & 28.4 & 4034306 & 27.8 & 3944706 & 26.7 & 27.6 \\
\hline Aniline & 4.763 & 398659 & 2.8 & 257240 & 1.8 & & & \\
\hline 2-EH & 5.141 & 9049021 & 62.8 & 6088817 & 41.9 & 9266297 & 62.6 & 55.8 \\
\hline Benzyl Alcohol & 5.283 & 333796 & 2.3 & 278392 & 1.9 & 187403 & 1.3 & 1.8 \\
\hline Phenylacetaldehyde & 5.412 & 1389825 & 9.6 & 1347572 & 9.3 & 896213 & 6.1 & 8.3 \\
\hline 1-Phenyl-1,2-propanedione & 5.716 & 290698 & 2.0 & 196429 & 1.4 & & & \\
\hline 2-Ethylhexyl ester acetic acid & 6.278 & 195482 & 1.4 & 141558 & 1.0 & 137994 & 0.9 & 1.1 \\
\hline Benzenecarboxylic acid & 6.377 & 500283 & 3.5 & 331292 & 2.3 & 409448 & 2.8 & 2.8 \\
\hline 2-Ethylhexyl ester 2-propenoic acid & 7.084 & 918112 & 6.4 & 500482 & 3.4 & 692837 & 4.7 & 4.8 \\
\hline 2-Ethylhexyl methacrylate & 7.838 & 122416 & 0.8 & & & & & \\
\hline
\end{tabular}




\begin{tabular}{|c|c|c|c|c|c|c|c|c|}
\hline Propionanilide & 9.316 & 14415944 & 100 & 14534791 & 100 & 14797242 & 100 & 100 \\
\hline Acrylanilide & 9.363 & & & 133545 & 0.9 & 118115 & 0.8 & \\
\hline $\mathrm{N}$-(2-phenylethyl)-formamide & 9.612 & 329710 & 2.3 & & & 442899 & 3.0 & \\
\hline 2-EEFA & 10.290 & 361085 & 2.5 & 193354 & 1.3 & 378222 & 2.6 & 2.1 \\
\hline Fentanyl & 19.267 & 219598 & 1.5 & 213646 & 1.5 & 289585 & 2.0 & 1.7 \\
\hline
\end{tabular}

\begin{tabular}{|c|c|c|c|c|c|c|c|c|}
\hline \multirow{2}{*}{$\begin{array}{l}400^{\circ} \mathrm{C} \\
\text { Compound }\end{array}$} & \multirow[b]{2}{*}{ RT (min) } & \multicolumn{2}{|c|}{ Trial \#1 } & \multicolumn{2}{|c|}{ Trial \#2 } & \multicolumn{2}{|c|}{ Trial \#3 } & \multirow{2}{*}{$\begin{array}{c}\text { Average } \\
\% \text { Area } \\
\end{array}$} \\
\hline & & Area & $\%$ Area & Area & \% Area & Area & $\%$ Area & \\
\hline Pyridine & 3.019 & 4075441 & 18.7 & 5375025 & 24.0 & 6757820 & 26.9 & 23.2 \\
\hline 3-Methylene-heptane & 3.208 & 10180024 & 46.7 & 11440491 & 51.0 & 13149918 & 52.4 & 50.0 \\
\hline 3-Heptanone & 3.867 & 1268850 & 5.8 & 1278998 & 5.7 & 1319572 & 5.3 & 5.6 \\
\hline Styrene & 4.032 & 3403062 & 15.6 & 4004466 & 17.8 & 5023552 & 20.0 & 17.8 \\
\hline 2-Ethyl-2-hexenal & 4.207 & 742942 & 3.4 & 803378 & 3.6 & 669983 & 2.7 & 3.2 \\
\hline 2-Ethyl-hexanal & 4.473 & 2995224 & 13.7 & 3284885 & 14.6 & 3084095 & 12.3 & 13.6 \\
\hline Benzaldehyde & 4.659 & 4107472 & 18.8 & 4787727 & 21.3 & 5808772 & 23.2 & 21.1 \\
\hline 2-EH & 5.141 & 21795820 & 100 & 22435959 & 100 & 25087109 & 100 & 100 \\
\hline Phenylacetaldehyde & 5.410 & 939843 & 4.3 & 988776 & 4.4 & 1558080 & 6.2 & 5.0 \\
\hline 2-Ethylhexyl ester acetic acid & 6.276 & 345049 & 1.6 & 378476 & 1.7 & 564615 & 2.3 & 1.8 \\
\hline Benzenecarboxylic acid & 6.382 & 588258 & 2.7 & 548783 & 2.4 & 707275 & 2.8 & 2.7 \\
\hline 2-Ethylhexyl ester 2-propenoic acid & 7.083 & 2804275 & 12.9 & 2713098 & 12.1 & 3613154 & 14.4 & 13.1 \\
\hline 2-Ethylhexyl methacrylate & 7.836 & 360879 & 1.7 & 365715 & 1.6 & 406327 & 1.6 & 1.6 \\
\hline 2-EECA & 8.609 & 408126 & 1.9 & 405280 & 1.8 & 466286 & 1.9 & 1.8 \\
\hline Butyl 2-ethylhexyl ester sulfurous acid & 8.791 & & & & & 263892 & 1.1 & \\
\hline Propionanilide & 9.319 & 13467368 & 61.8 & 14903654 & 66.4 & 19821574 & 79.0 & 69.1 \\
\hline 2-Ethylhexyl ester pentanoic acid & 9.637 & 934487 & 4.3 & 934811 & 4.2 & 763266 & 3.0 & 3.8 \\
\hline 2-EEFA & 10.288 & 813202 & 3.7 & 928862 & 4.1 & 899133 & 3.6 & 3.8 \\
\hline Fentanyl & 19.264 & 1499527 & 6.9 & 78130 & 0.3 & 198013 & 0.8 & 2.7 \\
\hline
\end{tabular}

$450{ }^{\circ} \mathrm{C}$

Trial \#1

Trial \#2

Trial \#3

Average 


\begin{tabular}{|c|c|c|c|c|c|c|c|c|}
\hline Compound & RT (min) & Area & $\%$ Area & Area & $\%$ Area & Area & \% Area & $\%$ Area \\
\hline Pyridine & 3.017 & 9734424 & 21.2 & 7903034 & 21.9 & 6348045 & 27.3 & 23.5 \\
\hline 3-Methylene-heptane & 3.206 & 30031724 & 65.5 & 23002960 & 63.7 & 15959897 & 68.6 & 65.9 \\
\hline 3-Heptanone & 3.863 & 2965207 & 6.5 & 2171713 & 6.0 & 2595286 & 11.2 & 7.9 \\
\hline Styrene & 4.029 & 5215870 & 11.4 & 4198655 & 11.6 & 4062135 & 17.5 & 13.5 \\
\hline 2-Ethyl-hexanal & 4.470 & 5077234 & 11.1 & 3883741 & 10.7 & 3723561 & 16.0 & 12.6 \\
\hline Benzaldehyde & 4.654 & 10988711 & 24.0 & 9112778 & 25.2 & 6807454 & 29.2 & 26.1 \\
\hline 2-EH & 5.139 & 45832553 & 100 & 36134710 & 100 & 23274294 & 100 & 100 \\
\hline Phenylacetaldehyde & 5.407 & 1873290 & 4.1 & 1352711 & 3.7 & 1110295 & 4.8 & 4.2 \\
\hline 2-Ethylhexyl ester acetic acid & 6.274 & 2075541 & 4.5 & 1514618 & 4.2 & 957883 & 4.1 & 4.3 \\
\hline Benzenecarboxylic acid & 6.386 & 1696268 & 3.7 & 869219 & 2.4 & 922505 & 4.0 & 3.4 \\
\hline 6-Methylheptyl ester 2-propenoic acid & 7.079 & 12678473 & 27.7 & 10943290 & 30.3 & 6016383 & 25.8 & 27.9 \\
\hline 2-Ethylhexyl methacrylate & 7.832 & 1665919 & 3.6 & 927896 & 2.6 & 718823 & 3.1 & 3.1 \\
\hline n-Butyric acid 2-ethylhexyl ester & 7.970 & 674654 & 1.5 & 423399 & 1.2 & 295891 & 1.3 & 1.3 \\
\hline 2-EECA & 8.605 & 1286234 & 2.8 & 1022424 & 2.8 & 547821 & 2.4 & 2.7 \\
\hline Propionanilide & 9.317 & 26278124 & 57.3 & 21534669 & 59.6 & 16798918 & 72.2 & 63.0 \\
\hline 2-Ethylhexyl ester pentanoic acid & 9.633 & 2462353 & 5.4 & 1821194 & 5.0 & 1201459 & 5.2 & 5.2 \\
\hline 2-EEFA & 10.284 & 1042763 & 2.3 & 459647 & 1.3 & 481726 & 2.1 & 1.9 \\
\hline Fentanyl & 19.256 & 227510 & 0.5 & 556264 & 1.5 & 213243 & 0.9 & 1.0 \\
\hline
\end{tabular}




\section{Appendix C: Extended data and GC Chromatograms of the pyromarkers of the pyrolysis of heroin and fentanyl mixes.}

\section{3:1 Heroin to Fentanyl Mix}

\begin{tabular}{|c|c|c|c|c|c|c|c|c|}
\hline $200{ }^{\circ} \mathrm{C}$ & & Tri & & Tri: & & Tri & & Average \\
\hline Compound & RT (min) & Area & $\%$ Area & Area & $\%$ Area & Area & $\%$ Area & \% Area \\
\hline Pyridine & 3.082 & 427125 & 1.7 & 1025486 & 5.6 & 1340271 & 6.7 & 4.7 \\
\hline Styrene & 4.073 & 353368 & 1.4 & 857860 & 4.7 & 936433 & 4.7 & 3.6 \\
\hline Benzaldehyde & 4.692 & 174712 & 0.7 & 424453 & 2.3 & 473994 & 2.4 & 1.8 \\
\hline Aniline & 4.784 & & & 58580 & 0.3 & 67187 & 0.3 & \\
\hline Phenylacetaldehyde & 5.433 & 91625 & 0.4 & 159302 & 0.9 & 218861 & 1.1 & 0.8 \\
\hline Acetylbenzoyl & 5.736 & & & 63068 & 0.3 & 75212 & 0.4 & \\
\hline Propionanilide & 9.306 & 5094048 & 20.3 & 6047432 & 33.1 & 6798119 & 34.1 & 29.1 \\
\hline Norfentanyl & 13.511 & 46558 & 0.2 & 25679 & 0.1 & 50073 & 0.3 & 0.2 \\
\hline 6-MAM & 17.509 & 1555767 & 6.2 & 1057359 & 5.8 & 1307222 & 6.6 & 6.2 \\
\hline Heroin & 18.391 & 25139123 & 100 & 18289879 & 100 & 19926264 & 100 & 100 \\
\hline Fentanyl & 19.275 & 5020428 & 20.0 & 4034237 & 22.1 & 4599114 & 23.1 & 21.7 \\
\hline
\end{tabular}

\begin{tabular}{|c|c|c|c|c|c|c|c|c|}
\hline $250{ }^{\circ} \mathrm{C}$ & & Tri & & Tri: & & Tri & & Average \\
\hline Compound & RT (min) & Area & $\%$ Area & Area & $\%$ Area & Area & \% Area & $\%$ Area \\
\hline Pyridine & 3.087 & 852063 & 3.6 & 1025486 & 5.6 & 1726495 & 15.2 & 8.1 \\
\hline Styrene & 4.077 & 699069 & 3.0 & 857860 & 4.7 & 1026517 & 9.0 & 5.6 \\
\hline Benzaldehyde & 4.691 & 285818 & 1.2 & 424453 & 2.3 & 881822 & 7.8 & 3.8 \\
\hline Aniline & 4.792 & & & 58580 & 0.3 & 122678 & 1.1 & \\
\hline Phenylacetaldehyde & 5.432 & 124750 & 0.5 & 159302 & 0.9 & 165779 & 1.5 & 1.0 \\
\hline Acetylbenzoyl & 5.734 & 52547 & 0.2 & 63068 & 0.3 & 68516 & 0.6 & 0.4 \\
\hline Propionanilide & 9.300 & 4844623 & 20.5 & 6047432 & 33.1 & 3816356 & 33.6 & 29.1 \\
\hline 6-MAM & 17.505 & 3538088 & 15.0 & 1057359 & 5.8 & 578118 & 5.1 & 8.6 \\
\hline Heroin & 18.383 & 23614437 & 100 & 18289879 & 100 & 11343491 & 100 & 100 \\
\hline
\end{tabular}




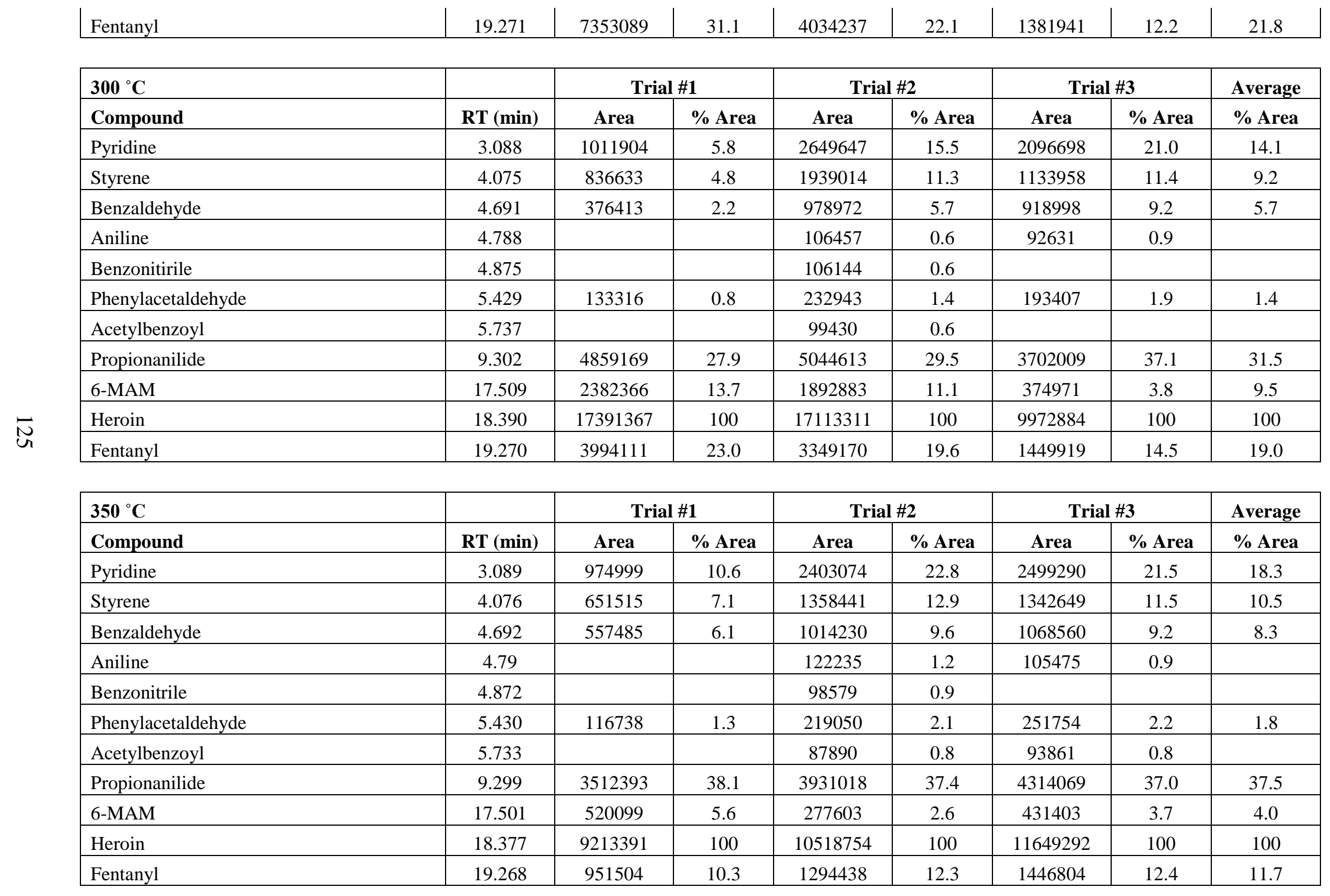




\begin{tabular}{|c|c|c|c|c|c|c|c|c|}
\hline \multirow{2}{*}{$\begin{array}{l}400^{\circ} \mathrm{C} \\
\text { Compound }\end{array}$} & \multirow[b]{2}{*}{ RT (min) } & \multicolumn{2}{|c|}{ Trial \#1 } & \multicolumn{2}{|c|}{ Trial \#2 } & \multicolumn{2}{|c|}{ Trial \#3 } & \multirow{2}{*}{$\begin{array}{c}\text { Average } \\
\% \text { Area } \\
\end{array}$} \\
\hline & & Area & $\%$ Area & Area & $\%$ Area & Area & $\%$ Area & \\
\hline Styrene & 4.077 & 1154659 & 9.9 & 1639437 & 12.7 & 1382670 & 14.1 & 12.2 \\
\hline Aniline & 4.784 & & & 132486 & 1.0 & & & \\
\hline Benzonitrile & 4.871 & & & & & 94087 & 1.0 & \\
\hline Phthalic anhydride & 8.166 & 50878 & 0.4 & & & & & \\
\hline Propionanilide & 9.299 & 5124945 & 43.8 & 4033329 & 31.3 & 3062012 & 31.1 & 35.4 \\
\hline 6-MAM & 17.502 & 325164 & 2.8 & 428586 & 3.3 & 351808 & 3.6 & 3.2 \\
\hline Heroin & 18.379 & 11705004 & 100 & 12891518 & 100 & 9831045 & 100 & 100 \\
\hline Fentanyl & 19.267 & 1328710 & 11.4 & 1532001 & 11.9 & 1035027 & 10.5 & 11.3 \\
\hline
\end{tabular}

\begin{tabular}{|l|c|c|c|c|c|c|c|c|}
\hline $\mathbf{4 5 0}{ }^{\circ} \mathbf{C}$ & & \multicolumn{2}{|c|}{ Trial \#1 } & \multicolumn{2}{c|}{ Trial \#2 } & \multicolumn{2}{c|}{ Trial \#3 } & Average \\
\hline Compound & RT (min) & Area & \% Area & Area & \% Area & Area & \% Area & \% Area \\
\hline Pyridine & 3.143 & 1524262 & 4.6 & 3530622 & 51.4 & 2348809 & 10.3 & 22.1 \\
\hline Styrene & 4.12 & 1012630 & 3.1 & 2256962 & 32.9 & 1617539 & 7.1 & 14.4 \\
\hline Benzaldehyde & 4.729 & 649691 & 2.0 & 1203888 & 17.5 & 898336 & 4.0 & 7.8 \\
\hline Phenylacetaldehyde & 5.463 & 208919 & 0.6 & 343847 & 5.0 & 281550 & 1.2 & 2.3 \\
\hline Acetylbenzoyl & 5.766 & & & 148537 & 2.2 & & & \\
\hline Propionanilide & 9.325 & 7299502 & 22.1 & 2647695 & 38.6 & 9959385 & 43.9 & 34.9 \\
\hline Norfentanyl & 13.521 & & & & & 107615 & 0.5 & \\
\hline 6-MAM & 17.528 & 2247466 & 6.8 & 842975 & 12.3 & 7267983 & 32.0 & 17.0 \\
\hline Heroin & 18.403 & 32965334 & 100 & 6862895 & 100 & 22701106 & 100 & 100 \\
\hline Fentanyl & 19.289 & 6856632 & 20.8 & 15439623 & 225.0 & 9091553 & 40.0 & 95.3 \\
\hline
\end{tabular}




\section{1:1 Heroin to Fentanyl Mix}

\begin{tabular}{|c|c|c|c|c|c|c|c|c|}
\hline $200{ }^{\circ} \mathrm{C}$ & & \multicolumn{2}{|c|}{ Trial \#1 } & \multicolumn{2}{|c|}{ Trial \#2 } & \multicolumn{2}{|c|}{ Trial \#3 } & Average \\
\hline Compound & RT (min) & Area & $\%$ Area & Area & $\%$ Area & Area & $\%$ Area & $\%$ Area \\
\hline Pyridine & 3.084 & 1106715 & 6.3 & 1963516 & 10.8 & 2623180 & 13.8 & 10.3 \\
\hline Styrene & 4.076 & 947187 & 5.4 & 1787957 & 9.8 & 2292694 & 12.1 & 9.1 \\
\hline Benzaldehyde & 4.690 & 309520 & 1.8 & 722239 & 4.0 & 1087617 & 5.7 & 3.8 \\
\hline Aniline & 4.784 & & 0.0 & 77173 & 0.4 & 241858 & 1.3 & \\
\hline Phenylacetaldehyde & 5.431 & 204072 & 1.2 & 397955 & 2.2 & 422599 & 2.2 & 1.9 \\
\hline Acetylbenzoyl & 5.733 & 57874 & 0.3 & 97432 & 0.5 & 104884 & 0.6 & 0.5 \\
\hline Propionanilide & 9.305 & 9509159 & 53.8 & 12917882 & 71.0 & 12826091 & 67.6 & 64.1 \\
\hline Norfentanyl & 13.497 & 79533 & 0.5 & 183653 & 1.0 & 221110 & 1.2 & 0.9 \\
\hline 6-MAM & 17.494 & 1130945 & 6.4 & 1113491 & 6.1 & 1875776 & 9.9 & 7.5 \\
\hline Heroin & 18.370 & 17673836 & 100 & 16565965 & 91.0 & 17067313 & 90.0 & 93.7 \\
\hline Fentanyl & 19.264 & 15925706 & 90.1 & 18203484 & 100 & 18966113 & 100 & 96.7 \\
\hline
\end{tabular}

\begin{tabular}{|c|c|c|c|c|c|c|c|c|}
\hline \multirow{2}{*}{$\begin{array}{l}250^{\circ} \mathrm{C} \\
\text { Compound }\end{array}$} & \multirow[b]{2}{*}{ RT (min) } & \multicolumn{2}{|c|}{ Trial \#1 } & \multicolumn{2}{|c|}{ Trial \#2 } & \multicolumn{2}{|c|}{ Trial \#3 } & \multirow{2}{*}{$\begin{array}{c}\text { Average } \\
\text { \% Area }\end{array}$} \\
\hline & & Area & $\%$ Area & Area & \% Area & Area & \% Area & \\
\hline Pyridine & 3.091 & 1648630 & 8.4 & 3797643 & 26.2 & 4024882 & 23.8 & 19.4 \\
\hline Styrene & 4.078 & 1363144 & 6.9 & 2595296 & 17.9 & 2987687 & 17.7 & 14.2 \\
\hline Benzaldehyde & 4.692 & 415025 & 2.1 & 1505520 & 10.4 & 1491748 & 8.8 & 7.1 \\
\hline Aniline & 4.791 & & & 147632 & 1.0 & & & \\
\hline Phenylacetaldehyde & 5.432 & 250671 & 1.3 & 488198 & 3.4 & 567651 & 3.4 & 2.7 \\
\hline Acetylbenzoyl & 5.730 & 74496 & 0.4 & 158243 & 1.1 & 174696 & 1.0 & 0.8 \\
\hline Isothiocyanato-cyclohexane & 7.564 & 132391 & 0.7 & & 0.0 & & & \\
\hline Propionanilide & 9.304 & 10569080 & 53.6 & 12014280 & 82.8 & 13196551 & 78.0 & 71.5 \\
\hline Norfentanyl & 13.495 & & & 124623 & 0.9 & 127016 & & \\
\hline 6-MAM & 17.492 & 2452277 & 12.4 & 917676 & 6.3 & 921671 & 5.4 & 8.1 \\
\hline Heroin & 18.370 & 19727933 & 100 & 13197787 & 91.0 & 14810783 & 87.5 & 92.8 \\
\hline Fentanyl & 19.261 & 18635750 & 94.5 & 14506232 & 100 & 16917636 & 100 & 98.2 \\
\hline
\end{tabular}




\begin{tabular}{|c|c|c|c|c|c|c|c|c|}
\hline \multirow{2}{*}{$\frac{300^{\circ} \mathrm{C}}{\text { Compound }}$} & \multirow[b]{2}{*}{ RT (min) } & \multicolumn{2}{|c|}{ Trial \#1 } & \multicolumn{2}{|c|}{ Trial \#2 } & \multicolumn{2}{|c|}{ Trial \#3 } & \multirow{2}{*}{$\begin{array}{c}\text { Average } \\
\text { \% Area }\end{array}$} \\
\hline & & Area & \% Area & Area & $\%$ Area & Area & $\%$ Area & \\
\hline Styrene & 4.081 & 1740787 & 19.2 & 2965312 & 23.2 & 2858251 & 24.8 & 22.4 \\
\hline Aniline & 4.792 & & & & & 200051 & 1.7 & \\
\hline Benzonitrile & 4.879 & & & 173656 & 1.4 & 155069 & 1.3 & \\
\hline Phthalic anhydride & 8.115 & & & 59599 & 0.5 & 76991 & 0.7 & \\
\hline Propionanilide & 9.304 & 8985753 & 99.0 & 10484422 & 82.0 & 11123282 & 96.5 & 92.5 \\
\hline Norfentanyl & 13.499 & & & 98637 & 0.8 & 86796 & 0.8 & \\
\hline 6-MAM & 17.494 & 786149 & 8.7 & 1191441 & 9.3 & 840717 & 7.3 & 8.4 \\
\hline Heroin & 18.369 & 9076491 & 100 & 11872286 & 92.9 & 10729043 & 93.1 & 95.3 \\
\hline
\end{tabular}

\begin{tabular}{|c|c|c|c|c|c|c|c|c|}
\hline $350{ }^{\circ} \mathrm{C}$ & & Tri & & Tri & & Tri & & Average \\
\hline Compound & RT (min) & Area & $\%$ Area & Area & $\%$ Area & Area & \% Area & $\%$ Area \\
\hline Pyridine & 3.095 & 2256598 & 30.3 & 5187093 & 38.9 & 4787853 & 31.3 & 33.5 \\
\hline Styrene & 4.079 & 1885619 & 25.3 & 3091721 & 23.2 & 3222107 & 21.1 & 23.2 \\
\hline Benzaldehyde & 4.692 & 892174 & 12.0 & 2294462 & 17.2 & 1962840 & 12.8 & 14.0 \\
\hline Phenylacetaldehyde & 5.431 & 257583 & 3.5 & 588078 & 4.4 & 546698 & 3.6 & 3.8 \\
\hline Acetylbenzoyl & 5.734 & 81199 & 1.1 & & & 186201 & 1.2 & \\
\hline Phthalic anhydride & 8.171 & 37321 & 0.5 & & & & & \\
\hline Propionanilide & 9.304 & 7444606 & 100 & 13339386 & 100 & 12042474 & 78.8 & 92.9 \\
\hline Norfentanyl & 13.498 & & & 126643 & 0.9 & 122799 & 0.8 & \\
\hline 6-MAM & 17.497 & 285379 & 3.8 & 986108 & 7.4 & 1956774 & 12.8 & 8.0 \\
\hline Heroin & 18.372 & 5324947 & 71.5 & 12024124 & 90.1 & 13319359 & 87.1 & 82.9 \\
\hline
\end{tabular}




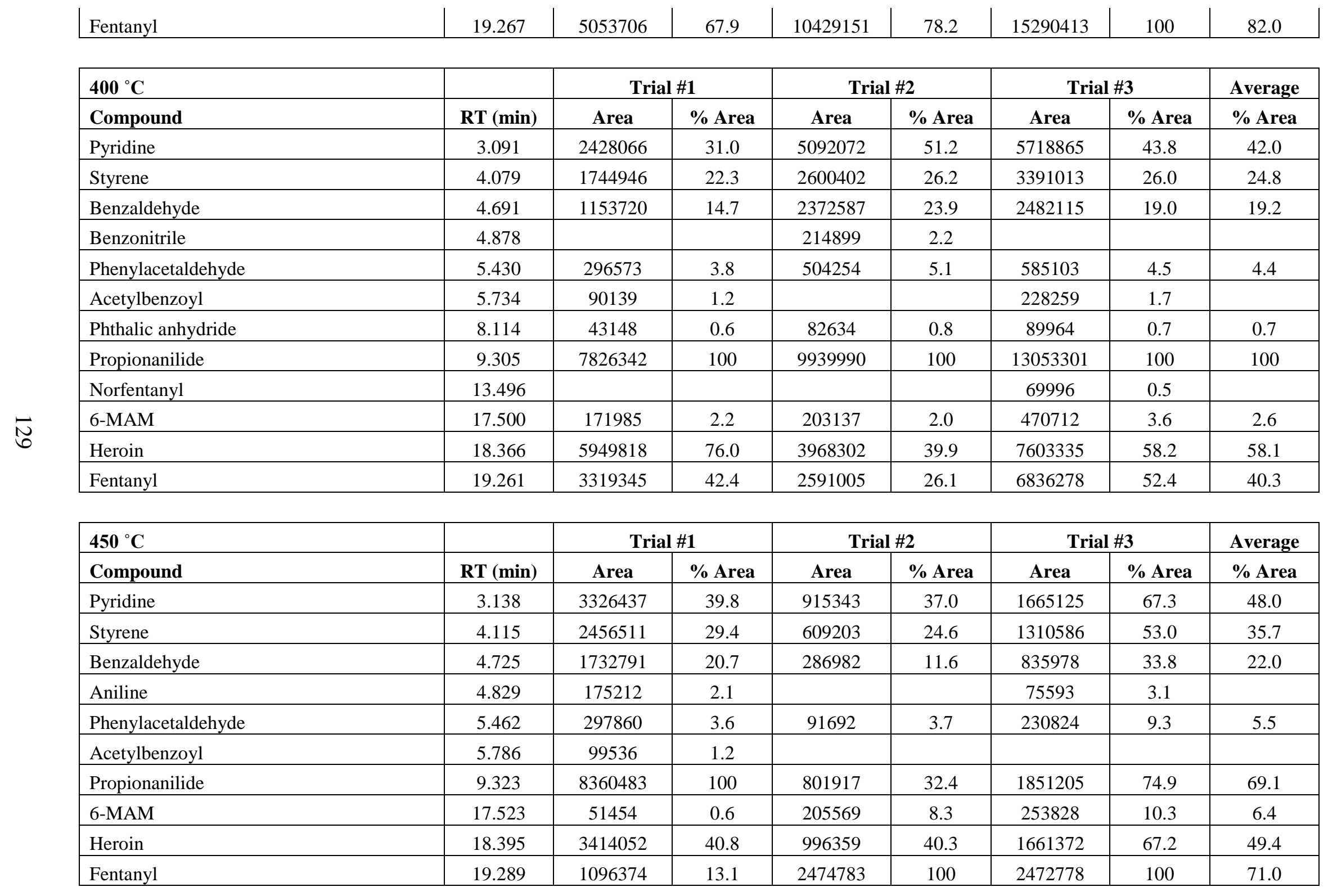




\section{1:3 Heroin to Fentanyl Mix}

\begin{tabular}{|c|c|c|c|c|c|c|c|c|}
\hline $200{ }^{\circ} \mathrm{C}$ & & \multicolumn{2}{|c|}{ Trial \#1 } & \multicolumn{2}{|c|}{ Trial \#2 } & \multicolumn{2}{|c|}{ Trial \#3 } & Average \\
\hline Compound & RT (min) & Area & $\%$ Area & Area & $\%$ Area & Area & $\%$ Area & $\%$ Area \\
\hline Pyridine & 3.083 & 1461784 & 8.6 & 3521836 & 11.9 & 4717374 & 16.8 & 12.5 \\
\hline Styrene & 4.075 & 1628668 & 9.6 & 3182182 & 10.8 & 3963862 & 14.1 & 11.5 \\
\hline Benzaldehyde & 4.692 & 519299 & 3.1 & 1491855 & 5.0 & 2020698 & 7.2 & 5.1 \\
\hline Phenylacetaldehyde & 5.430 & 291565 & 1.7 & 635000 & 2.1 & 802720 & 2.9 & 2.2 \\
\hline Acetylbenzoyl & 5.856 & 63443 & 0.4 & & & & & \\
\hline Propionanilide & 9.316 & 11067919 & 65.5 & 18923590 & 64.0 & 20335617 & 72.4 & 67.3 \\
\hline $\mathrm{N}$-(2-phenylethyl)-formamide & 9.606 & & & 57328 & 0.2 & 73871 & 0.3 & \\
\hline Norfentanyl & 13.496 & & & 217260 & 0.7 & 215350 & 0.8 & \\
\hline 6-MAM & 17.480 & 389732 & 2.3 & 1394198 & 4.7 & 1605513 & 5.7 & 4.2 \\
\hline Heroin & 18.339 & 2686647 & 15.9 & 5845676 & 19.8 & 5113120 & 18.2 & 18.0 \\
\hline Fentanyl & 19.248 & 16902522 & 100 & 29558706 & 100 & 28069395 & 100 & 100 \\
\hline
\end{tabular}

\begin{tabular}{|c|c|c|c|c|c|c|c|c|}
\hline \multirow{2}{*}{$\begin{array}{l}250^{\circ} \mathrm{C} \\
\text { Compound }\end{array}$} & \multirow[b]{2}{*}{ RT (min) } & \multicolumn{2}{|c|}{ Trial \#1 } & \multicolumn{2}{|c|}{ Trial \#2 } & \multicolumn{2}{|c|}{ Trial \#3 } & \multirow{2}{*}{$\begin{array}{c}\text { Average } \\
\text { \% Area }\end{array}$} \\
\hline & & Area & $\%$ Area & Area & \% Area & Area & \% Area & \\
\hline Pyridine & 3.089 & 3218908 & 28.3 & 5212996 & 17.4 & 5848535 & 20.9 & 22.2 \\
\hline Styrene & 4.077 & 2409551 & 21.2 & 3648197 & 12.2 & 4341288 & 15.5 & 16.3 \\
\hline Benzaldehyde & 4.692 & 1380504 & 12.1 & 2189712 & 7.3 & 2424710 & 8.7 & 9.4 \\
\hline Aniline & 4.793 & 358250 & 3.2 & 328143 & 1.1 & & & \\
\hline Phenylacetaldehyde & 5.432 & 323627 & 2.8 & 684887 & 2.3 & 793078 & 2.8 & 2.7 \\
\hline Acetylbenzoyl & 5.735 & 91005 & 0.8 & 197361 & 0.7 & 232550 & 0.8 & 0.8 \\
\hline Propionanilide & 9.313 & 11368092 & 100 & 16872011 & 56.4 & 18090895 & 64.7 & 73.7 \\
\hline $\mathrm{N}$-(2-phenylethyl)-formamide & 9.605 & & & & & 67179 & 0.2 & \\
\hline Norfentanyl & 13.493 & & & 155110 & 0.5 & 201272 & 0.7 & \\
\hline 6-MAM & 17.478 & 179332 & 1.6 & 606577 & 2.0 & 864436 & 3.1 & 2.2 \\
\hline Heroin & 18.345 & 1896847 & 16.7 & 6761275 & 22.6 & 6134716 & 21.9 & 20.4 \\
\hline Fentanyl & 19.246 & 9686494 & 85.2 & 29902873 & 100 & 27965102 & 100 & 95.1 \\
\hline
\end{tabular}




\begin{tabular}{|c|c|c|c|c|c|c|c|c|}
\hline \multirow{2}{*}{$\begin{array}{l}300^{\circ} \mathrm{C} \\
\text { Compound }\end{array}$} & \multirow[b]{2}{*}{ RT (min) } & \multicolumn{2}{|c|}{ Trial \#1 } & \multicolumn{2}{|c|}{ Trial \#2 } & \multicolumn{2}{|c|}{ Trial \#3 } & \multirow{2}{*}{$\begin{array}{c}\text { Average } \\
\text { \% Area }\end{array}$} \\
\hline & & Area & \% Area & Area & $\%$ Area & Area & \% Area & \\
\hline Phenylethyne & 3.933 & & & 70667 & 0.9 & & & \\
\hline Benzaldehyde & 4.693 & 1197178 & 3.8 & 3632648 & 44.4 & 3203154 & 12.3 & 20.2 \\
\hline Benzonitrile & 4.872 & & & 326031 & 4.0 & & & \\
\hline Acetylbenzoyl & 5.733 & 140400 & 0.4 & 169009 & 2.1 & 249728 & 1.0 & 1.2 \\
\hline Phthalic anhydride & 8.115 & & & & & 77435 & 0.3 & \\
\hline Propionanilide & 9.309 & 12820902 & 40.8 & 7938451 & 97.1 & 16943450 & 65.1 & 67.7 \\
\hline Azobenzene & 10.928 & & & 102838 & 1.3 & & & \\
\hline Norfentanyl & 13.488 & & & & & 139117 & 0.5 & \\
\hline $350^{\circ} \mathrm{C}$ & & \multicolumn{2}{|c|}{ Trial \#1 } & \multicolumn{2}{|c|}{ Trial \#2 } & \multicolumn{2}{|c|}{ Trial \#3 } & Average \\
\hline Compound & RT (min) & Area & \% Area & Area & \% Area & Area & \% Area & \% Area \\
\hline Pyridine & 3.091 & 3062943 & 32.4 & 7180368 & 41.5 & 7940002 & 40.9 & 38.3 \\
\hline Styrene & 4.076 & 2490113 & 26.4 & 5217575 & 30.2 & 5885985 & 30.3 & 28.9 \\
\hline Benzaldehyde & 4.689 & 1317977 & 13.9 & 2695383 & 15.6 & 3012354 & 15.5 & 15.0 \\
\hline Aniline & 4.789 & 137722 & 1.5 & 304021 & 1.8 & & & \\
\hline Benzonitrile & 4.875 & & & & & 225151 & 1.2 & \\
\hline Phenylacetaldehyde & 5.427 & 389348 & 4.1 & 838200 & 4.8 & 898867 & 4.6 & 4.5 \\
\hline Acetylbenzoyl & 5.729 & 99239 & 1.1 & 263501 & 1.5 & 305404 & 1.6 & 1.4 \\
\hline Phthalic anhydride & 8.109 & & & 69247 & 0.4 & 80293 & 0.4 & \\
\hline
\end{tabular}




\begin{tabular}{|c|c|c|c|c|c|c|c|c|}
\hline Propionanilide & 9.308 & 9448930 & 100 & 16789818 & 97.1 & 18195805 & 93.6 & 96.9 \\
\hline N-(2-phenylethyl)-formamide & 9.601 & & & & & 63208 & 0.3 & \\
\hline Norfentanyl & 13.499 & & & & & 95481 & 0.5 & \\
\hline 6-MAM & 17.491 & 9730 & 0.1 & 252186 & 1.5 & 275057 & 1.4 & 1.0 \\
\hline Heroin & 18.358 & 693618 & 7.3 & 3584401 & 20.7 & 4092342 & 21.1 & 16.4 \\
\hline Fentanyl & 19.263 & 4436447 & 47.0 & 17283755 & 100 & 19432079 & 100 & 82.3 \\
\hline
\end{tabular}

\begin{tabular}{|c|c|c|c|c|c|c|c|c|}
\hline \multirow{2}{*}{$\begin{array}{l}400^{\circ} \mathrm{C} \\
\text { Compound }\end{array}$} & \multirow[b]{2}{*}{ RT (min) } & \multicolumn{2}{|c|}{ Trial \#1 } & \multicolumn{2}{|c|}{ Trial \#2 } & \multicolumn{2}{|c|}{ Trial \#3 } & \multirow{2}{*}{$\begin{array}{l}\text { Average } \\
\text { \% Area }\end{array}$} \\
\hline & & Area & $\%$ Area & Area & $\%$ Area & Area & $\%$ Area & \\
\hline Pyridine & 3.093 & 5500189 & 38.6 & 8671796 & 51.9 & 6984427 & 39.8 & 43.4 \\
\hline Styrene & 4.078 & 4839220 & 33.9 & 6011796 & 36.0 & 4182648 & 23.8 & 31.3 \\
\hline Benzaldehyde & 4.690 & 2473203 & 17.3 & 3274332 & 19.6 & 2733848 & 15.6 & 17.5 \\
\hline Benzonitrile & 4.879 & & & 215480 & 1.3 & & & \\
\hline Phenylacetaldehyde & 5.428 & 597690 & 4.2 & 776247 & 4.6 & 794230 & 4.5 & 4.5 \\
\hline Acetylbenzoyl & 5.729 & 150940 & 1.1 & 267496 & 1.6 & 279152 & 1.6 & 1.4 \\
\hline Phthalic anhydride & 8.110 & & & 74009 & 0.4 & 73374 & 0.4 & \\
\hline Propionanilide & 9.305 & 14266149 & 100 & 16701184 & 100 & 15899473 & 90.7 & 96.9 \\
\hline Norfentanyl & 13.496 & 85155 & 0.6 & 59458 & 0.4 & 78561 & 0.4 & 0.5 \\
\hline 6-MAM & 17.489 & 9476 & 0.1 & 131203 & 0.8 & 208156 & 1.2 & 0.7 \\
\hline Heroin & 18.358 & 553879 & 3.9 & 2672195 & 16.0 & 4733121 & 27.0 & 15.6 \\
\hline Fentanyl & 19.260 & 3840375 & 26.9 & 6433219 & 38.5 & 17538159 & 100 & 55.1 \\
\hline $450{ }^{\circ} \mathrm{C}$ & & Trie & & Tri & & Tria & & Average \\
\hline Compound & RT (min) & Area & \% Area & Area & \% Area & Area & \% Area & \% Area \\
\hline Pyridine & 3.083 & 5007970 & 38.3 & 10501543 & 23.8 & 2463071 & 100 & 54.0 \\
\hline Styrene & 4.084 & 4169439 & 31.9 & 7751148 & 17.6 & 1434261 & 58.2 & 35.9 \\
\hline Benzaldehyde & 4.702 & 2152395 & 16.5 & 3486491 & 7.9 & 876852 & 35.6 & 20.0 \\
\hline Aniline & 4.807 & & & & & 140136 & 5.7 & \\
\hline Phenylacetaldehyde & 5.444 & 504240 & 3.9 & 1289766 & 2.9 & 287314 & 11.7 & 6.1 \\
\hline
\end{tabular}




\begin{tabular}{|c|c|c|c|c|c|c|c|c|}
\hline Acetylbenzoyl & 5.777 & 136821 & 1.0 & & & & & \\
\hline Monoethyl ester phthalic acid & 8.144 & & & 118386 & 0.3 & & & \\
\hline Propionanilide & 9.322 & 13070145 & 100 & 9898687 & 22.5 & 2207919 & 89.6 & 70.7 \\
\hline Norfentanyl & 13.520 & & & 190647 & 0.4 & 22319 & 0.9 & \\
\hline 6-MAM & 17.518 & 30395 & 0.2 & 3973140 & 9.0 & 150384 & 6.1 & 5.1 \\
\hline Heroin & 18.387 & 673423 & 5.2 & 14981797 & 34.0 & 559021 & 22.7 & 20.6 \\
\hline Fentanyl & 19.283 & 2966421 & 22.7 & 44091052 & 100 & 1686900 & 68.5 & 63.7 \\
\hline
\end{tabular}




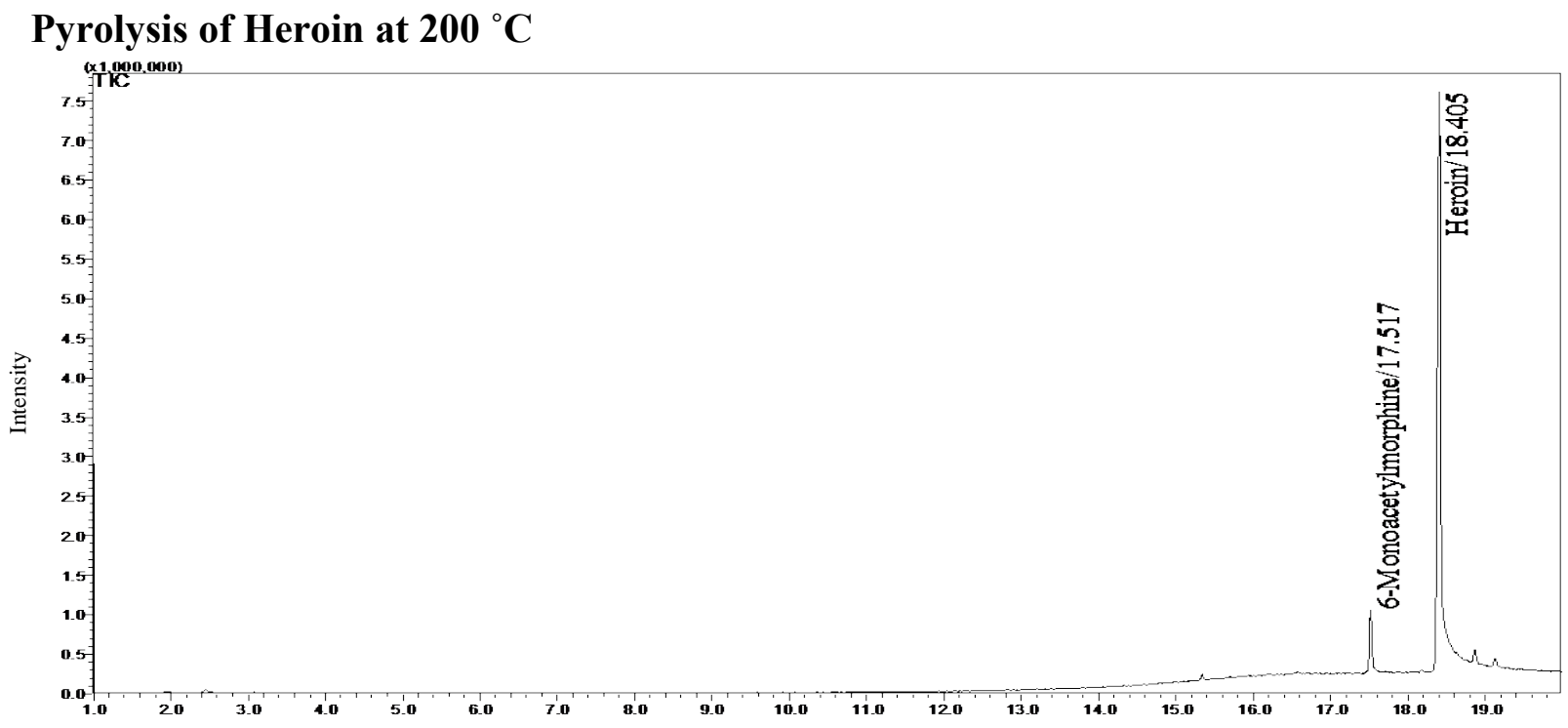

Pyrolysis of Heroin at $450{ }^{\circ} \mathrm{C}$

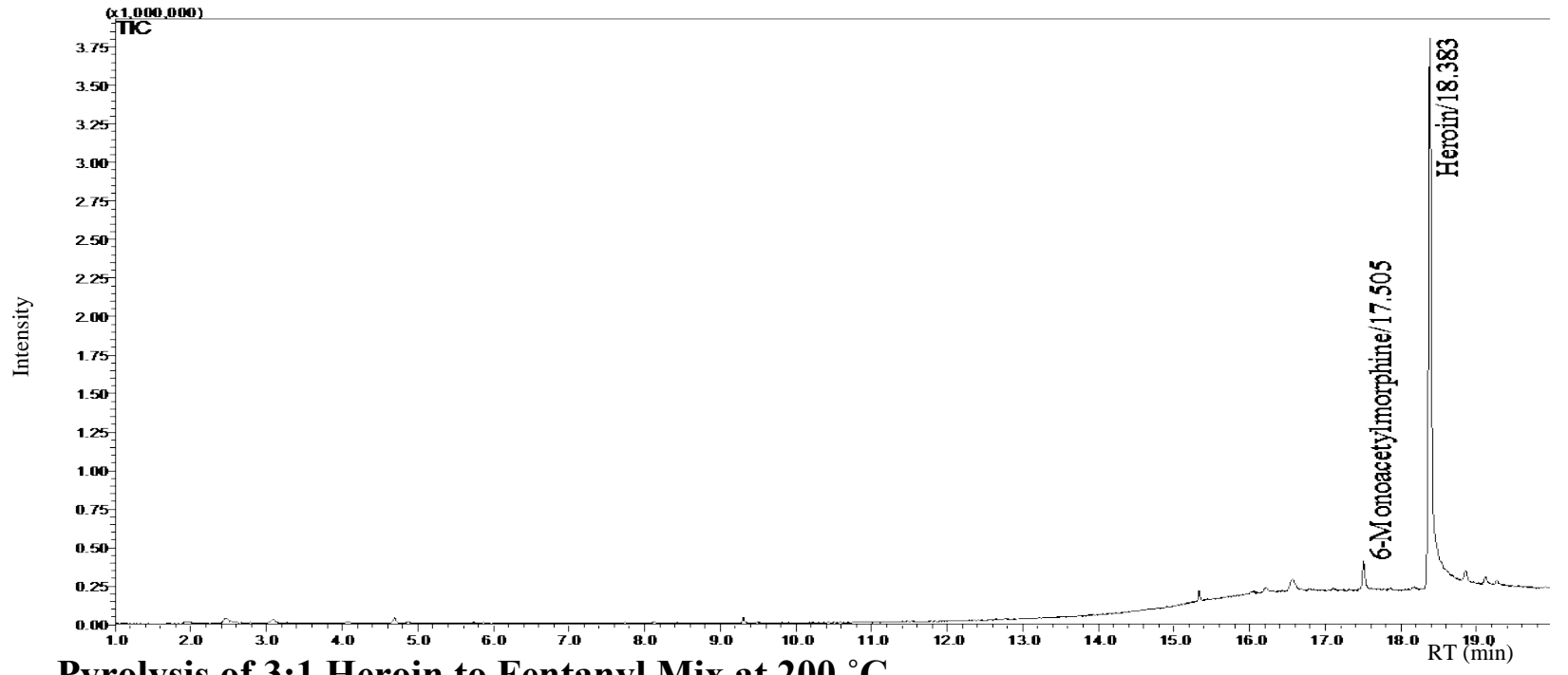

Pyrolysis of 3:1 Heroin to Fentanyl Mix at $200{ }^{\circ} \mathrm{C}$

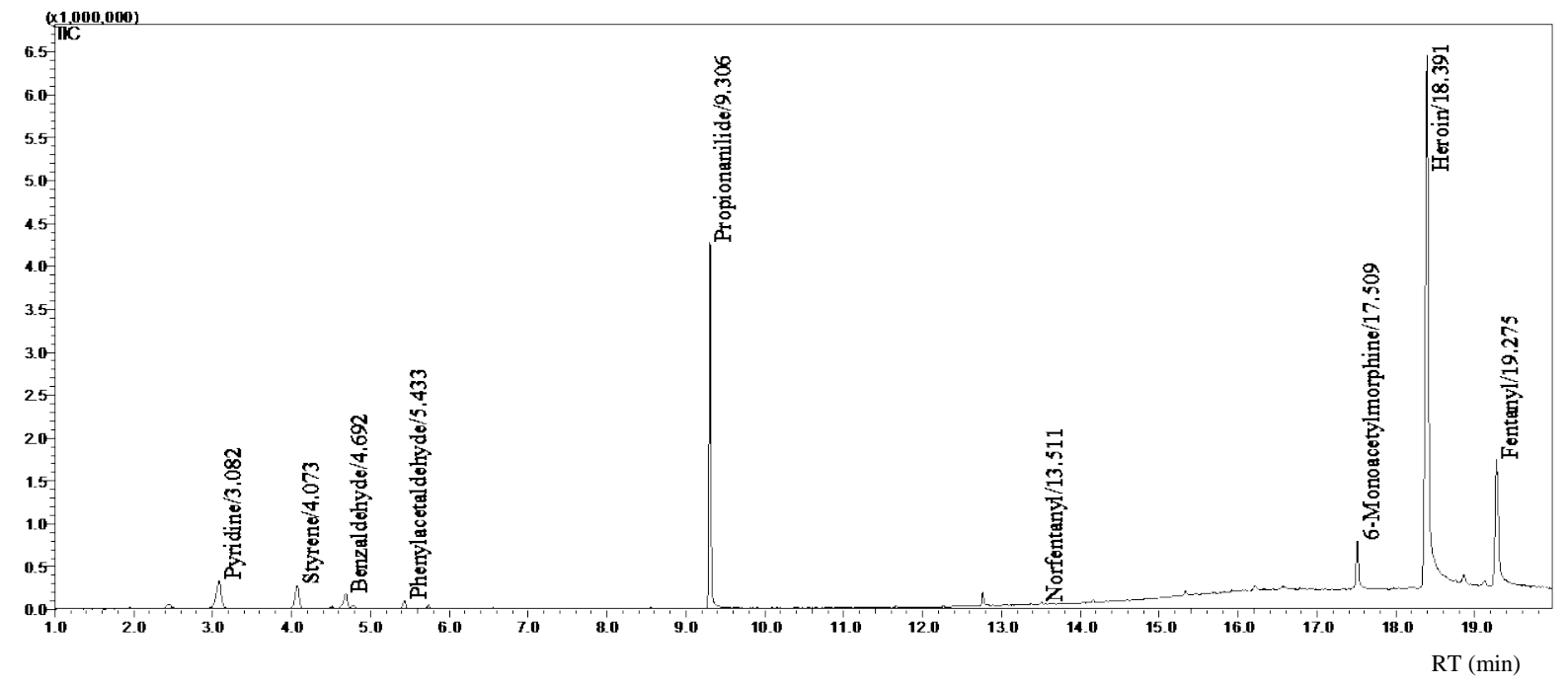




\section{Pyrolysis of 3:1 Heroin to Fentanyl Mix at $250{ }^{\circ} \mathrm{C}$}

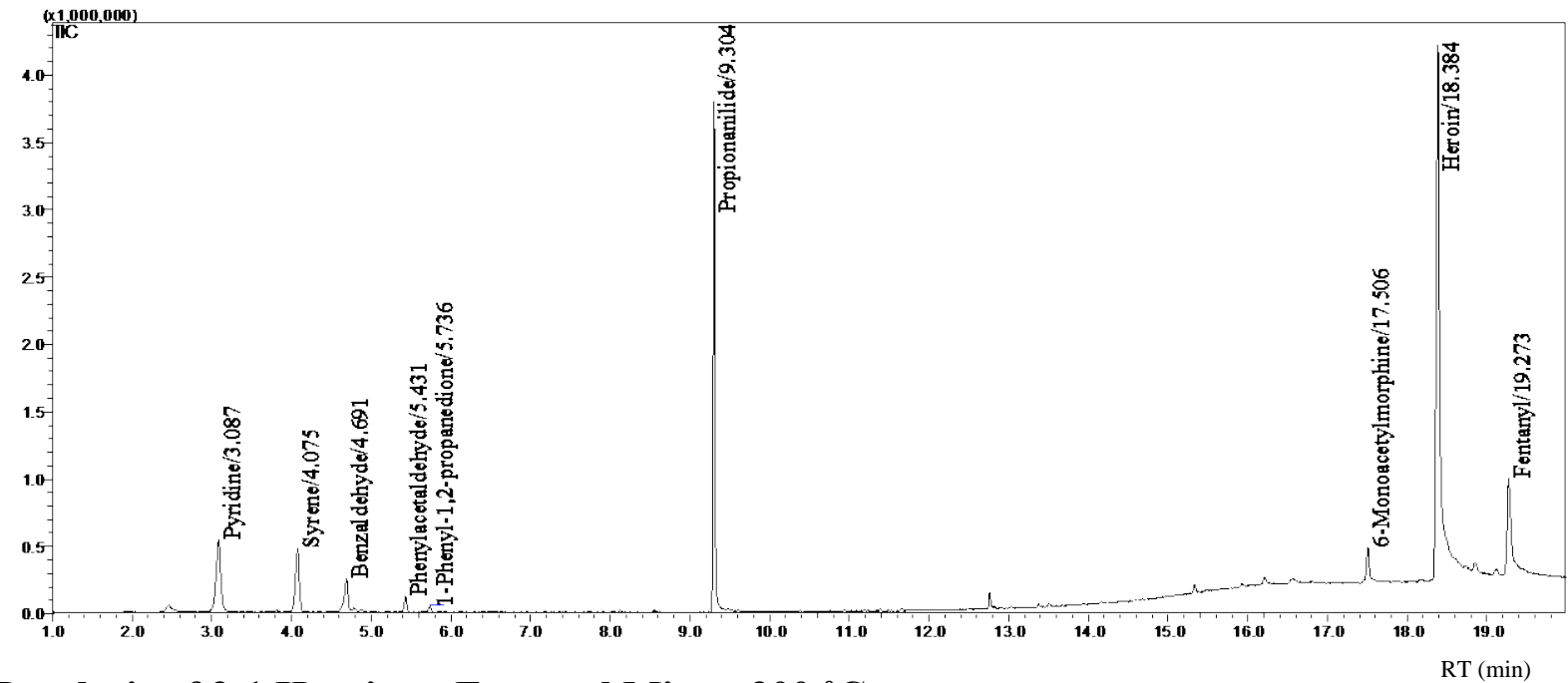

Pyrolysis of 3:1 Heroin to Fentanyl Mix at $300{ }^{\circ} \mathrm{C}$

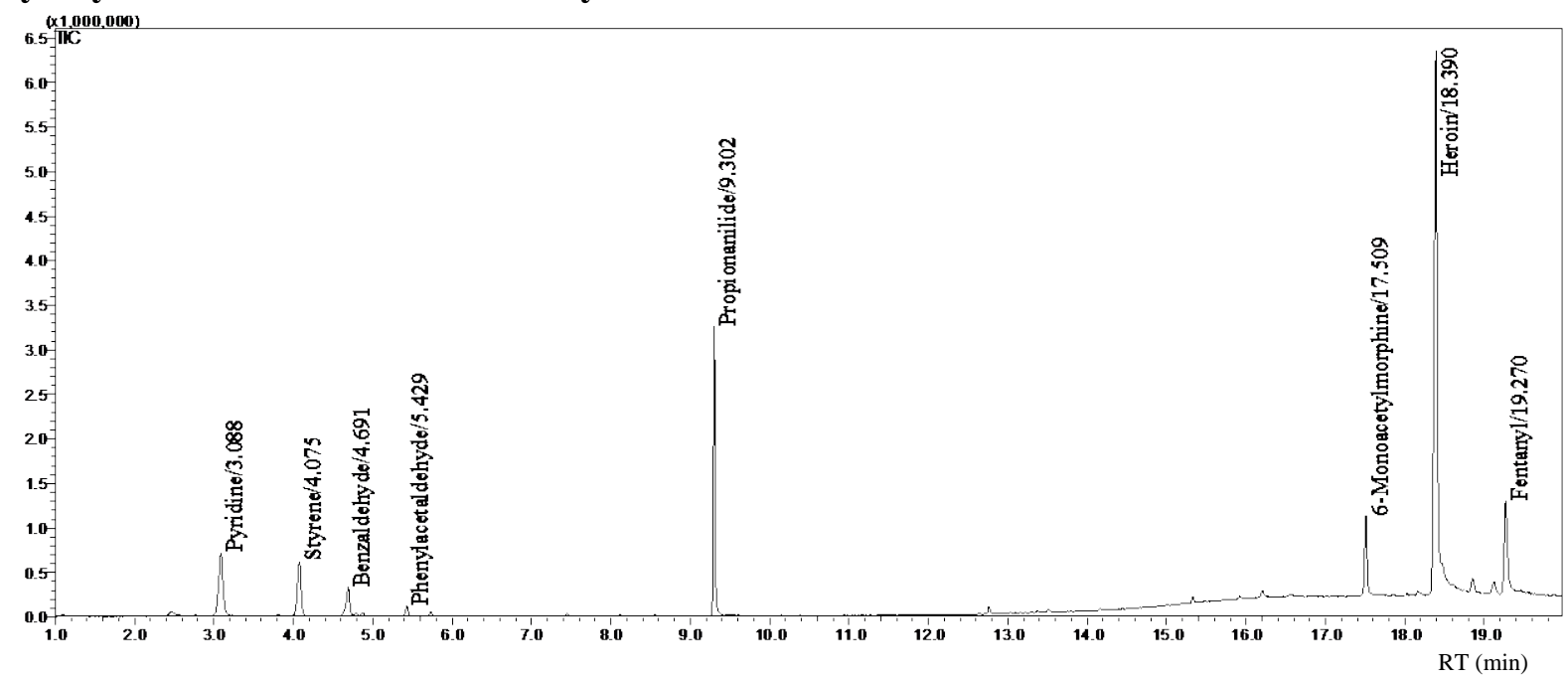

\section{Pyrolysis of 3:1 Heroin to Fentanyl Mix at $350{ }^{\circ} \mathrm{C}$}

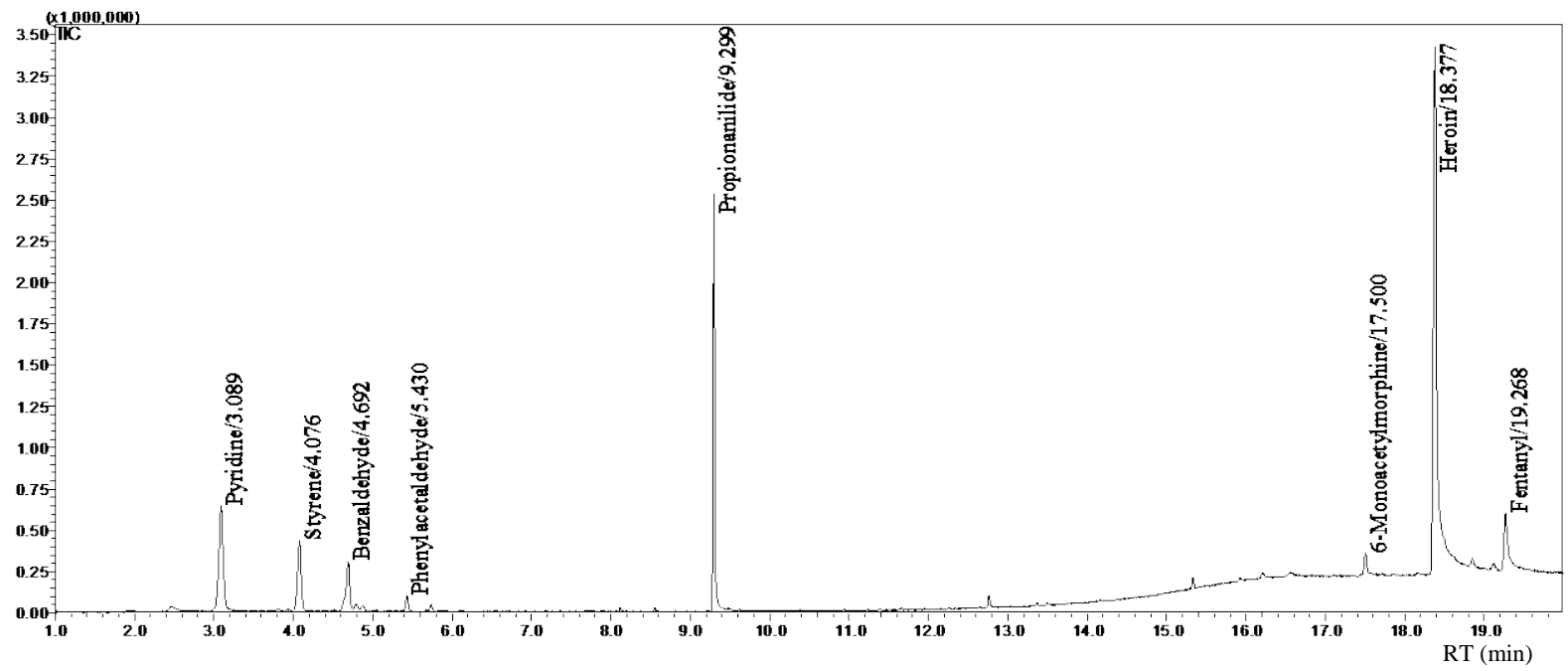




\section{Pyrolysis of 3:1 Heroin to Fentanyl Mix at $400{ }^{\circ} \mathrm{C}$}

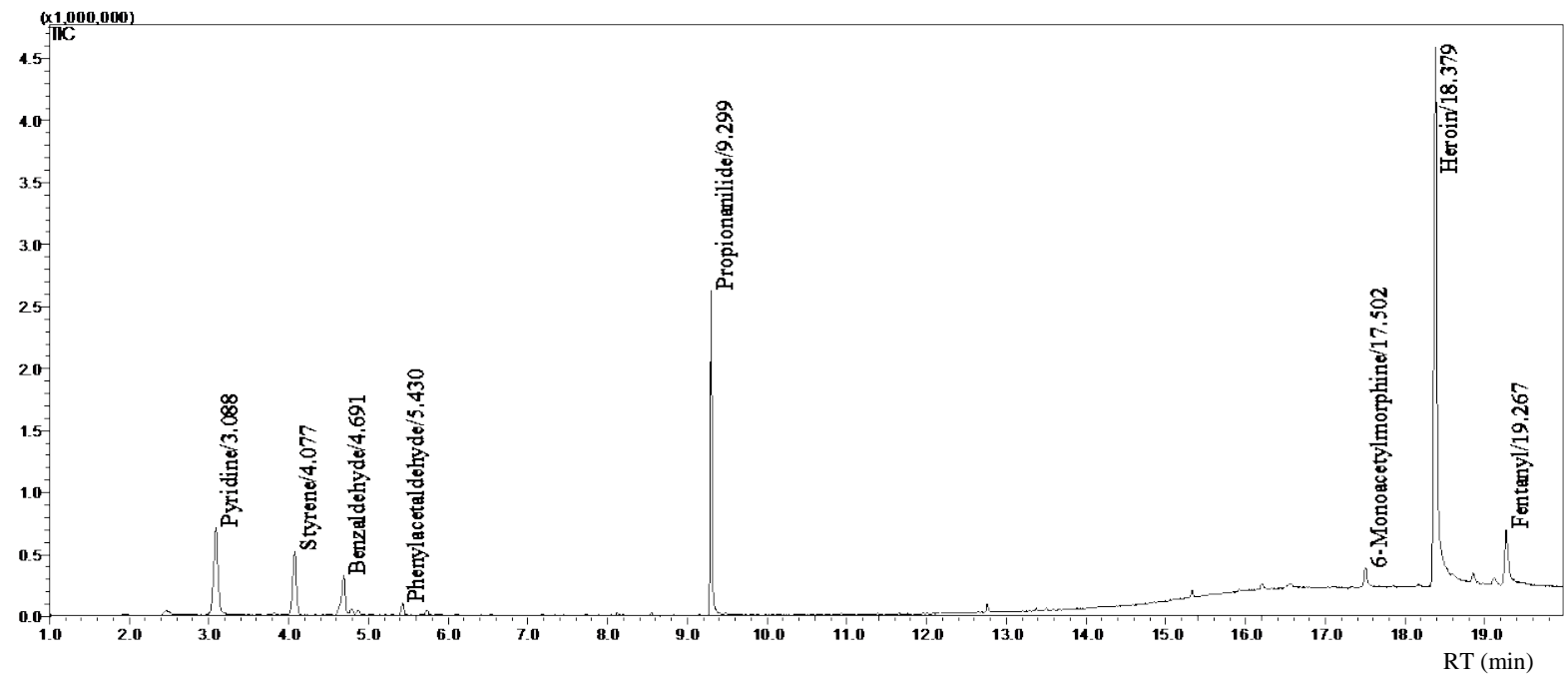

\section{Pyrolysis of 3:1 Heroin to Fentanyl Mix at $450{ }^{\circ} \mathrm{C}$}

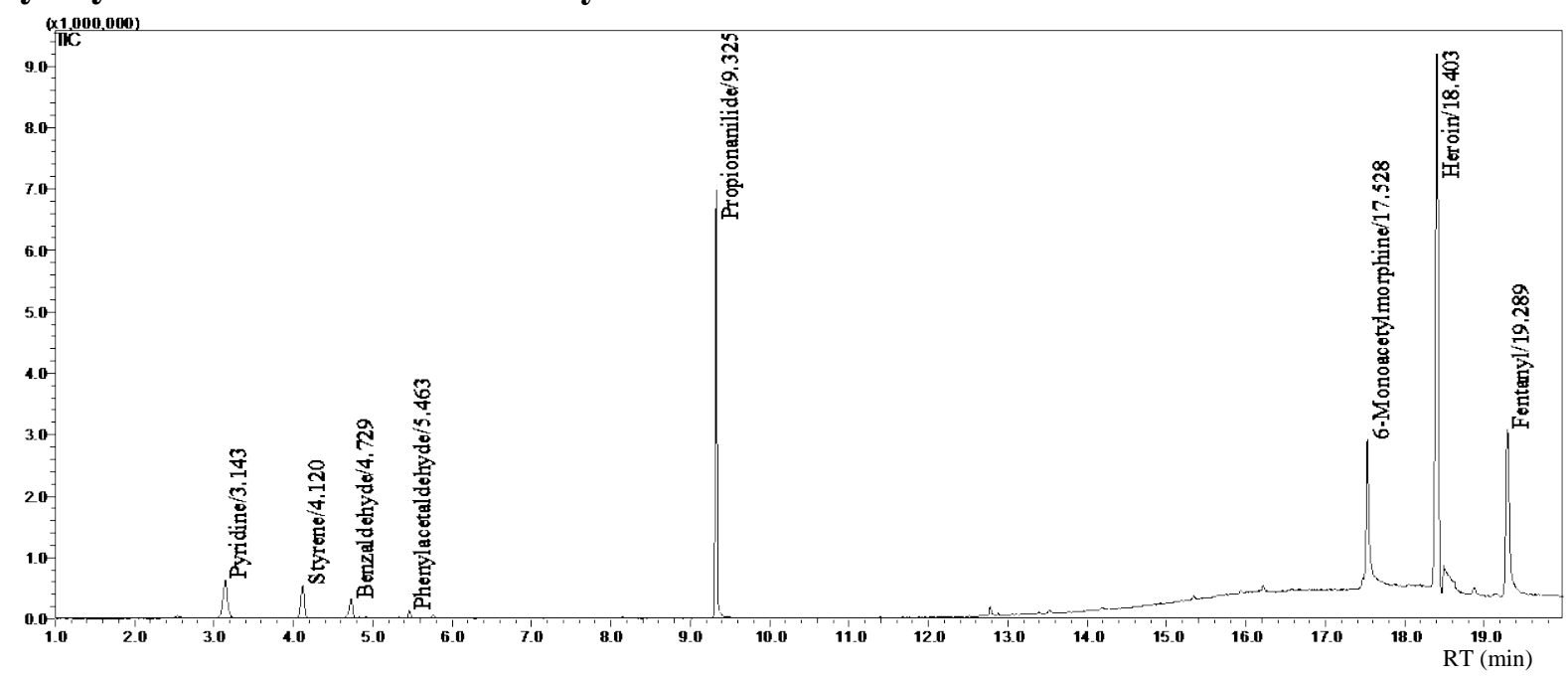

\section{Pyrolysis of 1:1 Heroin to Fentanyl Mix at $200{ }^{\circ} \mathrm{C}$}

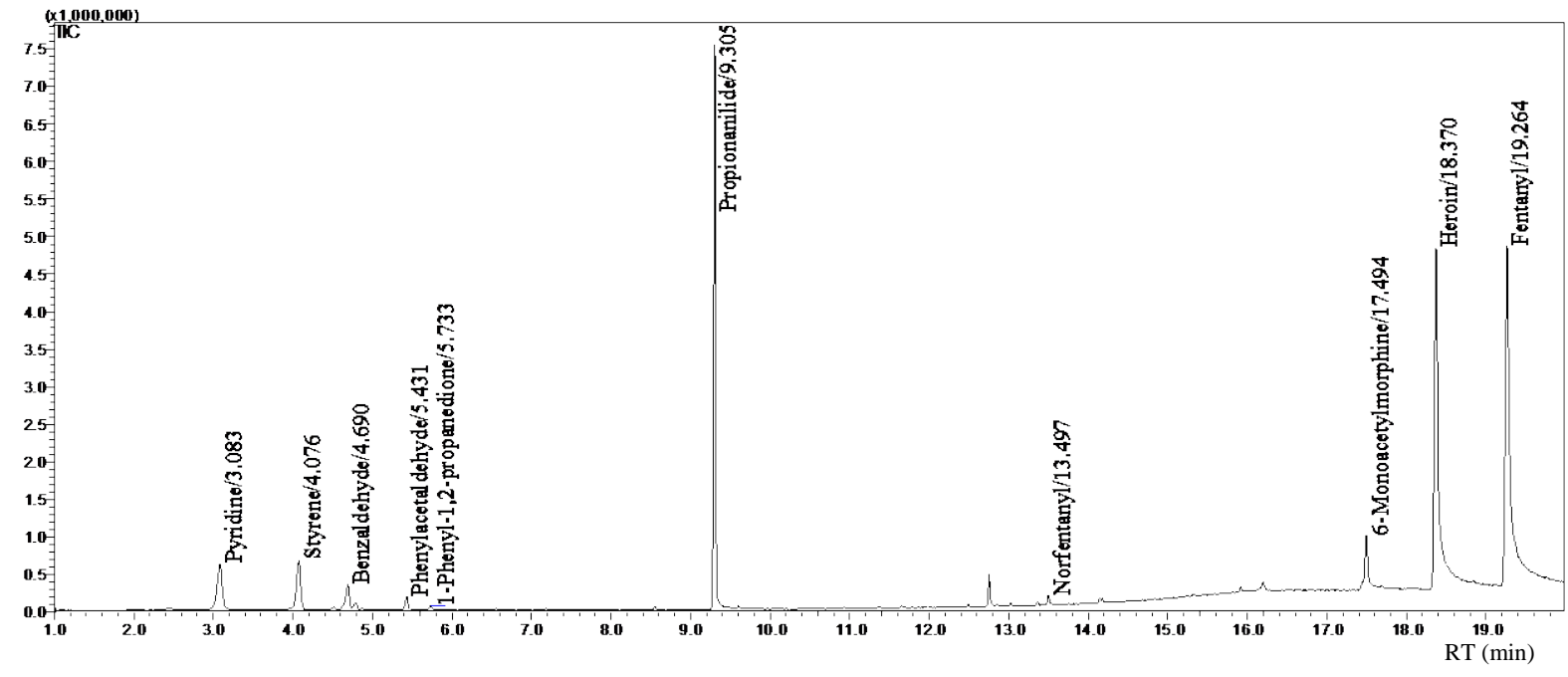




\section{Pyrolysis of 1:1 Heroin to Fentanyl Mix at $250{ }^{\circ} \mathrm{C}$}

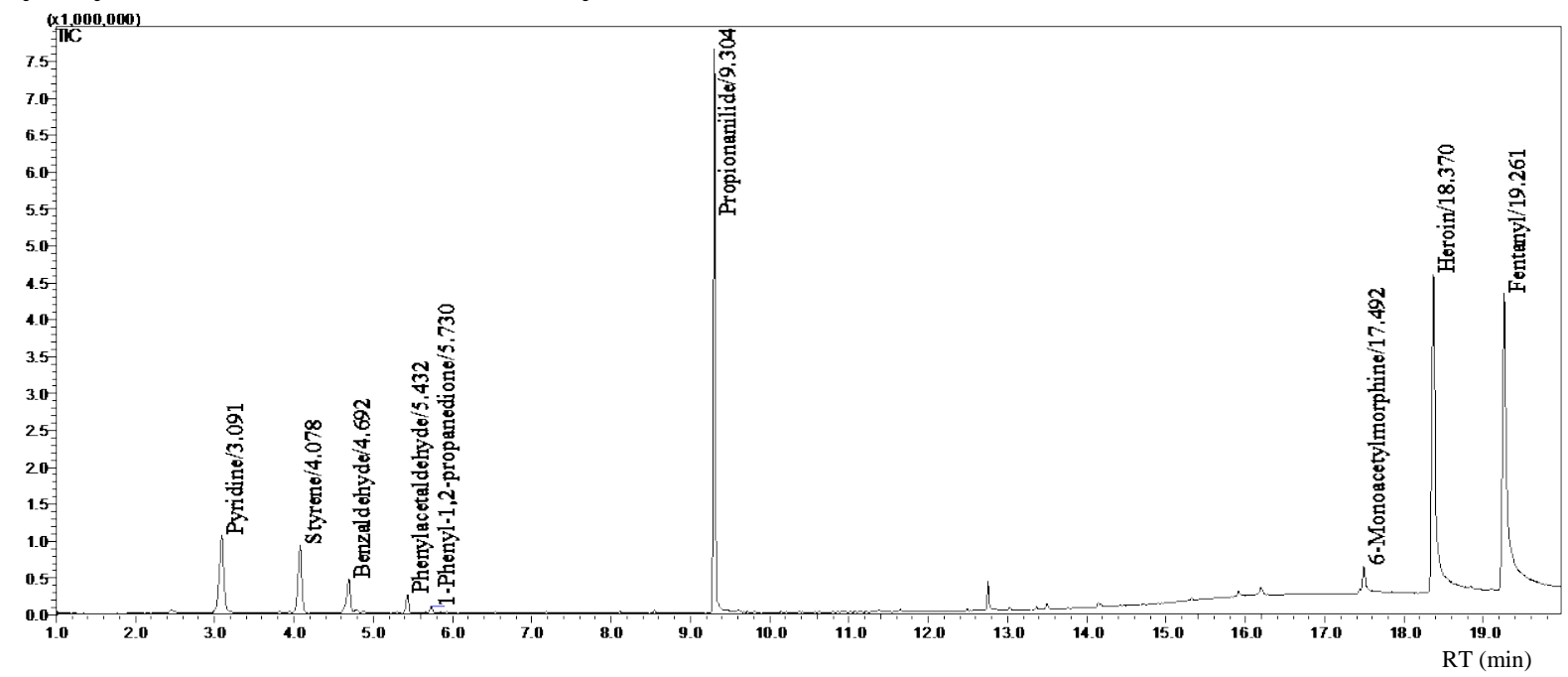

\section{Pyrolysis of 1:1 Heroin to Fentanyl Mix at $300{ }^{\circ} \mathrm{C}$}

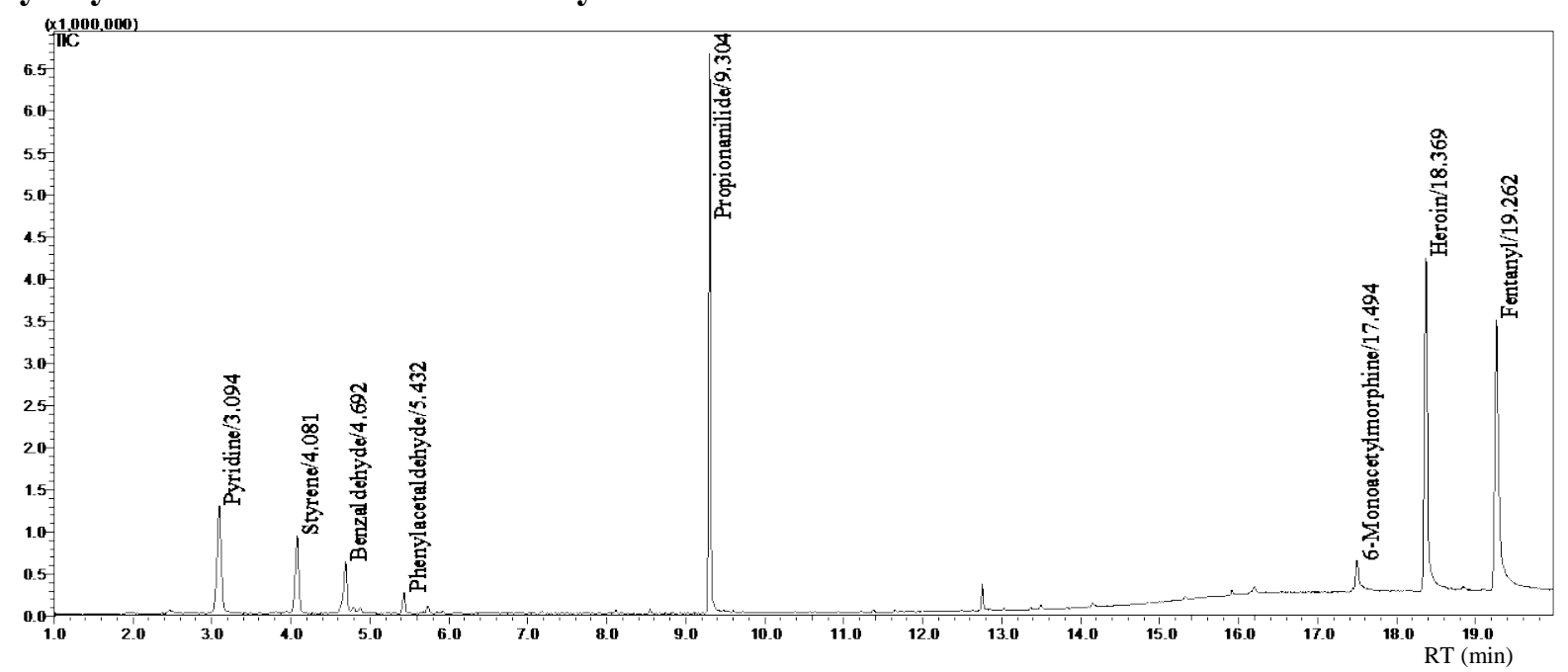

\section{Pyrolysis of 1:1 Heroin to Fentanyl Mix at $350{ }^{\circ} \mathrm{C}$}

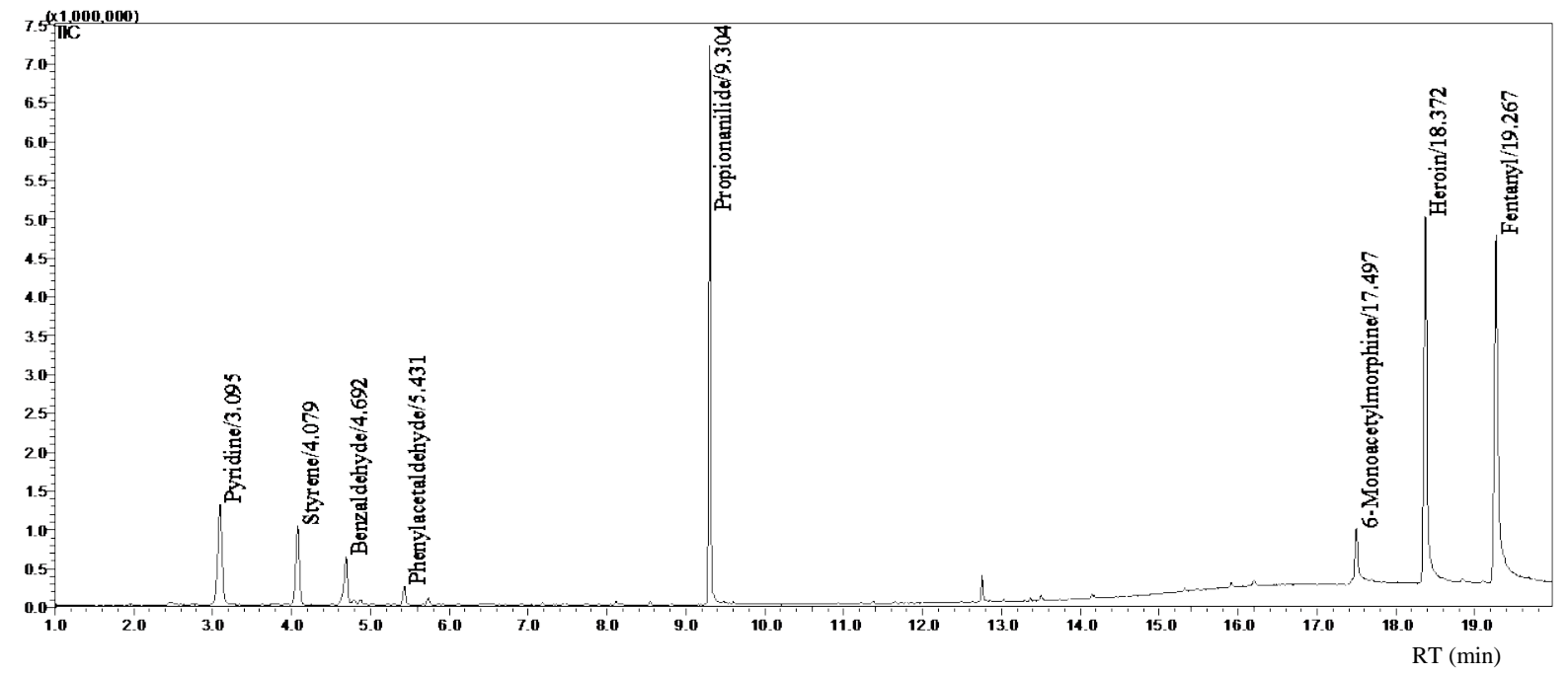




\section{Pyrolysis of 1:1 Heroin to Fentanyl Mix at $400{ }^{\circ} \mathrm{C}$}

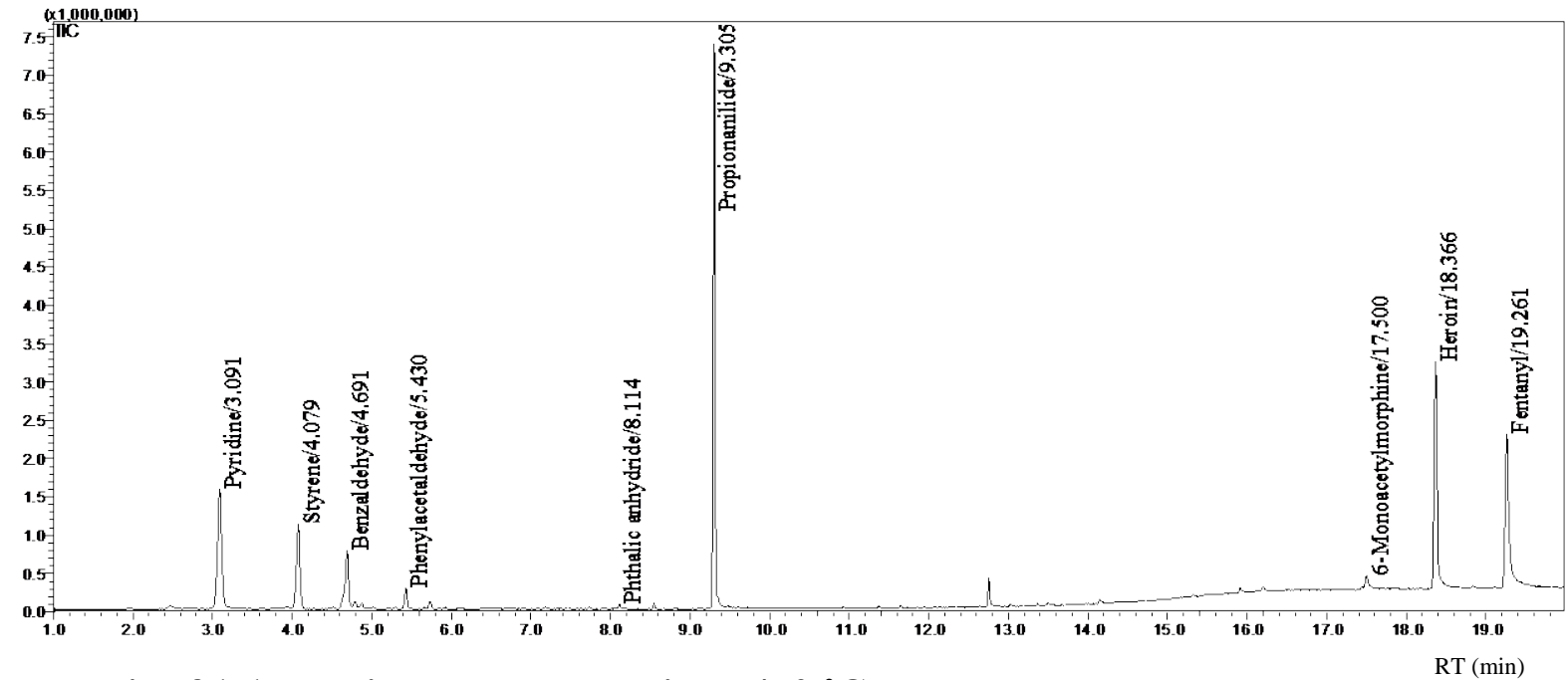

\section{Pyrolysis of 1:1 Heroin to Fentanyl Mix at $450{ }^{\circ} \mathrm{C}$}

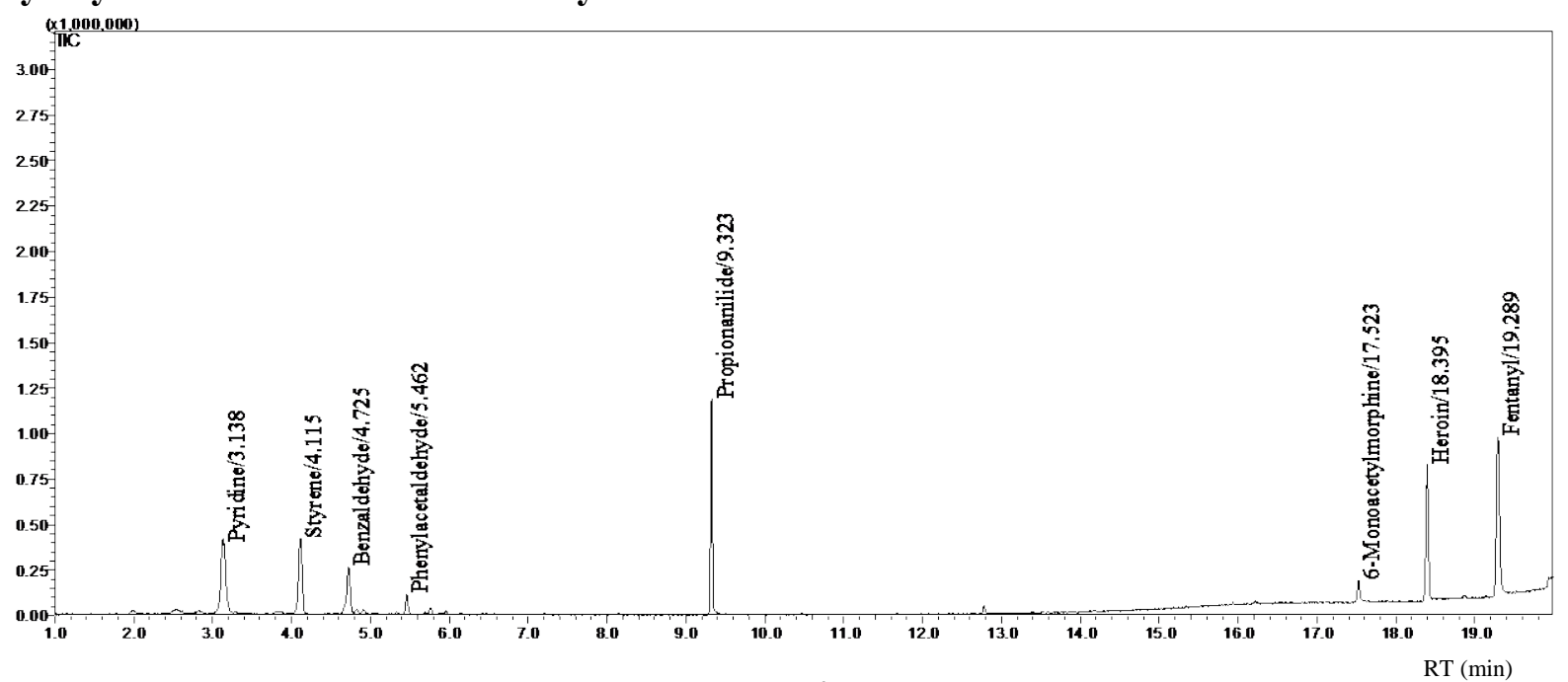

Pyrolysis of 1:3 Heroin to Fentanyl Mix at $200{ }^{\circ} \mathrm{C}$

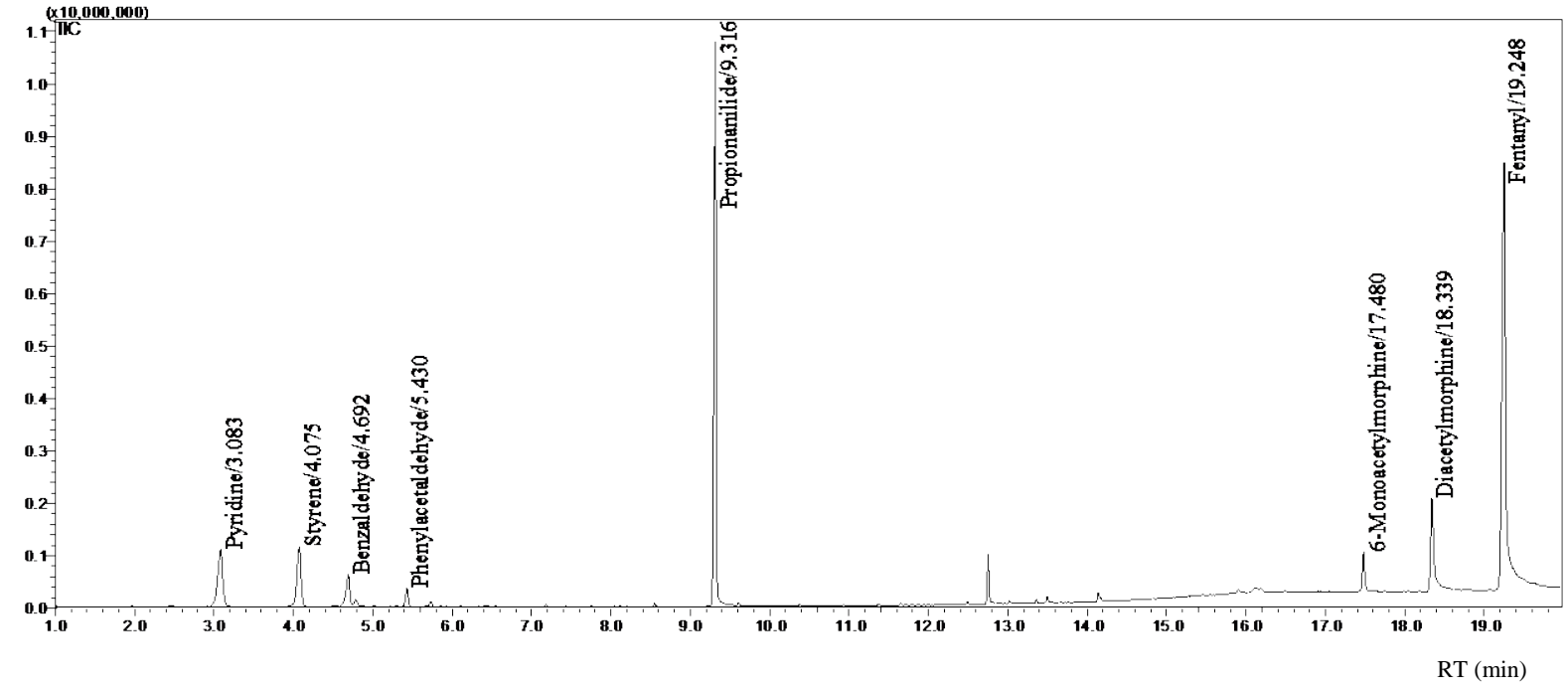




\section{Pyrolysis of 1:3 Heroin to Fentanyl Mix at $250{ }^{\circ} \mathrm{C}$}

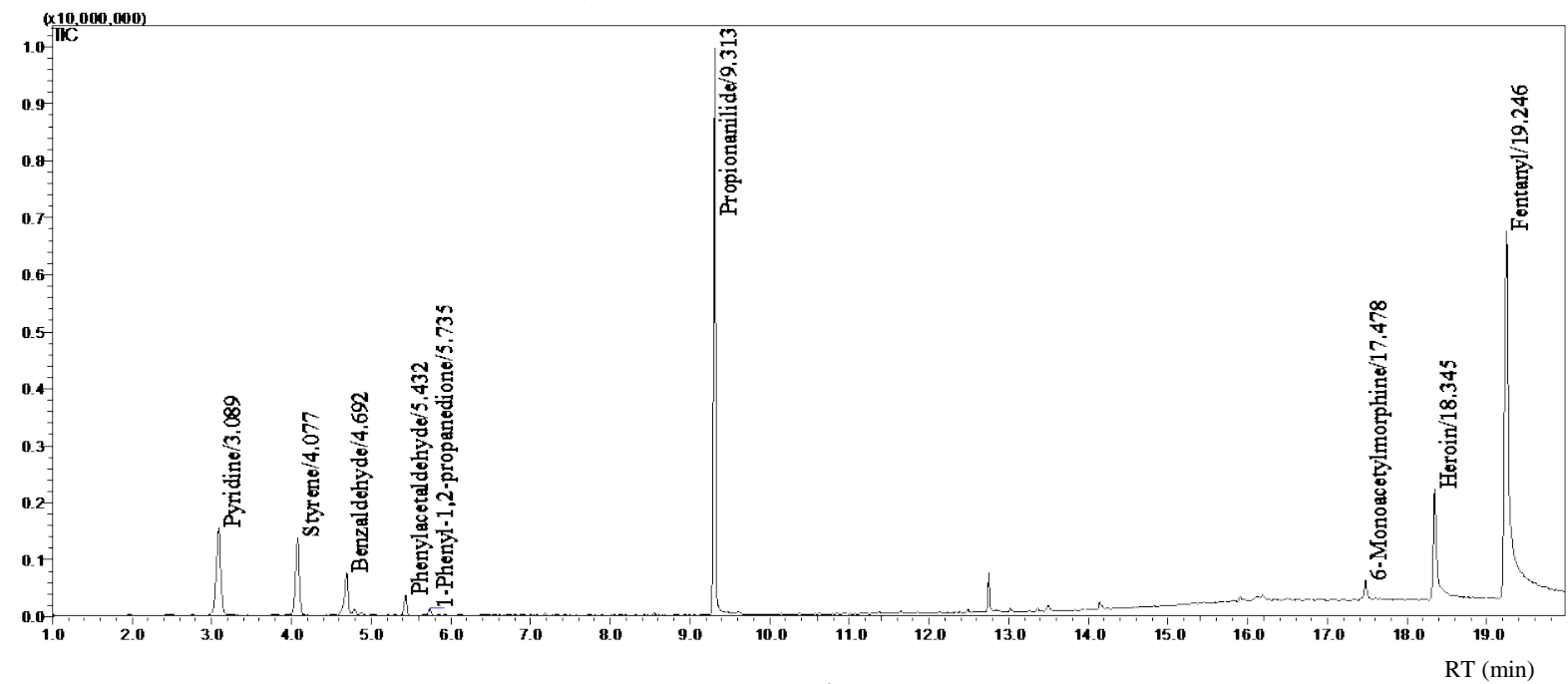

\section{Pyrolysis of 1:3 Heroin to Fentanyl Mix at $300{ }^{\circ} \mathrm{C}$}

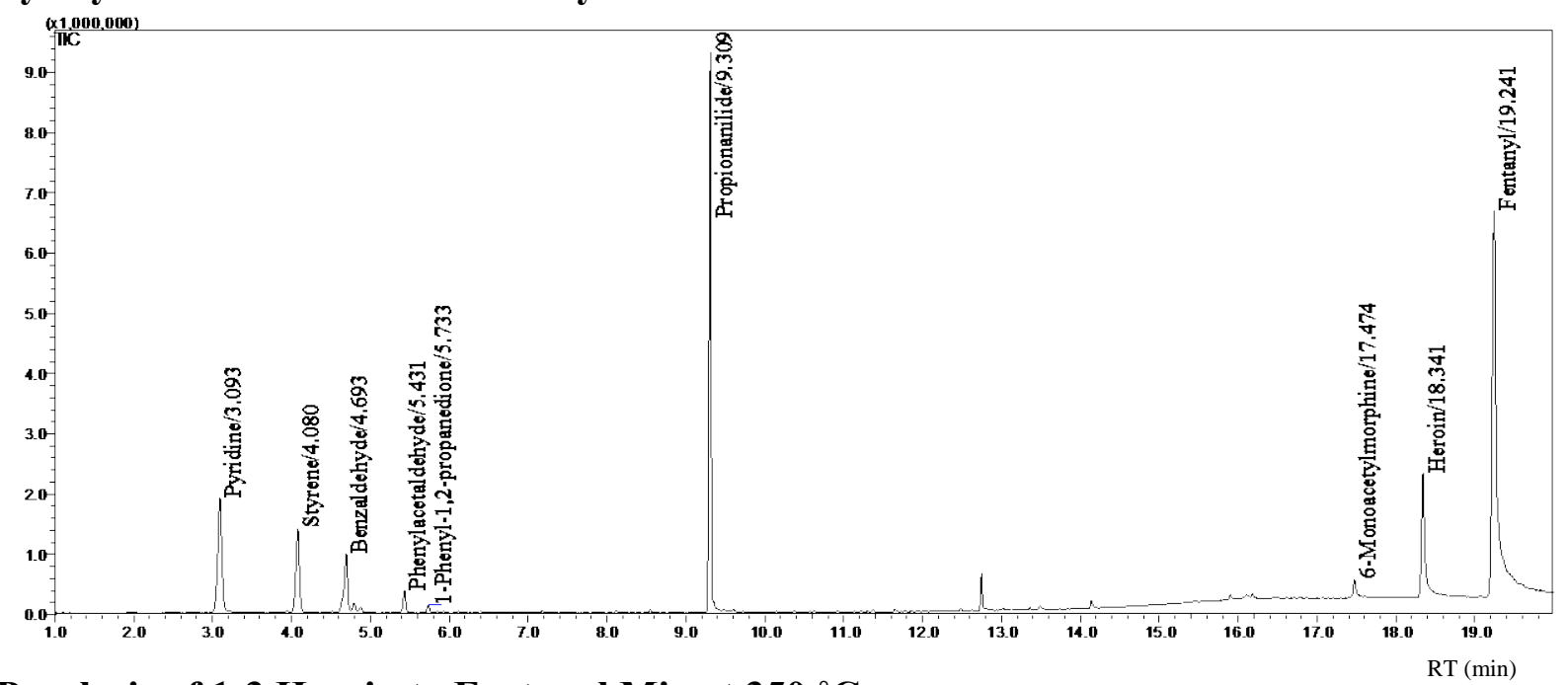

Pyrolysis of 1:3 Heroin to Fentanyl Mix at $350{ }^{\circ} \mathrm{C}$

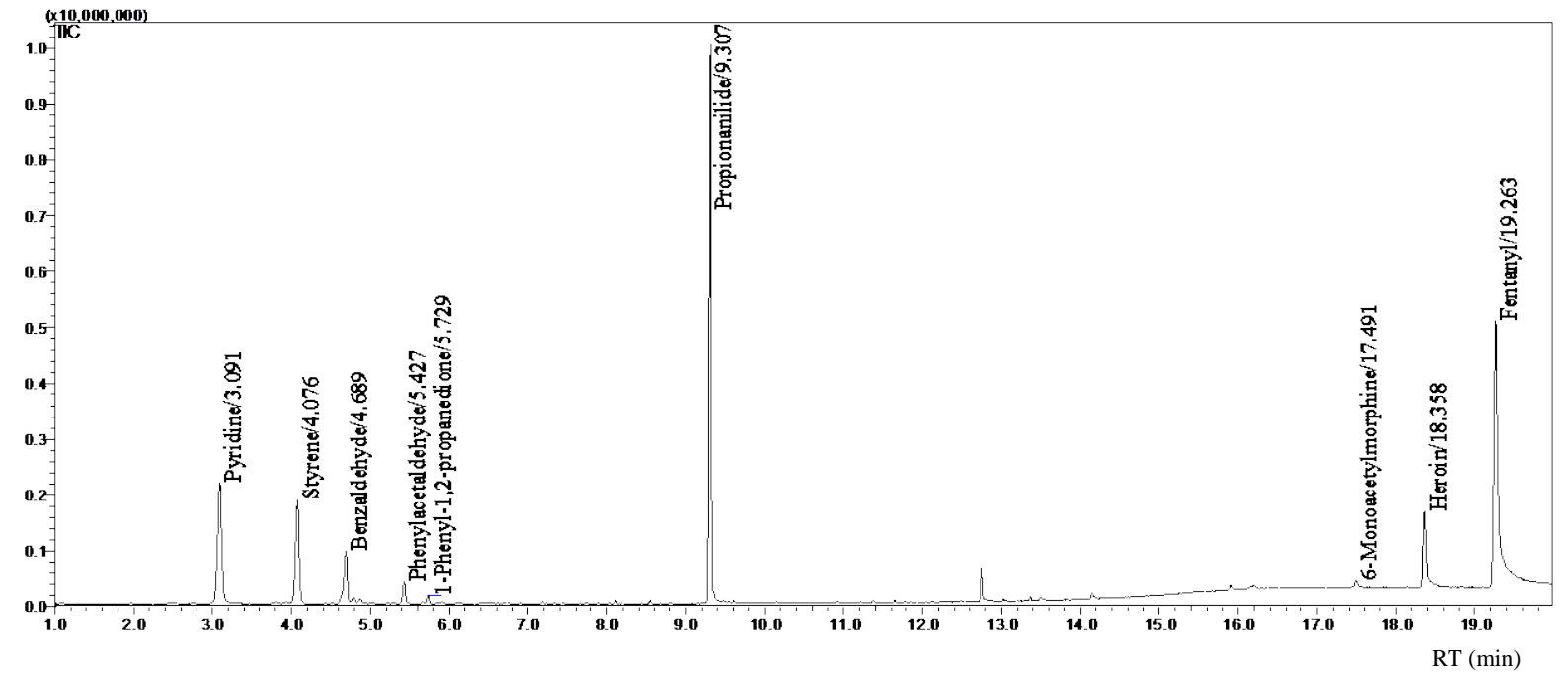




\section{Pyrolysis of 1:3 Heroin to Fentanyl Mix at $400{ }^{\circ} \mathrm{C}$}

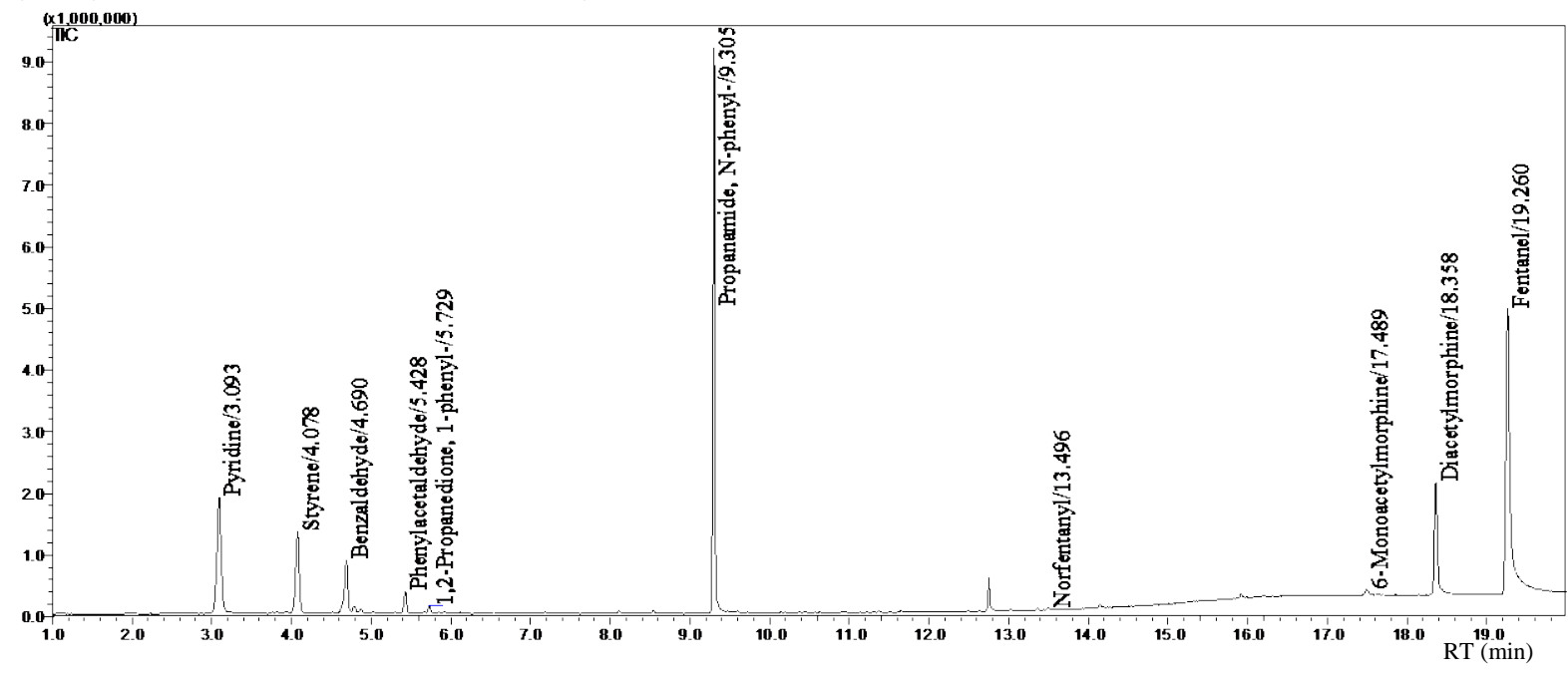

Pyrolysis of 1:3 Heroin to Fentanyl Mix at $450{ }^{\circ} \mathrm{C}$

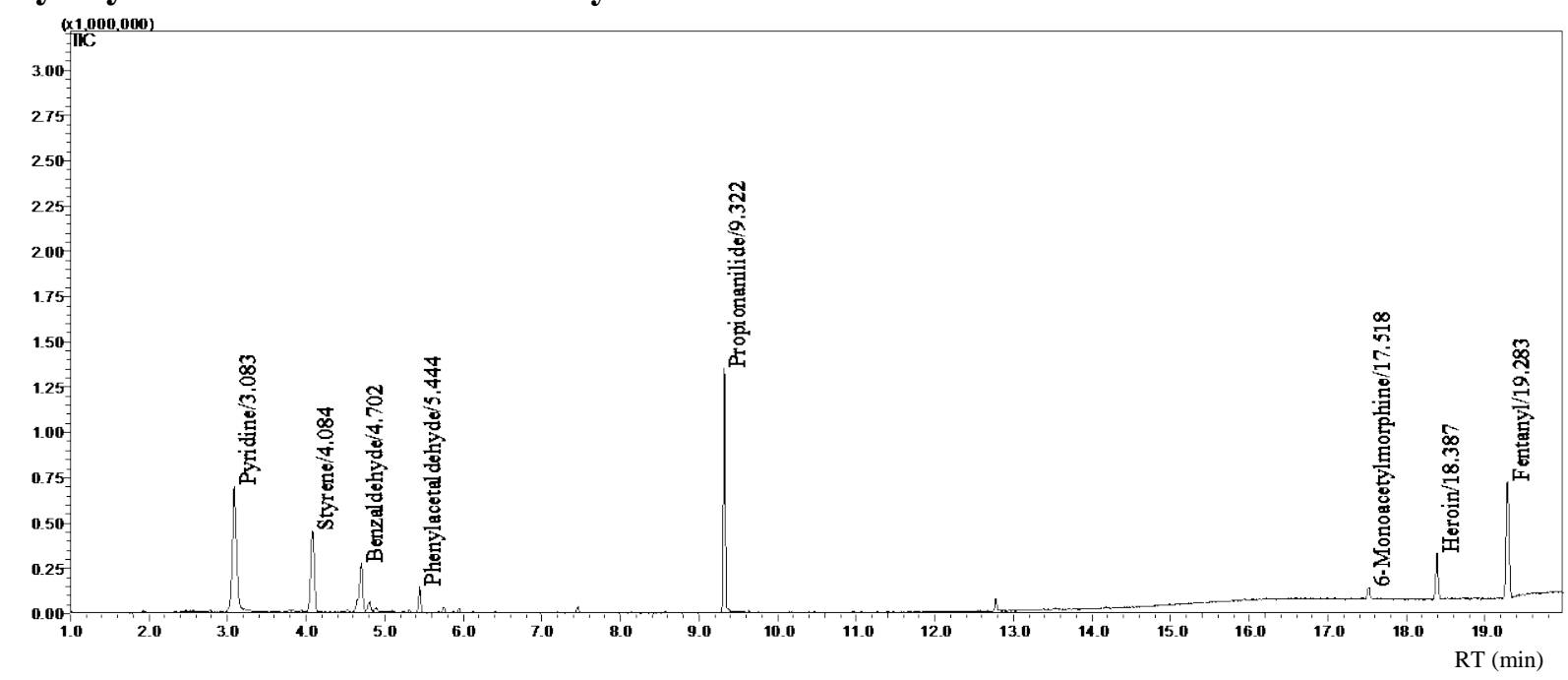




\section{References}

1. Drugs of Abuse. Joseph, D. E., Ed. Drug Enforcement Administration: U.S.

Department of Justice: 2005.

2. $\quad$ Commonly Abused Drugs. National Institute of Drug Abuse: 2010.

3. Fenton, J. J., Toxicology: A Case-Oriented Approach. CRC Press: Boca Raton, FL, 2001.

4. Shafizadeh, F., The Chemistry of Pyrolysis and Combustion. Adv. Chem. Ser. 1984, (207), 491-529.

5. Applied Pyrolysis Handbook. 2nd ed.; Taylor \& Francis Group: Boca Raton, FL, 2007; p 1-288.

6. Meng, Y.; Lichtman, A. H.; Bridgen, T.; Martin, B. R., Inhalation Studies with Drugs of Abuse. National Institute on Drug Abuse Research Monograph 1997, 173, 201224.

7. $\quad$ Klous, M. G.; Van den Brink, W.; Van Ree, J. M.; Beijnen, J. H., Development of Pharmaceutical Heroin Preparations for Medical Co-Prescription to Opioid Dependent Patients. Drug Alcohol Depend. 2005, 80 (3), 283-295.

8. Wesson, D. R., Current Patterns of Drug Abuse That Involve Smoking. National Institute on Drug Abuse Research Monograph 1990, 99, 5-11.

9. Inchiosa, M. A., Toxicokinetics: Deposition, Absorption, Distribution, and Excretion. In Inhalation Toxicology, 2nd ed.; Salem, H.; Katz, S. A., Eds. CRC Press: Boca Raton, FL, 2006.

10. Pharmacokinetics and Pharmacodynamics of Abused Drugs. CRC Press: Boca Raton, FL, 2008.

11. Menzel, D. B.; McClellan, R. O., Toxic Responses and the Respiratory System. In Casarett and Doull's Toxicology, 2nd ed.; Doull, J.; Klaassen, C. D.; Amdur, M. O., Eds. Macmillan Publishing Co.: New York, 1980; pp 246-274.

12. Guyton, A. C., Textbook of Medical Physiology. 11th ed.; Elsevier Saunders: Philadelphia, 2006.

13. Weibel, E. R., Morphometry of the Human Lung. Springer: Berlin, 1963.

14. von Hayek, H., The Human Lung. Hafner Pub. Co.: New York, NY, 1960.

15. Castell, J. V.; Donato, M. T.; Gomez-Lechon, M. J., Metabolism and Bioactivation of Toxicants in the Lung. The in Vitro Cellular Approach. Exp. Toxicol. Pathol. 2005, 57, 189-204.

16. Tan, T. P.; Algra, P. R.; Valk, J.; Wolters, E. C., Toxic Leukoencephalopathy after Inhalation of Poisoned Heroin - MR Findings. Am. J. Neuroradiol. 1994, 15 (1), 175178.

17. Wolters, E. C.; Stam, F. C.; Lousberg, R. J.; Vanwijngaarden, G. K.; Rengelink, H.; Schipper, M. E. I.; Verbeeten, B., Leukoencephalopathy after Inhaling Heroin Pyrosylate. Lancet 1982, 2 (8310), 1233-1237.

18. Wampler, T. P., Practical Applications of Analytical Pyrolysis. J. Anal. Appl. Pyrolysis 2004, 71 (1), 1-12.

19. Gayton-Ely, M. Detection and Determination of Degradation and Metabolic Products of Drugs of Abuse and Explosives. West Virginia University, Morgantown, 2009. 
20. Gayton-Ely, M.; Shakleya, D. M.; Bell, S. C., Application of a Pyroprobe to Simulate Smoking and Metabolic Degradation of Abused Drugs through Analytical Pyrolysis. J. Forensic Sci. 2007, 52 (2), 473-478.

21. Shakleya, D. M.; Kraner, J. C.; Clay, D. J.; Callery, P. S.; Bell, S. C., Validation of a Headspace Gc Method for the Analysis of a Pyrolytic Product of Methamphetamine in Urine. J. Anal. Toxicol. 2006, 30 (8), 559-562.

22. Shakleya, D. M.; Plumley, A. E.; Kraner, J. C.; Bell, S. C.; Callery, P. S., Trace Evidence of Trans-Phenyl Propene as a Marker of Smoked Methamphetamine. $J$. Anal. Toxicol. 2008, 32 (8), 705-708.

23. Baker, R. R.; Bishop, L. J., The Pyrolysis of Tobacco Ingredients. J. Anal. Appl. Pyrolysis 2004, 71 (1), 223-311.

24. Baker, R. R.; Bishop, L. J., The Pyrolysis of Non-Volatile Tobacco Ingredients Using a System That Simulates Cigarette Combustion Conditions. J. Anal. Appl. Pyrolysis 2005, 74 (1-2), 145-170.

25. Commonly Abused Prescription Drugs. National Institute of Drug Abuse: 2011

26. Pagliaro, L. A.; Pagliaro, A. M., Pagliaro's Comprehensive Guide to Drugs and Substances of Abuse. 2nd Edition ed.; American Pharmacists Association: Washington, DC, 2009.

27. Martin, M.; Hecker, J.; Clark, R.; Frye, J.; Jehle, D.; Lucid, E. J.; Harchelroad, F., China White Epidemic: An Eastern United States Emergency Department Experience. Ann. Emerg. Med. 1991, 20 (2), 158-164.

28. Clarke's Analysis of Drugs and Poisons in Pharmaceuticals, Body Fluids and Postmortem Material. Pharmaceutical Press: London, UK, 2004.

29. Thurlkill, R. L.; Cross, D. A.; Scholtz, J. M.; Pace, C. N., Pka of Fentanyl Varies with Temperature: Implications for Acid-Base Management During Extremes of Body Temperature. J. Cardiothorac. Vasc. Anesth. 2005, 19 (6), 759-762.

30. Salem, H.; Ballantyne, B.; Katz, S. A., Inhalation Toxicology of Riot Control Agents. In Inhalation Toxicology, 2nd Edition ed.; Salem, H.; Katz, S. A., Eds. CRC Press: Boca Raton, FL, 2006.

31. Smialek, J. E.; Levine, B.; Chin, L.; Wu, S. C.; Jenkins, A. J., A Fentanyl Epidemic in Maryland 1992. J. Forensic Sci. 1994, 39 (1), 159-164.

32. Kuhlman, J. J., Jr.; McCaulley, R.; Valouch, T. J.; Behonick, G. S., Fentanyl Use, Misuse, and Abuse: A Summary of 23 Postmortem Cases. J. Anal. Toxicol. 2003, 27 (7), 499-504.

33. Martin, T. L.; Woodall, K. L.; McLellan, B. A., Fentanyl-Related Deaths in Ontario, Canada: Toxicological Findings and Circumstances of Death in 112 Cases (20022004). J. Anal. Toxicol. 2006, 30 (8), 603-610.

34. Schumann, H.; Erickson, T.; Thompson, T. M.; Zautcke, J. L.; Denton, J. S., Fentanyl Epidemic in Chicago, Illinois and Surrounding Cook County. Clin. Toxicol. 2008, 46 (6), 501-506.

35. Thompson, J. G.; Baker, A. M.; Bracey, A. H.; Seningen, J.; Kloss, J. S.; Strobl, A. Q.; Apple, F. S., Fentanyl Concentrations in 23 Postmortem Cases from the Hennepin County Medical Examiner's Office. J. Forensic Sci. 2007, 52 (4), 978-981.

36. Control of a Chemical Precursor Used in the Illicit Manufacture of Fentanyl as a List I Chemical. Fed. Regist. 2007, 72 (77), 20039-20047. 
37. Hanks, G. W.; de Conno, F.; Cherny, N.; Hanna, M.; Kalso, E.; McQuay, H. J.; Mercadante, S.; Meynadier, J.; Poulain, P.; Ripamonti, C.; Radbruch, L.; Casas, J. R. I.; Sawe, J.; Twycross, R. G.; Ventafridda, V.; European Assoc Palliative, C., Morphine and Alternative Opioids in Cancer Pain: The Eapc Recommendations. Br. J. Cancer 2001, 84 (5), 587-593.

38. Kress, H. G.; Boss, H.; Delvin, T.; Lahu, G.; Lophaven, S.; Marx, M.; Skorjanec, S.; Wagner, T., Transdermal Fentanyl Matrix Patches Matrifen (R) and Durogesic (R) Dtrans (R) Are Bioequivalent. Eur. J. Pharm. Biopharm. 2010, 75 (2), 225-231.

39. Clarke's Analysis of Drugs and Poisons in Pharmaceuticals, Body Fluids and Postmortem Material. 3rd ed.; Pharmaceutical Press: London, UK, 2004.

40. Arvanitis, M. L.; Satonik, R. C., Transdermal Fentanyl Abuse and Misuse. Am. J. Emerg. Med. 2002, 20 (Journal Article), 58-59.

41. Marquardt, K. A.; Tharratt, R. S., Inhalation Abuse of Fentanyl Patch. Clin. Toxicol. 1994, 33 (1), 75-78.

42. Woodall, K. L.; Martin, T. L.; McLellan, B. A., Oral Abuse of Fentanyl Patches (Duragesic): Seven Case Reports. J. Forensic Sci. 2008, 53 (1), 222-225.

43. Tharp, A. M.; Winecker, R. E.; Winston, D. C., Fatal Intravenous Fentanyl Abuse: Four Cases Involving Extraction of Fentanyl from Transdermal Patches. Am. J. Forensic Med. Pathol. 2004, 25 (2), 178-181.

44. Arvanitis, M. L.; Satonik, R. C., Transdermal Fentanyl Abuse and Misuse. Am. J. Emerg. Med. 2002, 20, 58-9.

45. Coon, T. P.; Miller, M.; Kaylor, D.; Jones-Spangle, K., Rectal Insertion of Fentanyl Patches: A New Route of Toxicity. Ann. Emerg. Med. 2005, 46 (5), 473.

46. Labroo, R. B.; Paine, M. F.; Thummel, K. E.; Kharasch, E. D., Fentanyl Metabolism by Human Hepatic and Intestinal Cytochrome P450 3A4: Implications for Interindividual Variability in Disposition, Efficacy, and Drug Interactions. Drug Metab. Dispos. 1997, 25 (9), 1072-1080.

47. Silverstein, J. H.; Rieders, M. F.; McMullin, M.; Schulman, S.; Zahl, K., An Analysis of the Duration of Fentanyl and Its Metabolites in Urine and Saliva. Anesth. Analg. 1993, 76 (3), 618-621.

48. Collett, B. J., Opioid Tolerance: The Clinical Perspective. Br. J. Anaesth. 1998, 81 (1), 58-68.

49. Kamendulis, L. M.; Brzezinski, M. R.; Pindel, E. V.; Bosron, W. F.; Dean, R. A., Metabolism of Cocaine and Heroin Is Catalyzed by the Same Human Liver Carboxylesterases. J. Pharmacol. Exp. Ther. 1996, 279 (2), 713-717.

50. Lockridge, O.; Mottershawjackson, N.; Eckerson, H. W.; Ladu, B. N., Hydrolysis of Diacetylmorphine (Heroin) by Human-Serum Cholinesterase. J. Pharmacol. Exp. Ther. 1980, 215 (1), 1-8.

51. Salmon, A. Y.; Goren, Z.; Avissar, Y.; Soreq, H., Human Erythrocyte but Not Brain Acetylcholinesterase Hydrolyses Heroin to Morphine. Clin. Exp. Pharmacol. Physiol. 1999, 26 (8), 596-600.

52. Moffat, A. C.; Osselton, M. D.; Widdop, B.; Watts, J., Clarke's Analysis of Drugs and Poisons : In Pharmaceuticals, Body Fluids and Postmortem Material. Pharmaceutical Press: 2011; p 2609p.

53. Dancer, S. J.; McNair, D.; Finn, P.; Kolsto, A. B., Bacillus Cereus Cellulitis from Contaminated Heroin. J. Med. Microbiol. 2002, 51 (3), 278-281. 
54. McLachlan-Troup, N.; Taylor, G. W.; Trathen, B. C., Diamorphine Treatment for Opiate Dependence: Putative Markers of Concomitant Heroin Misuse. Addict. Biol. 2001, 6 (3), 223-231.

55. McLauchlin, J.; Mithani, V.; Bolton, F. J.; Nichols, G. L.; Bellis, M. A.; Syed, Q.; Thomson, R. P. M.; Ashton, J. R., An Investigation into the Microflora of Heroin. $J$. Med. Microbiol. 2002, 51 (11), 1001-1008.

56. Moustoukas, N. M.; Nichols, R. L.; Smith, J. W.; Garey, R. E.; Egan, R. R., Contaminated Stree Herion - Relationship to Clinical Infections. Arch. Surg. 1983, 118 (6), 746-749.

57. Cook, C. E., Pyrolytic Characteristics, Pharmacokinetics, and Bioavailability of Smoked Heroin, Cocaine, Phencyclidine, and Methamphetamine. In National Institute on Drug Abuse Research Monograph Series 115: Methamphetamine Abuse: Epidemiologic Issues and Implications, Miller, M. A.; Kozel, N. J., Eds. National Institute on Drug Abuse: Rockville, MD, 1991; Vol. 115.

58. Cook, C. E.; Brine, D. R., Pyrolysis Products of Heroin. J. Forensic Sci. 1985, 30 (1), 251-261.

59. Cook, C. E.; Jeffcoat, A. R., Pyrolytic Degradation of Heroin, Phencyclidine, and Cocaine: Identification of Products and Some Observations on Their Metaboism. In National Institute on Drug Abuse Research Monograph Series 99: Research Findings on Smoking of Abused Substances, Chiang, C. N.; Hawks, R. L., Eds. National Institute on Drug Abuse: Rockville, MD, 1990; Vol. 99, pp 97-120.

60. Lichtman, A. H.; Meng, Y.; Martin, B. R., Inhalation Exposure to Volatilized Opioids Produces Antinociception in Mice. J. Pharmacol. Exp. Ther. 1996, 279 (1), 69-76.

61. Huizer, H., Analytical Studies on Illicit Heroin. Pharm. Weekbl. 1989, 11 (5), 179180.

62. The Mysterious Heroin Pills for Smoking. Bull. Narc. 1953, 5 (2), 49-54.

63. Huizer, H.; Vanzuilen, K.; Svendsen, A. B., From Opium to Illicit Heroin. Pharm. Weekbl. 1987, 9 (4), 223-223.

64. Klous, M. G.; Lee, W. C.; Hillebrand, M. J. X.; van den Brink, W.; van Ree, J. M.; Beijnen, J. H., Analysis of Diacetylmorphine, Caffeine, and Degradation Products after Volatilization of Pharmaceutical Heroin for Inhalation. J. Anal. Toxicol. 2006, 30 (1), 6-13.

65. Klous, M. G.; Nuijen, B.; van den Brink, W.; van Ree, J. M.; Beijnen, J. H., Development and Manufacture of Diacetylmorphine/Caffeine Sachets for Inhalation Via 'Chasing the Dragon' by Heroin Addicts. Drug Dev. Ind. Pharm. 2004, 30 (7), 775-784.

66. Huizer, H., Analytical Studies on Illicit Heroin.5. Efficicacy of Volatilization During Heroin Smoking. Pharm. Weekbl. 1987, 9 (4), 203-211.

67. Friedman, L. S., Real-Time Surveillance of Illicit Drug Overdoses Using Poison Center Data. Clin. Toxicol. 2009, 47 (6), 573-579.

68. Henderson, G. L., Designer Drugs: Past History and Future Prospects. J. Forensic Sci. 1988, 33, 569-575.

69. Strang, J.; Griffiths, P.; Gossop, M., Heroin Smoking by 'Chasing the Dragon': Origins and History. Addiction 1997, 92 (6), 673-683.

70. The Smoking of Heroin in Hong Kong. Bull. Narc. 1958, (3), 6-7. 
71. Gruhzit, C. C. Pharmacological Investigation and Evaluation of the Effects of Combined Barbiturate and Heroin Inhalation, by Addicts Bull. Narc. [Online], 1958, p. 8-10. http://www.unodc.org/unodc/en/data-and-analysis/bulletin/bulletin_1958-0101_3_page004.html (accessed December 17, 2011).

72. Drugs Forum. http://www.drugs-forum.com/index.php (accessed July 6, 2010).

73. Erowid Experiences Vaults. http://www.erowid.org (accessed June 6, 2011).

74. Bluelight. http://www.bluelight.ru/vb/ (accessed June 4, 2011).

75. Gayton-Ely, M.; Shakleya, D. M.; Bell, S. C., Application of a Pyroprobe to Simulate Smoking and Metabolic Degradation of Abused Drugs through Analytical Pyrolysis. J Forensic Sci. 2007, 52 (2), 473-8.

76. Nishikawa, R. K.; Bell, S. C.; Kraner, J. C.; Callery, P. S., Potential Biomarkers of Smoked Fentanyl Utilizing Pyrolysis Gas Chromatography-Mass Spectrometry. $J$. Anal. Toxicol. 2009, 33 (8), 418-422.

77. Applied Pyrolysis Handbook. 2nd ed.; Taylor \& Francis Group: Boca Raton, FL, 2007; p 288.

78. Moldoveanu, S. C., Techniques and Instrumentation in Analytical Chemistry. Elsevier B.V.: Amsterdam, The Netherlands, 2010; Vol. 28, p 724.

79. Kinzie, P. A., Thermocouple Temperature Measurement. John Wiley \& Sons, Inc.: 1973.

80. Pollock, D. D., The Theory and Properties of Thermocouple Elements, Astm Stp 492. Omega Press: Stamford, CT, 1971.

81. Omega Temperature Measurement Handbook. 7th Edition ed.; Omega Engineering, Inc.: Stamford, CT, 2010; Vol. 2014.

82. Quinn, T. J., Monographs in Physical Measurements. Academic Press Inc.: London, 1983.

83. Wampler, T. P.; Levy, E. J., Reproducibility in Pyrolysis - Recent Developments. J. Anal. Appl. Pyrolysis 1987, 12 (2), 75-82.

84. CDS Analytical, I., Pyroprobe 5200 Manual. Oxford, PA.

85. Moldoveanu, S. C., Techniques and Instrumentation in Analytical Chemistry. Elsevier B.V: Amsterdam, The Netherlands, 2010; Vol. 28, p 724.

86. Uhde, E., Application of Solid Sorbents for Sampling of Volatile Organic Compounds in Indoor Air. In Organic Indoor Air Pollutants, Salthammer, T.; Uhde, E., Eds. Wiley-VCH Verlag GMbH \& Co. KGaA: Weinheim, 2009.

87. Skoog, D. A.; Holler, F. J.; Crouch, S. R., Principles of Instrumental Analysis. 6th ed.; Thomson Brooks/Cole: Belmont, CA, 2007.

88. Watson, J. T.; Sparkman, O. D., Introduction to Mass Spectrometry. 4th ed.; John Wiley \& Sons Ltd: England, 2007.

89. Rial-Otero, R.; Galesio, M.; Capelo, J. L.; Simal-Gandara, J., A Review of Synthetic Polymer Characterization by Pyrolysis-Gc-Ms. Chromatographia 2009, 70 (3-4), 339-348.

90. Sobeih, K. L.; Baron, M.; Gonzalez-Rodriguez, J., Recent Trends and Developments in Pyrolysis-Gas Chromatography. J. Chromatogr. A 2008, 1186 (1-2), 51-66.

91. Cognard, E.; Rudaz, S.; Bouchonnet, S.; Staub, C., Analysis of Cocaine and Three of Its Metabolites in Hair by Gas Chromatography-Mass Spectrometry Using Ion- Trap Detection for CI/MS/MS. J. Chromatogr. B. 2005, 826 (1-2), 17-25. 
92. Baker, R. R., A Review of Pyrolysis Studies to Unravel Reaction Steps in Burning Tobacco. J. Anal. Appl. Pyrolysis 1987, 11 (Journal Article), 555-573.

93. Baker, R. R., Product Formation Mechanisms inside a Burning Cigarette. Prog. Energy Combust. Sci. 1981, 7 (2), 135-153.

94. Baker, R. R., Temperature Distribution inside a Cigarette. Nature 1974, 247, 405406.

95. Baker, R. R., Temperature Variation within a Cigarette Combustion Coal During the Smoking Cycle. High Temp. Sci. 1975, 7, 236-247.

96. Baker, R. R., Combustion and Thermal-Decomposition Regions inside a Burning Cigarette. Combust. Flame 1977, 30 (1), 21-32.

97. Baker, R. R., Tobacco: Production, Chemistry, and Technology. Blackwell Science: 1999; pp 398-439.

98. Baker, R. R., Smoke Generation inside a Burning Cigarette: Modifying Combustion to Develop Cigarettes That May Be Less Hazardous to Health. Prog. Energy Combust. Sci. 2006, 32 (4), 373-385.

99. Baker, R. R., Variation of the Gas-Formation Regions within a Cigarette Combustion Coal During the Smoking Cycle. Beitr. Tabakforsch. Int. 1981, 11 (1), 1-17.

100. Shakleya, D. M.; Tarr, S. G.; Kraner, J. C.; Clay, D. J.; Callery, P. S., Potential Marker for Smoked Methamphetamine Hydrochloride Based on a Gas Chromatography-Mass Spectrometry Quantification Method for TransPhenylpropene. J. Anal. Toxicol. 2005, 29 (6), 552-5.

101. Physician's Desk Reference. 60 ed.; Thomson PDR: Montvale, NJ, 2006.

102. Manral, L.; Gupta, P. K.; Suryanarayana, M. V. S.; Ganesan, K.; Malhotra, R. C., Thermal Behaviour of Fentanyl and Its Analogues During Flash Pyrolysis. J. Therm. Anal. Calorim. 2009, 96 (2), 531-534.

103. Graham Solomons, T. W.; Fryhle, C. B., Organic Chemistry. John Wiley \& Sons, Inc.: New York, NY, 2002.

104. Damato, R. J.; Lipman, L. P.; Snyder, S. H., Selectivity of the Parkinsonian Neurotoxin MpTP - Toxic Metabolite MPP+ Binds to Neuromelanin. Science 1986, 231 (4741), 987-989.

105. Chiba, K.; Trevor, A. J.; Castagnoli, N., Active Uptake of MPP+, a Metabolite of MPTP, by Brain Synaptosomes. Biochem. Biophys. Res. Commun. 1985, 128, 12291232.

106. Langston, J. W.; Irwin, I.; Langston, E. B.; Forno, L. S., 1-Methyl-4Phenylpyridinium Ion (MPP+) - Identification of a Metabolite of MPTP, a Toxin Selective to the Substantia Nigra. Neurosci. Lett. 1984, pp 87-92.

107. Moehrle, H.; Ottersbach, D., Natriumquecksilberedetat-Dehydrierung N-Aliphatisch Substituierter 1,2,3,6-Tetrahydropyridin-Derivate. Arch. Pharm. 1990, 323 (2), 109115.

108. Garg, A.; Solas, D. W.; Takahashi, L. H.; Cassella, J. V., Forced Degradation of Fentanyl: Identification and Analysis of Impurities and Degradants. J. Pharm. Biomed. Anal. 2010, 53 (3), 325-334.

109. Holleyhead, R., Ignition of Flammable Gases and Liquids by Cigarettes: A Review. Sci. Justice 1996, 36 (4), 257-266.

110. Bartlett, E.; Mikulis, D. J., Chasing "Chasing the Dragon" with Mri: Leukoencephalopathy in Drug Abuse. Br. J. Radiol. 2005, 78 (935), 997-1004. 
111. Baker, R. R., Temperature Variation within a Cigarette Combustion Coal During the Smoking Cycle. High Temp. Sci. 1975, 7, 236-247.

112. Laszlo, T. S.; Watson Iii, F. M., A Scanning Infrared Technique for Cigarette Coal Peak Temperature Measurements. Beitr. Tabakforsch. Int. 1974, 269-275.

113. Haken, J. K., Pyrolysis Gas Chromatography of Coating Materials - a Bibliography. Prog. Org. Coat. 1999, 36 (1-2), 1-10.

114. Martin, K., Inert Reassessment: 2-Ehtyl-1-Hexanol; Cas\#104-76-7,2006

115. Cole, C.; Jones, L.; McVeigh, J.; Kicman, A.; Syed, Q.; Bellis, M., Adulterants in Illicit Drugs: A Review of Empirical Evidence. Drug Test. Anal. 2011, 3 (2), 89-96.

116. Reuters, P.; Caulkins, J. P., Illegal "Lemons": Price Dispersion in Cocaine and Heroin Markets. Bull. Narc. 2004, 56 (1 and 2), 141-165.

117. Sekine, H.; Nakahara, Y., Abuse of Smoking Methamphetamine Mixed with Tobacco .1. Inhalation Efficiency and Pyrolysis Products of Methamphetamine. J. Forensic Sci. 1987, 32 (5), 1271-1280.

118. Sekine, H.; Nakahara, Y., Abuse of Smoking Methamphetamine Mixed with Tobacco .2. The Formation Mechanism of Pyrolysis Products. J. Forensic Sci. 1990, 35 (3), 580-590.

119. Klous, M. G.; Lee, W. C.; van den Brink, W.; van Ree, J. M.; Beijnen, J. H., Volatilisation of Diacetylmorphine: In Vitro Simulation of 'Chasing the Dragon'. Pharmazie 2006, 61 (5), 438-445.

120. Wang, Y. S.; Hwang, K. L.; Chen, Y. L., Absorption, Translocation and Metabolism of the Herbicide Naproanilide in Tobacco. Pestic. Sci. 1994, 42 (1), 53-58.

121. Snyder, R., Ethyl Browning's Toxicity and Metabolism of Industrial Solvents. Elsevier: Amsterdam-NewYork-Oxford, 1990; Vol. II.

122. Propionanilide; MSDS No. S813990. Sigma-Aldrich Co. LLC: St. Louis, Missouri.

123. Phenylacetaldehyde; MSDS No. 107395. Sigma-Aldrich Co. LLC: St. Louis, Missouri.

124. 6-Acetylmorphine; MSDS No. A-003. Cerilliant: Round Rock, TX.

125. Aniline; MSDS No. 242284. Sigma-Aldrich Co. LLC: St. Louis, Missouri. 